\title{
(4)
}

UNIVERSIDAD PERUANA DE CIENCIAS APLICADAS

FACULTAD DE INGENIERÍA

CARRERA DE INGENIERÍA DE SISTEMAS

\section{PROPUESTA DE UNA ARQUITECTURA EMPRESARIAL PARA UNA ENTIDAD ASEGURADORA EN LIMA}

TESIS
Para optar por el título profesional de Ingeniero de Sistemas

AUTORES:

BENITES CISNEROS LORENZO JUNIOR - 0000-0002-9230-1040 GAMBA FAGGIANI JONATHAN - 0000-0001-7010-7688

ASESOR:

ARMAS AGUIRRE, JIMMY ALEXANDER 0000-0002-1176-8969

Lima, Junio de 2018 


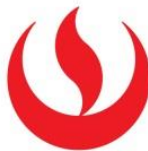

DEDICATORIA

A mi Dios por su infinita misericordia y bendición para lograr mis metas, a mis padres por su apoyo incondicional, a mi amada esposa por todo el amor y apoyo que recibo día a día, y a mi querida hija, por ser el tesoro más grande que he recibido en mi vida.

Jonathan Gamba Faggiani

En primer lugar a Dios por su bendición, a mi familia, en especial a mis padres y esposa por su amor incondicional y por todo el apoyo que me brindan día a día.

Lorenzo Benites Cisneros. 


\section{$(1)$}

\section{AGRADECIMIENTOS}

A la Universidad Peruana de Ciencias Aplicadas por permitirnos culminar la etapa de estudios universitarios y poder graduarnos como Ingenieros de Sistemas.

Asimismo, a los profesores del curso del Programa de Actualización Profesional, por todo su apoyo, experiencia, conocimientos y dedicación, para poder culminar este programa con éxito.

Por último, a nuestras familias, quienes son nuestro motor y motivo, para alcanzar nuestros sueños.

A todos los mencionados: ¡Muchas Gracias! 


\section{(1)}

\section{RESUMEN}

El presente proyecto tiene como propuesta, implementar una arquitectura empresarial para una entidad aseguradora en Lima. La organización es un grupo asegurador con más de 80 años en el mercado asegurador peruano y cuenta con más de 3 millones de asegurados en todo el Perú. La arquitectura empresarial permite a las organizaciones alinear la estrategia de sistemas con la de negocio. Mediante este, se obtendrá un proyecto que agregue valor a los objetivos estratégicos de la organización, al cual se aplicará metodologías agiles de desarrollo de software.

Por lo tanto, el presente trabajo está dividido en cuatro capítulos. En el primer capítulo, se describe a la entidad objeto de estudio, la misión, visión y objetivos estratégicos, así como también los objetivos y beneficios de trabajo profesional. Luego, en el segundo capítulo se describirá el marco teórico sobre arquitectura empresarial y métodos ágiles para el desarrollo de Software y casos de éxito de los mismos. En el tercer capítulo se realizará un análisis de la arquitectura AS IS de la entidad aseguradora que propone una arquitectura TO BE utilizando para ello el marco de referencia TOGAF. Por último, en el capítulo cuatro se muestra la propuesta del proyecto con su resumen ejecutivo y la organización del mismo.

Palabras clave: Arquitectura Empresarial, Marco de trabajo ágil para el desarrollo de software. 


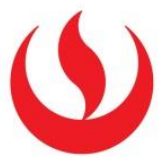

\begin{abstract}
The present project has as a proposal, to implement a business architecture for an insurance entity in Lima. The organization is an insurance group with more than 80 years in the Peruvian insurance market and has more than 3 million policyholders throughout Peru. The enterprise architecture allows organizations to align the systems strategy with the business strategy. Through this, a project that adds value to the strategic objectives of the organization will be obtained, to which agile methodologies of software development will be applied.

Therefore, the present work is divided into four chapters. In the first chapter, the entity under study, the mission, vision and strategic objectives are described, as well as the objectives and benefits of professional work. Then, in the second chapter will describe the theoretical framework on business architecture and agile methods for the development of Software and cases of success of the same. In the third chapter, an analysis of the AS IS architecture of the insurance entity that proposes a TO BE architecture using the TOGAF reference framework will be carried out. Finally, chapter four shows the project proposal with its executive summary and its organization.
\end{abstract}

Keywords: Business Architecture, Agile framework for software development. 


\section{(1)}

\section{ÍNDICE}

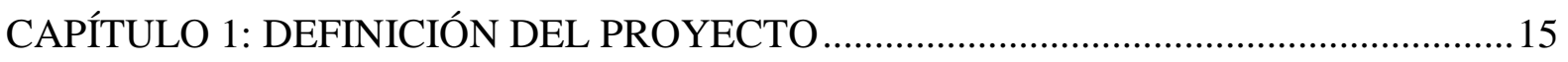

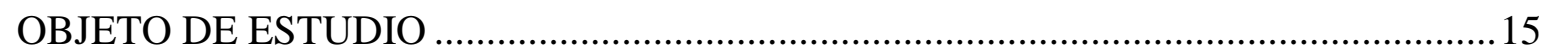

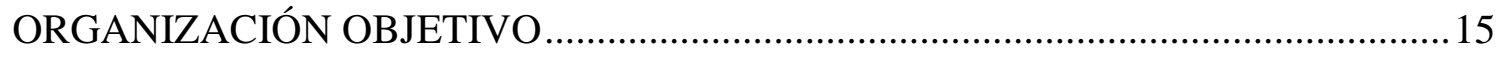

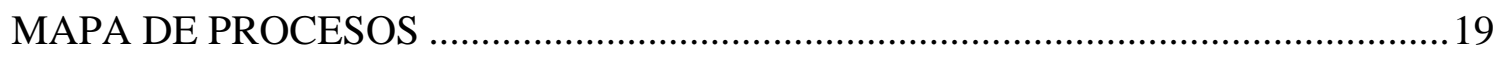

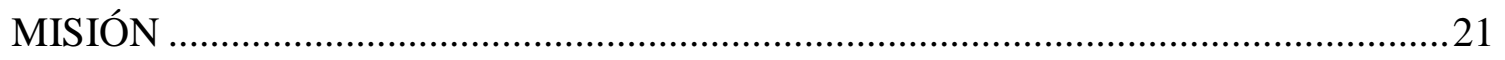

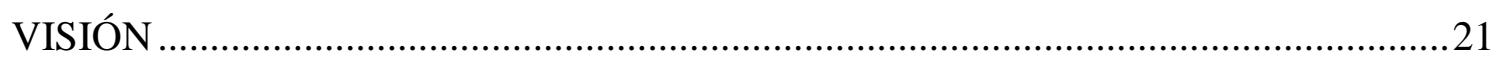

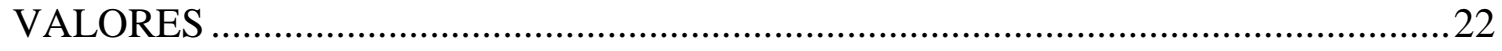

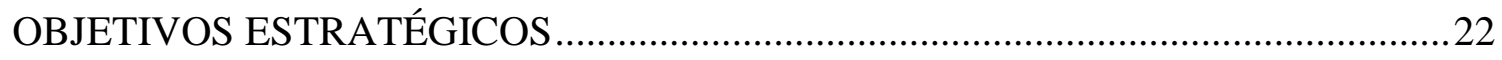

MATRIZ DE OBJETIVOS ESTRATÉGICOS VERSUS PROCESOS DE NEGOCIO 24

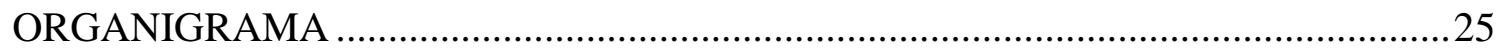

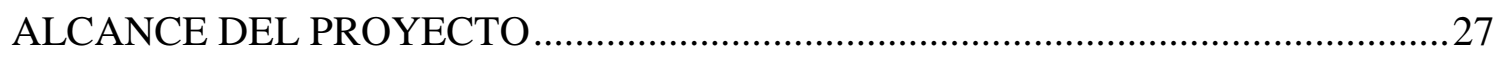

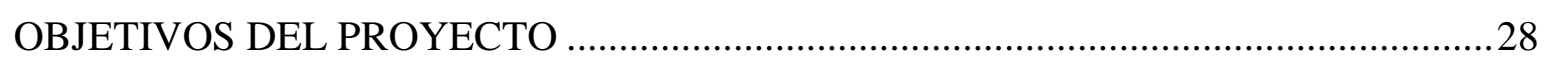

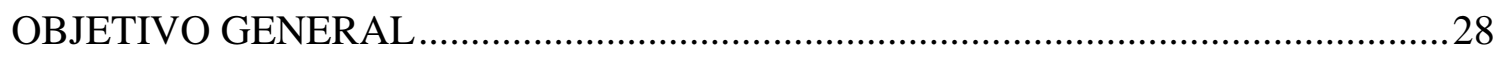

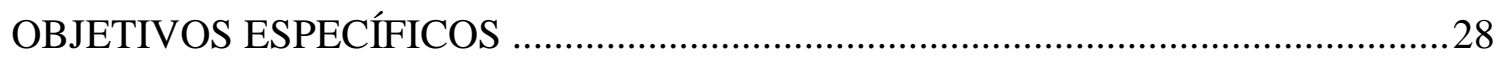

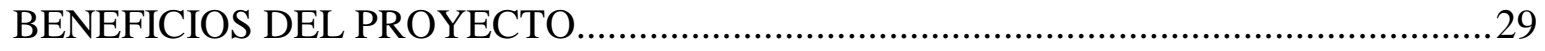

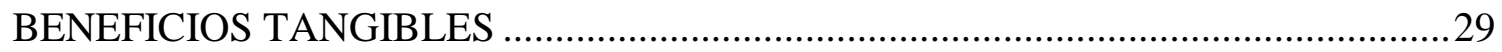

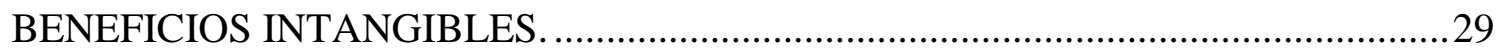

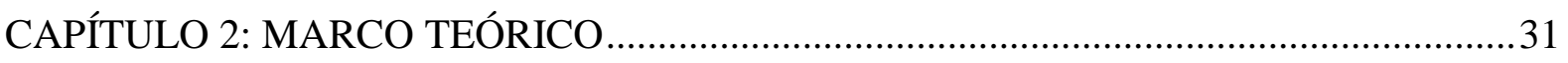

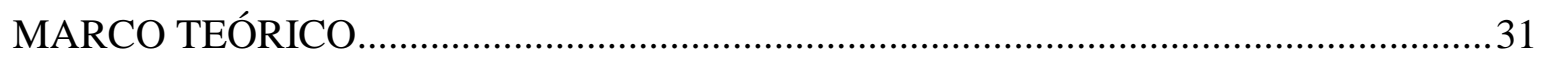

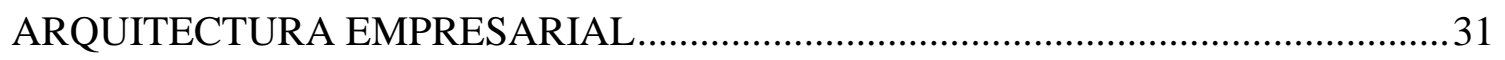

METODOLOGÍAS ÁGILES PARA EL DESARROLLO DE SOFTWARE..................38

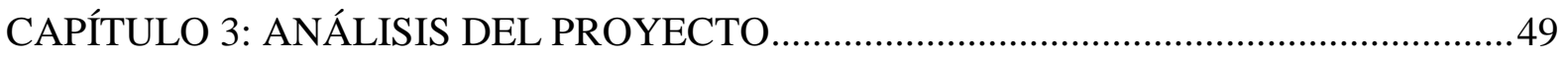

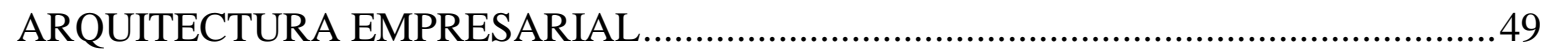

PETICIÓN DEL TRABAJO DE ARQUITECTURA ...................................................49

DOCUMENTO DE DEFINICIÓN DE ARQUITECTURA .........................................55

PLAN DE IMPLEMENTACIÓN Y MIGRACIÓN.................................................... 131

MÉTODOS ÁGILES PARA EL DESARROLLO DE SOFTWARE ............................... 137 
IDENTIFICACIÓN DE FORTALEZAS Y DEBILIDADES

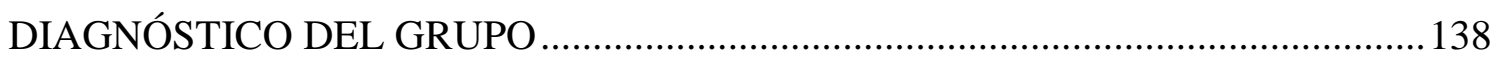

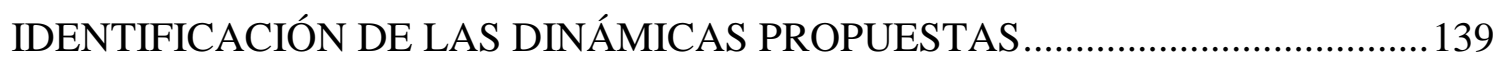

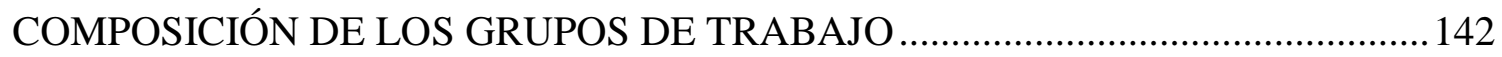

DEFINICIÓN DE LAS HERRAMIENTAS A UTILIZAR ......................................... 148

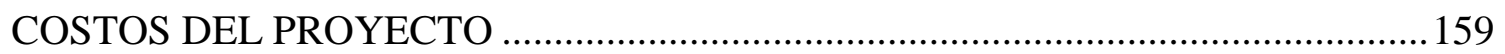

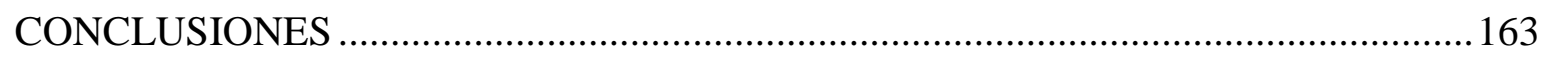

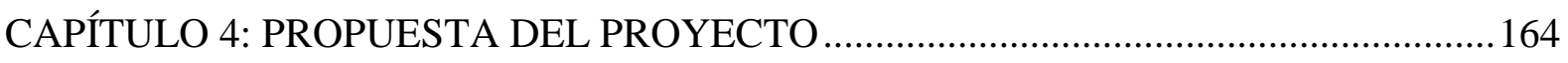

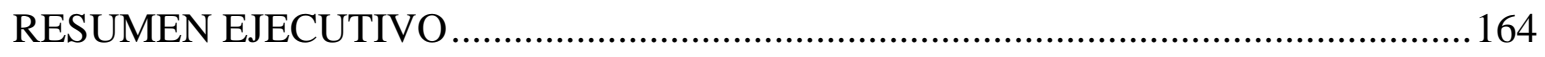

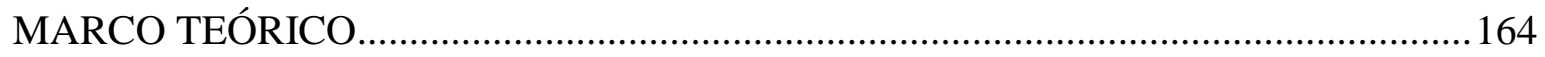

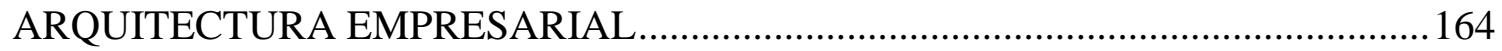

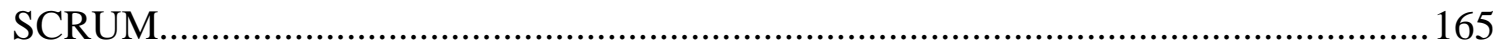

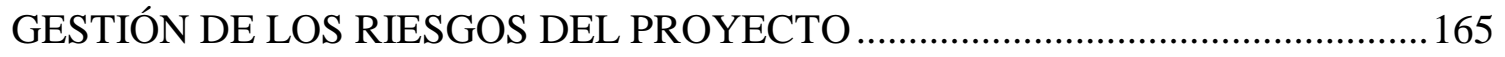

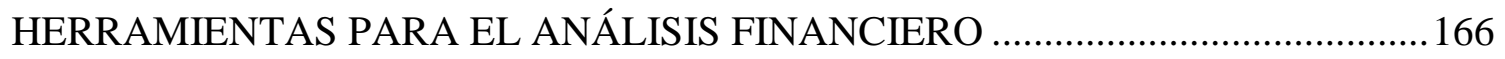

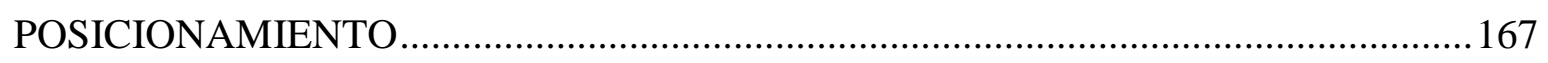

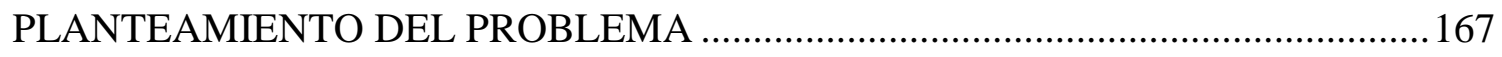

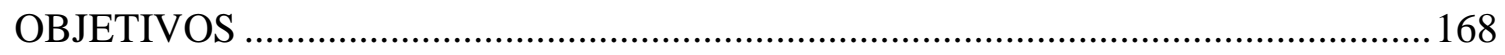

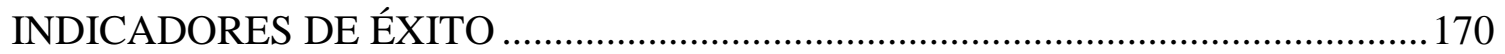

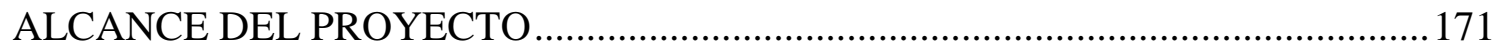

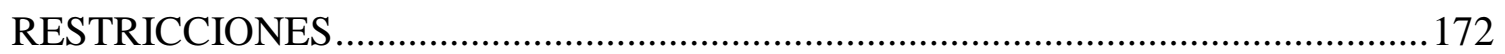

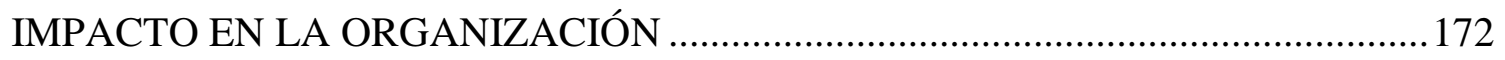

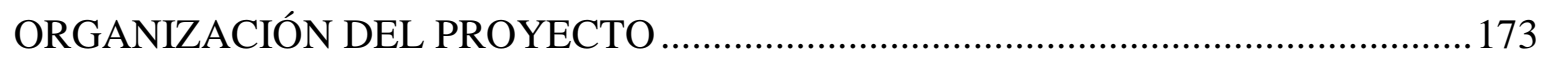

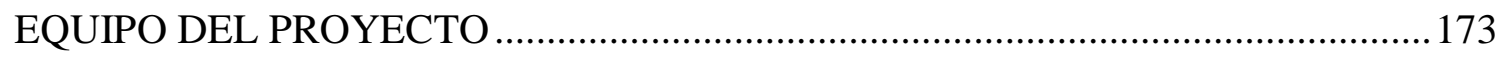

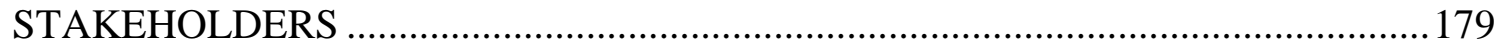

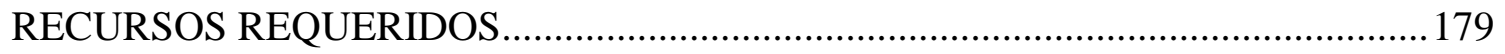

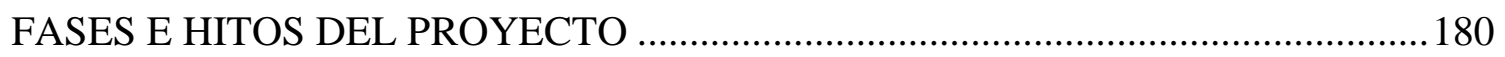

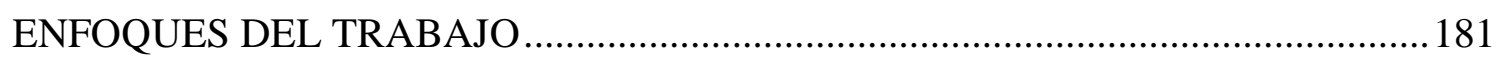

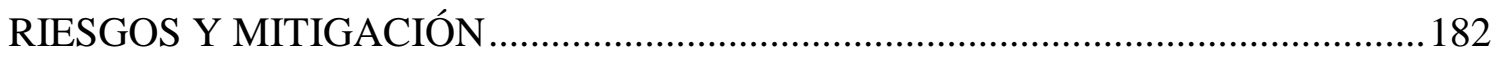

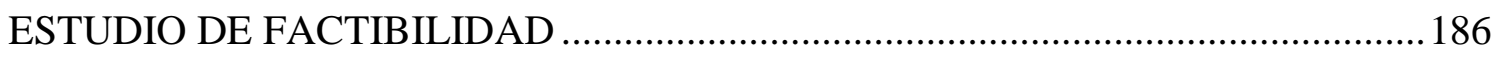

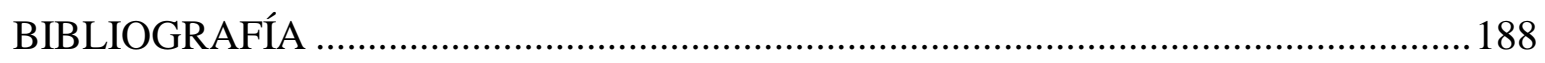

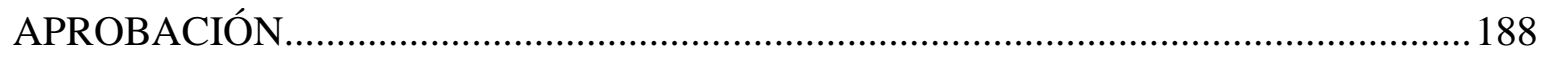

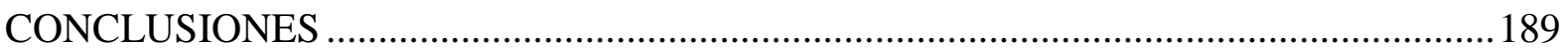




\section{(}

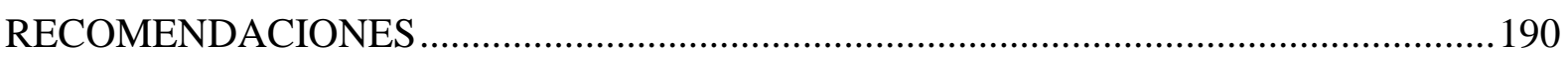

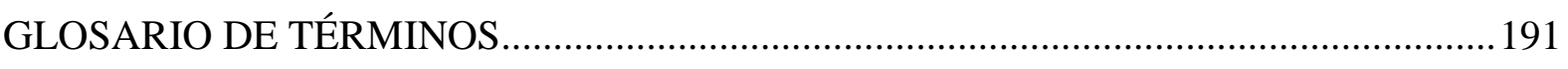

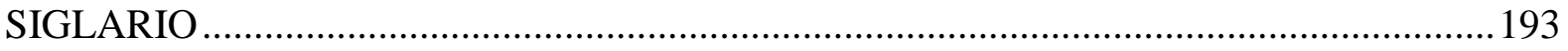

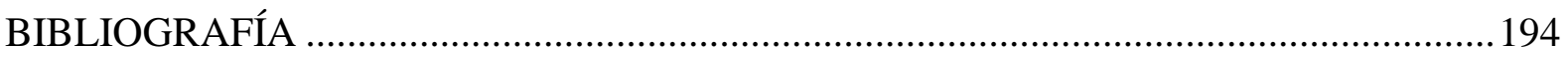

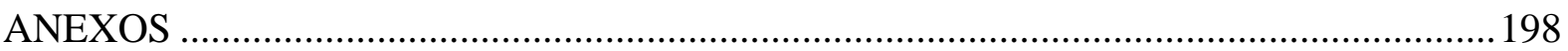




\section{(1)}

\section{INDICE DE TABLAS}

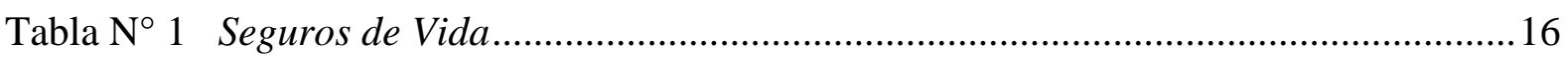

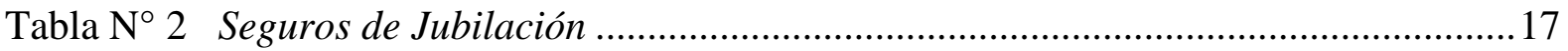

Tabla $\mathrm{N}^{\circ} 3$ Seguros de Riesgos Laborales................................................................................ 18

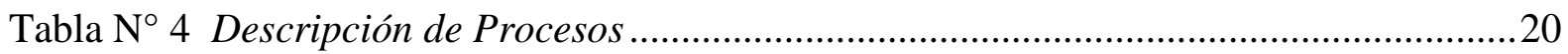

Tabla $\mathrm{N}^{\circ} 5$ Matriz de objetivos estratégicos versus procesos de negocio................................24

Tabla $\mathrm{N}^{\circ} 6$ Descripción de funciones por cargo en la organización. .......................................26

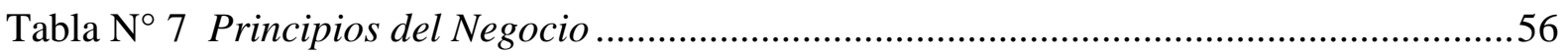

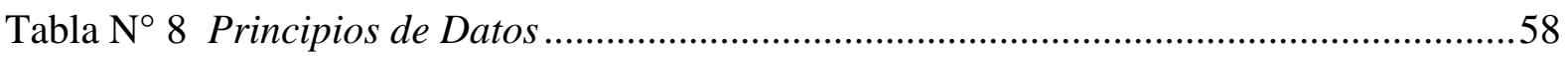

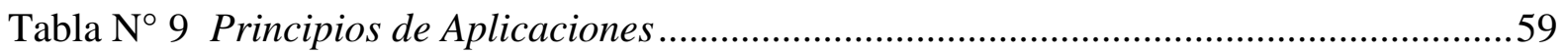

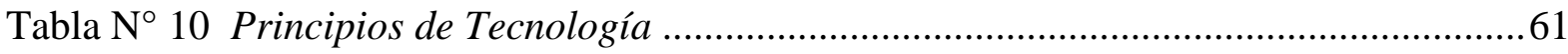

Tabla $N^{\circ} 11$ Descripción de funciones por cargo del proceso seleccionado. .........................64

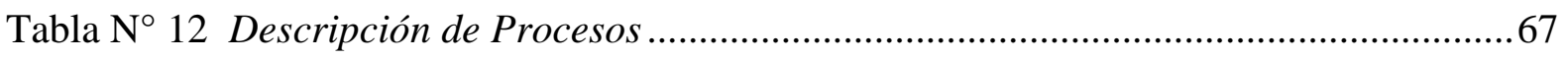

Tabla $\mathrm{N}^{\circ} 13$ Matriz de objetivos estratégicos versus procesos de negocio. ............................69

Tabla N 14 Matriz RACI - Sub proceso Emitir Póliza SCTR ................................................ 71

Tabla N 15 Matriz RACI - Sub proceso Inclusión de Asegurados en Póliza SCTR ..............73

Tabla № 16 Matriz RACI - Sub proceso Exclusión de Asegurados en Póliza SCTR ............. 74

Tabla N 17 Matriz RACI - Sub proceso Renovación de Póliza SCTR ................................... 76

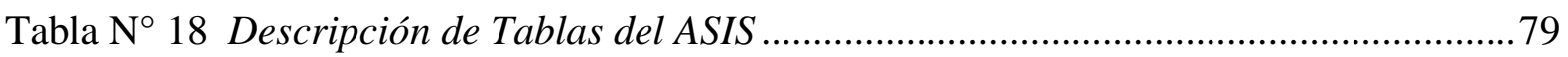

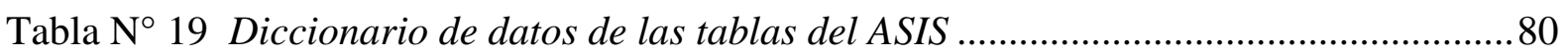

Tabla $\mathrm{N}^{\circ} 20$ Matriz de Entidades de Datos versus Proceso de Negocio del ASIS ..................87

Tabla $\mathrm{N}^{\circ} 21$ Descripción de funciones por cargo del proceso seleccionado. ..........................93

Tabla $\mathrm{N}^{\circ} 22$ Descripción de Procesos ...................................................................................95

Tabla $\mathrm{N}^{\circ} 23$ Matriz de objetivos estratégicos versus procesos de negocio. ............................97

Tabla № 24 Tabla de Descripción de Tablas del TOBE ....................................................... 101

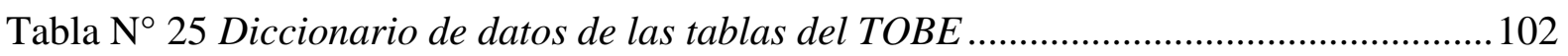

Tabla $\mathrm{N}^{\circ} 26$ Matriz de Entidades de Datos versus Proceso de Negocio TOBE..................... 117

Tabla $\mathrm{N}^{\circ} 27$ Descripción de componentes de Arquitectura Tecnológica ................................ 122

Tabla $\mathrm{N}^{\circ} 28$ Análisis de Brechas - Emisión de Póliza SCTR-Arquitectura de Negocio ..... 123 


\section{(1)}

Tabla N²9 Análisis de Brechas - Inclusión de Asegurados en Póliza SCTR-Arquitectura de Negocio 124

Tabla N 30 Análisis de Brechas - Exclusión de Asegurados en Póliza SCTR-Arquitectura de Negocio

Tabla $\mathrm{N}^{\circ} 31$ Análisis de Brechas - Renovación de Póliza SCTR-Arquitectura de Negocio 126

Tabla N 32 Análisis de Brechas - Arquitectura de Datos

Tabla №33 Análisis de Brechas - Arquitectura de Aplicación.

Tabla No 34 Análisis de Brechas - Arquitectura Tecnológica

Tabla $\mathrm{N}^{\circ} 35$ Cuadro resumen del Plan de Migración. 132

Tabla $\mathrm{N}^{\circ} 36$ Plan de Implementación y Migración 135

Tabla N ${ }^{\circ} 37$ Users Stories Del Proyecto PROYO1 150

Tabla N 38 Estimación en días de las Users Stories del Proyecto PROYO1 152

Tabla N 39 Tareas del Sprint 0 del Proyecto PROYO1 154

Tabla $\mathrm{N}^{\circ} 40$ Sprint 1 del Proyecto PROYO1 155

Tabla $N^{\circ} 41$ Tareas del Sprint 1 del Proyecto PROYO1 155

Tabla $\mathrm{N}^{\circ} 42$ Costos del Sprint 0 160

Tabla $\mathrm{N}^{\circ} 43$ Costos del Sprint 1 161

Tabla $\mathrm{N}^{\circ} 44$ Relación de atención de Users Stories por Sprint.. 162

Tabla $\mathrm{N}^{\circ} 45$ Resumen general de los costos del proyecto 162 


\section{(1) \\ INDICE DE FIGURAS}

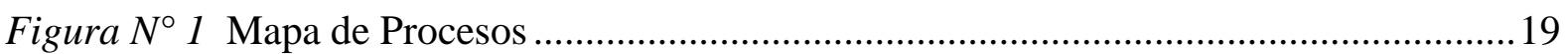

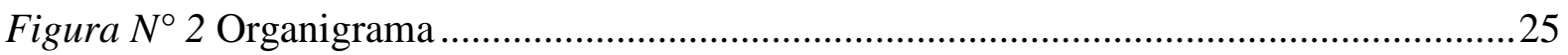

Figura $N^{\circ} 3$ Metodologías y Framework de Arquitectura Empresarial. Adaptado de “Metodologías y frameworks de Arquitectura Empresarial”, por Colombia Digital, 2018.

Figura $N^{\circ} 4$ Componentes de la Arquitectura Empresarial. Adaptado de "Componentes de la Arquitectura Empresarial”, Colombia Digital, 2018. .33

Figura $N^{\circ} 5$ Fases de ADM. Adaptado de "El Ciclo del Método de Desarrollo de la Arquitectura", Colombia Digital, 2018. .35

Figura $N^{\circ} 6$. Características más notables entre los Métodos Ágiles y los Tradicionales. Adaptado de "Comparativa metodologías ágiles vs tradicionales”, Avante, 2018...........39

Figura $N^{\circ} 7$. Descripción gráfica de los ciclos de Scrum. Adaptado de "Ciclos Scrum", Proyectos Ágiles, 2018.

Figura $N^{\circ} 8$. Soporte de Arquitectura Cloud a una entidad aseguradora. Adaptado de "Caso de éxito Aseguradora Internacional”, Everis, 2018. .45

Figura $N^{\circ} 9$. Soporte de Arquitectura Cloud a una entidad aseguradora. Adaptado de "Caso de éxito Grupo Santillana", Everis, 2018.

Figura $N^{\circ} 10$. Captura de pantalla de sitio web institucional de La Positiva Seguros, por lapositiva.com.pe, 2018 .52

Figura $N^{\circ} 11$. Captura de pantalla de sitio web institucional de La Positiva Seguros, por lapositiva.com.pe, 2018

Figura $N^{\circ} 12$. Captura de pantalla de sitio web institucional de La Positiva Seguros, por lapositiva.com.pe, 2018 .54

Figura $N^{\circ} 13$ Organigrama del Proceso Seleccionado. Adaptado de "Organigrama de una entidad aseguradora en Lima”, Elaboración propia, 2018.

Figura $N^{\circ} 14$ Mapa de Procesos. Adaptado de "Mapa de Procesos y Funciones de Negocio y descripción de una entidad aseguradora en Lima”, Elaboración propia, 2018. .66

Figura $N^{\circ} 15$ Diagrama de procesos. Adaptado de "Gestión de Pólizas SCTR - Proceso General”, Elaboración propia, 2018. .70 


\section{(1)}

Figura $N^{\circ} 16$ Diagrama de procesos. Adaptado de "Emisión de Póliza SCTR", Elaboración

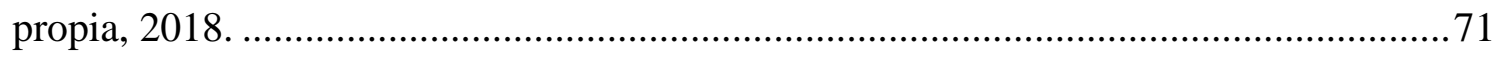

Figura $N^{\circ} 17$ Diagrama de procesos. Adaptado de "Inclusión de Asegurados en Póliza

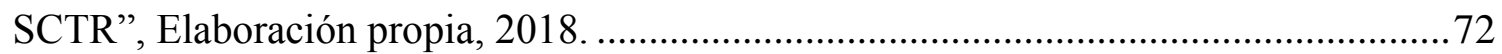

Figura $N^{\circ} 18$ Diagrama de procesos. Adaptado de "Exclusión de Asegurados en Póliza SCTR", Elaboración propia, 2018.

Figura $N^{\circ} 19$ Diagrama de procesos. Adaptado de "Renovación de Póliza SCTR", Elaboración propia, 2018. .75

Figura $N^{\circ} 20$ Modelo de Datos. Adaptado de "Modelo de Datos del Proceso Seleccionado (AS IS)", Elaboración propia, 2018. .78

Figura $N^{\circ} 21$ Arquitectura de Aplicación. Adaptado de "Arquitectura de Aplicación SED (AS IS)", Elaboración propia, 2018.

Figura $N^{\circ} 22$ Arquitectura Tecnológica. Adaptado de “Arquitectura Tecnológica SED (AS IS)", Elaboración propia, 2018. .90

Figura $N^{\circ} 23$ Organigrama. Adaptado de “Organigrama (TOBE)”, Elaboración propia, 2018.

Figura $N^{\circ} 24$ Mapa de Procesos, Adaptado de "Mapa de Procesos y funciones de Negocio y descripción de una entidad aseguradora en Lima”, Elaboración propia, 2018 .94

Figura $N^{\circ} 25$ Arquitectura de Datos. Adaptado de "Modelo de Datos del Proceso Seleccionado (TO BE)", Elaboración propia, 2018. 100

Figura $N^{\circ} 26$ Arquitectura de Aplicación. Adaptado de “Arquitectura de Aplicación SED (TO BE)", Elaboración propia, 2018.

Figura $N^{\circ} 27$ Arquitectura Tecnológica, Adaptado de "Arquitectura Tecnológica SED (TO BE)”, Elaboración propia, 2018. 120

Figura $N^{\circ} 28$ EDT 136

Figura $N^{\circ} 29$ Cuadro de Roles Scrum. Adaptado de "Roles Scrum", por Jerónimo Palacios, 2018 148

Figura $N^{\circ} 30$ Planing Poker. Adaptado de "Barajas Planning Poker", Elaboración propia, 2018. 152

Figura $N^{\circ} 31$ Diagrama Burndown. Adaptado de "Guía Fundamental de Scrum”, Elaboración propia. 157 


\section{(1)}

Figura $N^{\circ} 32$ Scrum Taskboard del Sprint 1 para el proyecto PROY01, Adaptado del

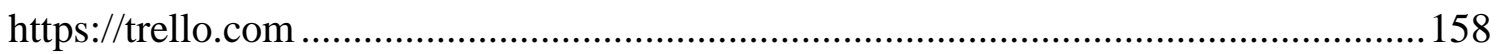

Figura $N^{\circ} 33$ Clasificación de los riegos, Elaboración propia, 2018 ................................... 182 


\section{(1) \\ INTRODUCCIÓN}

En la actualidad, las organizaciones consideran al área de tecnología de información como un área estratégica, de manera que las expectativas sobre esta para la generación de valor al negocio con altas. Por lo cual, deben dedicar un gran esfuerzo en la optimización de sus procesos, y para ello adopta estándares y el uso de mejores prácticas para lograr el alineamiento con sus objetivos estratégicos. Con ello se asegura un eficiente uso del esfuerzo y de las inversiones de la organización.

La organización objetivo es un grupo asegurador con más de 80 años en el mercado asegurador peruano y cuenta con más de 3 millones de asegurados en todo el Perú. El alcance del proyecto es proponer una arquitectura empresarial para esta organización.

En este documento se aplica el marco de referencia TOGAF para desarrollar los cuatro dominios de la arquitectura empresarial (negocio, datos, aplicaciones y tecnología), para lo cual se analiza el proceso de gestión de emisión de pólizas SCTR. Como resultado del análisis de estas arquitecturas se obtiene una relación de brechas, las cuales se consolidan en un plan de migración. Adicionalmente, se plantea la implementación de un proyecto tecnológico bajo el marco de SCRUM. Para asegurar que el proyecto sea exitoso, se analizaron las fortalezas y debilidades del equipo. Luego se realiza un diagnóstico de grupo y se plantean las dinámicas, el equipo de proyecto y las herramientas necesarias. 


\section{(1) \\ CAPÍTULO 1: DEFINICIÓN DEL PROYECTO}

\section{OBJETO DE ESTUDIO}

\section{ORGANIZACIÓN OBJETIVO}

La organización objetivo de la presente propuesta es una entidad aseguradora, la cual cuenta con más de 80 años de experiencia en el mercado peruano y más de 3 millones de asegurados a nivel nacional.

\section{Breve descripción de productos y servicios}

La organización se encuentra enfocada a brindar servicios de seguros y reaseguros, los cuales según la ley y clasificación internacional, comprendería servicio de financiamiento de planes de seguros de vida, los cuales comprenden seguros de jubilación, seguros de vida, seguros de riesgos laborales. Estos productos son ofrecidos a nivel Nacional, para lo cual, cuenta con diversas oficinas a nivel nacional.

La organización ofrece Seguros de Vida, Seguros de Jubilación y Seguros de Riesgos Laborales. A continuación se describen los productos antes mencionados:

- Seguros de vida. Orientados a brindar coberturas para fallecimiento, invalidez y más. Se encuentran divididos en ahorros, protección familiar, educativa, temporal, desgravamen, y accidentes personales, encontrándose dentro de cada agrupación se encuentran diferentes planes para cada tipo de necesidad del cliente. En la tabla 1 se detalla los diferentes productos que componen la categoría de seguros de vida. 


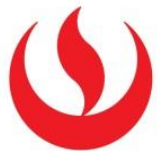

Tabla $\mathrm{N}^{\circ} 1$

Seguros de Vida

\begin{tabular}{|c|c|c|}
\hline $\begin{array}{l}\text { Categoría del } \\
\text { producto }\end{array}$ & Nombre & Descripción \\
\hline \multirow{3}{*}{ Ahorro } & Vida Positiva Ahorro & $\begin{array}{l}\text { Brinda una completa cobertura por } \\
\text { fallecimiento o por invalidez permanente } \\
\text { y absoluta en planes de } 10,15 \text {, o } 20 \text { años } \\
\text { o hasta llegar a los } 65 \text { años. }\end{array}$ \\
\hline & $\begin{array}{l}\text { Vida Positiva Jubilación } \\
\text { Privada }\end{array}$ & $\begin{array}{l}\text { Brinda cobertura para familiares en caso } \\
\text { de fallecimiento pudiendo contratar este } \\
\text { seguro a partir de los } 18 \text { años hasta los } \\
64 \text { años. }\end{array}$ \\
\hline & Vida Positiva Futuro & $\begin{array}{l}\text { Brinda cobertura vitalicia por } \\
\text { fallecimiento y por invalidez total y } \\
\text { permanente. }\end{array}$ \\
\hline \multirow{3}{*}{ Protección Familiar } & Familia Protegida & $\begin{array}{l}\text { Brinda cobertura ante el fallecimiento de } \\
\text { algún miembro de la familia. }\end{array}$ \\
\hline & Continuidad de Negocio & $\begin{array}{l}\text { Dirigido a los pequeños y medianos } \\
\text { empresarios que garantizar la } \\
\text { continuidad de sus negocios. }\end{array}$ \\
\hline & Pensión Educativa Segura & $\begin{array}{l}\text { Dirigido a proteger la educación de los } \\
\text { hijos de loa asegurados así como por } \\
\text { fallecimiento. }\end{array}$ \\
\hline \multirow[t]{2}{*}{ Educativo } & Vida Positiva Académico & $\begin{array}{l}\text { Brinda una completa cobertura por } \\
\text { fallecimiento, pudiendo contratar este } \\
\text { seguro a partir de los } 18 \text { años hasta los } \\
64 \text { años. }\end{array}$ \\
\hline & Renta Estudiantil & $\begin{array}{l}\text { Dirigido a solventar la educación escolar } \\
\text { de los hijos. }\end{array}$ \\
\hline $\begin{array}{l}\text { Seguro } \\
\text { Desgravamen }\end{array}$ & $\begin{array}{l}\text { Orientada a indemnizar al } \\
\text { beneficiario de la Póliza } \\
\text { en } \\
\text { caso de fallecimiento o } \\
\text { invalidez total y } \\
\text { permanente } \\
\text { por accidente }\end{array}$ & $\begin{array}{l}\text { Seguro de Desgravamen Individual. } \\
\text { Seguro de Desgravamen Individual - } \\
\text { Prima } \\
\text { Mensual. } \\
\text { Seguro de Desgravamen. }\end{array}$ \\
\hline $\begin{array}{l}\text { Seguro de } \\
\text { accidentes } \\
\text { personales }\end{array}$ & $\begin{array}{l}\text { Accidentes personales en } \\
\text { grupo } \\
\text { Protección Oro }\end{array}$ & $\begin{array}{l}\text { Brinda una cobertura principal en caso de } \\
\text { muerte } \\
\text { El Protección Oro es un seguro de } \\
\text { Accidentes Personales a bajo costo. }\end{array}$ \\
\hline
\end{tabular}

Nota. Relación de productos seguros vida de la organización. Elaboración propia. 


\section{(1)}

- Seguros de jubilación. Destinadas para ofrecer a los afiliados de las AFP la seguridad de contar con una pensión mensual de por vida. En la tabla 2 se detalla los diferentes productos que componen la categoría de seguros de jubilación.

Tabla $\mathrm{N}^{\circ} 2$

Seguros de Jubilación

\begin{tabular}{ll}
\multicolumn{1}{c}{\begin{tabular}{c}
\multicolumn{1}{c}{ Nombre del } \\
producto
\end{tabular}} & \multicolumn{1}{c}{ Descripción } \\
\hline $\begin{array}{l}\text { Renta Vitalicia } \\
\text { Jubilación Edad } \\
\text { Legal }\end{array}$ & $\begin{array}{l}\text { Brinda cobertura por fallecimiento o por invalidez permanente y } \\
\text { absoluta. }\end{array}$ \\
$\begin{array}{l}\text { Renta Vitalicia } \\
\text { Jubilación Anticipada }\end{array}$ & $\begin{array}{l}\text { Constituye una modalidad de jubilación que permite contar con una } \\
\text { pensión mensual de por vida si está el asegurado afiliado a una AFP y } \\
\text { ya cumplió los } 55 \text { años (hombres) o los } 50 \text { años (mujeres). }\end{array}$ \\
$\begin{array}{l}\text { Renta Vitalicia } \\
\begin{array}{l}\text { Pensión } \\
\text { por Invalidez }\end{array}\end{array}$ & $\begin{array}{l}\text { Permite recibir al asegurado una pensión mensual de por vida, ante la } \\
\text { pérdida mayor o igual al 50\% de tu capacidad productiva, para acceder a }\end{array}$ \\
$\begin{array}{l}\text { Renta Vitalicia } \\
\text { Pensión } \\
\text { por Sobrevivencia encontrarse afiliado a una AFP. }\end{array}$ & $\begin{array}{l}\text { Se otorga a los beneficiarios de los asegurados de por vida, ya sean } \\
\text { cónyuges o hijos menores de 18 años. }\end{array}$ \\
\hline Nota. Relación de productos seguros de jubilación. Elaboración propia.
\end{tabular}

Nota. Relación de productos seguros de jubilación. Elaboración propia.

- Seguros de riesgos laborales. Incluye los seguros de vida individual, masivos, vida ley, complementario de trabajo en riesgo (SCTR) y desgravamen. Algunos de estos conforman los seguros de Affinity, que son colocados a través de una amplia red de auspiciadores (e.g., cajas municipales, instituciones financieras, ONG, casas comerciales, entre otros), estando orientados a brindar asesoría completa para organizaciones de modo que pueda cumplir con la normativa laboral y otorgar seguridad a sus trabajadores. En la Tabla 3 se detalla los diferentes productos que componen la categoría de seguros de riesgos laborales. 


\section{(}

Tabla $\mathrm{N}^{\circ} 3$

Seguros de Riesgos Laborales

\begin{tabular}{|c|c|}
\hline Nombre del producto & Descripción \\
\hline Vida Ley & 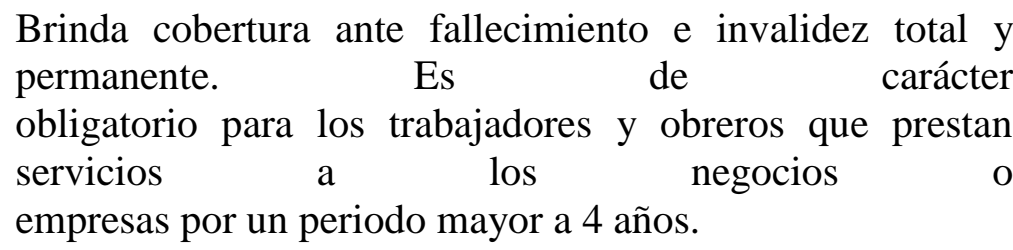 \\
\hline $\begin{array}{l}\text { Seguro Complementario de } \\
\text { Trabajo de Riesgo }\end{array}$ & $\begin{array}{l}\text { Otorga cobertura adicional a la establecida por el régimen } \\
\text { de pensiones a cargo de la ONP o AFP y se activa cuando } \\
\text { los trabajadores asegurados sufren algún accidente de } \\
\text { trabajo o enfermedad profesional como consecuencia de las } \\
\text { labores que desempeñan en la organización. Es de carácter } \\
\text { obligatorio para los trabajadores que realizan } \\
\text { actividades económicas de riesgo descritas en el Anexo } 5 \\
\text { del Decreto Supremo }{ }^{\circ} 003-98-S A \text {, como por ejemplo: } \\
\text { extracción de madera, explotación de minas, } \\
\text { producción de petróleo, entre otras. }\end{array}$ \\
\hline
\end{tabular}

Nota. Relación de productos seguros de riesgos laborales. Elaboración propia. 


\section{()}

\section{MAPA DE PROCESOS}

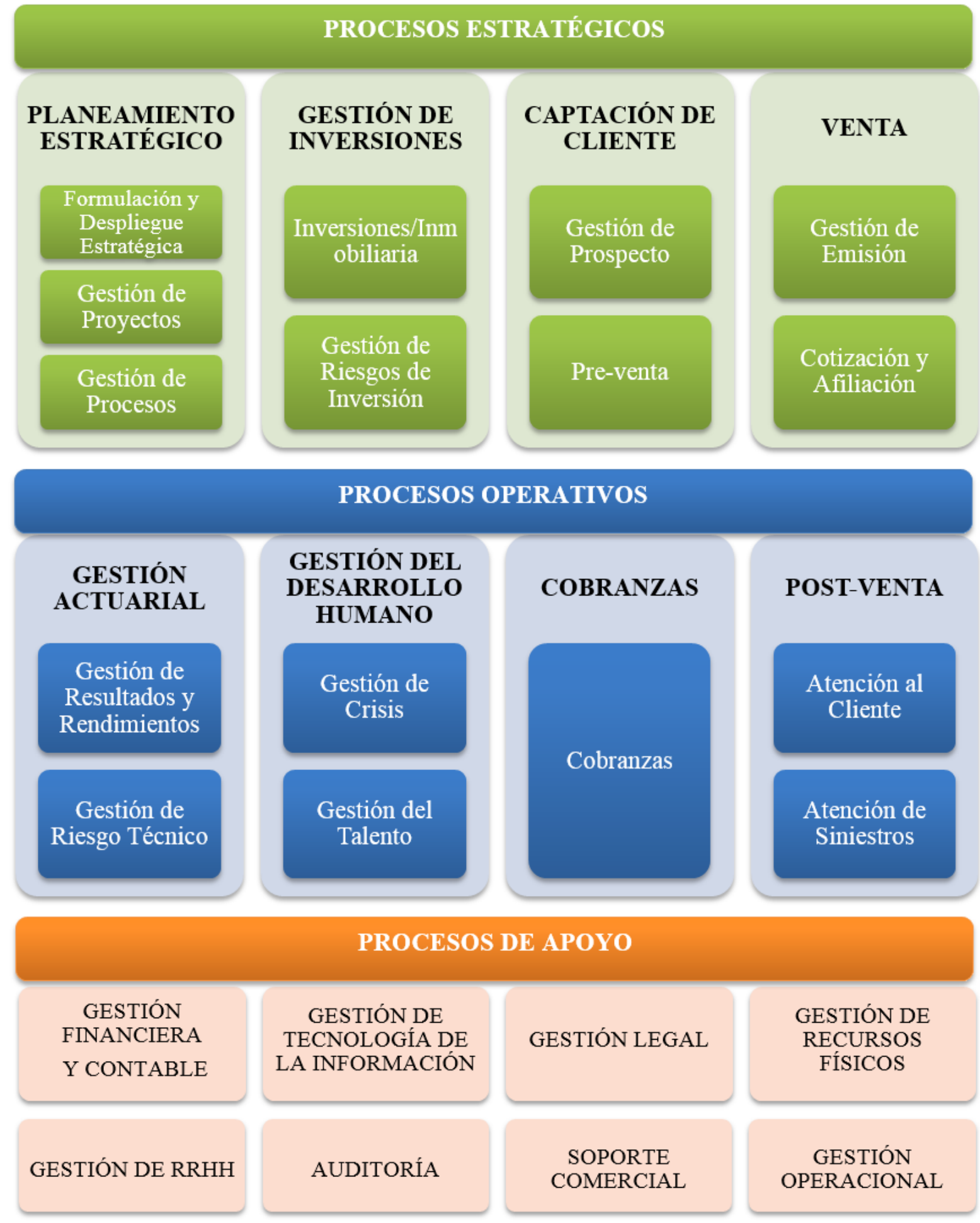

Figura $N^{\circ} 1$

Mapa de Procesos

Fuente: Elaboración propia. 


\section{(}

Tabla $N^{\circ} 4$

Descripción de Procesos

\begin{tabular}{ccl}
\hline Tipo & \multicolumn{1}{c}{ Procesos } & \multicolumn{1}{c}{ Descripción } \\
\hline & & Es el proceso que se encarga de definir la visión de la \\
& & empresa a mediano y largo plazo, así como también las \\
& estrategias para alcanzarlas a través del análisis de las \\
& Planeamiento & fortalezas, debilidades, oportunidades y amenazas. Es el \\
& Eroceso que da inicio al proceso de planificación de la \\
& &
\end{tabular}

Estratégico Gestión de

Inversiones

Captación de Cliente

Venta

Gestión Actuarial

Gestión del

Desarrollo Humano

Operativos Cobranzas

Post-Venta

Gestión Financiera y

Contable

Apoyo

Gestión de

Tecnología de la

Información
Es la gestión que se encarga de ofrecer funciones para ayudar en la planificación, la inversión y los procesos de financiación.

Es el proceso que se encarga de la búsqueda de clientes potenciales para convertirlos en clientes finales.

Es el proceso que se encarga de las ventas de productos o servicios, la cual constituye la base de las operaciones de la empresa.

Es el proceso que se encarga de definir la gestión de resultados, rendimiento y riesgos técnicos de la empresa.

Es el proceso que se encarga de la gestión de crisis y del talento humano.

Se encarga del desarrollo de actividades y estrategias para alcanzar el cobro de deudas.

Estable los canales de comunicación hacía el Cliente. Con el fin de que el Cliente tenga manera para manifestar reclamos, sugerencias, solicitar información o plantear inquietudes sobre el producto y/o servicio de la organización.

Es el proceso que se encarga de la eficiencia administrativa del capital de trabajo dentro de un criterio de riesgos y rentabilidad; además, de orientar la estrategia financiera para garantizar la disponibilidad de fuentes de financiación. Asimismo se encarga de llevar un registro y control de las operaciones financieras que se lleva a cabo en la organización.

Es el proceso que se encarga de planificar, diseñar, ejecutar y monitorear la estrategia de las tecnologías de la información. Además, de supervisar y evaluar el alineamiento de los sistemas de información a los procesos de la organización. 


\section{(1)}

Gestión Legal administrativos y emisión de conceptos jurídicos

Es la que se encarga de controlar la legalidad de los actos relacionados con el objeto y función de la empresa.

Es el proceso que se encarga de la adquisición, manejo y

Gestión de Recursos administración de elementos, equipos e inmuebles y los procesos para su almacenamiento, custodia, inventario, Físicos distribución y mantenimiento, servicios generales, archivos y correspondencia.

Este proceso se encarga de gestionar y coordinar la

Gestión de RRHH aplicación de las normas y los procedimientos de los recursos humanos. Las cuales desarrollan y aplican en los sistemas de información en la gestión del talento humano.

Es el proceso que se encarga de regular la planificación,

Auditoría organización, realización y comunicación de las auditorías internas de la empresa.

Está integrado por el gerente comercial y da a conocer la definición de actividades relacionadas con el cliente, de tal

Soporte Comercial modo de asegurar la correcta determinación de los requisitos relacionados con el producto y/o servicio estableciendo disposiciones eficaces para la comunicación con los clientes.

Es el proceso que se encarga de la producción de bienes y Gestión Operacional servicios, basados en toma de decisiones sobre eficiencia y efectividad.

Nota. Descripción de procesos del negocio. Elaboración propia.

\section{MISIÓN}

"Superarnos día a día para ofrecerte la tranquilidad que mereces".

(La Positiva, 2018)

\section{VISIÓN}

"Ser la mejor opción del mercado asegurador".

(La Positiva, 2018) 


\section{(}

\section{VALORES}

Vida y Fidelidad: Promovemos el continuo desarrollo, estimulando en nuestros colaboradores el balance entre su vida personal y laboral.

Integridad y Profesionalismo: Creemos en la transparencia y congruencia entre el pensamiento y la acción. La confianza es el pilar de nuestro servicio

Respeto y Sensibilidad: Somos personas que respetamos a las personas y sus derechos. Escuchamos, comprendemos y actuamos.

Excelencia y agilidad: La atención oportuna nos impulsa a tomar decisiones rápidas y actuar de manera ágil y eficaz, evolucionando nuestros productos.

Liderazgo y Sustentabilidad: Desarrollamos líderes con capacidad de inspirar energía, pasión y entusiasmo en otros.

Innovación: La mejora continua de nuestros procesos y creación de nuevos productos son clave en nuestro día a día. Nuestro Laboratorio de Innovación es la palanca de cambio que necesitamos. (La Positiva, 2018)

\section{OBJETIVOS ESTRATÉGICOS}

La organización tiene dentro de sus objetivos la diversificación y masificación de sus productos, la gestión eficiente de sus recursos para el incremento de valor, incrementar su competitividad en el mercado, lograr incrementar su presencia en el sector mejorando su participación en el sector de seguros de vida; para el logro de estos objetivos desde el 2016 se encuentra realizando cambios sustanciales e invirtiendo en el desarrollo de proyectos que ayudaran al logro de los mismos. Dentro de las acciones tomadas para el logro de los objetivos se están realizando acciones y estrategias para lograr insertar sus productos en las regiones aun no cubiertas para cubrir todos los mercados tanto en Lima como en provincias, para esto viene repotenciando su área comercial, fundamentándose esta masificación en la potenciación de su marca. Para el logro de la maximización de valor tanto internamente como externamente, se encuentra desarrollando proyectos en los cuales se analizan los procesos que vienen desarrollando la compañía en su gestión y se encuentra tomando medidas para su optimización y así lograr el mayor rendimiento de la gestión actual entre las compañías que forman parte del Grupo asegurador, 


\section{$(1$}

Los objetivos estratégicos de la empresa se nombran a continuación:

- OE1: Asegurar la generación de valor para el accionista y la sociedad.

- OE2: Garantizar eficiencia en los gastos y costos.

- OE3: Cada Cliente de la organización debe ser capaz de realizar la interacción con los Productos y Servicios que se ofrecen desde cualquier canal de atención y en cualquier momento.

- OE4: Garantizar la satisfacción de las necesidades y expectativas del cliente.

- OE5: Incrementar la cartera de clientes con respecto al periodo pasado

- OE6: La organización debe seguir una ruta de ejecución para transformarse en un Negocio Digital de Seguros.

- OE7: Garantizar la cobertura nacional de los sistemas integrales de gestión.

- OE8: Asegurar un sistema integral de gestión y control de proveedores alineados con la estrategia de la organización.

- OE9: Fortalecer la cultura corporativa enfocado al servicio.

- OE10: Incrementar el posicionamiento y la participación del mercado.

- OE11: Elevar la satisfacción del clima laboral con respecto al año anterior.

Nota: Información adaptada de los objetivos estratégicos de una Entidad Aseguradora en Lima. 


\section{MATRIZ DE OBJETIVOS ESTRATÉGICOS VERSUS PROCESOS DE NEGOCIO}

Tabla $\mathrm{N}^{\circ} 5$

Matriz de objetivos estratégicos versus procesos de negocio.

\begin{tabular}{|c|c|c|c|c|c|c|c|c|c|c|c|}
\hline \multirow{2}{*}{ MACRO PROCESO } & \multicolumn{11}{|c|}{ OBJETIVO ESTRATEGICOS } \\
\hline & OE1 & OE2 & OE3 & OE4 & OE5 & OE6 & OE7 & OE8 & OE9 & OE10 & OE11 \\
\hline 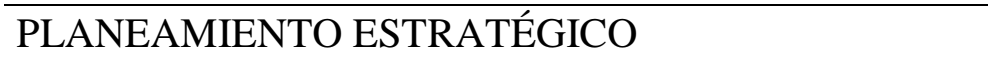 & $\mathrm{X}$ & & & & & $\mathrm{X}$ & & $\mathrm{X}$ & & $\mathrm{X}$ & \\
\hline GESTIÓN DE INVERSIONES & & $\mathrm{X}$ & & & & $\mathrm{X}$ & & & & $X$ & \\
\hline CAPTACIÓN DE CLIENTE & & & & $\mathrm{X}$ & $\mathrm{X}$ & & & & & & \\
\hline VENTA & $\mathrm{X}$ & & $\mathrm{X}$ & $\mathrm{X}$ & $X$ & & & & & & \\
\hline GESTIÓN ACTUARIAL & $X$ & & & & & & & & & & \\
\hline GESTIÓN DEL DESARROLLO HUMANO & & & & & & & & & $X$ & & $\mathrm{X}$ \\
\hline COBRANZAS & & & & & & & & & & & \\
\hline POST-VENTA & & & & $\mathrm{X}$ & $\mathrm{X}$ & & & & & & \\
\hline GESTIÓN FINANCIERA Y CONTABLE & & $\mathrm{X}$ & & & & & & & & & \\
\hline GESTIÓN DE TECNOLOGÍA DE LA INFORMACIÓN & & & $\mathrm{X}$ & & & $\mathrm{X}$ & $\mathrm{X}$ & & & & \\
\hline GESTIÓN LEGAL & & & & & & & & & & & \\
\hline GESTIÓN DE RECURSOS FÍSICOS & & & & & & & $\mathrm{X}$ & & & & \\
\hline GESTIÓN DE RRHH & & & & & & & & & $X$ & & $\mathrm{X}$ \\
\hline AUDITORÍA & & & & & & & & $X$ & & & \\
\hline SOPORTE COMERCIAL & & & & & & & & $X$ & & & \\
\hline GESTIÓN OPERACIONAL & & & $\mathrm{X}$ & & & & $X$ & & & & \\
\hline
\end{tabular}

Nota. Matriz de objetivos estratégicos versus procesos de negocio. Elaboración propia. 


\section{$\boldsymbol{( 1 )}$}

\section{ORGANIGRAMA}

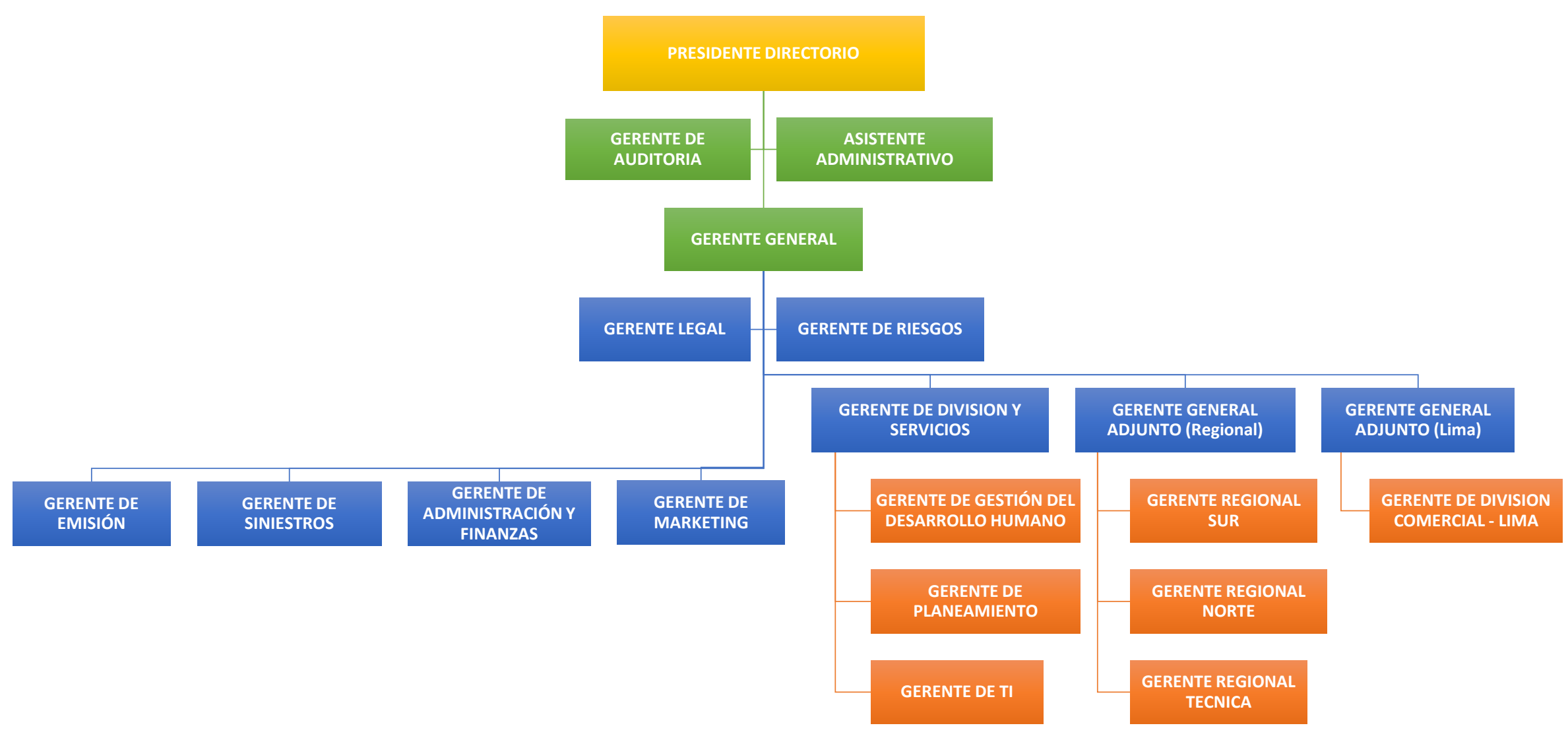

Figura $N^{\circ} 2$ Organigrama

Fuente: Elaboración propia. 


\section{()}

Tabla $\mathrm{N}^{\circ} 6$

Descripción de funciones por cargo en la organización.

\begin{tabular}{ll}
\hline Cargo & Descripción \\
\hline Presidente & Responsable de hacer cumplir en la estrategia y control de gestión, \\
Directorio & las compensaciones de los ejecutivos, la relación con los accionistas \\
& y otros Stakeholders y la gestión de riesgos.
\end{tabular}

Gerente de

Auditoria

Es el encargado de liderar los proyectos de cada cliente de la línea de servicio de auditoría. Además, realiza el presupuesto del proyecto como también de la selección del equipo que tendrá por proyecto. Por último, se encarga del seguimiento y control de su equipo de trabajo hasta la finalización del proyecto.

- Atención inmediata de los requerimientos de la Gerencia General

Asistente

(Gerentes y demás colaboradores del área.

Administrativo

- Administrar y controlar la Agenda del Gerente General LPV.

- Realizar la coordinación y convocatoria de reuniones internas y externas del Gerente General.

'- Elaborar el plan estratégico de la empresa, coordinando apoyo, soporte y recursos de las áreas de soporte y sinergias de las gerencias
Gerente General a su cargo, garantizando que el negocio tenga la rentabilidad esperada y que las metas en el corto plazo se armonicen con los objetivos estratégicos.
-' Hacer seguimiento al cumplimiento del plan estratégico.
- Representar, judicial y extrajudicialmente, a la empresa, con la finalidad de salvaguardar los intereses de la misma. - Elaborar y revisar los contratos y convenios que soliciten las Gerente Legal diferentes áreas de la empresa y coordinar lo concerniente a los términos de su suscripción. - Elaborar y revisar los contratos y convenios que soliciten las diferentes áreas de la empresa y coordinar lo concerniente a los términos de su suscripción.

Controlar los circuitos de gestión de siniestros tanto para daños

Gerente de Siniestros

Gerente de Riesgos
Asegurar el cumplimiento de la evaluación de los riesgos de forma previa a nuevos emprendimientos, al lanzamiento de nuevos productos, operaciones, servicios y antes cambios importantes en el ambiente operativo o informático. 


\section{$(1)$}

Gerente de Emisión

Es el encargado de gestionar los procesos de emisión de pólizas y de definir sus características funcionales.

Contribuir a la toma de decisiones por parte de la Gerencia General a

Gerente de través de la evaluación de la ejecución presupuestal, de la Administración y interpretación de los Estados Financieros, la solidez patrimonial y la Finanzas liquidez de la compañía, así como participando en el Comité de Inversiones.

Gerente de

Marketing

Gerente de División y Servicios

Es el encargado de desarrollar estrategias de marketing a corto y largo plazo en la organización. Entre las cuales están estrategias como: desarrollo de la marca, inteligencia competitiva y relaciones públicas.

- Lograr la satisfacción del cliente a través de una oferta de servicio estandarizado a nivel nacional que exceda las expectativas del cliente, con la finalidad de fidelizarlos. - Optimizar los recursos y garantizar un nivel de atención óptimo en Línea y en Plataforma de Servicio.

- Responsable y representante directo de la empresa en ausencia, o Gerente General Adjunto (Regional) no, del Gerente General. Responsable del correcto funcionamiento de las áreas de Administración, Finanzas, Recursos Humanos, Ventas, Logística, etc. Encargado de tomar decisiones en ausencia del Gerente General o en coordinación con el mismo a nivel Regional.

- Responsable y representante directo de la empresa en ausencia, o Gerente General Adjunto (Lima) no, del Gerente General. Responsable del correcto funcionamiento de las áreas de Administración, Finanzas, Recursos Humanos, Ventas, Logística, etc. Encargado de tomar decisiones en ausencia del Gerente General o en coordinación con el mismo a nivel de Lima.

Nota. Descripción de funciones por cargo en la organización. Elaboración propia.

\section{ALCANCE DEL PROYECTO}

El presente proyecto propone elaborar una arquitectura empresarial para una entidad aseguradora. Para ello, se tomará un proceso de negocio dentro de todos los conformados dentro de las líneas de servicios de la organización; en este caso, se tomará el proceso de Gestión de Emisión el cual pertenece al macro proceso de venta el cual es de suma importancia para la organización. Por lo tanto, se debe plantear lineamientos necesarios para 


\section{(1)}

mejorar los procesos y dar soporte a los objetivos estratégicos relacionados de la organización.

En lo que corresponde a la arquitectura empresarial se realizará un análisis de la situación actual de la arquitectura empresarial de la organización mediante el AS-IS, revisando sus tres componentes como son: arquitectura de negocio, arquitectura de sistemas de información y arquitectura tecnológica. Para luego, realizar una nueva propuesta de la arquitectura empresarial mediante el TO-BE, en el cual, se evidenciará el detalle de sus tres componentes definidos anteriormente en el marco de referencia, que estará basado en TOGAF. Para lo cual se desarrollarán los artefactos petición de trabajo de arquitectura, documento de definición de arquitectura y plan de la implementación de la migración respectivamente.

Por parte del alcance del enfoque de desarrollo de software ágil. Previamente, se hará la identificación de fortalezas y debilidades del equipo de trabajo, con el fin de realizar un diagnóstico para identificar sus habilidades blandas y duras. Posteriormente, se harán dinámicas para fortalecer las habilidades del equipo y convertir en oportunidades las debilidades identificadas. Para luego, conformar el equipo y trabajar el proyecto que de valor al negocio de forma productiva.

\section{OBJETIVOS DEL PROYECTO}

\section{OBJETIVO GENERAL}

Elaborar una propuesta de arquitectura empresarial para la organización, la cual permita alinear los proyectos de TI a las estrategias del negocio; incorporando marco de trabajo ágil para el desarrollo de proyectos en el proceso de gestión de emisión.

\section{OBJETIVOS ESPECÍFICOS}

- Reconocer los objetivos estratégicos y procesos de negocio de la organización objetivo.

- Elegir un proceso clave o estratégico, e identificar la relación con los objetivos estratégicos de la organización.

- Determinar los beneficios tangibles e intangibles del proyecto. 


\section{(1)}

- Desarrollar los cuatro dominios de arquitectura base y destino enfocados en el proceso seleccionado.

- Reconocer las brechas entre la arquitectura base y destino desarrollados.

- Definir un plan de migración para alcanzar la arquitectura destino y proponer una solución tecnológica que permita reducir las brechas encontradas.

- Identificar las fortalezas y debilidades del equipo para afrontar un proyecto del plan de migración.

- Realizar un diagnóstico del grupo de trabajo que va a ejecutar el proyecto tecnológico.

- Identificar las dinámicas que deben implementarse para ejecutar el proyecto.

- Formar un equipo de trabajo con los conocimientos necesarios para la implementación de la solución tecnológica.

- Identificar las herramientas que se deben utilizar en el proyecto tecnológico seleccionado.

\section{BENEFICIOS DEL PROYECTO}

\section{BENEFICIOS TANGIBLES}

- Mejora en el tiempo de respuesta de las peticiones entrantes en el proceso de gestión de emisión de pólizas SCTR en un 30\%.

- Garantizar en un 100\% la disponibilidad del sistema de gestión de emisión de pólizas SCTR.

- Reducir en un 98\% el bloqueo en la base de datos del core business.

- Incremento en un $40 \%$ de productividad en áreas operativas y estratégicas de la organización.

\section{BENEFICIOS INTANGIBLES.}

- Un mejor alineamiento de los proyectos a los objetivos estratégicos de la organización.

- Incremento de la calidad en el servicio de gestión de emisión de pólizas SCTR. 


\section{(1)}

- El cliente debe ser capaz de realizar la interacción con los productos y servicios desde cualquier canal de atención y en cualquier momento.

- Empoderar a los clientes y/o corredores. 


\section{(1)}

\section{CAPÍTULO 2: MARCO TEÓRICO}

\section{MARCO TEÓRICO}

El presente capítulo presenta fundamentos teóricos sobre Arquitectura Empresarial la cual se presentará de acuerdo al uso de un marco de referencia determinado por TOGAF, la cual proporcionará un enfoque para el diseño, planificación y gobierno de la arquitectura empresarial. Asimismo se presenta los fundamentos teóricos para Métodos Agiles para el desarrollo de Software y su comparación con metodologías tradicionales.

\section{ARQUITECTURA EMPRESARIAL}

Según Felipe Millán (Millán 2012) "Arquitectura Empresarial es una práctica que busca alinear la estrategia de un negocio con su ejecución, lo cual es un aspecto crítico en las organizaciones modernas que requieren gran flexibilidad y agilidad para ser competitivas y adaptables al cambio."

La arquitectura empresarial es un conjunto de métodos, principios y modelos de la estructura organizacional, asimismo sus procesos de negocio, infraestructura tecnológica y sus sistemas de información, es importante para el buen gobierno de la empresa, debido a que muestra una visión integral de la organización y poder realizar las mejoras continuas del negocio.

Según María Isabel Mejia (Mejia 2013) "La Arquitectura Empresarial es una metodología que, basada en una visión integral de las organizaciones o en este caso, de todo el Estado, permite alinear procesos, datos, aplicaciones e infraestructura tecnológica con los objetivos estratégicos del negocio o con la razón de ser de las entidades."

Por tanto, la arquitectura empresarial garantiza que los procesos de la organización cumplan con el propósito de alcanzar los objetivos estratégicos. 


\section{(1)}

Según J.A. Zachman (Zachman 1987) “Con el aumento del tamaño y la complejidad de las implementaciones de los sistemas de información, es necesario utilizar algún constructor lógico (o arquitectura) para definir y controlar las interfaces y la integración de todos los componentes del sistema.” (p. 276).

Las organizaciones que logren desarrollar su Arquitectura Empresarial tienen desde ya una gran herramienta para la toma de decisiones, optimizar recursos y de esta manera lograr sus objetivos. Una función de la arquitectura es definir los lineamientos informáticos para resolver las necesidades actuales y prever las futuras. La arquitectura de los sistemas de información se define desarrollando un marco descriptivo de disciplinas, neutral y objetivo.

Existen cuatro metodologías o marcos de trabajo ('frameworks') de alto reconocimiento para desarrollar la AE:

\section{Metodologías y frameworks de Arquitectura Empresarial}

\begin{tabular}{|c|}
\hline MARCO DE TRABAJO DE ZACHMAN \\
\hline $\begin{array}{l}\text { - Primer modelo de AE (1987) } \\
\text { - Demasiados elementos estructurados y organizados } \\
\text { - No propone un método para obtener cada elemento }\end{array}$ \\
\hline MARCO FEDERAL DE ARQUITECTURA EMPRESARIAL \\
\hline $\begin{array}{l}\text { - Modelo de AE desarrollado por y para el Gobierno de los Estados Unidos } \\
\text { - Emitido por la Casa Blanca } \\
\text { - Orientado a integrar el trabajo de las distintas Agencias del Gobierno y sus stakeholders }\end{array}$ \\
\hline MÉTODO GARTNER \\
\hline $\begin{array}{l}\text { - Conocido como el "Cuadrante mágico" } \\
\text { - Busca integrar, analizar y comunicar información estructurada y no estructurada } \\
\text { - A modo de plano cartesiano, reúne en un cuadrante a líderes, competidores, jugadores de nicho y visionarios }\end{array}$ \\
\hline TOGAF ("The Open Architecture Framework") \\
\hline $\begin{array}{l}\text { - Creado por "The Open Group" (creadores de UNIX, reúne sector público y privado a nivel mundial) } \\
\text { - Desarrolla el proceso de AE en } 8 \text { fases sistemáticas y entrega manuales de emplementación para que } \\
\text { la organización los siga }\end{array}$ \\
\hline
\end{tabular}

Figura $N^{\circ} 3$ Metodologías y Framework de Arquitectura Empresarial. Adaptado de "Metodologías y frameworks de Arquitectura Empresarial”, por Colombia Digital, 2018. 


\section{(}

\section{Componentes de la Arquitectura Empresarial}

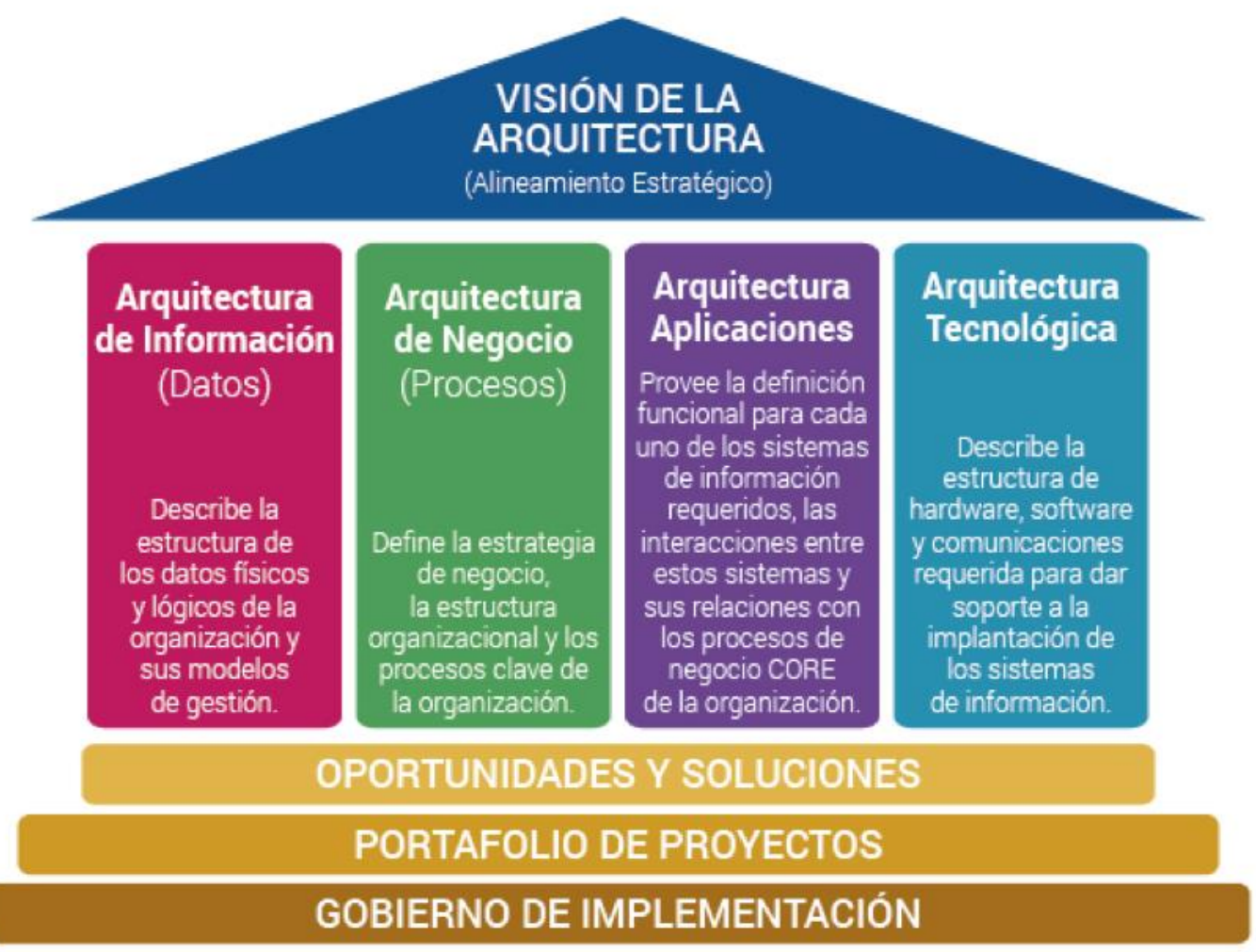

Figura $N^{\circ} 4$ Componentes de la Arquitectura Empresarial. Adaptado de "Componentes de la Arquitectura Empresarial”, Colombia Digital, 2018.

\section{TOGAF}

"TOGAF es un marco de arquitectura empresarial que ayuda a definir los objetivos comerciales y alinearse con los objetivos comerciales en torno al desarrollo de software empresarial. El Open Group Architecture Framework (TOGAF) es una arquitectura empresarial que ofrece un marco de alto nivel para el desarrollo de software empresarial. Ayuda a organizar el proceso de desarrollo a través de un enfoque sistemático para reducir los errores, mantener los plazos, mantenerse dentro del presupuesto y alinear la TI con las unidades de negocios para producir resultados de calidad.” CIO España. (2018)

\section{Método de desarrollo de la Arquitectura TOGAF}




\section{(1)}

"La clave de TOGAF es el método - Método de Desarrollo de la Arquitectura (ADM por sus siglas en inglés) - para desarrollar una Arquitectura Empresarial que aborda las necesidades del negocio". El ADM de TOGAF funciona de modo iterativo, es decir, por fases que avanzan progresivamente pero que a la vez permiten la revisión y ajuste de cada una de ellas durante el proceso."

Corporación Colombia Digital. (2018)

\section{El Ciclo del Método de Desarrollo de la Arquitectura}

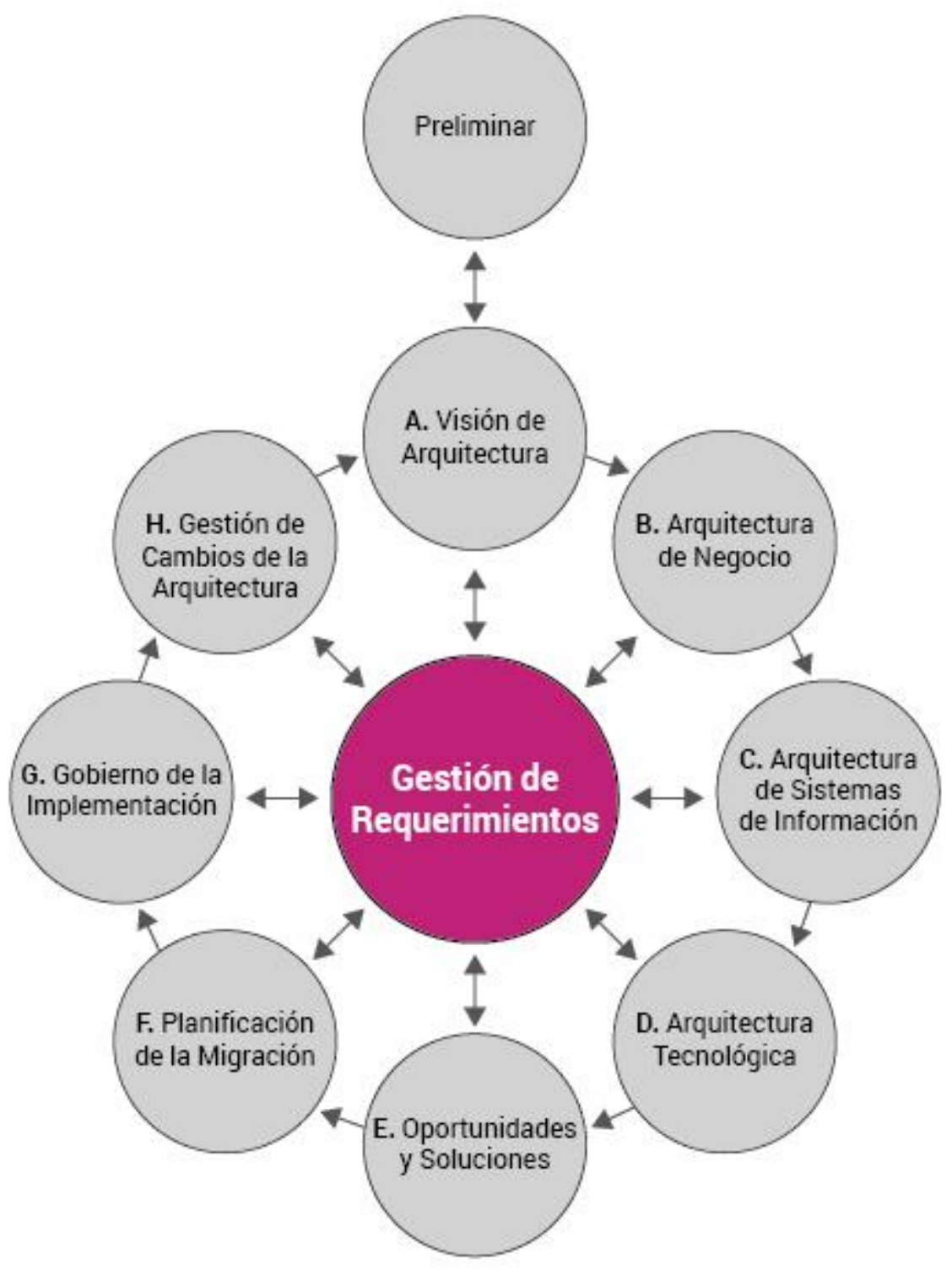




\section{(1)}

Figura $N^{\circ} 5$ Fases de ADM. Adaptado de "El Ciclo del Método de Desarrollo de la Arquitectura”, Colombia Digital, 2018.

\section{Fases de Desarrollo de TOGAF}

TOGAF se compone de 10 fases donde la gestión de requerimientos interactúa con las demás. La metodología provee y necesita mucha documentación, por tal motivo se puede aprovechar la reusabilidad de la misma.

\section{Fase Preliminar}

Es una de las más críticas puestos que es donde se prepara y se inician las actividades en todo el proceso. Acá se entienden los entornos del negocio y se establece los principios y la estructura de gobierno.

"Todos los cambios que se hagan tienen que estar soportados por escrito"

\section{Fase A Visión de la Arquitectura}

En esta fase se definen los Stakeholders, la visión de la Arquitectura Empresarial y se desarrolla el documento de visión de arquitectura, la cual proporcionará una guía general de los cambios que se tendrán que realizar en la organización. Adicionalmente se definen los objetivos, misión, visión y demás.

\section{Fase B Arquitectura del Negocio}

Muestra como la organización conoce sus objetivos del negocio. Se establece la relación de los procesos entre sí, los principios de gobierno, diseño y evolución. Intervienen las funciones del negocio, servicios del negocio, procesos del negocio, roles del negocio y los objetivos del negocio. Dispone de 8 pasos

- Seleccionar los modelos de referencia, puntos de vista y herramientas

- Definición de la descripción de la arquitectura base

- Definición de la descripción de la arquitectura objetivo

- Ejecutar análisis de brechas 


\section{(1)}

- Definir la trayectoria candidata para componentes

- Revisión formal de las conductas de los Stakeholders

- Finalizar la arquitectura

- Crear el documento que define la arquitectura

\section{Fase C Arquitecturas de los sistemas de información}

El objetivo a perseguir con los sistemas de información en las empresas es automatizar la empresa. Si logramos que los SI resuelvan la automatización de la empresa entonces se podría escalar a los llamados sistemas de conocimiento.

Se debe hacer un proceso de iteración entre ambos para tener los modelos balanceados. La forma más ordenada de llegar a un mejor balanceo es partiendo de un enfoque orientado a procesos.

\section{Fase D Arquitectura tecnológica}

Se tiene la tecnología misma sobre la que se van a implementar las soluciones como: hardware, protocolos, software de desarrollo, sistemas de soporte para desarrollar los SI y tecnología de comunicaciones.

Se requerirá de diagramas de la tecnología para la implementación.

\section{Fase E Oportunidades y soluciones}

En esta fase de realiza el plan de implementación, y se especifica cómo se van a implementar esas soluciones.

Se ejecutará el inventario de todos los proyectos que necesito tener para lo que voy a hacer.

Determinar si se va a pasar de un punto "A" a un punto "B" de modo incremental o de un solo paso.

Decidir sobre el enfoque:

- Hacerlo o Comprarlo o Re-usarlo. 


\section{(1)}

- Proceso de tercerización (que se contrata y que no).

- Mirar si en el mercado existen soluciones que yo pueda comprar.

- Mirar soluciones híbridas.

- Open Source: Comprar cajas negras o blancas.

- Problemas desde el punto de la implementación:

La nube o no la nube.

Priorización (el orden en que se van a hacer las cosas, cómo se van a afrontar esos proyectos).

Cumplimiento (cumplimientos regulatorios).

\section{Fase F Planificación de la Migración}

Una vez definida la solución de la arquitectura, se implementan los paquetes de trabajo (de qué forma se trabajará) con sus respectivas oficinas de proyecto para definir las arquitecturas intermedias en la fase de migración.

En esta fase, los proyectos de migración identificados en la etapa anterior son priorizados. Para ello, se debe realizar la evaluación costo/beneficio, análisis de riesgo y la asignación del valor para el negocio que se obtiene con ellos. Además, la hoja de ruta de arquitectura debe ser confirmada, el documento de definición de arquitectura debe ser actualizado y el plan de implementación y migración debe ser finalizado.

\section{Fase G Gobierno de la implementación}

Se busca que todo el proceso de implementación que se estableció siga su curso.

Verificar que los contratos estén bien elaborados y orientados a alcanzar los objetivos planteados.

Garantizar que lo que se está haciendo cumpla especificaciones, normas, políticas y directrices.

Garantizar que todo lo que se está haciendo le está agregando valor a la organización.

Una ventaja de la gobernanza es que brinda una visión global de toda la problemática 


\section{(}

\section{Fase H Gestión del Cambio}

Los Ingenieros de sistemas somos gestores de cambio de manera permanente.

Hay que pensar en cómo hacer para que el cambio sea aceptado por una población que normalmente tiene inercia a seguir como venía haciéndolo.

En esta fase se revisa que la arquitectura resultante alcance el valor para el negocio que se había establecido como objetivo. Además, también deben estar establecidos los procedimientos necesarios para poder gestionar el cambio, tanto el proceso para la implementación del cambio como el seguimiento y la gestión de riesgos.

\section{Gestión de requerimientos}

La fase central, la "gestión de requerimientos", afecta a todas las fases del ciclo ADM, porque en cualquier fase se puede hacer una petición de requerimientos y se va a tener que evaluar y gestionar.

\section{METODOLOGÍAS ÁGILES PARA EL DESARROLLO DE SOFTWARE}

"Las metodologías ágiles nacen bajo la necesidad de centrarse en el desarrollo del software y entregar productos que sean usables antes que la documentación o procesos estrictos para lograrlos.” (Pérez, 2011).

El desarrollo ágil de software se basa en métodos de ingeniería de software, la cual se realiza en ciclos iterativos e incrementales debido a los frecuentes cambios a la que está expuesto un proyecto. Para ello, se deben considerar los requisitos y soluciones de cada proyecto para poder formar un equipo de trabajo auto organizado y multidisciplinario.

\section{Comparativa metodologías ágiles vs tradicionales}

Los métodos tradicionales consideran el uso constante de documentación durante todo el ciclo del proyecto y su énfasis en el total cumplimiento del mismo, mientras que los ágiles se 


\section{(1)}

enfocan en la capacidad de respuesta ante los cambios, en las habilidades del equipo y a mantener una buena relación con el cliente.

Entre las metodologías tradicionales se encuentran RUP y MSF cuyas características son los altos costos ante posibles cambios en el ciclo de desarrollo; mientras que, en las metodologías ágiles se basa en la adaptación a los cambios, permitiendo de esta manera potenciar el desarrollo de software, y entre las cuales se encuentran: XP, SCRUM, ICONIX y CRISTAL METHODS.

A continuación, veremos una tabla comparativa con los aspectos más destacados que establecen diferencias entre ambas metodologías:

\begin{tabular}{|c|c|}
\hline METODOS AGILES & METODOS TRADICIONALES \\
\hline $\begin{array}{l}\text { Basadas en eucarísticas provenientes de prácticas de } \\
\text { producción de código. }\end{array}$ & $\begin{array}{l}\text { Basadas en normas provenientes de estándares seguidos } \\
\text { por el entorno de desarrollo }\end{array}$ \\
\hline Impuestas internamente (por el equipo). & Impuestas externamente. \\
\hline Proceso menos controlado, con pocos principios & $\begin{array}{l}\text { Proceso mucho más controlado, con numerosas } \\
\text { políticas/normas. }\end{array}$ \\
\hline No existe contrato tradicional o al menos & Existe un contrato prefijado. \\
\hline \multicolumn{2}{|l|}{ Es bastante flexible. } \\
\hline El cliente es parte del equipo de desarrollo. & $\begin{array}{l}\text { El cliente interactúa con el equipo de desarrollo } \\
\text { mediante reuniones. }\end{array}$ \\
\hline $\begin{array}{l}\text { Grupos pequeños ( }<10 \text { integrantes) y trabajando en el } \\
\text { mismo sitio. }\end{array}$ & Grupos grandes y posiblemente distribuidos. \\
\hline Pocos artefactos. & Más artefactos. \\
\hline Pocos roles & Más roles. \\
\hline Menos énfasis en la arquitectura del software. & $\begin{array}{l}\text { La arquitectura del software es esencial y se expresa } \\
\text { mediante modelos. }\end{array}$ \\
\hline
\end{tabular}

Figura $N^{\circ} 6$. Características más notables entre los Métodos Ágiles y los Tradicionales. Adaptado de "Comparativa metodologías ágiles vs tradicionales", Avante, 2018.

\section{SCRUM}




\section{(1)}

"SCRUM es un proceso en el que se aplican de manera regular un conjunto de buenas prácticas para trabajar colaborativamente, en equipo, y obtener el mejor resultado posible de un proyecto. Estas prácticas se apoyan unas a otras y su selección tiene origen en un estudio de la manera de trabajar de equipos altamente productivos.” Proyectos Ágiles ORG (2018).

Durante el desarrollo de SCRUM se realizan entregas parciales en forma consecuente y regular del producto final. La prioridad de cada entrega está basada en su beneficio aplicado al proyecto. La aplicación de Scrum mayormente se encuentra en escenarios complejos, donde se necesitan resultados a corto plazo y cuyos requisitos son cambiantes o poco definidos, y donde son fundamentales la competitividad, flexibilidad, productividad e innovación.

Scrum también es de utilidad cuando no se está entregando al cliente lo que necesita realmente, cuando los entregables son tardíos, los costos de elevan o la calidad no es aceptable.

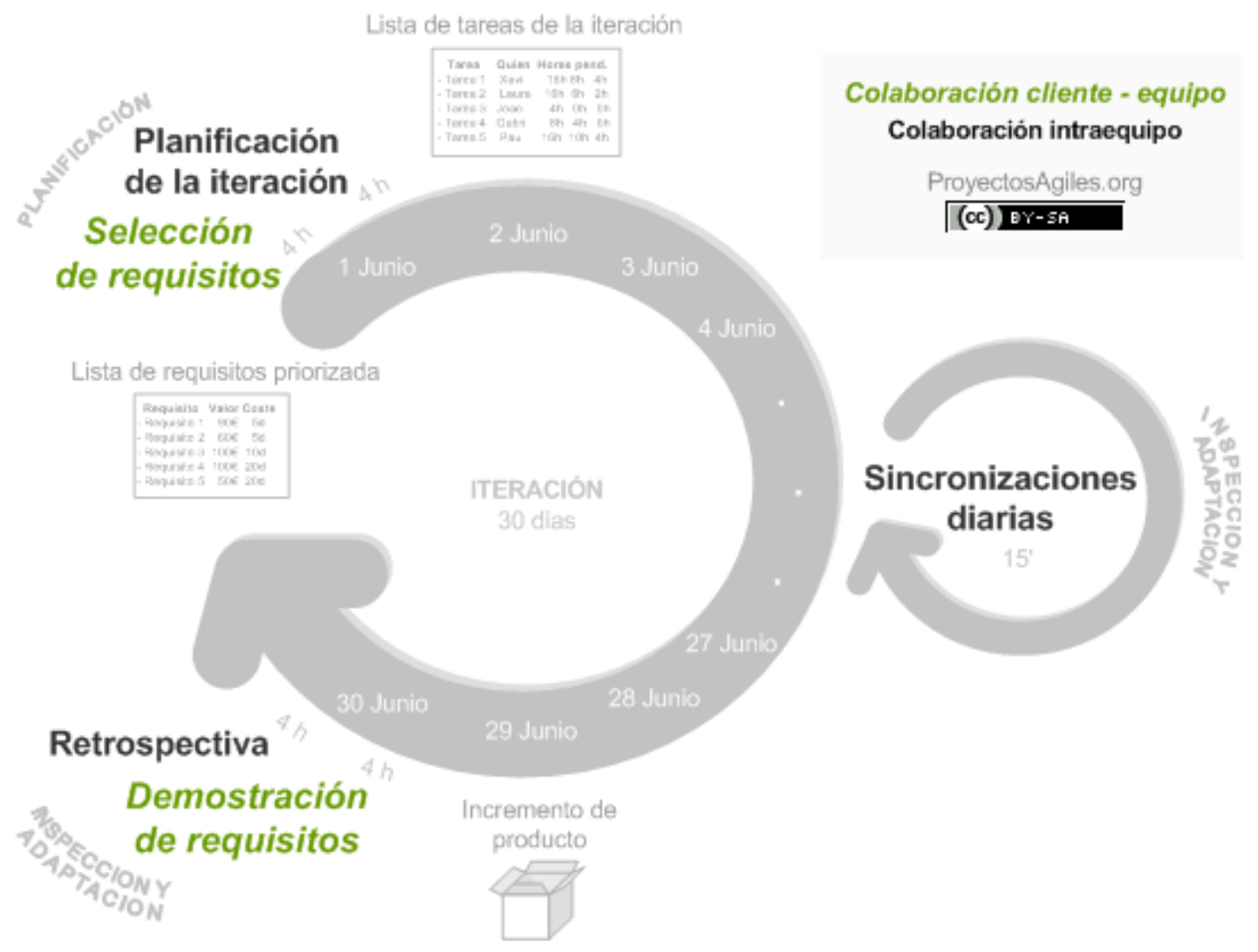




\section{(1)}

Figura $N^{\circ} 7$. Descripción gráfica de los ciclos de Scrum. Adaptado de "Ciclos Scrum", Proyectos Ágiles, 2018.

\section{Etapas en los "Sprint" de un desarrollo SCRUM}

Los Sprint son los que dan vida a SCRUM y tiene la característica de ser intervalos que originan el incremento en el producto "Hecho o Terminado" usable.

Durante el desarrollo pueden existir Sprints de duración constante y. Son considerados como proyectos pequeños de duración menor o igual a un mes. La finalidad de cada Spring es alcanzar un objetivo y se define claramente lo que se tiene que construir, un diseño y un plan que guíe el trabajo y el producto final.

\section{Artefactos de SCRUM:}

\section{Product Backlog}

Es un listado que contiene todo lo que necesita el producto para satisfacer las necesidades del cliente.

\section{Sprint Backlog}

Son los ítems o elementos de Product Backlog considerados en el Sprint, los cuales se entregarán en forma incremental para poder conseguir el objetivo del Sprint.

\section{Sprint}

Es cada iteración de desarrollo, y es considerado el motor que genera cada avance en tiempos prefijados.

\section{Incremento}

Es el resultado de cada Sprint.

SCRUM consta de 5 etapas:

\section{Reunión de planificación de Sprint}

Aquí es donde se planifica el trabajo a realizar en el Sprint y se elabora con la colaboración de todo el equipo SCRUM. 


\section{(1)}

Cada reunión de planificación es de tiempo variable y por ejemplo para Sprint de duración de un mes se podría determinar hasta 8 horas de duración, y por el contrario para Sprint mas cortos se toma un tiempo proporcional al sugerido.

La finalidad de la reunión de planificación de Sprint es definir la funcionalidad en el incremento planificado y como será llevado a cabo dicho incremento, así como también definir el objetivo de cada Sprint. La reunión constara de 2 partes, las cuales responderán a las siguientes preguntas:

- ¿Qué va a ser entregado en el incremento resultante del próximo Sprint?

- ¿Cómo se va a realizar el trabajo seleccionado?

\section{EI SCRUM Diario}

Tiene como objetivo la sincronización de las actividades y cada evento tendrá una duración de 15 minutos, el cual servirá para crear un plan para las próximas 24 horas. Antes de empezar el SCRUM diario se revisa el trabajo realizado el día anterior y suele realizarse a la misma hora y lugar cada día para reducir la complejidad.

El equipo de desarrollo evalúa el progreso del Sprint mediante el uso de SCRUM Diario, asimismo podrá verificar la tendencia del avance en cuanto al trabajo definido en el Sprint Backlog. Diariamente el equipo de desarrollo debe ser capaz de explicar al Product Owner y al Scrum Master la forma de trabajo del equipo para el logro del objetivo.

Con los Scrum diarios se obtiene una mejora en la comunicación, identificación y eliminación de obstáculos en el desarrollo, se promueve la rápida toma de decisiones y se mejora el nivel de conocimiento en cuanto al proyecto por parte del equipo. El Scrum diario es la clave para el seguimiento y adaptación.

\section{Trabajo de desarrollo durante el Sprint}

Durante el Sprint se asegura lo siguiente:

- No realizar modificaciones que impacten en el objetivo del Sprint

- No disminuir los objetivos de calidad

- El alcance podrá re-negociarse entre el Product Owner y el equipo de desarrollo a medida del avance 


\section{(1)}

Si el Sprint es muy largo, la definición de lo que se construye puede cambiar, aumentando la complejidad y el riesgo. Los Spring nos permiten prever y adaptarnos según los avances hacia la meta cada mes.

\section{Revisión del Sprint}

Se realizan al final de cada Sprint, con la finalidad de inspeccionar el incremento y adaptar, en caso fuera necesario el Product Backlog. El equipo Scrum y los Stakeholders aportan durante la revisión lo que se realizó en el Sprint. Si se realiza cualquier modificación en el Product Backlog, se tiene que trabajar en las próximas horas sobre lo que se debe hacer mediante una reunión informal, donde se exponga el incremento destinado a obtener retroalimentación y se fomente la colaboración.

Los participantes son el Equipo Scrum y los Stakeholders invitados por el Product Owner, el cual identifica lo que ha "hecho" y lo que no. El equipo expone lo que sucedió con normalidad durante el Spring, los problemas y como se resolvieron estos últimos.

El equipo de desarrollo demuestra el trabajo realizado y si hubiera incremento, expone las causas.

El Product Owner analiza el estado actual, y propone las fechas estimadas de acuerdo al progreso.

Se revisa la línea de tiempo, presupuesto y el mercado, para la próxima entrega programada del producto.

\section{Retrospectiva del Sprint}

En esta parte se revisa la experiencia del último Sprint, respecto a personas, procesos y herramientas. Se identifican y ordenan los temas principales que tuvieron éxito y las posibles mejoras. Crear un plan para la implementación de mejoras de acuerdo al método de trabajo del Equipo Scrum.

\section{CYNEFIN}

Es un framework que muestra tipologías, dominios y modelos en los que un equipo de trabajo se desenvuelve, para entender las diferentes situaciones y ayudar de manera eficiente a responder ante una situación que pueda presentarse en un proyecto. 


\section{(1)}

Citando el paper Making Sense of IS with the Cynefin Framework (julio 2009, Helen Hasan), “Cynefin es el nombre de un marco de creación de sentido propuesto por Snowden (2002), el marco tiene cinco dominios que reflejan las diferentes relaciones entre causa y efecto en cada dominio y entre central y formas de trabajar en los diversos dominios. Cada dominio tiene un modo diferente de comportamiento de la comunidad y cada uno implica la necesidad de una forma diferente de gestión y un estilo de liderazgo diferente con la adopción de diferentes herramientas, prácticas y conceptos comprensión.”

Cynefin evalúa 4 dominios, y estos son:

\section{Simple o conocido}

En la cual la relación causa y efecto en evidente para todos, y se puede aplicar las mejores prácticas.

\section{Complicado}

En la cual la relación causa y efecto requiere de un análisis o alguna forma de investigación y se aplican buenas prácticas, así como también del conocimiento experto.

\section{Complejo}

En la cual la relación causa y efecto solo puede ser percibido en retrospectiva, pero no de antemano. Se permiten las prácticas emergentes.

\section{Caótico}

No existe una relación entre la causa y efecto a nivel de sistemas. Se descubren nuevas prácticas.

\section{Desorden}

Es el estado de no saber qué tipo de causalidad existe, por tanto, no se sabe qué forma de trabajar es la mejor.

\section{FODA}

Para Espinoza (2007) el análisis FODA es una herramienta de gestión que facilita el proceso de planeación estratégica, proporcionando la información necesaria para la implementación de acciones y medidas correctivas, y para el desarrollo de proyectos de mejora.

El análisis FODA considera los factores económicos, políticos, sociales y culturales que puedan influir, provenientes del ámbito externo que tengan impacto positivo o negativo en el interno. 


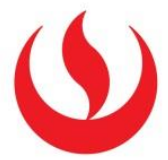

\section{CASO DE ÉXITO: ASEGURADORA INTERNACIONAL}

El caso de éxito significó dar soporte de Arquitectura Cloud a una entidad aseguradora internacional, la cual tuvo como alcance la Arquitectura Empresarial, Arquitectura de Soluciones y Arquitectura de Aplicaciones.

Se cumplieron los siguientes objetivos:

- Incorporación de Cloud como plataforma de desarrollo

- Identificación de proyectos para ser incorporados a arquitecturas Cloud

- Análisis y plan para transferir aplicaciones a plataforma IaaS

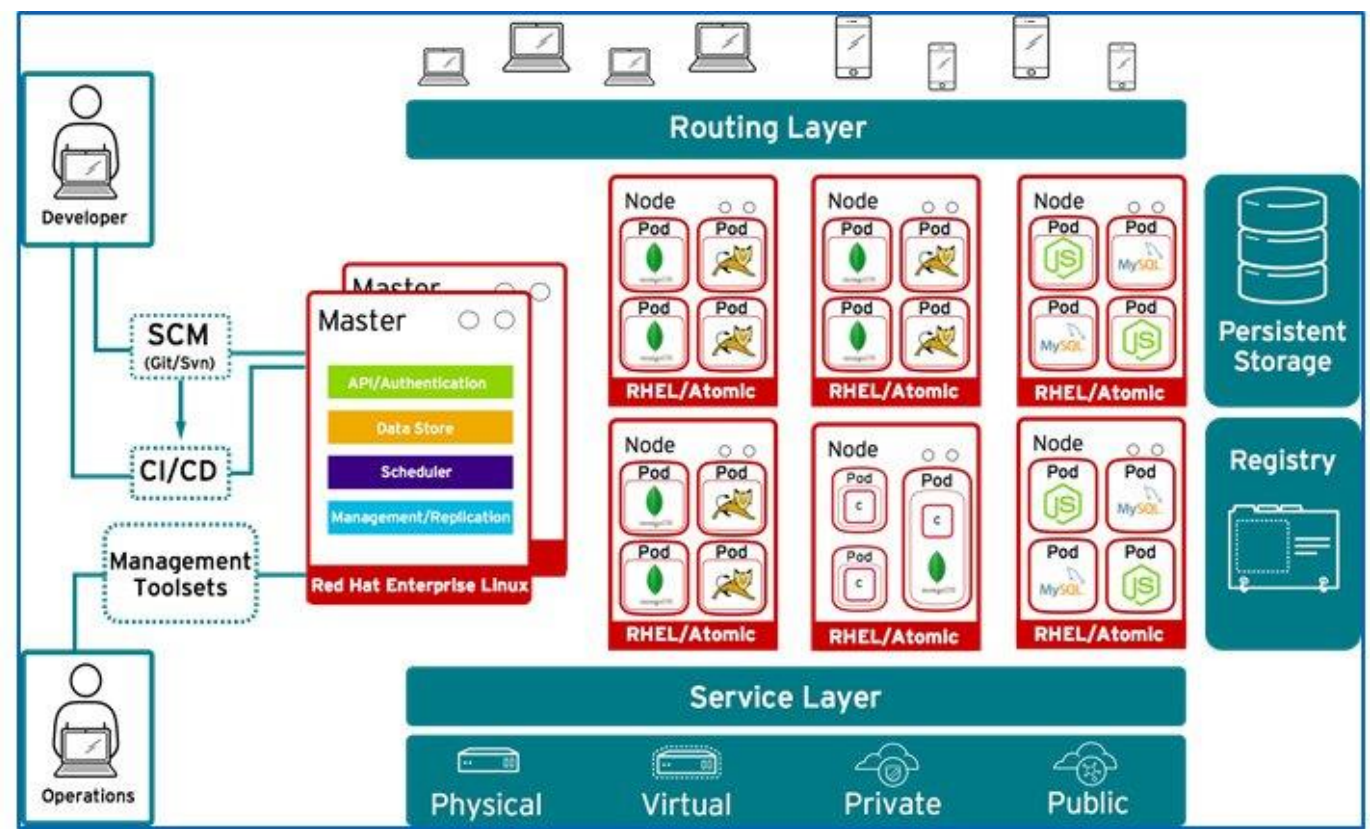

Figura $N^{\circ} 8$. Soporte de Arquitectura Cloud a una entidad aseguradora. Adaptado de "Caso de éxito Aseguradora Internacional", Everis, 2018.

La empresa se propuso adoptar la estrategia de Cloud definida desde su grupo matriz, y para eso adquirió nuevas capacidades sobre la arquitectura existente y el alineamiento con la hoja de ruta de los proyectos de su programa transformación @2020.

Para la puesta en marcha del proyecto de Arquitectura Cloud, se consideraron las siguientes Arquitecturas: 


\section{(1)}

- Arquitectura Empresarial: comprendió el gobierno de la incorporación del Cloud como plataforma en la construcción de aplicaciones.

- Arquitectura de Soluciones: comprendió el análisis del portafolio de proyectos de evolución del mapa de sistemas e identificación de candidatos para incorporar arquitecturas Cloud autorizadas por Grupo.

- Arquitectura de Aplicaciones: comprendió el análisis y planificación para el movimiento de aplicaciones core a plataforma IaaS, así como también el entendimiento y prueba de concepto de la plataforma OpenPaaS como alternativa en la construcción de nuevas aplicaciones digitales.

Como resultado del proyecto, se logró que el equipo de Arquitectura de la entidad aseguradora sea el nexo entre las políticas y capacidades tecnológicas y las necesidades que conllevan los proyectos de TI.

Asimismo, se consigue la puesta en marcha del servicio cloud en la empresa en TI y en el Negocio.

Por tanto, se obtuvo un máximo beneficio del uso de la nube logrando mantener la homogeneidad y reutilización, en cumplimiento de las políticas definidas.

\section{CASO DE ÉXITO: GRUPO SANTILLANA}

El caso de éxito significó realizar un proyecto de Arquitectura Cloud que promueva la transformación digital, apoyado en la implementación de metodologías ágiles, cuyos objetivos eran permitir un crecimiento ágil, la innovación continua, riesgos controlados y una rápida recuperación de la inversión. 


\section{(1)}

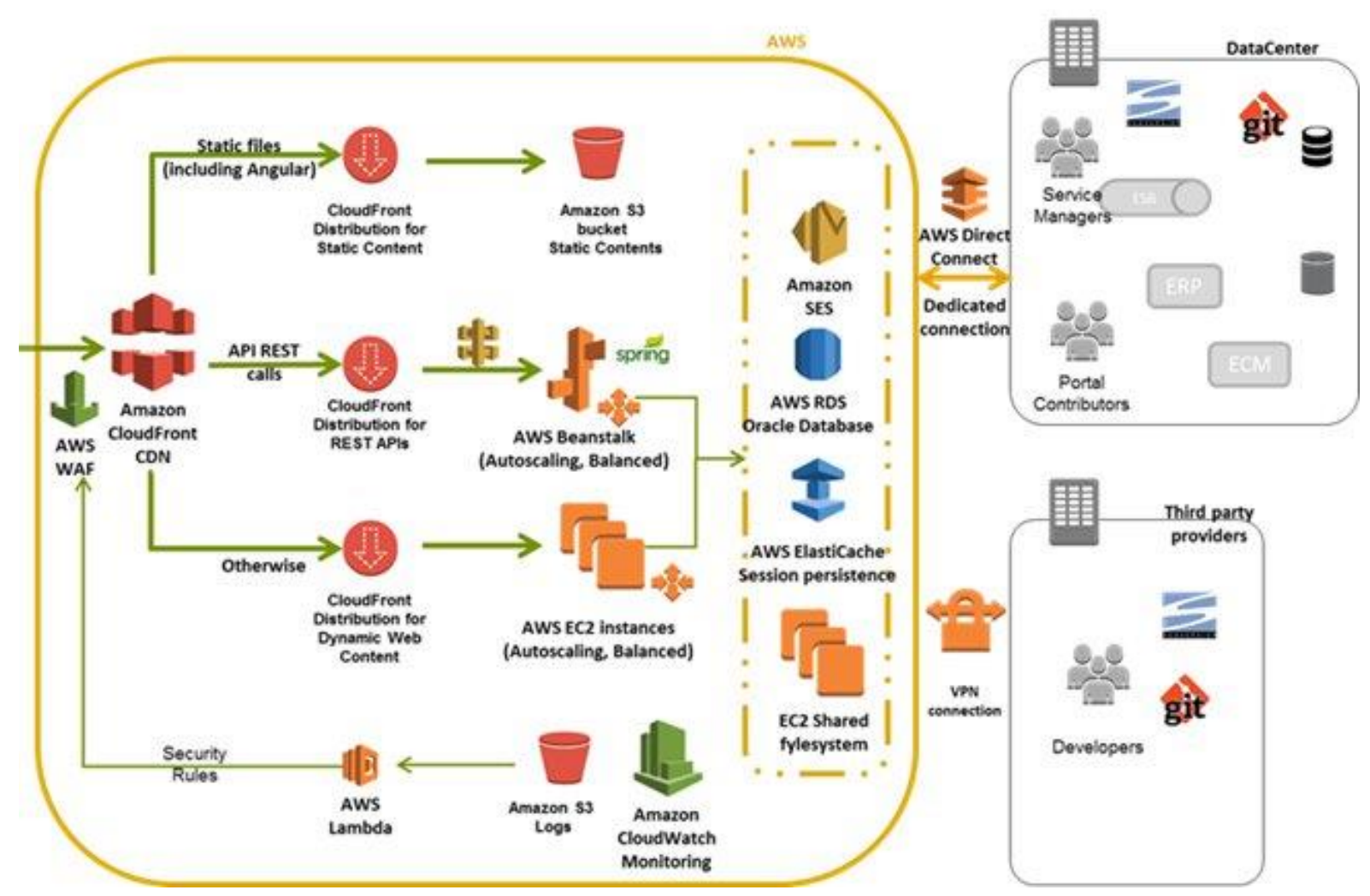

Figura $N^{\circ} 9$. Soporte de Arquitectura Cloud a una entidad aseguradora. Adaptado de "Caso de éxito Grupo Santillana”, Everis, 2018.

Como parte de su plan estratégico el Grupo Santillana incorpora en el 2011 la adopción de soluciones y tecnología de Cloud Publico como soporte al proceso de transformación digital. El reto era transformar el negocio tradicional en un modelo digital la cual permitiría entre sus beneficios mantener un ratio de eficiencia económica muy alto.

El proyecto tuvo como punto de partida la migración "as-is" hacia una arquitectura Cloud, para luego implementar metodologías ágiles e ir transformando los sistemas hacia arquitecturas PaaS y Serverless.

Se lograron los siguientes objetivos:

- Se estableció una oficina técnica de transición de las plataformas originales hacia un modelo de Cloud Público.

- Se construyó un servicio de operación y explotación 24x7 para la atención en mas de 22 países donde trabaja el Grupo Santillana. 
- Se construyó una oficina de Arquitectura y transformación de sistemas del Grupo Santillana.

- Diseño y soporte a nuevas arquitecturas sobre el Cloud público basadas en tecnologías Serverless.

Como resultado del proyecto se redujeron los costos de forma continua con un $40 \%$ el primer año, y un $15 \%$ anual mantenido. Se logó una escalabilidad sin precedentes para el negocio en los 22 países con presencia de la empresa, eficiencia y economía de escala en el modelo desarrollado, disponibilidad del $100 \%$ en los entornos durante dos años consecutivos e innovación tecnológica y referente en el sector educativo. 


\section{(1)}

\section{CAPÍTULO 3: ANÁLISIS DEL PROYECTO}

\section{ARQUITECTURA EMPRESARIAL}

La arquitectura empresarial permite realizar el análisis de la situación actual (AS IS) y el estado objetivo (TO BE), se considera los cuatros dominios de la arquitectura empresarial: Negocio, Datos, Aplicaciones y Tecnología. Además, se identifica las brechas entre ambos estados. Asimismo, se desarrolla los fundamentos y propuestas de mejora para cerrar con un plan de proyectos, denominado plan de migración, to esto enfocado en el proceso clave de despachos.

\section{PETICIÓN DEL TRABAJO DE ARQUITECTURA}

\section{LÍMITES DE TIEMPO}

- El presente estudio de arquitectura empresarial debe realizarse en un plazo de 4 meses.

\section{LIMITACIONES ORGANIZACIONALES}

- La propuesta abarca a la Gerencia General, la Gerencia Emisión, y a la Gerencia de Tecnologías de la Información.

- En la arquitectura empresarial debe considerar las normas ISO a las cuales está regida la organización.

\section{LIMITACIONES FINANCIERAS}

- El presupuesto destinado para hacer el presente estudio de arquitectura deberá ser de PEN 350,000 a PEN 550,000. Cualquier ampliación presupuestal deberá ser presentada y sustentada ante la Gerencia General. 


\section{(1)}

\section{LIMITACIONES EXTERNAS}

- Normas y Leyes de la Superintendencia de Banca y Seguros y AFP (SBS).

- Ley 29946: Ley del Contrato de Seguro (http://www.leyes.congreso.gob.pe/Documentos//ExpVirPal/Normas_Legales/29946LEY.pdf)

- Ley $\mathrm{N}^{\circ}$ 29733: Ley de protección de datos personales PCM (https://www.minjus.gob.pe/wp-content/uploads/2013/04/LEY-29733.pdf)

- Ley No 29571: Código de Protección y Defensa del Consumidor (http://portal.andina.com.pe/EDPEspeciales/especiales/2010/setiembre/codigo_consumid or.pdf)

- La organización está condicionada a normas de organismos reguladores como la SUNAT (Superintendencia Nacional de Administración Tributaria).

\section{DESCRIPCION DE LA SITUACION ACTUAL DEL NEGOCIO (PRINCIPALES PROBLEMAS Y REQUERIMIENTOS)}

La organización se encuentra enfocada en brindar servicios de seguros y reaseguros, los cuales según la ley y clasificación internacional comprenden: Seguros de Vida, Seguros de Jubilación y Seguros de Riesgos Laborales.

Uno de los productos tops de la organización es el producto SCTR (Seguro Complementario de Trabajo de Riesgos). Hasta mediados del 2017 las pólizas de SCTR solicitadas por Cliente o Corredor se realizaban a través de los siguientes canales:

\section{$\underline{\text { Cliente (Empresa) }}$}

El cliente solicita una póliza nueva u operación posterior a la emisión (Declaración, Renovación, Inclusión) de la siguiente forma:

a) El cliente se acerca a las oficinas de la organización y presenta una solicitud al área de Atención al Cliente adjuntando la documentación respectiva (Información del cliente y planilla de asegurados). 


\section{(1)}

b) Plataforma maneja un tarifario, si la tasa a emitir está dentro de políticas y tarifario, operaciones emite directamente. En caso la solicitud del cliente exceda políticas, se deriva al Área de Suscripción.

c) El Área de Suscripción valida la información, da visto bueno a las condiciones requeridas y deriva al área de Emisión.

d) El área de Emisión procede con la generación del número de la póliza y documentación. Los documentos generados los deriva al área de Despacho.

e) En caso de rechazo por parte de Suscripción, se finaliza el trámite seleccionando.

f) El área de despacho envía la documentación al cliente vía correo electrónico.

\section{Corredor}

El corredor utiliza dos vías para solicitar una póliza nueva u operación posterior a la emisión: Oficina Virtual o casilla de correo

a) Para el caso de póliza nueva: La negociación se realiza vía correo electrónico.

b) Para renovación e inclusión: El Corredor genera a través del Sistema Oficina Virtual un trámite adjuntando información del cliente más planilla de asegurados.

c) El Área de suscripción valida la información, da visto bueno a las condiciones requeridas y deriva al área de Emisión.

d) El área de Emisión procede con la generación del número de la póliza y documentación. Los documentos generados los deriva al área de Despacho.

e) En caso de rechazo por parte de suscripción, se finaliza el trámite seleccionando.

f) El área de despacho envía la documentación al bróker vía correo electrónico.

Existen diversos sistemas encargados de la generación y mantenimiento de pólizas de los productos antes mencionado, uno de los productos tops de ventas es el seguro SCTR (Seguro Complementario de Trabajo de Riesgo) el cual es gestionado por el sistema SED (Sistema de Emisión a Distancia). Este sistema esta implementado sobre una plataforma web.

Como se menciona el área de emisión se encarga de la emisión y post operaciones de una póliza, para la cual emplea el sistema SED (Sistema de Emisión a Distancia). Este sistema 


\section{()}

fue un desarrollo propio por el área de TI de la organización el cual se implementó el año 2014 para uso interno. El sistema tuvo buena acogida por parte de los usuarios; debido a que les facilitaba el trabajo operativo, lo cual originó que fuera promocionado a nivel gerencial. Por lo cual, a mediados del 2017 se promociono el sistema a nivel externo; es decir, como un sistema público por medio del acceso portal corporativo, tal como se muestra a continuación:

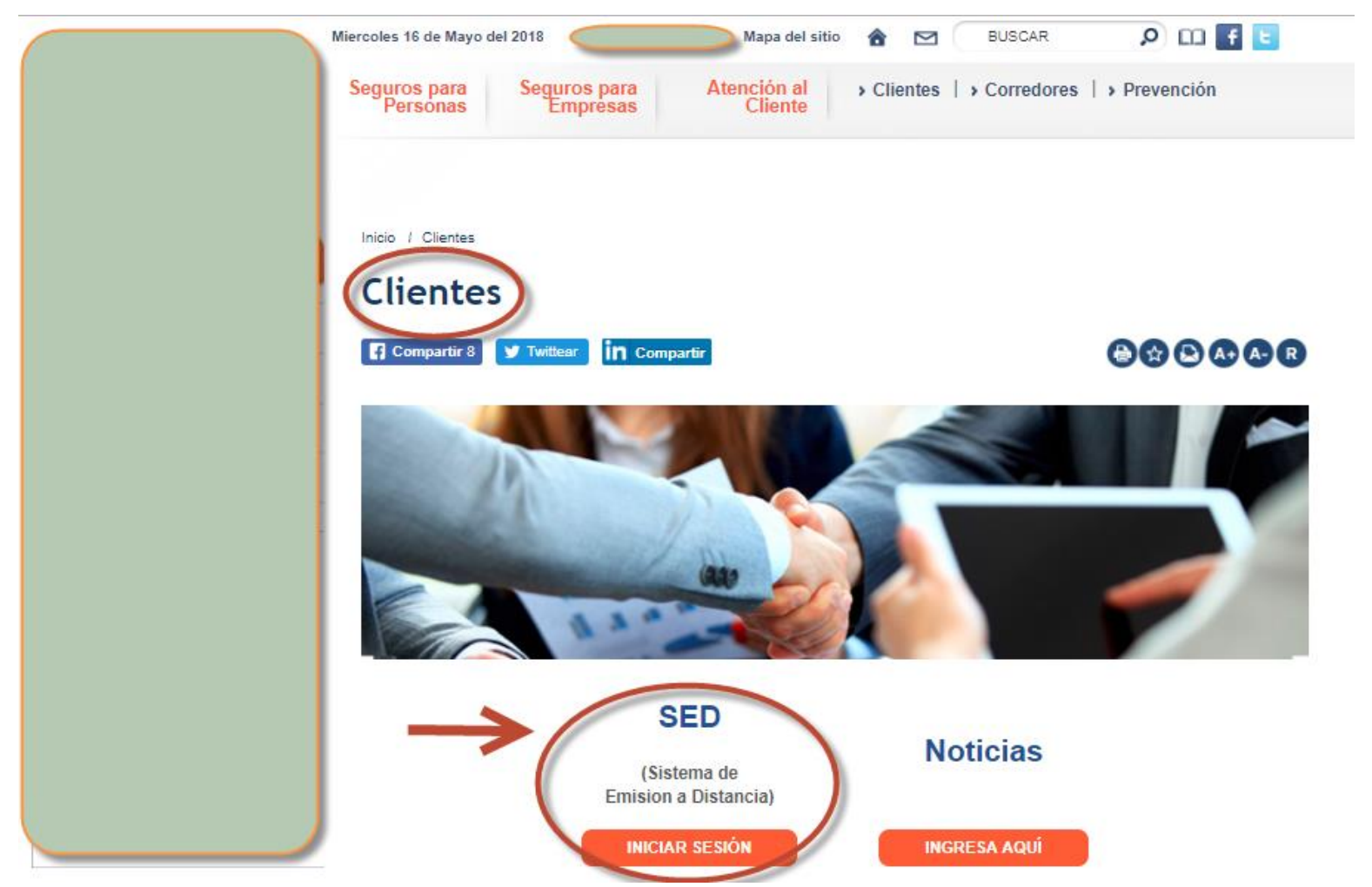

Figura $N^{\circ} 10$. Captura de pantalla de sitio web institucional de La Positiva Seguros, por lapositiva.com.pe, 


\section{(4)}

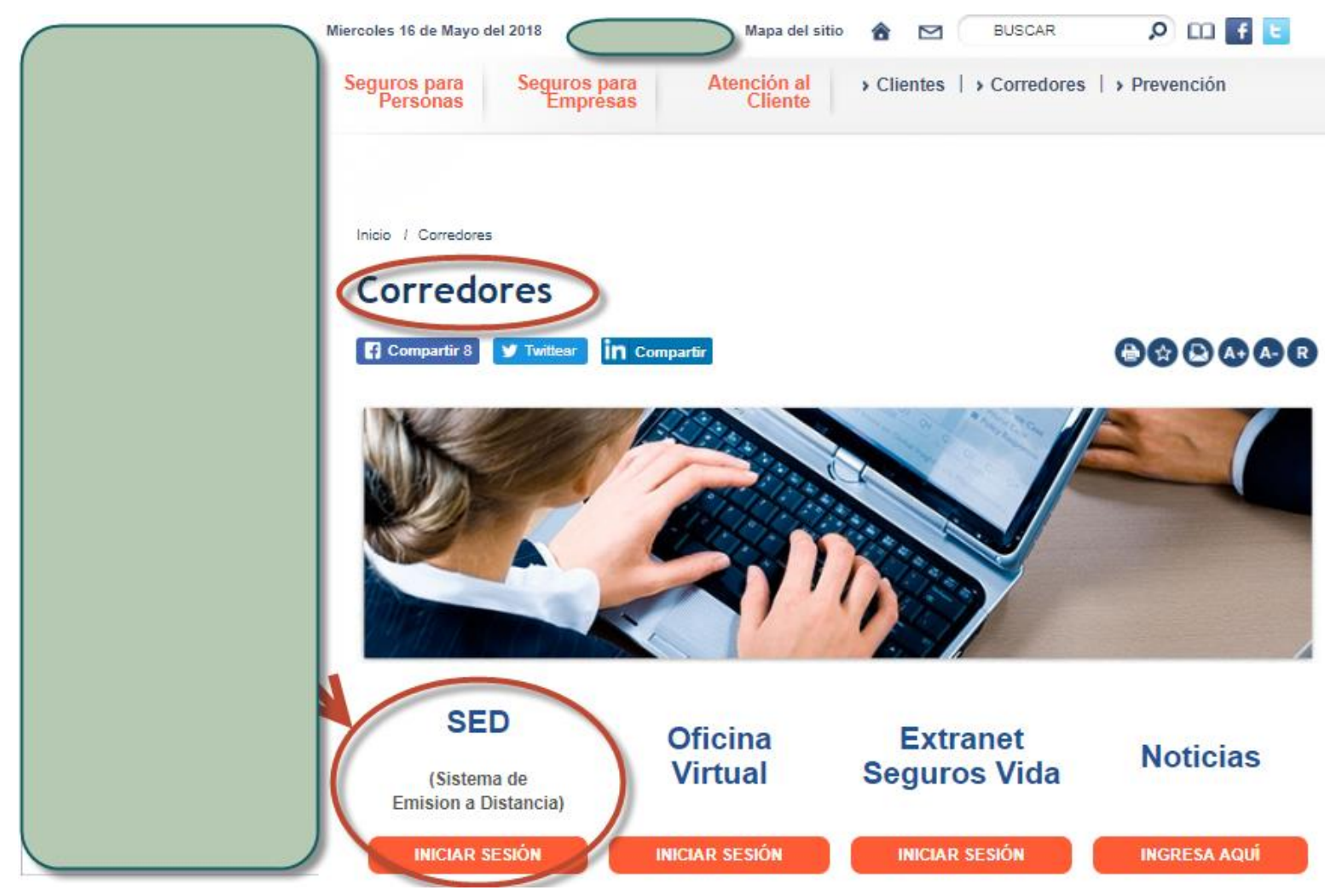

Figura $N^{\circ} 11$. Captura de pantalla de sitio web institucional de La Positiva Seguros, por lapositiva.com.pe, 


\section{(9)}

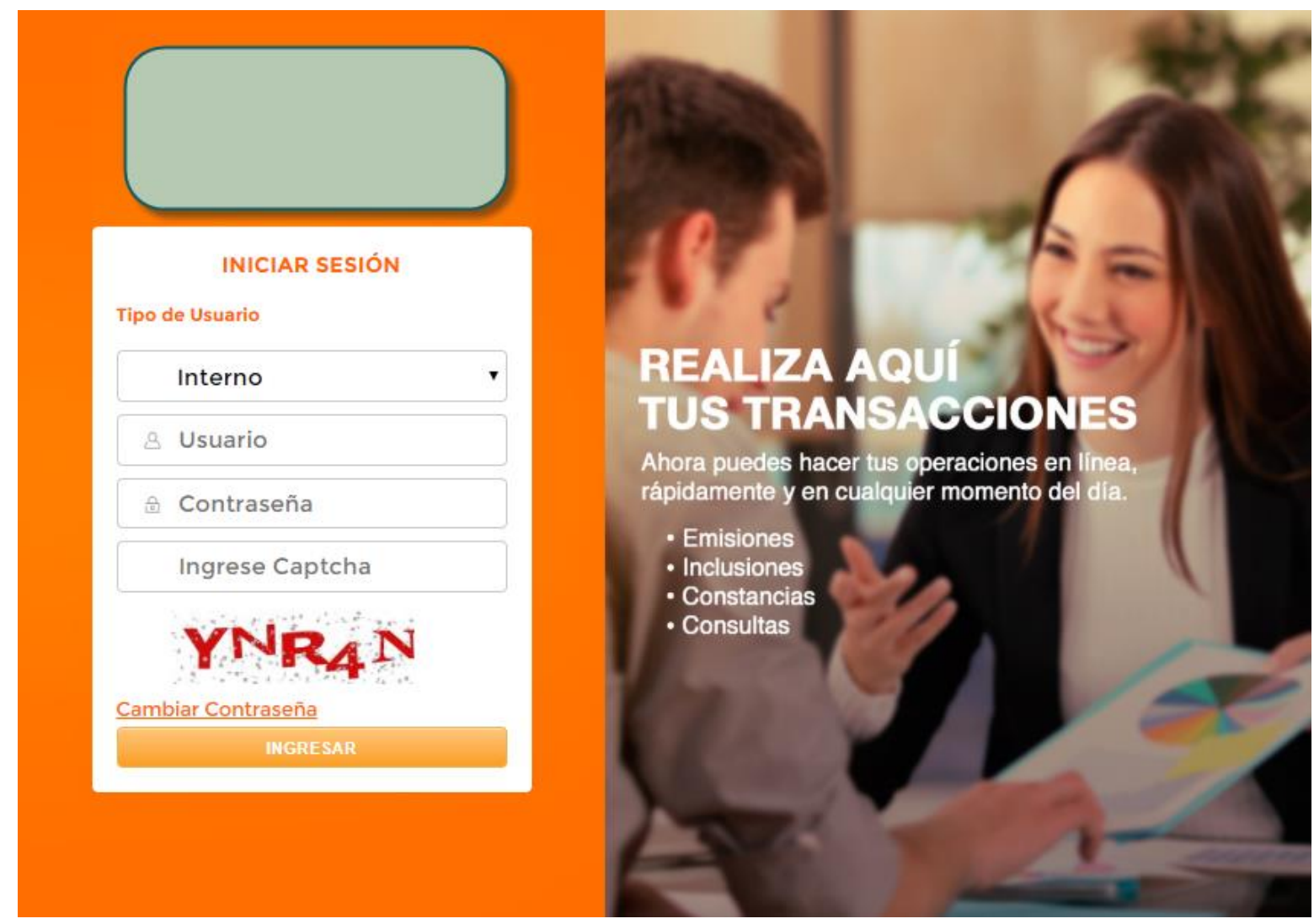

Figura $N^{\circ} 12$. Captura de pantalla de sitio web institucional de La Positiva Seguros, por lapositiva.com.pe,

Esta exposición fue con el fin de que tanto como el Cliente o Corredor, cuenten con la opción de poder realizar las operaciones que tienen que ver con el tratamiento de pólizas SCTR mediante el sistema SED. Sin embargo, el sistema no fue expuesto a un control de calidad adecuado, debido a esto se presentaron problemas de rendimiento, a continuación se describe los principales problemas.

- Problemas de procesamiento; debido a que la arquitectura implementada en la aplicación no permite el procesamiento en paralelo de emisión y gestión de las pólizas.

- Problemas con el manejo de concurrencia con lo cual los usuarios finales experimentan bloqueo en la aplicación, indisponibilidad del sistema y pérdida de transacciones con lo cual el procesamiento no se llega a completar, ocasionando retraso en sus procesos y atención a sus usuarios finales, así como inconsistencia de información. 


\title{
(1)
}

Debido a los problemas antes mencionados genera pérdida de venta de pólizas o renovaciones de las mismas, lo cual impacta de forma directa a los objetivos de la organización.

\section{DESCRIPCION DE LA SITUACION ACTUAL DE LA ARQUITECTURA DE TI}

Los procesos de la gestión emisión se encuentran trabajando mediante el sistema SED desde el año 2015, el cual soporta todos los procesos asociados a la comercialización de pólizas y emisión de las mismas.

El proceso de Gestión de Emisión de Pólizas SCTR es soportado por el sistema SED, el cual permite realizar las operaciones de Emisión, Renovación, Inclusión y Exclusión de los productos SCTR. El sistema esta implementado en tecnología ASP.NET, diseñado en una arquitectura de N-Capas.

El usuario accede mediante estaciones de trabajo (computadora de escritorio, laptop o móvil), al sistema SED se encuentra en un servidor web; el cual interactúa con los servidores de base de datos y al servidor de aplicaciones.

Actualmente, se necesita que el sistema SED atienda gran carga de procesamiento de emisión de pólizas según la alta demanda presentada por las sedes descentralizadas.

\section{DOCUMENTO DE DEFINICIÓN DE ARQUITECTURA}

\begin{abstract}
ALCANCE
El presente estudio de arquitectura empresarial está orientado al proceso seleccionado. Este esfuerzo de arquitectura deberá alcanzar a todos los procesos y subprocesos que son parte del proceso elegido. En la actualidad, el proceso cuenta con notables oportunidades de mejora y toda mejora en sus actividades contribuye significativamente con los objetivos estratégicos de la organización objetivo.
\end{abstract}




\section{(1)}

El marco de trabajo sobre el cual se desarrolla la arquitectura empresarial es TOGAF, del cual se desarrolla la petición de trabajo arquitectura, el documento de definición de arquitectura y el plan de implementación de la migración. El periodo de tiempo requerido es de seis semanas de esfuerzo.

- Amplitud: el proyecto se centra en la gerencia de emisión.

- Profundidad: el esfuerzo de arquitectura llega solo a nivel de la propuesta de mejora.

- Periodo de tiempo: seis semanas.

- Dominios de arquitectura: la propuesta contiene los cuatro dominios de arquitectura: Arquitectura de Negocio, Arquitectura de Datos, Arquitectura de Aplicaciones y Arquitectura Tecnológica.

\section{PRINCIPIOS DE ARQUITECTURA}

En el presenta apartado se detallarán los principios de arquitectura del presente proyectos los cuales son: Principios de Negocio, Principio de Datos, Principios de Aplicaciones y Principios de Tecnología.

A continuación, se detallan los principios mencionados:

\section{$\underline{\text { PRINCIPIOS DE NEGOCIO }}$}

Tabla $\mathrm{N}^{\circ} 7$

Principios del Negocio

\begin{tabular}{ll}
\hline Nombre & PN01 - Continuidad del negocio \\
\hline Enunciado & La operatividad no puede ser interrumpida, a pesar de las fallas del sistema. \\
Fundamento & $\begin{array}{l}\text { En la organización la mayoría de procesos se encuentran automatizados. Estos } \\
\text { pueden ser afectados por eventos como: fallas del sistema, servidores, desastres }\end{array}$ \\
& $\begin{array}{l}\text { naturales, entre otros. Por esta razón, se debe contar con planes de contingencia } \\
\text { para el resguardo de información y respaldo de los sistemas. }\end{array}$ \\
& La para de operatividad podría causar a la empresa pérdida de tiempo y dinero. \\
\hline
\end{tabular}




\section{(1)}

\begin{tabular}{ll}
\hline Nombre & PN02 - Relaciones con los clientes \\
\hline Enunciado & $\begin{array}{l}\text { La satisfacción del cliente es tarea fundamental en organización. En } \\
\text { consecuencia, se busca servir al cliente con cordialidad, prontitud }\end{array}$ \\
& $\begin{array}{l}\text { y pleno conocimiento de lo que somos y hacemos. } \\
\text { Fundamento }\end{array}$ \\
& $\begin{array}{l}\text { Importancia de fidelizar a los clientes, con un buen servicio tanto en el venta } \\
\text { como en la post venta. }\end{array}$ \\
Repercusiones & Fidelización de clientes.
\end{tabular}

\begin{tabular}{ll}
\hline Nombre & PN03 - Relaciones con los Trabajadores \\
\hline Enunciado & El personal de organización cuenta con la misma oportunidad de superación \\
& laboral, sin discriminación alguna. Por ello, la atribución de funciones y \\
& responsabilidades prevalecen la calidad de su preparación. El desarrollo dentro \\
& de la empresa, será en mérito a sus calificaciones personales y profesionales; \\
& además de la educación y respeto que demuestre con las demás personas de su \\
& entorno.
\end{tabular}

Fundamento El reto constante de organización será alcanzar la excelencia, cumpliendo con los objetivos y metas propuestos por la empresa. Es por ello, que es necesario estar comprometidos con sus trabajadores, ya que el buen desempeño de estos repercute en la calidad de sus servicios y productos.

Repercusiones Buen clima laboral, asi como, obtener compromiso del personal para lograr en conjunto las metas de la organización.

\begin{tabular}{ll}
\hline Nombre & PNO4 - Relaciones con los proveedores \\
\hline Enunciado & $\begin{array}{l}\text { La identificación, evaluación y contratación de un proveedor, se basa en } \\
\text { exigentes criterios técnicos, económicos y morales }\end{array}$ \\
Fundamento & $\begin{array}{l}\text { Los proveedores forman parte de nuestro equipo global de trabajo, por } \\
\text { consiguiente, debemos exigirles calidad, seriedad y honestidad. }\end{array}$ \\
Repercusiones & Calidad en los productos y servicios. \\
\hline Nota. Relación de Principios del negocio. Elaboración propia.
\end{tabular}




\section{()}

\section{$\underline{\text { PRINCIPIOS DE DATOS }}$}

Tabla $\mathrm{N}^{\circ} 8$

Principios de Datos

\begin{tabular}{ll}
\hline Nombre & PD01 - Integración de Información \\
\hline Enunciado & Cada área, tanto operativa como de apoyo, genera información en distintas \\
& $\begin{array}{l}\text { plataformas. Es primordial que dicha información sea compartida y difundida } \\
\text { entre la empresa. }\end{array}$
\end{tabular}

Fundamento Evitar doble trabajo y disponer de información oportuna y precisa genera ahorro económico y permite una mejor toma de decisiones en la gestión de DELCROSA.

Repercusiones Genera ahorro tiempo y por consiguiente económico. Asimismo, permite una mejor toma de decisiones en la gestión.

\begin{tabular}{ll}
\hline Nombre & PD02 - Seguridad de la Información \\
\hline Enunciado & $\begin{array}{l}\text { La información tiene que contar con medidas de seguridad para que no sea } \\
\text { empleada de forma malintencionada }\end{array}$ \\
Fundamento & $\begin{array}{l}\text { La información tiene que estar asegurada de acuerdo a los distintos niveles de la } \\
\text { organización. }\end{array}$ \\
Repercusiones & $\begin{array}{l}\text { Al no tener una política de uso de la información hará que personal no autorizado } \\
\text { haga un mal uso de la información, perjudicando a la organización }\end{array}$ \\
\hline
\end{tabular}

\begin{tabular}{ll}
\hline Nombre & PD03 - Activo de los procesos de la organización \\
\hline Enunciado & $\begin{array}{l}\text { La información debe considerarse como un activo de la organización y no puede } \\
\text { ser publicado ni difundido. }\end{array}$ \\
Fundamento & $\begin{array}{l}\text { La información es de suma importancia para toda la organización, por lo que } \\
\text { debe ser administrada por determinadas reglas para asegurar su contenido y evitar } \\
\text { que sea utilizada como fuente fuera de la empresa. }\end{array}$ \\
Repercusiones & $\begin{array}{l}\text { El publicar la información fuera de los límites de la organización, se expondrá a } \\
\text { la organización a que otras entidades tomen ventaja frente a la empresa. Inclusive } \\
\text { de denuncias legales. }\end{array}$
\end{tabular}

Nota. Relación de Principios de datos. Elaboración propia. 


\section{(1)}

\section{PRINCIPIOS DE APLICACIONES}

Tabla $\mathrm{N}^{\circ} 9$

Principios de Aplicaciones

\begin{tabular}{ll}
\hline Nombre & PA01 - Toda aplicación debe estar licenciada \\
\hline Enunciado & Todas las aplicaciones deben estar con licencia \\
Fundamento & $\begin{array}{l}\text { Es política de la organización que todo software que se instale en los equipos } \\
\text { de su propiedad tenga las licencias correspondientes. En promedio, una vez al } \\
\text { año se realiza un inventario de software y su respectiva licencia. }\end{array}$
\end{tabular}

Repercusiones El uso de un software sin su licencia respectiva puede ocasionar sanciones económicas por parte del Estado.

\begin{tabular}{ll}
\hline Nombre & PA02 - Acceso restringido a las aplicaciones \\
\hline Enunciado & El personal tendrá asignado aplicaciones según su cargo. \\
Fundamento & $\begin{array}{l}\text { El personal cuenta con aplicaciones según el rol que desempeñe en la } \\
\text { organización. Estas aplicaciones serán instaladas por el área de mesa de ayuda. }\end{array}$
\end{tabular}

Repercusiones El tener instalados aplicaciones que no forman parte del trabajo del personal conlleva a posibles gastos de licencia por parte de la organización y un riesgo en la seguridad de la información de la organización.

\begin{tabular}{ll}
\hline Nombre & PA03 - Fácil manejo en aplicaciones \\
\hline Enunciado & Los sistemas deben ser de fácil usabilidad. \\
Fundamento & Las aplicaciones deben ser fáciles de usar. La tecnología utilizada debe ser \\
& transparente a los usuarios, para que estos se orienten a las tareas más \\
& productivas. La definición y diseño de la experiencia del usuario debe utilizar \\
& patrones de interfaz gráfica de la industria como: Java Script, Node.JS.
\end{tabular}

Repercusiones El no hacer fácil el uso para cada miembro de la organización, haría que estos se confundan y se retrasen en vez de mejorar su trabajo. 


\section{(1)}

\begin{tabular}{ll}
\hline Nombre & PA04 - Aplicaciones con soporte garantizado en el tiempo \\
\hline Enunciado & $\begin{array}{l}\text { Toda adquisición de un aplicativo o software debe pasar por una evaluación } \\
\text { previa para garantizar un servicio de soporte posterior a la implementación y } \\
\text { durante el tiempo que dure el tiempo de vida útil estimado. }\end{array}$ \\
Fundamento & $\begin{array}{l}\text { Los nuevos sistemas deben ser de fácil uso. Esto quiere decir que se adapten al } \\
\text { entorno de la organización, y que sean de ayuda en el trabajo diario del } \\
\text { personal. }\end{array}$ \\
Repercusiones & $\begin{array}{l}\text { El no hacer fácil el uso para cada miembro de la organización, haría que estos } \\
\text { se confundan y se retrasen en vez de mejorar su trabajo. }\end{array}$ \\
\hline Nombre & PA05 - Toda solución debe ser escalable \\
\hline Enunciado & $\begin{array}{l}\text { La solución debe ser escalable } \\
\text { Fundamento solución debe brindar capacidades para escalar en caso de que el número } \\
\text { de usuarios que requieren de usar la aplicación incremente. }\end{array}$ \\
Repercusiones & $\begin{array}{l}\text { El no realizar una solución no escalable puede incurrir en problemas de } \\
\text { mantenimiento. }\end{array}$ \\
\hline
\end{tabular}

\begin{tabular}{ll}
\hline Nombre & PA06 - Adquirir o reutilizar componentes en lugar de construirlos. \\
\hline Enunciado & $\begin{array}{l}\text { Se de adquirir o reutilizar componentes en lugar de construirlos donde sea } \\
\text { posible. }\end{array}$ \\
Fundamento & $\begin{array}{l}\text { Para lograr la eficiencia requerida y reducir los tiempos de desarrollo, } \\
\text { considerar el uso de componentes cuando sea aplicable y herramientas de } \\
\text { terceros deben adquirirse de considerarse necesario. }\end{array}$ \\
Repercusiones & $\begin{array}{l}\text { Realizar trabajo innecesario en implementar soluciones que ya existen en el } \\
\text { mercado o dentro de la organización. }\end{array}$ \\
\hline
\end{tabular}

Nota. Relación de Principios de aplicaciones. Elaboración propia. 


\section{(1)}

\section{PRINCIPIOS DE TECNOLOGÍA}

Tabla $\mathrm{N}^{\circ} 10$

Principios de Tecnología

\begin{tabular}{ll}
\hline Nombre & PT01 - Copias de seguridad de Datos \\
\hline Enunciado & Copias de seguridad de información importante de la organización \\
& Se realiza en forma recurrente el respaldo de la información que la \\
& organización constantemente actualiza, ya sea desde documentos u archivos \\
& hasta sistema de información u base de datos. Esto ayuda que a pesar que \\
& ocurra un imprevisto en la información por situaciones como la eliminación \\
& de información o por algún desastre natural.
\end{tabular}

Repercusiones Tener en todo momento la información que la organización necesite

\begin{tabular}{ll}
\hline Nombre & PT02 - Soporte a los usuarios de la organización \\
\hline Enunciado & Brindar soporte tecnológico a los miembros de la organización. \\
Fundamento & $\begin{array}{l}\text { La organización cuenta con un área especializada en dar soporte a los } \\
\text { distintos miembros de la organización, en temas directamente tecnológicos. }\end{array}$
\end{tabular}

Repercusiones Al no dar soporte a los miembros de la organización, estos pierden tiempo en realizar su trabajo diario, lo que causa contratiempos en los entregables. Esto conlleva a que la organización sea vista como una entidad que no es confiable en realizar un trabajo en el tiempo estimado.

\begin{tabular}{ll}
\hline Nombre & PT03 - Adquisición de equipos informáticos \\
\hline Enunciado & $\begin{array}{l}\text { Adquisición de equipos que respalden los sistemas de información y } \\
\text { comunicación de la empresa. }\end{array}$ \\
Fundamento & $\begin{array}{l}\text { Existe un procedimiento de compras, el cual consiste en la solicitud de } \\
\text { requisición, la aprobación del jefe o gerente del área y la emisión de la orden } \\
\text { de compra. Para el caso de equipos informáticos, la requisición requiere de }\end{array}$ \\
adicionalmente el visto bueno del Jefe de informática.
\end{tabular}




\begin{tabular}{ll}
\hline Nombre & PT04 - Independencia de Tecnología \\
\hline Enunciado & Las aplicaciones son independientes de las elecciones de tecnologías \\
& específicas y por ellos pueden operar sobre una variedad de plataformas \\
& tecnológicas. La independencia de aplicaciones desde el punto de vista \\
& tecnológico permite a las aplicaciones ser desarrolladas, actualizadas y operar \\
& de una manera más efectiva en costos y tiempos. Se debe impedir que el \\
& Software de Aplicación sea dependiente de un hardware y software de \\
& sistema operativo.
\end{tabular}

Fundamento Flexibilidad en el uso de las aplicaciones de la organización, independientemente de donde se acceda. (Ejemplo: Windows, Linux, etc.)

Repercusiones Necesidad de depender de una plataforma específica.

Nota. Relación de Principios de tecnología. Elaboración propia.

\section{ARQUITECTURA DE LA LÍNEA BASE}

En esta sección se realiza el análisis de la situación actual (AS IS).

\section{$\underline{\text { ARQUITECTURA DE NEGOCIO }}$}




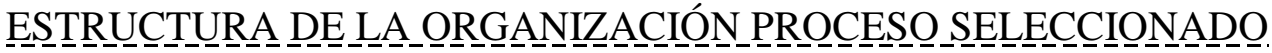

En el siguiente gráfico se muestra el organigrama del proceso seleccionado.

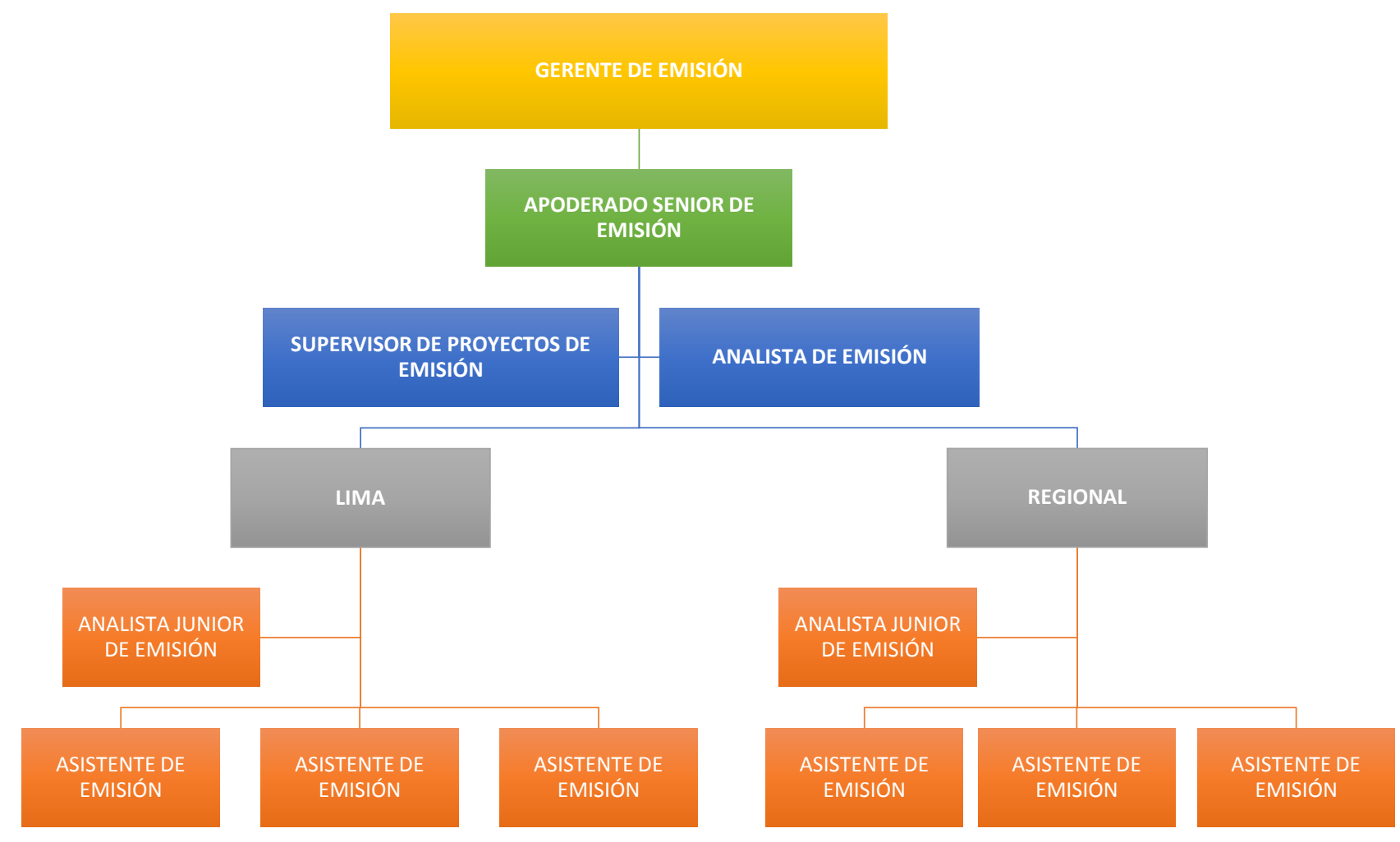

Figura $N^{\circ} 13$ Organigrama del Proceso Seleccionado. Adaptado de “Organigrama de una entidad aseguradora en Lima”, Elaboración propia, 2018. 


\section{(1)}

Tabla $\mathrm{N}^{\circ} 11$

Descripción de funciones por cargo del proceso seleccionado.

Cargo $\quad$ Descripción

Evaluar y mejorar la eficacia de los procesos de gestión de riesgos, control y gobierno de acuerdo al marco internacional para la práctica de auditoría interna, a lo establecido por la Superintendencia de Banca, Seguros y AFP y por las normas internas de la empresa

Presentar al Directorio, al Comité de Auditoría, al nivel Gerencial y a la Gerente de Emisión Superintendencia de Banca, Seguros y AFP el resultado de la labor realizada por la Gerencia Corporativa de Auditoría.

Realizar el seguimiento de las recomendaciones para su implementación, incluyendo las de Auditoría Interna, las formuladas por la Superintendencia de Banca, Seguros y AFP, y los Auditores Externos.

Garantizar que la emisión de pólizas se realice cumpliendo con los tiempos establecidos y de acuerdo a las Políticas de Suscripción.

Optimizar los criterios y lineamientos básicos de la Política de Emisión Apoderado Senior de de Pólizas buscando la mejora continua. Emisión

Garantizar el cumplimiento de la política de firmas establecida, la confidencialidad y seguridad de los documentos manejados por el Área de Emisión.

Asegurar que los proyectos internos e institucionales sean exitosos.

Supervisor de Proyectos de Emisión

Analista de Emisión

Alinear los proyectos del Área de Emisión con los Proyectos Estratégicos de la Compañía.

Optimizar los procesos internos, buscando la mejora continua en productividad, calidad y control de gestión.

Garantizar la correcta emisión de pólizas, y mejorar la calidad de la emisión a través de capacitaciones continuas al personal.

Promover el cumplimiento de las políticas y procedimientos del Área de Emisión.

Garantizar la correcta emisión de pólizas, y mejorar la calidad de la emisión a través de capacitaciones continuas al personal.

Analista Junior de Emisión

Promover el cumplimiento de las políticas y procedimientos del Área de Emisión. 


\section{(}

Emitir correctamente las pólizas asignadas por la Oficina Virtual de manera oportuna.

$\begin{array}{llc}\text { Asistente de Emisión } & \begin{array}{l}\text { Verificar que se tenga toda la información necesaria para realizar la } \\ \text { emisión }\end{array} & \text { póliza. }\end{array}$

Realizar las renovaciones y endosos que se soliciten validando que los datos sean consistentes.

Nota. Relación de funciones por cargo del proceso seleccionado. Elaboración propia. 


\section{(1)}

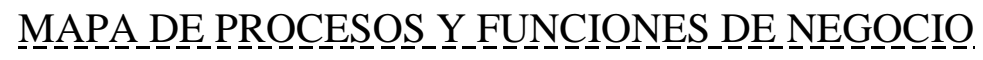

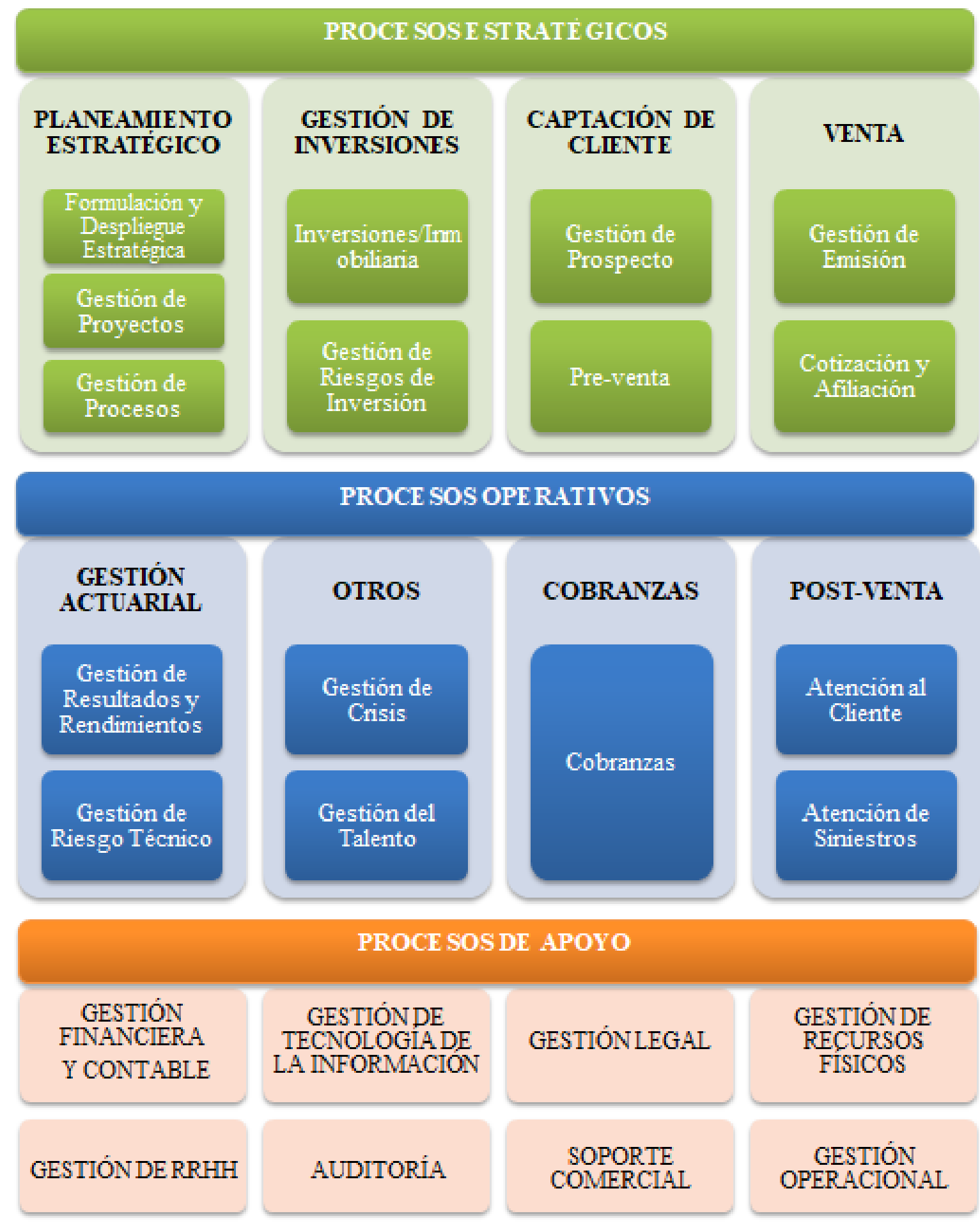

Figura $N^{\circ} 14$ Mapa de Procesos. Adaptado de "Mapa de Procesos y Funciones de Negocio y descripción de una entidad aseguradora en Lima”, Elaboración propia, 2018. 


\section{()}

Tabla $N^{\circ} 12$

Descripción de Procesos

\begin{tabular}{|c|c|c|}
\hline Tipo & Procesos & Descripción \\
\hline \multirow{4}{*}{ Estratégico } & $\begin{array}{l}\text { Planeamiento } \\
\text { Estratégico }\end{array}$ & $\begin{array}{l}\text { Es el proceso que se encarga de definir la visión de la } \\
\text { empresa a mediano y largo plazo, así como también las } \\
\text { estrategias para alcanzarlas a través del análisis de las } \\
\text { fortalezas, debilidades, oportunidades y amenazas. Es el } \\
\text { proceso que da inicio al proceso de planificación de la } \\
\text { empresa. }\end{array}$ \\
\hline & $\begin{array}{l}\text { Gestión de } \\
\text { Inversiones }\end{array}$ & $\begin{array}{l}\text { Es la gestión que se encarga de ofrecer funciones para } \\
\text { ayudar en la planificación, la inversión y los procesos de } \\
\text { financiación. }\end{array}$ \\
\hline & Captación de Cliente & $\begin{array}{l}\text { Es el proceso que se encarga de la búsqueda de clientes } \\
\text { potenciales para convertirlos en clientes finales. }\end{array}$ \\
\hline & Venta & $\begin{array}{l}\text { Es el proceso que se encarga de las ventas de productos o } \\
\text { servicios, la cual constituye la base de las operaciones de la } \\
\text { empresa. }\end{array}$ \\
\hline \multirow{4}{*}{ Operativos } & Gestión Actuarial & $\begin{array}{l}\text { Es el proceso que se encarga de definir la gestión de } \\
\text { resultados, rendimiento y riesgos técnicos de la empresa. }\end{array}$ \\
\hline & $\begin{array}{l}\text { Gestión del } \\
\text { Desarrollo Humano }\end{array}$ & $\begin{array}{l}\text { Es el proceso que se encarga de la gestión de crisis y del } \\
\text { talento humano. }\end{array}$ \\
\hline & Cobranzas & $\begin{array}{l}\text { Se encarga del desarrollo de actividades y estrategias para } \\
\text { alcanzar el cobro de deudas. }\end{array}$ \\
\hline & Post-Venta & $\begin{array}{l}\text { Estable los canales de comunicación hacía el Cliente. Con } \\
\text { el fin de que el Cliente tenga manera para manifestar } \\
\text { reclamos, sugerencias, solicitar información o plantear } \\
\text { inquietudes sobre el producto y/o servicio de la } \\
\text { organización. }\end{array}$ \\
\hline \multirow[t]{2}{*}{ Ароуо } & $\begin{array}{l}\text { Gestión Financiera y } \\
\text { Contable }\end{array}$ & $\begin{array}{l}\text { Es el proceso que se encarga de la eficiencia administrativa } \\
\text { del capital de trabajo dentro de un criterio de riesgos y } \\
\text { rentabilidad; además, de orientar la estrategia financiera } \\
\text { para garantizar la disponibilidad de fuentes de financiación. } \\
\text { Asimismo se encarga de llevar un registro y control de las } \\
\text { operaciones financieras que se lleva a cabo en la } \\
\text { organización. }\end{array}$ \\
\hline & $\begin{array}{l}\text { Gestión de } \\
\text { Tecnología de la } \\
\text { Información }\end{array}$ & $\begin{array}{l}\text { Es el proceso que se encarga de planificar, diseñar, ejecutar } \\
\text { y monitorear la estrategia de las tecnologías de la } \\
\text { información. Además, de supervisar y evaluar el } \\
\text { alineamiento de los sistemas de información a los procesos } \\
\text { de la organización. }\end{array}$ \\
\hline
\end{tabular}




\section{(1)}

Gestión Legal

Es la que se encarga de controlar la legalidad de los actos

Gestión de Recursos
Físicos

administrativos y emisión de conceptos jurídicos relacionados con el objeto y función de la empresa.

Es el proceso que se encarga de la adquisición, manejo y administración de elementos, equipos e inmuebles y los procesos para su almacenamiento, custodia, inventario, distribución y mantenimiento, servicio general, archivos y correspondencia.

Este proceso se encarga de gestionar y coordinar la

Gestión de RRHH aplicación de las normas y los procedimientos de los recursos humanos. Las cuales desarrollan y aplican en los sistemas de información en la gestión del talento humano.

Es el proceso que se encarga de regular la planificación,

Auditoría organización, realización y comunicación de las auditorías internas de la empresa.

Está integrado por el gerente comercial y da a conocer la definición de actividades relacionadas con el cliente, de tal

Soporte Comercial modo de asegurar la correcta determinación de los requisitos relacionados con el producto y/o servicio estableciendo disposiciones eficaces para la comunicación con los clientes.

Es el proceso que se encarga de la producción de bienes y Gestión Operacional servicios, basados en toma de decisiones sobre eficiencia y efectividad.

Nota. Descripción de los procesos del negocio. Elaboración propia. 


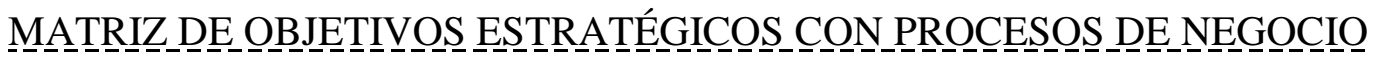

Tabla $\mathrm{N}^{\circ} 13$

Matriz de objetivos estratégicos versus procesos de negocio.

\begin{tabular}{|c|c|c|c|c|c|c|c|c|c|c|c|}
\hline \multirow{2}{*}{ MACRO PROCESO } & \multicolumn{11}{|c|}{ OBJETIVO ESTRATEGICOS } \\
\hline & OE1 & OE2 & OE3 & OE4 & OE5 & OE6 & OE7 & OE8 & OE9 & OE10 & OE11 \\
\hline PLANEAMIENTO ESTRATÉGICO & $\mathrm{X}$ & & & & & $\mathrm{X}$ & & $\mathrm{X}$ & & $\mathrm{X}$ & \\
\hline GESTIÓN DE INVERSIONES & & $\mathrm{X}$ & & & & $X$ & & & & $\mathrm{X}$ & \\
\hline CAPTACIÓN DE CLIENTE & & & & $\mathrm{X}$ & $\mathrm{X}$ & & & & & & \\
\hline VENTA & $\mathrm{X}$ & & $\mathrm{X}$ & $\mathrm{X}$ & $\mathrm{X}$ & & & & & & \\
\hline GESTIÓN ACTUARIAL & $X$ & & & & & & & & & & \\
\hline OTROS & & & & & & & & & $\mathrm{X}$ & & $\mathrm{X}$ \\
\hline COBRANZAS & & & & & & & & & & & \\
\hline POST-VENTA & & & & $\mathrm{X}$ & $\mathrm{X}$ & & & & & & \\
\hline GESTIÓN FINANCIERA Y CONTABLE & & $\mathrm{X}$ & & & & & & & & & \\
\hline GESTIÓN DE TECNOLOGÍA DE LA INFORMACIÓN & & & $\mathrm{X}$ & & & $\mathrm{X}$ & $\mathrm{X}$ & & & & \\
\hline GESTIÓN LEGAL & & & & & & & & & & & \\
\hline GESTIÓN DE RECURSOS FÍSICOS & & & & & & & $\mathrm{X}$ & & & & \\
\hline GESTIÓN DE RRHH & & & & & & & & & $\mathrm{X}$ & & $\mathrm{X}$ \\
\hline AUDITORÍA & & & & & & & & $\mathrm{X}$ & & & \\
\hline SOPORTE COMERCIAL & & & & & & & & $\mathrm{X}$ & & & \\
\hline GESTIÓN OPERACIONAL & & & $\mathrm{X}$ & & & & $\mathrm{X}$ & & & & \\
\hline
\end{tabular}

Nota. Matriz de objetivos estratégicos versus procesos de negocio. Elaboración propia. 


\section{(4)}

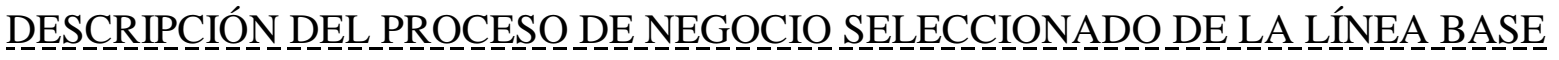

El proceso seleccionado de Gestión de Pólizas SCTR tiene como finalidad la emisión y post operaciones de una póliza.

\section{- Gestión de Pólizas SCTR}

En la siguiente imagen se describe el procedimiento general para la gestión de pólizas SCTR mediante el sistema SED.

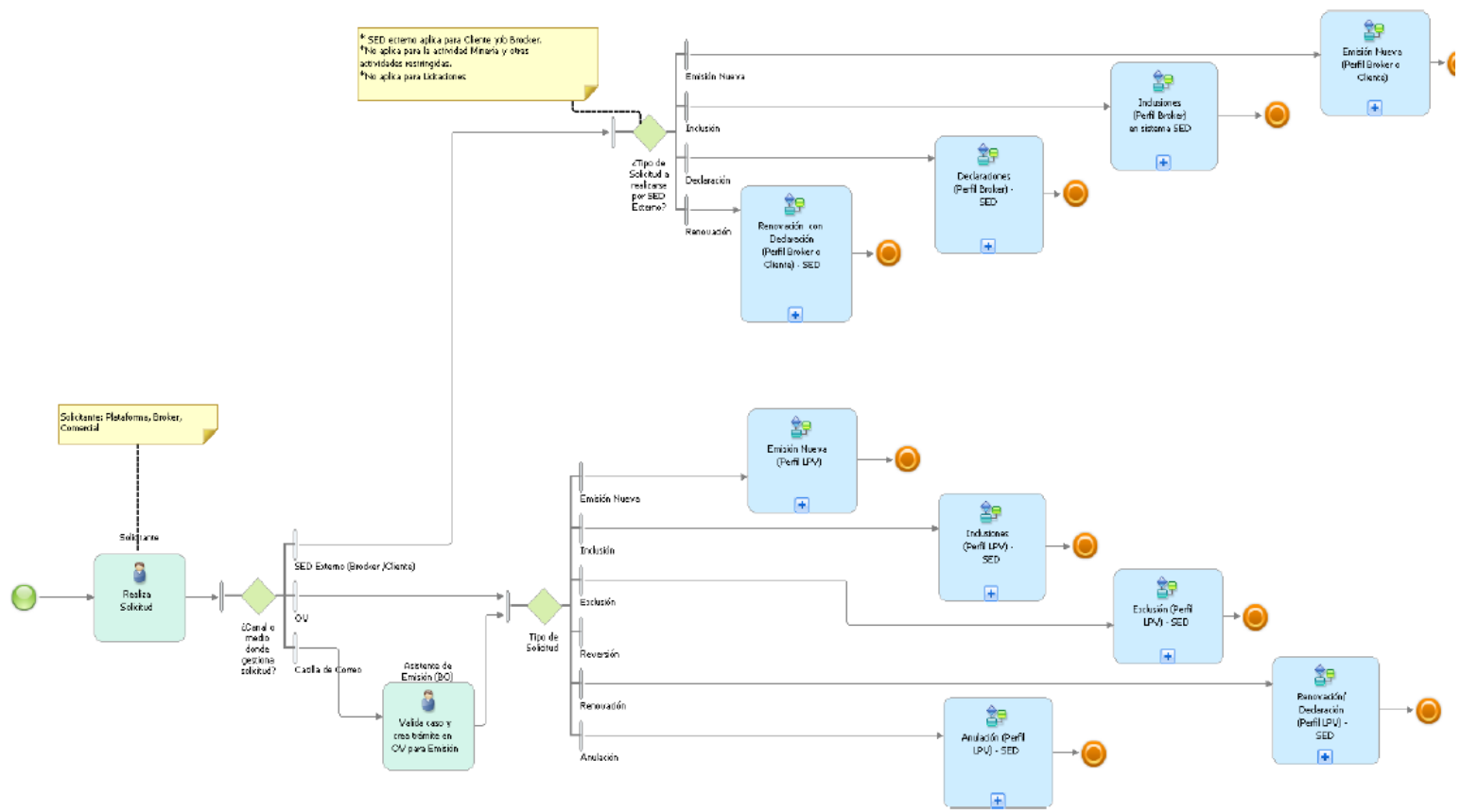

Figura $N^{\circ} 15$ Diagrama de procesos. Adaptado de "Gestión de Pólizas SCTR - Proceso General", Elaboración propia, 2018.

\section{- Sub Proceso Emisión de Póliza SCTR}

En la siguiente imagen se describe el procedimiento en el sistema SED para realizar la emisión de pólizas SCTR Pensión y SCTR Salud, la emisión se puede realizar considerando uno de los ramos o ambos a la vez. 


\section{(1)}

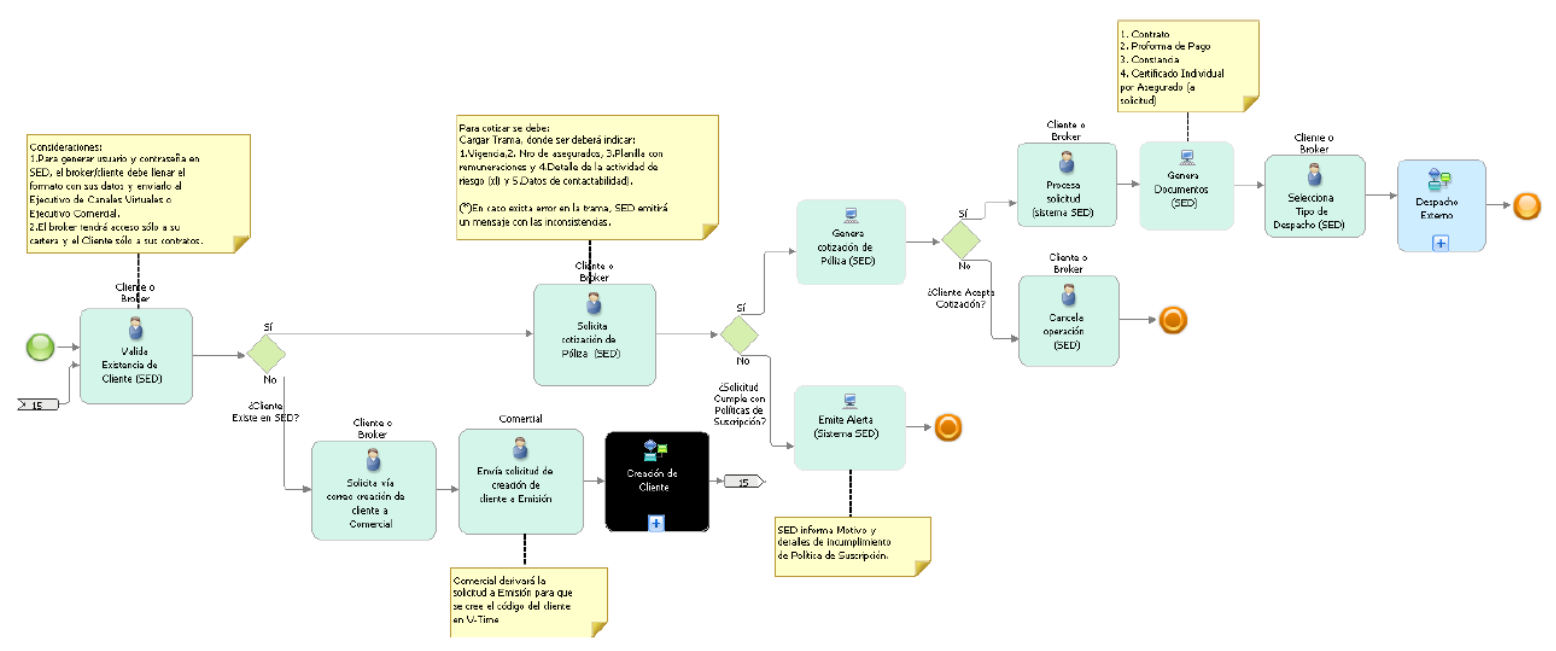

Figura $N^{\circ} 16$ Diagrama de procesos. Adaptado de "Emisión de Póliza SCTR", Elaboración propia, 2018.

Tabla $N^{\circ} 14$

Matriz RACI - Sub proceso Emitir Póliza SCTR

\begin{tabular}{|c|c|c|c|c|c|}
\hline \multirow[b]{2}{*}{ Actividades } & \multicolumn{5}{|c|}{ Roles } \\
\hline & Broker & Cliente & Comercial & Suscriptor & $\begin{array}{c}\text { Asistente } \\
\text { de Emisión }\end{array}$ \\
\hline $\begin{array}{l}\text { Valida existencia de } \\
\text { cliente (SED) }\end{array}$ & $\mathrm{R}$ & $\mathrm{R}$ & & & $\mathrm{R}$ \\
\hline $\begin{array}{l}\text { Solicita cotización de } \\
\text { Póliza (SED) }\end{array}$ & $\mathrm{R} / \mathrm{A}$ & $\mathrm{R} / \mathrm{A}$ & & & $\mathrm{R} / \mathrm{A}$ \\
\hline $\begin{array}{l}\text { Solicita vía correo } \\
\text { creación de cliente a } \\
\text { comercial }\end{array}$ & $\mathrm{R}$ & $\mathrm{R}$ & & & $\mathrm{R}$ \\
\hline $\begin{array}{l}\text { Envía solicitud de } \\
\text { creación de Cliente a } \\
\text { Emisión }\end{array}$ & & & $\mathrm{R} / \mathrm{A}$ & & $\mathrm{R}$ \\
\hline $\begin{array}{l}\text { Genera cotización de } \\
\text { póliza (SED) }\end{array}$ & $\mathrm{R} / \mathrm{A}$ & $\mathrm{R}$ & & & $\mathrm{R}$ \\
\hline Envía Alerta (SED). & $\mathrm{R}$ & $\mathrm{R}$ & & I & $\mathrm{R}$ \\
\hline Procesar solicitud (SED) & $\mathrm{R}, \mathrm{A}$ & $\mathrm{R}, \mathrm{A}$ & & & $\mathrm{R}, \mathrm{A}$ \\
\hline Cancela Operación (SED) & $\mathrm{R}$ & $\mathrm{R}$ & & & $\mathrm{R}$ \\
\hline $\begin{array}{l}\text { Selecciona tipo de } \\
\text { despacho (SED) }\end{array}$ & $\mathrm{R}$ & $\mathrm{R}$ & & & $\mathrm{R}$ \\
\hline
\end{tabular}




\section{4}

$\mathrm{R}=$ Responsable .

$\mathrm{A}=$ Aprobador

$\mathrm{C}=$ Consultado.

I = Informado.

Nota. Matriz RACI del sub proceso Emitir Póliza SCTR. Elaboración propia.

\section{- Sub Proceso Inclusión de Asegurados en Póliza SCTR}

En la siguiente imagen se describe el procedimiento en el sistema SED para realizar la inclusión de asegurados en pólizas SCTR Pensión y SCTR Salud, la inclusión se puede realizar considerando uno de los ramos o ambos a la vez.

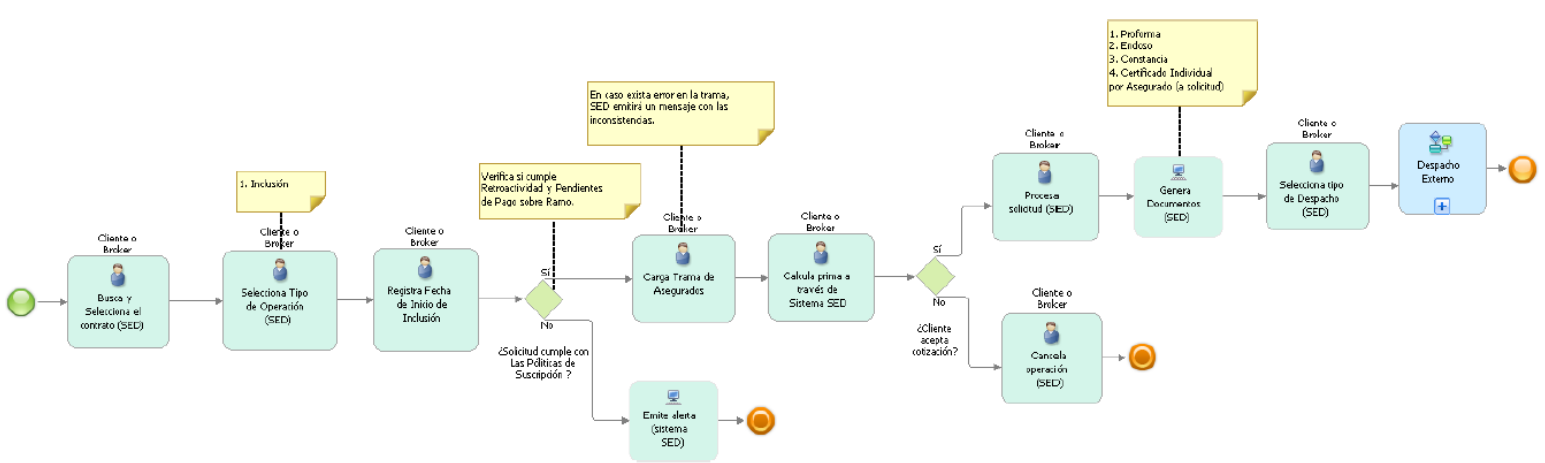

Figura $N^{\circ} 17$ Diagrama de procesos. Adaptado de "Inclusión de Asegurados en Póliza SCTR”, Elaboración propia, 2018. 


\section{(1)}

Tabla $\mathrm{N}^{\circ} 15$

Matriz RACI - Sub proceso Inclusión de Asegurados en Póliza SCTR

\begin{tabular}{|c|c|c|c|c|}
\hline \multirow[b]{2}{*}{ Actividades } & \multicolumn{4}{|c|}{ Roles } \\
\hline & Broker & Cliente & Suscriptor & $\begin{array}{l}\text { Asistente de } \\
\text { Emisión }\end{array}$ \\
\hline Busca y selecciona el contrato & $\mathrm{R}$ & $\mathrm{R}$ & & $\mathrm{R}$ \\
\hline $\begin{array}{l}\text { Seleccionar tipo de operación } \\
\text { (SED) }\end{array}$ & $\mathrm{R}$ & $\mathrm{R}$ & & $\mathrm{R}$ \\
\hline $\begin{array}{l}\text { Registrar fecha de inicio de } \\
\text { inclusión }\end{array}$ & $\mathrm{R}$ & $\mathrm{R}$ & & $\mathrm{R}$ \\
\hline Envía Alerta (SED). & $\mathrm{R}$ & $\mathrm{R}$ & I & $\mathrm{R}$ \\
\hline Cargar trama de asegurados & $\mathrm{R}$ & $\mathrm{R}$ & & $\mathrm{R}$ \\
\hline $\begin{array}{l}\text { Calcular prima a través del } \\
\text { Sistema SED. }\end{array}$ & $\mathrm{R} / \mathrm{A}$ & $\mathrm{R} / \mathrm{A}$ & & $\mathrm{R} / \mathrm{A}$ \\
\hline Cancela Operación (SED) & $\mathrm{R}$ & $\mathrm{R}$ & & $\mathrm{R}$ \\
\hline Procesar solicitud (SED) & $\mathrm{R} / \mathrm{A}$ & $\mathrm{R} / \mathrm{A}$ & & $\mathrm{R} / \mathrm{A}$ \\
\hline $\begin{array}{l}\text { Selecciona tipo de despacho } \\
\text { (SED) }\end{array}$ & $\mathrm{R}$ & $\mathrm{R}$ & & $\mathrm{R}$ \\
\hline
\end{tabular}

$\mathrm{R}=$ Responsable.

$\mathrm{A}=$ Aprobador.

$\mathrm{C}=$ Consultado.

$\mathrm{I}=$ Informado.

Nota. Matriz RACI del sub proceso Inclusión de Asegurados en Póliza SCTR. Elaboración propia.

\section{- Sub Proceso Exclusión de Asegurados en Póliza SCTR}

En la siguiente imagen se describe el procedimiento en el sistema SED para realizar la exclusión de asegurados en pólizas SCTR Pensión y SCTR Salud, la exclusión se puede realizar considerando uno de los ramos o ambos a la vez. 


\section{(1)}

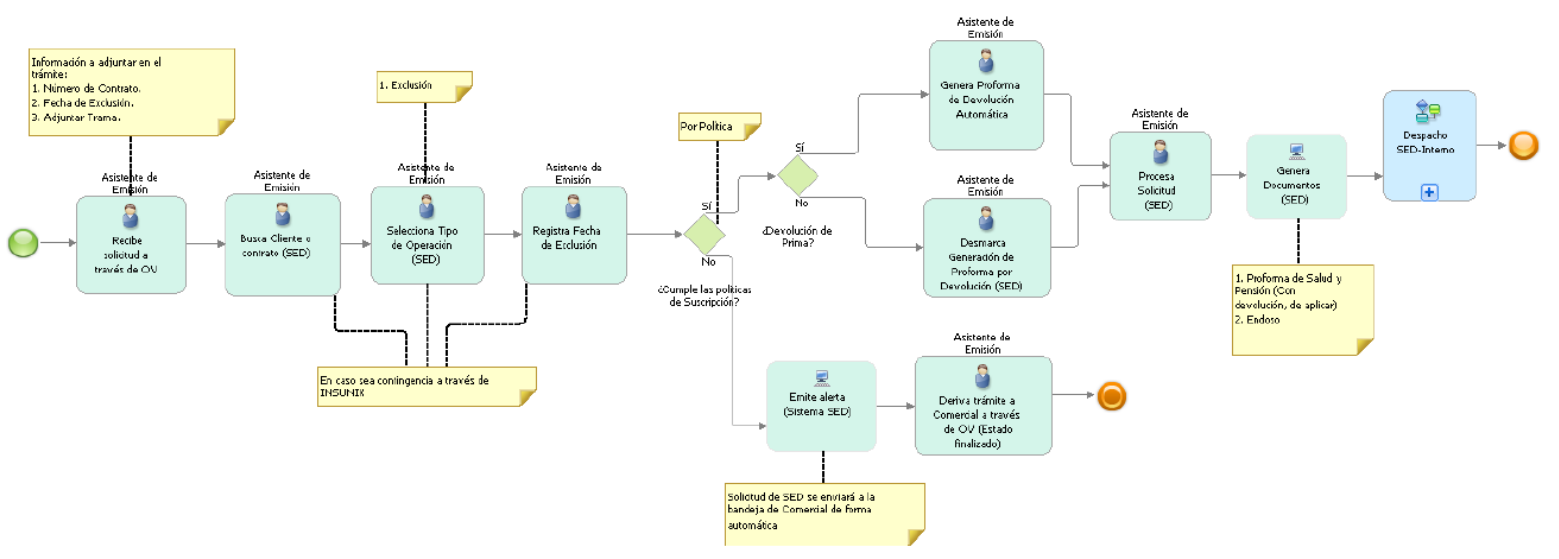

Figura $N^{\circ} 18$ Diagrama de procesos. Adaptado de "Exclusión de Asegurados en Póliza SCTR”, Elaboración propia, 2018.

Tabla $\mathrm{N}^{\circ} 16$

Matriz RACI - Sub proceso Exclusión de Asegurados en Póliza SCTR

\begin{tabular}{|c|c|c|c|c|c|}
\hline \multirow[b]{2}{*}{ Actividades } & \multicolumn{5}{|c|}{ Roles } \\
\hline & Broker & Cliente & Suscriptor & $\begin{array}{l}\text { Asistente } \\
\text { de Emisión }\end{array}$ & $\begin{array}{l}\text { Supervisión } \\
\text { de emisión }\end{array}$ \\
\hline $\begin{array}{l}\text { Recibe solicitud a través } \\
\text { de OV }\end{array}$ & & & & I & \\
\hline $\begin{array}{l}\text { Buscar Cliente o contrato } \\
\text { (SED) }\end{array}$ & & & & $\mathrm{R}$ & \\
\hline $\begin{array}{l}\text { Selecciona Tipo de } \\
\text { Operación (SED) }\end{array}$ & & & & $\mathrm{R}$ & \\
\hline $\begin{array}{l}\text { Registra Fecha de } \\
\text { Exclusión }\end{array}$ & & & & $\mathrm{R}$ & \\
\hline Envía Alerta (SED). & & & I & $\mathrm{R}$ & \\
\hline $\begin{array}{l}\text { Genera Proforma de } \\
\text { Devolución Automática }\end{array}$ & & & & $\mathrm{R} / \mathrm{A}$ & \\
\hline $\begin{array}{l}\text { Desmarca Generación de } \\
\text { Proforma por Devolución } \\
\text { (SED) }\end{array}$ & & & & $\mathrm{R} / \mathrm{A}$ & \\
\hline $\begin{array}{l}\text { Deriva trámite a } \\
\text { Comercial a través de } \mathrm{OV} \\
\text { (Estado finalizado) }\end{array}$ & & & & $\mathrm{R}$ & \\
\hline Procesa Solicitud (SED) & & & & $\mathrm{R} / \mathrm{A}$ & \\
\hline
\end{tabular}




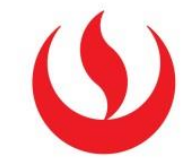

$\mathbf{R}=$ Responsable.

$\mathrm{A}=$ Aprobador .

$\mathrm{C}=$ Consultado.

I = Informado.

Nota. Matriz RACI del sub proceso Exclusión de Asegurados en Póliza SCTR. Elaboración propia.

\section{- Sub Proceso Renovación de Póliza SCTR}

En la siguiente imagen se describe el procedimiento en el sistema SED para realizar la renovación de pólizas SCTR Pensión y SCTR Salud, la renovación se puede realizar considerando uno de los ramos o ambos a la vez. Asimismo, la renovación se puede dar con o sin modificación de condiciones de póliza según requiera el negocio.

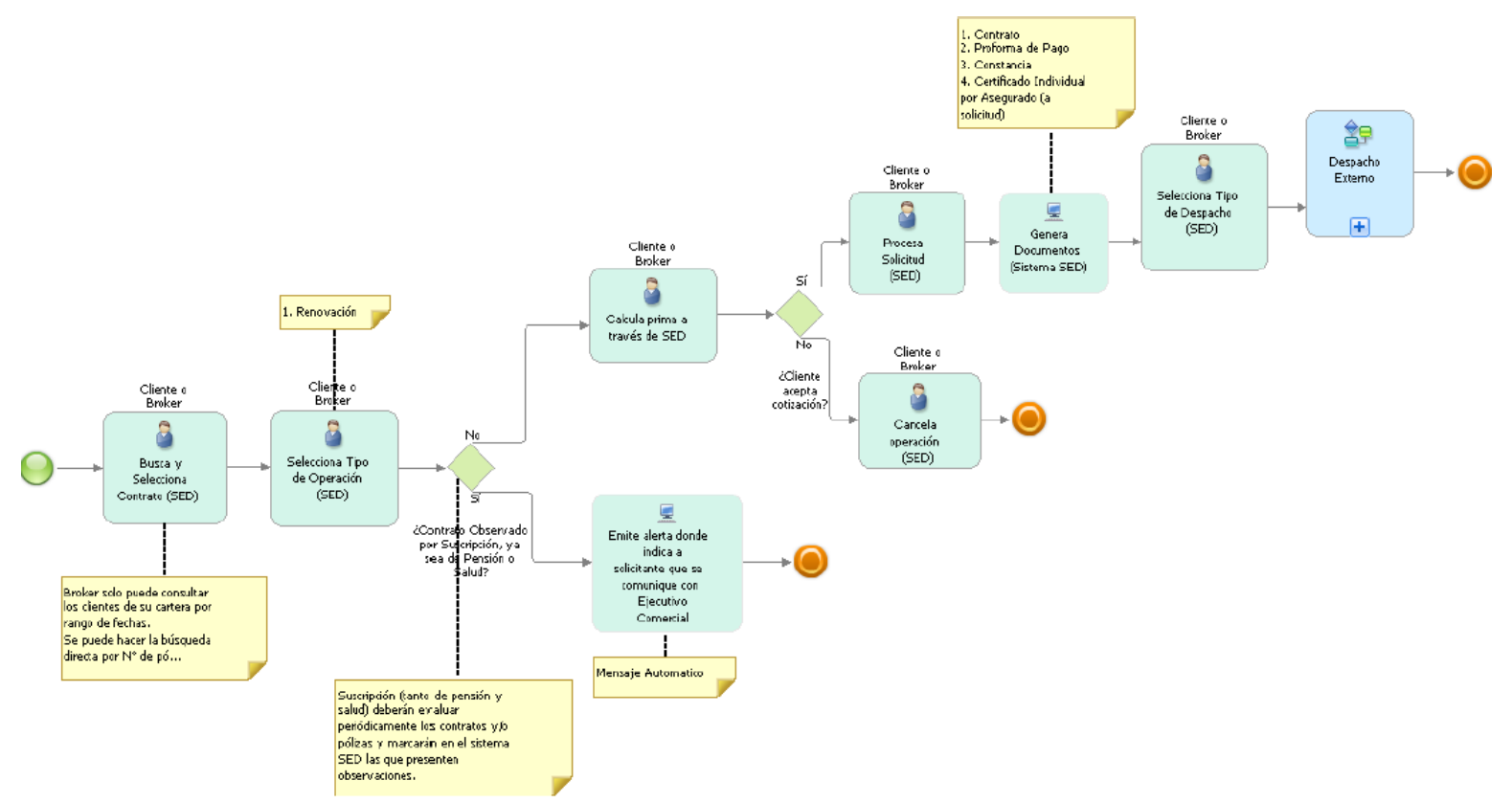

Figura $N^{\circ} 19$ Diagrama de procesos. Adaptado de "Renovación de Póliza SCTR", Elaboración propia, 2018. 
Tabla $\mathrm{N}^{\circ} 17$

Matriz RACI - Sub proceso Renovación de Póliza SCTR

\begin{tabular}{|c|c|c|c|c|c|}
\hline \multirow[b]{2}{*}{ Actividades } & \multicolumn{5}{|c|}{ Roles } \\
\hline & Broker & Cliente & Suscriptor & $\begin{array}{l}\text { Asistente } \\
\text { de } \\
\text { Emisión }\end{array}$ & $\begin{array}{l}\text { Supervisión } \\
\text { de emisión }\end{array}$ \\
\hline $\begin{array}{l}\text { Busca y selecciona el } \\
\text { contrato }\end{array}$ & $\mathrm{R}$ & $\mathrm{R}$ & & $\mathrm{R}$ & \\
\hline $\begin{array}{l}\text { Seleccionar tipo de } \\
\text { operación (SED) }\end{array}$ & $\mathrm{R}$ & $\mathrm{R}$ & A & $\mathrm{R}$ & \\
\hline Envía Alerta (SED). & & & $\mathrm{I}$ & & \\
\hline Calcular prima (SED) & $\mathrm{R}$ & $\mathrm{R}$ & & $\mathrm{R}$ & \\
\hline $\begin{array}{l}\text { Cancela Operación } \\
\text { (SED) }\end{array}$ & $\mathrm{R}$ & $\mathrm{R}$ & & $\mathrm{R}$ & \\
\hline Procesar solicitud (SED) & $\mathrm{R} / \mathrm{A}$ & $\mathrm{R} / \mathrm{A}$ & & $\mathrm{R} / \mathrm{A}$ & \\
\hline $\begin{array}{l}\text { Selecciona tipo de } \\
\text { despacho (SED) }\end{array}$ & $\mathrm{R}$ & $\mathrm{R}$ & & $\mathrm{R}$ & \\
\hline $\begin{array}{l}\mathbf{R}=\text { Responsable } \\
\text { A = Aprobador } \\
\text { C = Consultado. } \\
\text { I = Informado. }\end{array}$ & & & & & \\
\hline
\end{tabular}


ARQUITECTURA DE DATOS

MODELLODEDDATOS FÍSICICO 


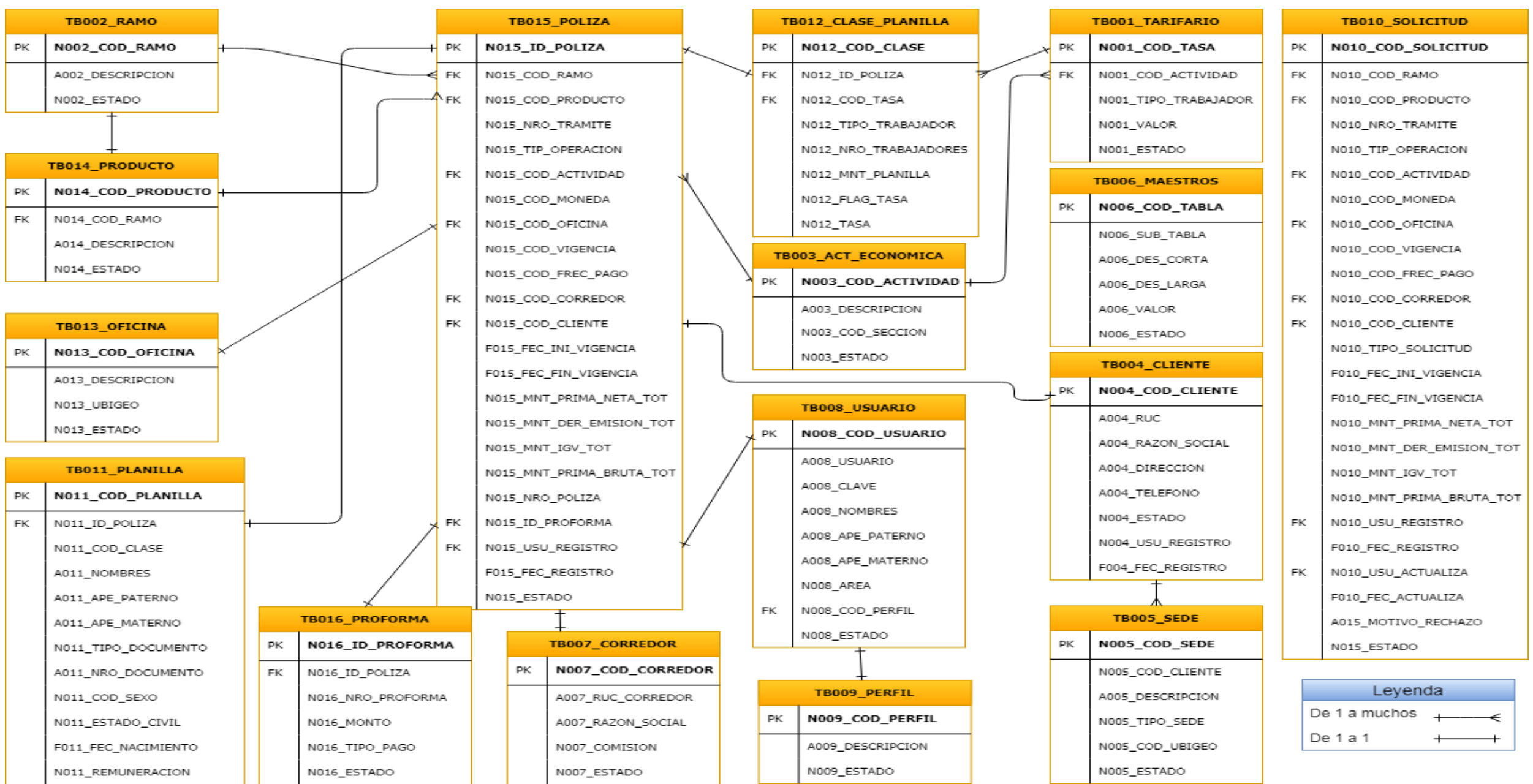

Figura $N^{\circ} 20$ Modelo de Datos. Adaptado de "Modelo de Datos del Proceso Seleccionado (AS IS)", Elaboración propia, 2018. 


\section{(1)}

Tabla $\mathrm{N}^{\circ} 18$

Descripción de Tablas del ASIS

\begin{tabular}{|c|c|}
\hline Nombre de Tabla & Descripción \\
\hline TB001_TARIFARIO & $\begin{array}{l}\text { Tabla que representa el tarifario asignado para las clases } \\
\text { trabajadoras. Ejemplo: Administrativo }=\text { Tasa } 0.95\end{array}$ \\
\hline TB002_RAMO & $\begin{array}{l}\text { Tabla que contiene información de los tipos de Ramos. } \\
\text { Ejemplo: SCTR Pensión y SCTR Salud. }\end{array}$ \\
\hline TB003_ACT_ECONOMICA & $\begin{array}{l}\text { Tabla que contiene la información de la actividad } \\
\text { económica a la que se dedica el cliente. Ejemplo: } \\
\text { Construcción. }\end{array}$ \\
\hline TB004_CLIENTE & Tabla que representa la información de Clientes. \\
\hline TB005_CLIENTE_SEDE & $\begin{array}{l}\text { Tabla que contiene la información de Sedes que pertenecen } \\
\text { a los clientes }\end{array}$ \\
\hline TB006_MAESTROS & $\begin{array}{l}\text { Tabla que representa la información de registros Maestros } \\
\text { de Información. Ejemplo: Estados de Póliza, Tipo de } \\
\text { Moneda, etc. }\end{array}$ \\
\hline TB007_CORREDOR & Tabla que representa la información de Corredores \\
\hline TB008_USUARIO & Tabla que tiene la información de Usuarios del Sistema. \\
\hline TB009_PERFIL & Tabla que contiene la información de Perfiles del Sistema. \\
\hline TB010_SOLICITUD & Tabla que contiene la información de Solicitudes de Póliza. \\
\hline TB011_PLANILLA & $\begin{array}{l}\text { Tabla que contiene la relación de asegurados relacionados a } \\
\text { una Póliza. }\end{array}$ \\
\hline TB012_CLASE_PLANILLA & $\begin{array}{l}\text { Tabla que comprende la información de los tipos de } \\
\text { asegurados con las que se generó una Póliza. Ejemplo: } \\
\text { Administrativo, Mediano Riesgo, Alto Riesgo. }\end{array}$ \\
\hline TB013_OFICINA & Tabla que representa las oficinas de la organización. \\
\hline TB014_PRODUCTO & Tabla que representa el producto perteneciente a un Ramo. \\
\hline TB015_POLIZA & Tabla que contiene la información de condiciones de Póliza. \\
\hline TB016_PROFORMA & $\begin{array}{l}\text { Tabla que contiene la información de Proforma de Pago de } \\
\text { una Póliza. }\end{array}$ \\
\hline
\end{tabular}

Nota. Descripción de tablas ASIS. Elaboración propia. 


\section{()}

Tabla $\mathrm{N}^{\circ} 19$

Diccionario de datos de las tablas del ASIS

\begin{tabular}{|c|c|c|c|c|}
\hline Tabla & \multicolumn{4}{|c|}{ TB001_TARIFARIO } \\
\hline Columna & Tipo de Dato & Descripción & PK & FK \\
\hline N001_COD_TASA & Number & Código de tasa & $\mathrm{Si}$ & \\
\hline N003_COD_ACTIVIDAD & Number & Código de actividad económica & & $\mathrm{Si}$ \\
\hline N001_TIPO_TRABAJADOR & Number & $\begin{array}{l}\text { Tipo de trabajador (Ejemplo: } \\
\text { Administrativo) }\end{array}$ & & \\
\hline N001_VALOR & Decimal & Valor de la tasa & & \\
\hline N001_ESTADO & Number & $\begin{array}{l}\text { Estado del registro (Ejemplo: } 1= \\
\text { Activo) }\end{array}$ & & \\
\hline Tabla & & TB002_RAMO & & \\
\hline Columna & Tipo de Dato & Descripción & $\mathrm{PK}$ & FK \\
\hline N002_COD_RAMO & Number & Código de ramo & $\mathrm{Si}$ & \\
\hline A002_DESCRIPCION & Number & Descripción de ramo & & $\mathrm{Si}$ \\
\hline N002_ESTADO & Number & $\begin{array}{l}\text { Estado del registro (Ejemplo: } 1= \\
\text { Activo) }\end{array}$ & & \\
\hline Tabla & & TB003_ACT_ECONOMICA & & \\
\hline Columna & Tipo de Dato & Descripción & PK & FK \\
\hline N003_COD_ACTIVIDAD & Number & Código de actividad económica & $\mathrm{Si}$ & \\
\hline A003_DESCRIPCION & Varchar & $\begin{array}{l}\text { Descripción de la actividad } \\
\text { económica }\end{array}$ & & \\
\hline N003_COD_SECCION & Number & $\begin{array}{l}\text { Código de la sección de la } \\
\text { actividad económica }\end{array}$ & & \\
\hline N003_ESTADO & Number & $\begin{array}{l}\text { Estado del registro (Ejemplo: } 1= \\
\text { Activo) }\end{array}$ & & \\
\hline
\end{tabular}




\begin{tabular}{|c|c|c|c|c|}
\hline Tabla & \multicolumn{4}{|c|}{ TB004_CLIENTE } \\
\hline Columna & Tipo de Dato & Descripción & PK & FK \\
\hline N004_COD_CLIENTE & Number & Código de cliente & $\mathrm{Si}$ & \\
\hline A004_RUC & Varchar & Ruc de cliente & & \\
\hline A004_RAZON_SOCIAL & Varchar & Razón social del cliente & & \\
\hline A004_DIRECCION & Varchar & Dirección del cliente & & \\
\hline A004_TELEFONO & Varchar & Teléfono del cliente & & \\
\hline N004_ESTADO & Number & $\begin{array}{l}\text { Estado del cliente (Ejemplo: } 1= \\
\text { Activo) }\end{array}$ & & \\
\hline N004_USU_REGISTRO & Number & Usuario de registro & & \\
\hline F004_FEC_REGISTRO & Date & Fecha de registro & & \\
\hline Tabla & & TB005_SEDE & & \\
\hline Columna & Tipo de Dato & Descripción & PK & FK \\
\hline N005_COD_SEDE & Number & Código de sede & $\mathrm{Si}$ & \\
\hline N005_COD_CLIENTE & Number & Código de cliente & & $\mathrm{Si}$ \\
\hline A005_DESCRIPCION & Varchar & Descripción de la sede & & \\
\hline N005_TIPO_SEDE & Number & Tipo de sede (Ejemplo: Principal) & & \\
\hline N005_COD_UBIGEO & Number & Código de ubigeo de la sede & & \\
\hline N005_ESTADO & Number & $\begin{array}{l}\text { Estado del registro (Ejemplo: } 1= \\
\text { Activo) }\end{array}$ & & \\
\hline Tabla & & TB006_MAESTROS & & \\
\hline Columna & Tipo de Dato & Descripción & PK & FK \\
\hline N006_COD_TABLA & Number & Código de Tabla & $\mathrm{Si}$ & \\
\hline N006_SUB_TABLA & Varchar & Código de Sub Tabla & & \\
\hline A006_DES_CORTA & Number & Descripción corta & & \\
\hline A006_DES_LARGA & Number & Descripción larga & & \\
\hline A006_VALOR & Number & Valor del registro & & \\
\hline N006_ESTADO & Number & $\begin{array}{l}\text { Estado del registro (Ejemplo: } 1= \\
\text { Activo) }\end{array}$ & & \\
\hline
\end{tabular}




\begin{tabular}{|c|c|c|c|}
\hline Tabla & & TB007_CORREDOR & \\
\hline Columna & Tipo de Dato & Descripción & PK FK \\
\hline N007_COD_CORREDOR & Number & Código de corredor & $\mathrm{Si}$ \\
\hline A007_RUC_CORREDOR & Varchar & Ruc de corredor & \\
\hline A007_RAZON_SOCIAL & Varchar & Razón social de corredor & \\
\hline N007_ESTADO & Number & $\begin{array}{l}\text { Estado del registro (Ejemplo: } 1 \\
=\text { Activo) }\end{array}$ & \\
\hline Tabla & & TB008_USUARIO & \\
\hline Columna & Tipo de Dato & Descripción & PK FK \\
\hline N008_COD_USUARIO & Number & Código de usuario & $\mathrm{Si}$ \\
\hline A008_USUARIO & Varchar & Usuario & \\
\hline A008_CLAVE & Number & Clave & \\
\hline A008_NOMBRES & Number & Nombres de usuario & \\
\hline A008_APE_PATERNO & Number & Apellido paterno & \\
\hline A008_APE_MATERNO & Number & Apellido materno & \\
\hline N008_AREA & Number & Área de organización & \\
\hline N008_COD_PERFIL & Number & Código de perfil & \\
\hline N008_ESTADO & Number & $\begin{array}{l}\text { Estado del registro (Ejemplo: } 1= \\
\text { Activo) }\end{array}$ & \\
\hline Tabla & & TB009_PERFIL & \\
\hline Columna & Tipo de Dato & Descripción & PK FK \\
\hline N009_COD_PERFIL & Number & Código de perfil & $\mathrm{Si}$ \\
\hline A009_DESCRIPCION & Varchar & Descripción de perfil & \\
\hline N009_ESTADO & Number & $\begin{array}{l}\text { Estado del registro (Ejemplo: } \\
1=\text { Activo) }\end{array}$ & \\
\hline
\end{tabular}




\section{(1)}

\begin{tabular}{|c|c|c|c|c|}
\hline Tabla & & TB010_SOLICITUD & & \\
\hline Columna & Tipo de Dato & Descripción & PK & FK \\
\hline N010_COD_SOLICITUD & Number & Código de solicitud & $\mathrm{Si}$ & \\
\hline N010_COD_RAMO & Number & Código de ramo & & $\mathrm{Si}$ \\
\hline N010_COD_PRODUCTO & Number & Código de producto & & $\mathrm{Si}$ \\
\hline N010_NRO_TRAMITE & Number & Número de trámite & & \\
\hline N010_TIP_OPERACION & Number & Tipo de operación & & \\
\hline N010_COD_ACTIVIDAD & Number & Código de actividad & & $\mathrm{Si}$ \\
\hline N010_COD_MONEDA & Number & Código de moneda & & \\
\hline N010_COD_OFICINA & Number & Código de oficina & & $\mathrm{Si}$ \\
\hline N010_COD_VIGENCIA & Number & $\begin{array}{l}\text { Código de vigencia ( Ejemplo: } \\
\text { Anual ) }\end{array}$ & & \\
\hline N010_COD_FREC_PAGO & Number & $\begin{array}{l}\text { Código de frecuencia pago ( } \\
\text { Ejemplo: Mensual ) }\end{array}$ & & \\
\hline N010_COD_CORREDOR & Number & Código de corredor & & $\mathrm{Si}$ \\
\hline N010_COD_CLIENTE & Number & Código de cliente & & $\mathrm{Si}$ \\
\hline N010_TIPO_SOLICITUD & Number & Tipo de solicitud & & \\
\hline F010_FEC_INI_VIGENCIA & Date & Fecha inicio de vigencia & & \\
\hline F010_FEC_FIN_VIGENCIA & Date & Fecha fin de vigencia & & \\
\hline $\begin{array}{l}\text { N010_MNT_PRIMA_NETA_TO } \\
\text { T }\end{array}$ & Decimal & Monto prima neta de póliza & & \\
\hline $\begin{array}{l}\text { N010_MNT_DER_EMISION_T } \\
\text { OT }\end{array}$ & Decimal & $\begin{array}{l}\text { Monto derecho de emisión de } \\
\text { póliza }\end{array}$ & & \\
\hline N010_MNT_IGV_TOT & Decimal & Monto IGV & & \\
\hline $\begin{array}{l}\text { N010_MNT_PRIMA_BRUTA_T } \\
\text { OT }\end{array}$ & Decimal & Monto prima bruta total & & \\
\hline N010_USU_REGISTRO & Number & Usuario de registro & & $\mathrm{Si}$ \\
\hline F010_FEC_REGISTRO & Date & Fecha de registro & & \\
\hline N010_USU_ACTUALIZA & Number & Usuario de actualización & & $\mathrm{Si}$ \\
\hline F010_FEC_ACTUALIZA & Date & Fecha de actualización & & \\
\hline A010_MOTIVO_RECHAZO & Varchar & $\begin{array}{l}\text { Descripción de motivo de rechazo } \\
\text { de solicitud }\end{array}$ & & \\
\hline N010_ESTADO & Number & $\begin{array}{l}\text { Estado de la solicitud (Ejemplo: } 1 \\
=\text { Vigente) }\end{array}$ & & \\
\hline
\end{tabular}




\section{(1)}

\begin{tabular}{|c|c|c|c|c|}
\hline Tabla & \multicolumn{4}{|c|}{ TB011_PLANILLA } \\
\hline Columna & Tipo de Dato & Descripción & PK & FK \\
\hline N011_COD_PLANILLA & Number & Código de planilla & $\mathrm{Si}$ & \\
\hline N011_ID_POLIZA & Number & Identificador de póliza & & $\mathrm{Si}$ \\
\hline A011_NOMBRES & Varchar & Nombres de asegurado & & \\
\hline A011_APE_PATERNO & Varchar & Apellido paterno de asegurado & & \\
\hline A011_APE_MATERNO & Varchar & Apellido materno de asegurado & & \\
\hline N011_TIPO_DOCUMENTO I & Number & Tipo de documento (Ejemplo: 1 = Dni ) & & \\
\hline A011_NRO_DOCUMENTO I & Varchar & Número de documento & & \\
\hline N011_COD_SEXO & Number & Código de sexo (Ejemplo: 1 = Femenino & & \\
\hline N011_ESTADO_CIVIL & Varchar & $\begin{array}{l}\text { Código de estado civil (Ejemplo: } 1= \\
\text { Soltero ) }\end{array}$ & & \\
\hline F011_FEC_NACIMIENTO & Date & Fecha de nacimiento de asegurado & & \\
\hline N011_REMUNERACION & Decimal & Remuneración del asegurado & & \\
\hline Tabla & & TB012_CLASE_PLANILLA & & \\
\hline Columna & $\begin{array}{l}\text { Tipo de } \\
\text { Dato }\end{array}$ & Descripción & PK & FK \\
\hline N012_COD_CLASE & Number & Código de clase trabajadora & $\mathrm{Si}$ & \\
\hline N012_ID_POLIZA & Number & Identificador de póliza & & $\mathrm{Si}$ \\
\hline N012_COD_TASA & Varchar & Código de tasa & & $\mathrm{Si}$ \\
\hline N012_TIPO_TRABAJADOR & Number & $\begin{array}{l}\text { Código clase trabajadora (Ejemplo: } \\
\text { 1=Administrativo) }\end{array}$ & & \\
\hline N012_NRO_TRABAJADORES & $S$ Number & Número de trabajadores & & \\
\hline N012_MNT_PLANILLA & Decimal & Monto de planilla por clase trabajadora & & \\
\hline N012_FLAG_TASA & Number & $\begin{array}{l}\text { Flag de cambio de tasa (Ejemplo: } 1= \\
\text { Cambio de tasa) }\end{array}$ & & \\
\hline N012_TASA & Decimal & Valor de tasa & & \\
\hline
\end{tabular}




\section{(1)}

\begin{tabular}{|c|c|c|c|c|}
\hline Tabla & \multicolumn{4}{|c|}{ TB013_OFICINA } \\
\hline Columna & Tipo de Dato & Descripción & PK & FK \\
\hline N013_COD_OFICINA & Number & Código de oficina & $\mathrm{Si}$ & \\
\hline N013_DESCRIPCION & Varchar & Descripción de oficina & & \\
\hline N013_UBIGEO & Number & Código de ubigeo de oficina & & \\
\hline N013_ESTADO & Number & $\begin{array}{l}\text { Estado del registro (Ejemplo: } 1= \\
\text { Activo) }\end{array}$ & & \\
\hline Tabla & & TB014_PRODUCTO & & \\
\hline Columna & Tipo de Dato & Descripción & PK & FK \\
\hline N014_COD_PRODUCTO & Number & Código de producto & $\mathrm{Si}$ & \\
\hline N014_COD_RAMO & Number & Código de ramo & & $\mathrm{Si}$ \\
\hline N014_DESCRIPCION & Number & Descripción del producto & & \\
\hline N014_ESTADO & Number & $\begin{array}{l}\text { Estado del registro (Ejemplo: } 1= \\
\text { Activo) }\end{array}$ & & \\
\hline
\end{tabular}

\begin{tabular}{|c|c|c|c|c|}
\hline Tabla & & TB015_POLIZA & & \\
\hline Columna & Tipo de Dato & Descripción & $\begin{array}{l}\mathrm{P} \\
\mathrm{K}\end{array}$ & $\begin{array}{l}\mathrm{F} \\
\mathrm{K}\end{array}$ \\
\hline N015_ID_POLIZA & Number & Identificador de póliza & $\mathrm{Si}$ & \\
\hline N015_COD_RAMO & Number & Código de ramo & & $\mathrm{Si}$ \\
\hline N015_COD_PRODUCTO & Number & Código de producto & & $\mathrm{Si}$ \\
\hline N015_NRO_TRAMITE & Number & Número de trámite & & \\
\hline N015_TIP_OPERACION & Number & Tipo de operación & & \\
\hline N015_COD_ACTIVIDAD & Number & Código de actividad & & $\mathrm{Si}$ \\
\hline N015_COD_MONEDA & Number & Código de moneda & & \\
\hline N015_COD_OFICINA & Number & Código de oficina & & $\mathrm{Si}$ \\
\hline N015_COD_VIGENCIA & Number & $\begin{array}{l}\text { Código de Vigencia ( Ejemplo: } \\
\text { Anual ) }\end{array}$ & & \\
\hline N015_COD_FREC_PAGO & Number & $\begin{array}{l}\text { Código de Frecuencia pago ( } \\
\text { Ejemplo: Mensual ) }\end{array}$ & & \\
\hline N015_COD_CORREDOR & Number & Código de corredor & & $\mathrm{Si}$ \\
\hline N015_COD_CLIENTE & Number & Código de cliente & & $\mathrm{Si}$ \\
\hline F015_FEC_INI_VIGENCIA & Date & Fecha inicio de vigencia & & \\
\hline
\end{tabular}




\section{(1)}

F015_FEC_FIN_VIGENCIA Date Fecha fin de vigencia

N015_MNT_PRIMA_NETA_T Decimal Monto prima neta de póliza

N015_MNT_DER_EMISION_T Decimal Monto derecho de emisión de póliza

N015_MNT_IGV_TOT Decimal Monto IGV

N015_MNT_PRIMA_BRUTA__ Decimal_ Monto prima bruta total

N015_NRO_POLIZA Varchar Número de póliza $\quad$ Si

N015_ID_PROFORMA Varchar Identificador de proforma

N015_USU_REGISTRO Number $\quad$ Usuario de registro $\quad$ Si

F015_FEC_REGISTRO Date Fecha de registro

N015_ESTADO Number Estado de la póliza (Ejemplo: $1=$ Vigente)

\begin{tabular}{|c|c|c|c|c|}
\hline Tabla & & TB016_PROFORMA & & \\
\hline Columna & Tipo de Dato & Descripción & PK & FK \\
\hline N016_ID_PROFORMA & Number & Identificador de proforma & $\mathrm{Si}$ & \\
\hline N016_ID_POLIZA & Number & Identificador de póliza & & $\mathrm{Si}$ \\
\hline N016_NRO_PROFORMA & Decimal & Número de proforma & & \\
\hline N016_MONTO & Number & Monto de la proforma generada & & \\
\hline N016_TIPO_PAGO & Number & Tipo de pago (Ejemplo: 1 = Contado) & & \\
\hline N016_ESTADO & Number & $\begin{array}{l}\text { Estado del registro (Ejemplo: } 1= \\
\text { Activo) }\end{array}$ & & \\
\hline
\end{tabular}

Nota. Descripción de tablas ASIS. Elaboración propia. 


\section{(1)}

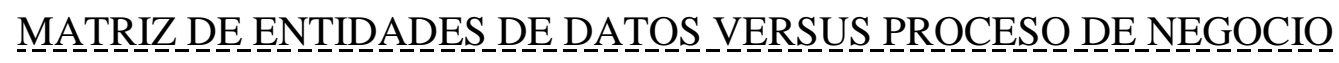

Tabla $N^{\circ} 20$

Matriz de Entidades de Datos versus Proceso de Negocio del ASIS

\begin{tabular}{|c|c|c|c|c|c|c|c|c|c|c|c|c|c|c|c|c|}
\hline \multirow[b]{2}{*}{ ENTIDAD DE DATOS } & \multicolumn{16}{|c|}{ MACRO PROCESOS } \\
\hline & 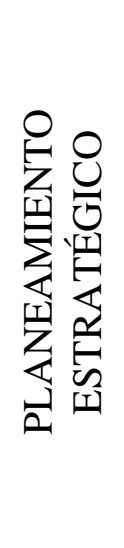 & 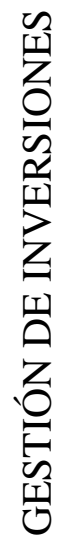 & 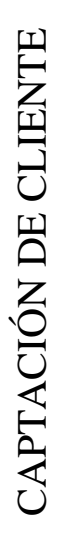 & $\underset{⿱ 亠 䒑}{\mathbb{5}}$ & 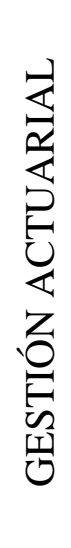 & $\begin{array}{l}\mathscr{2} \\
0 \\
0 \\
0 \\
0\end{array}$ & 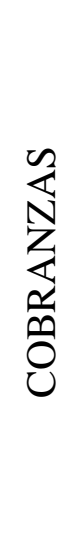 & 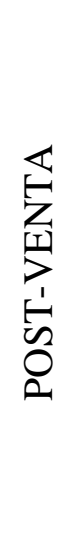 & 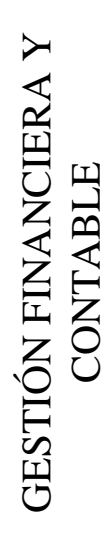 & 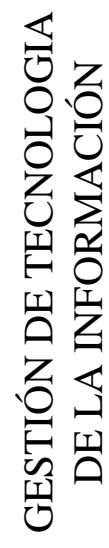 & 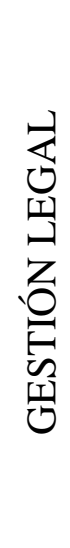 & 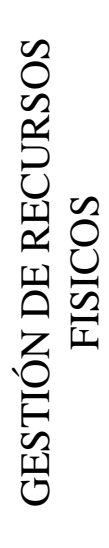 & 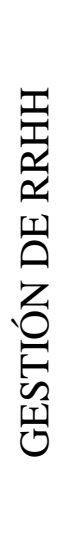 & 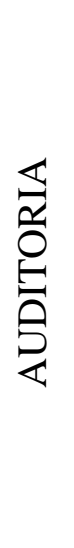 & 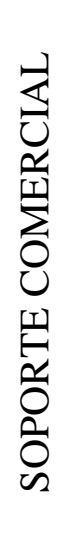 & 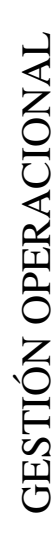 \\
\hline TB001_TARIFARIO & $\mathrm{X}$ & & & $\mathrm{X}$ & & & & & & $\mathrm{X}$ & $\mathrm{X}$ & & & & & \\
\hline TB002_RAMO & $X$ & $\mathrm{X}$ & $X$ & $\mathrm{X}$ & & & & & & $\mathrm{X}$ & & & & $\mathrm{X}$ & $\mathrm{X}$ & $\mathrm{X}$ \\
\hline TB003_ACT_ECONOMICA & & & $X$ & $\mathrm{X}$ & & & & & & $\mathrm{X}$ & & & & & & \\
\hline TB004_CLIENTE & & $\mathrm{X}$ & $X$ & $\mathrm{X}$ & & & & $\mathrm{X}$ & & $\mathrm{X}$ & $\mathrm{X}$ & & $\mathrm{X}$ & & & $\mathrm{X}$ \\
\hline TB005_CLIENTE_SEDE & & & $X$ & & & & & $\mathrm{X}$ & & $\mathrm{X}$ & & & & & & $\mathrm{X}$ \\
\hline TB006_MAESTROS & & & & & & & & & & $\mathrm{X}$ & & & & & & \\
\hline TB007_CORREDOR & & & & $\mathrm{X}$ & & & & & & $\mathrm{X}$ & & & & & & $\mathrm{X}$ \\
\hline TB008_USUARIO & & & & $\mathrm{X}$ & & & & & & $\mathrm{X}$ & & & $\mathrm{X}$ & & & $\mathrm{X}$ \\
\hline TB009_PERFIL & & & & & & & & & & $\mathrm{X}$ & & & & & & \\
\hline TB010_SOLICITUD & & & & & & & & & & $\mathrm{X}$ & & & & & & \\
\hline TB011_PLANILLA & & & & $\mathrm{X}$ & & & & & & $\mathrm{X}$ & & & & & & \\
\hline
\end{tabular}




\section{(1)}

TB012_CLASE_PLANILLA

TB013_OFICINA

TB014_PRODUCTO

TB015_POLIZA

TB016_PROFORMA

$\begin{array}{lllll}X & & X & X & \\ & & & X & X \\ X & X & & X & X \\ X & & & X & \end{array}$

$\begin{array}{lll} & \\ & \\ X & \\ X\end{array}$

$\begin{array}{ccc} & & X \\ X & & X \\ & X \\ & X \\ X & X\end{array}$

\begin{tabular}{lllll}
$X$ & & & & \\
$X$ & & & X & \\
$X$ & & & $X$ & \\
$X$ & $X$ & $X$ & & $X$ \\
$X$ & $X$ & $X$ & & \\
\hline
\end{tabular}

Nota. Matriz de entidades de datos versus proceso de negocio seleccionado. Elaboración propia. 


\section{(1)}

\section{$\underline{\text { ARQUITECTURA DE APLICACIÓN }}$}

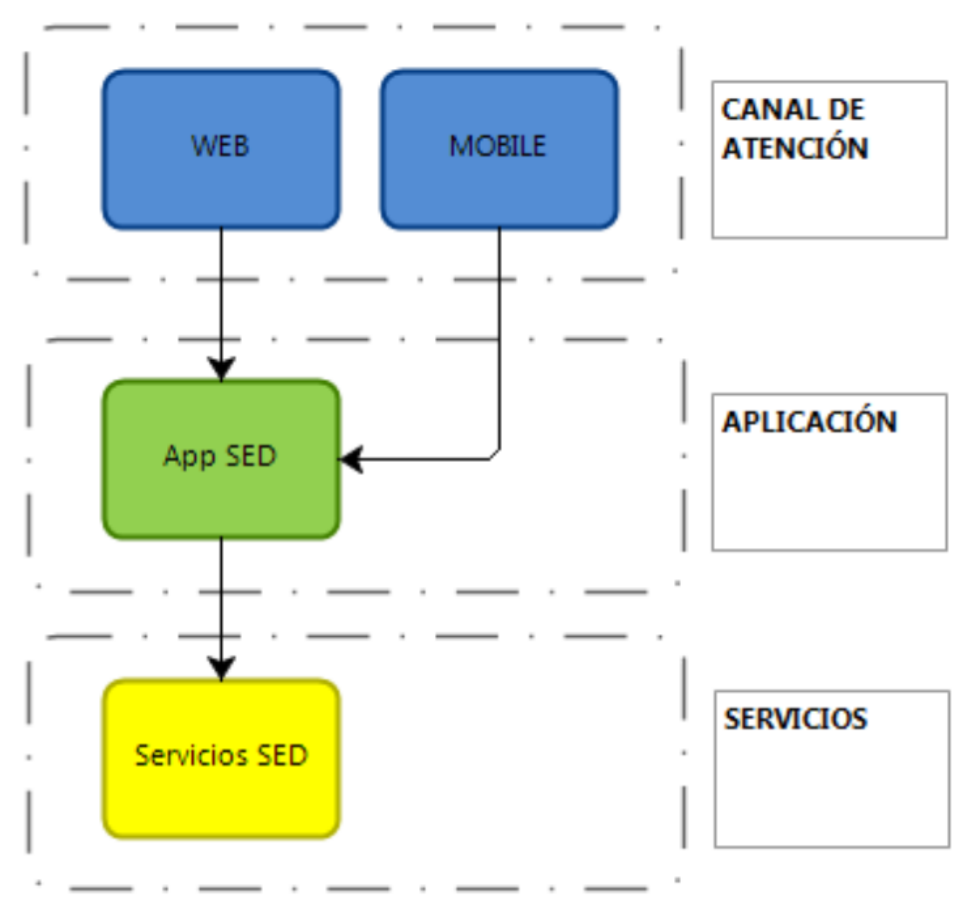

Figura $N^{\circ} 21$ Arquitectura de Aplicación. Adaptado de "Arquitectura de Aplicación SED (AS IS)", Elaboración propia, 2018.

El proceso de emisión de póliza utiliza el aplicativo web App SED mediante el cual el usuario accede desde un navegador de escritorio o móvil. El aplicativo App SED utiliza servicios para la emisión de documentos relacionados a las pólizas. 


\section{(1)}

\section{ARQUITECTURA TECNOLÓGICA}

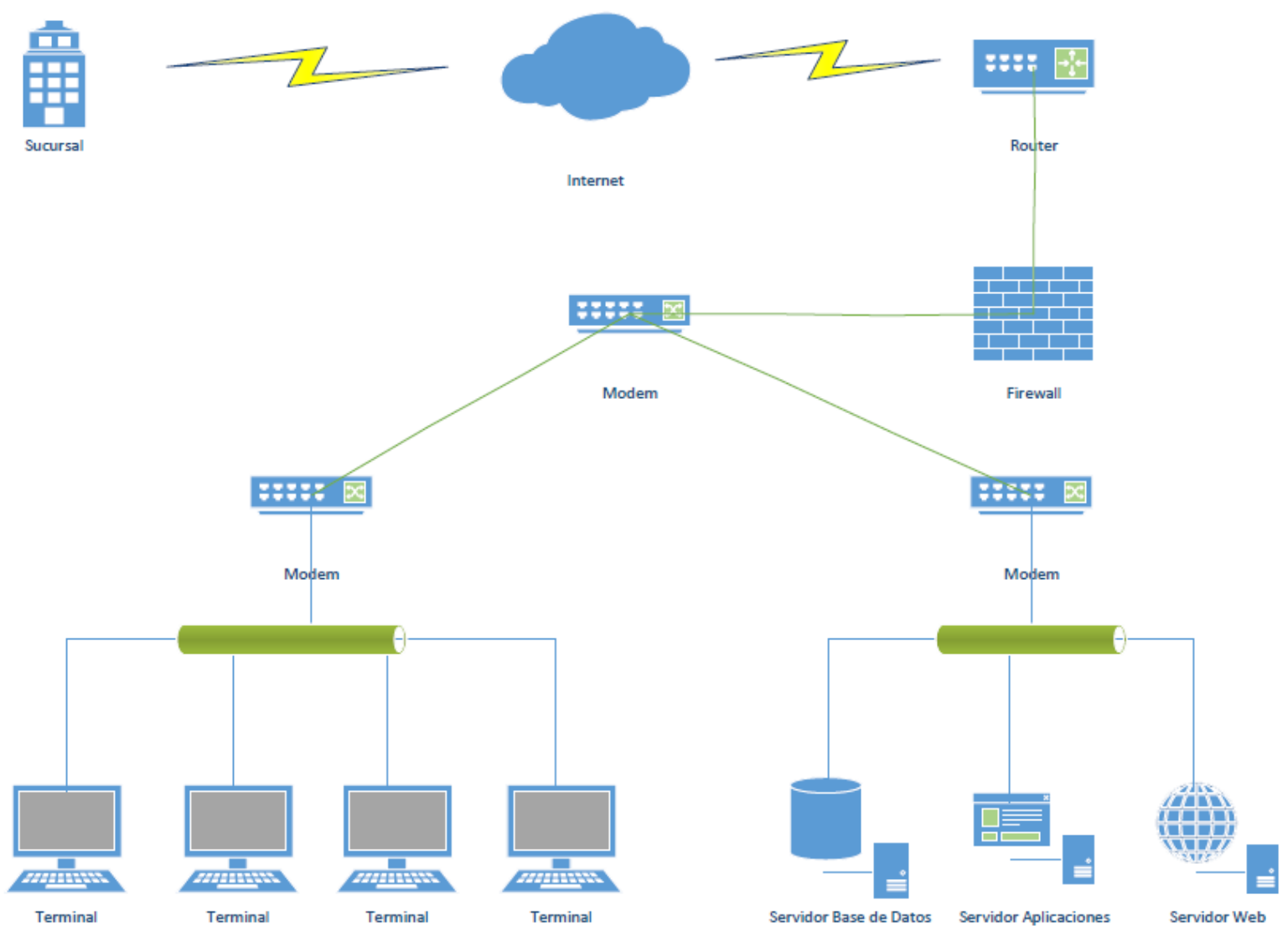

Figura $N^{\circ} 22$ Arquitectura Tecnológica. Adaptado de “Arquitectura Tecnológica SED (AS IS)”, Elaboración propia, 2018.

Desde las estaciones de trabajo del usuario (computadora de escritorio, laptop o móvil), el personal se conecta al Sistema de Emisión a Distancia el cual se encuentra en un servidor web; el sistema interactúa con los servidores de base de datos y al servidor de aplicaciones que aloja al servicio responsable de la emisión de documentos.

Servidor Web: IBM AIX, Procesador: 16 cores, Memoria: 32 GB

Servidor de Base de Datos (2): Redhat Linux, Procesador: 16 cores, Memoria: 32 GB y UNIX, Procesador: 8 cores, Memoria: 16 GB 


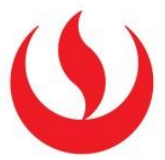

Servidor de Aplicaciones: Windows server 2012 R2, Procesador: 16 cores

\section{FUNDAMENTO Y JUSTIFICACIÓN DEL ENFOQUE ARQUITECTÓNICO}

En la situación actual del proceso de emisión de pólizas de SCTR, se ha identificado la siguiente problemática:

En lo que concierne a problemas técnico, el sistema SED no permite el procesamiento en paralelo de emisión y gestión de pólizas, debido a que no se maneja una adecuada concurrencia. Esto, en reiteradas ocasiones genera bloqueo en la base de datos del sistema, lo cual genera la indisponibilidad del mismo y pérdida de transacciones, ocasionando retraso en los procesos de atención a los usuarios; además de la potencial generación de información inconsistente. Por otro lado, los sub procesos antes mencionados se manejan de forma síncrona. Es decir, una vez que se lanza el proceso de generación de póliza, el usuario debe esperar a que el sistema devuelva la póliza generada, lo cual no permite al usuario poder realizar otras operaciones.

Esta problemática encontrada en la situación actual del proceso impide que este pueda ayudar al logro de los objetivos estratégicos de la empresa. Por tanto, en la siguiente sección, se propondrá una arquitectura de destino, la cual permite que se puedan realizar operaciones en concurrencia. Asimismo, esta solución debe permitir al usuario poder realizar operaciones en paralelo. Por último, esta solución debe permitir al proceso alinearse con los objetivos estratégicos de la empresa.

\section{ARQUITECTURAS DESTINO}

En esta sección se realiza el análisis de la situación deseada (TO BE).

\section{$\underline{\text { ARQUITECTURA DE NEGOCIO }}$}




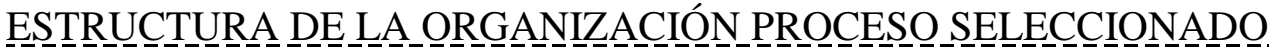

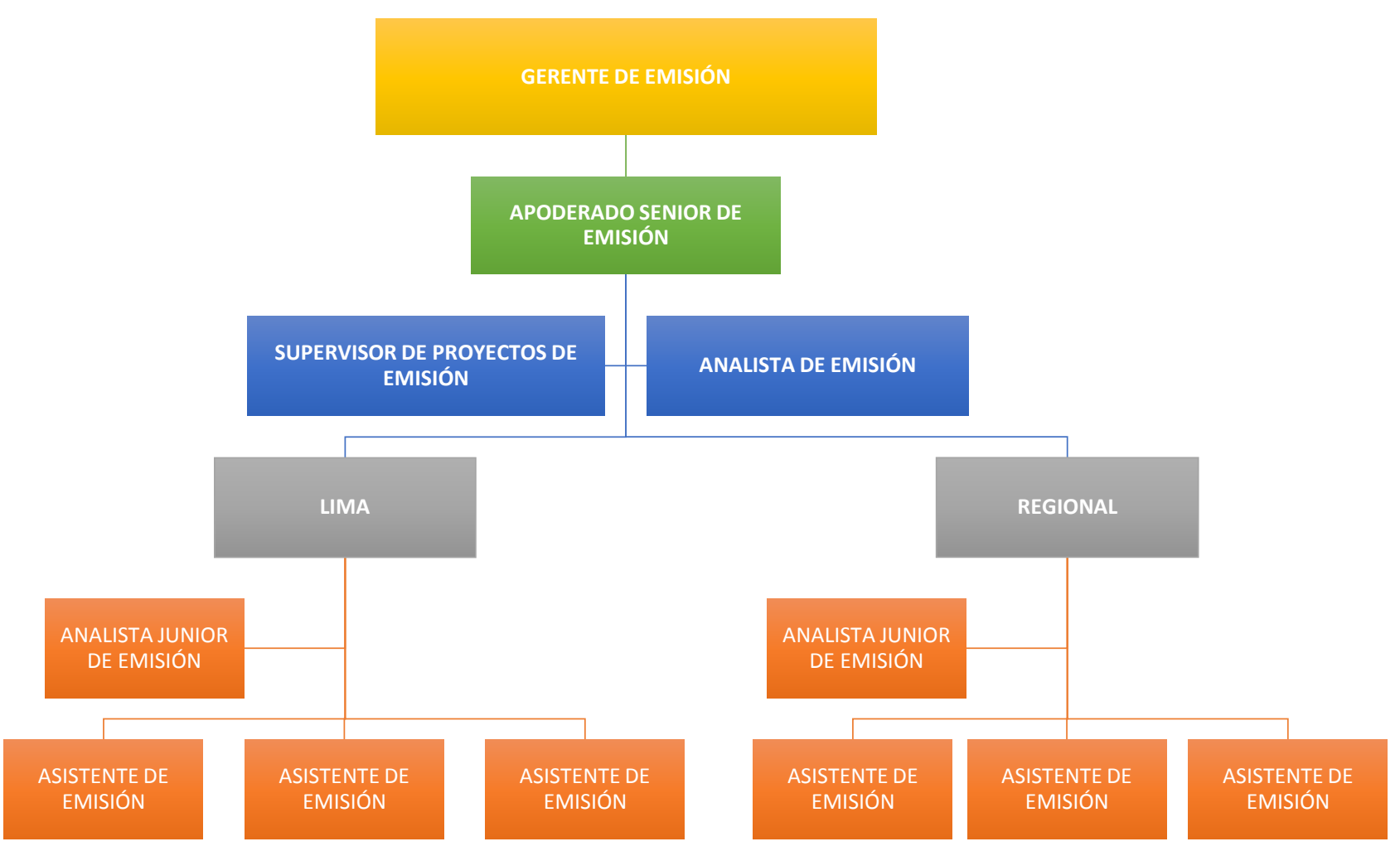

Figura $\quad N^{\circ} 23$ Organigrama. Adaptado de “Organigrama (TOBE)", Elaboración propia, 2018. 


\section{()}

Tabla $\mathrm{N}^{\circ} 21$

Descripción de funciones por cargo del proceso seleccionado.

\begin{tabular}{l} 
Cargo \\
\hline Gerente de Emisión \\
Apoderado Senior de \\
Emisión
\end{tabular}

Descripción

- Evaluar y mejorar la eficacia de los procesos de gestión de riesgos, control y gobierno de acuerdo al marco internacional para la práctica de auditoría interna, a lo establecido por la Superintendencia de Banca, Seguros y AFP y por las normas internas de la empresa - Presentar al Directorio, al Comité de Auditoría, al nivel Gerencial y a la Superintendencia de Banca, Seguros y AFP el resultado de la labor realizada por la Gerencia Corporativa de Auditoría. - Realizar el seguimiento de las recomendaciones para su implementación, incluyendo las de Auditoría Interna, las formuladas por la Superintendencia de Banca, Seguros y AFP, y los Auditores Externos.

- Garantizar que la emisión de pólizas se realice cumpliendo con los tiempos establecidos y de acuerdo a las Políticas de Suscripción. - Optimizar los criterios y lineamientos básicos de la Política de Emisión de Pólizas buscando la mejora continua. - Garantizar el cumplimiento de la política de firmas establecida, la confidencialidad y seguridad de los documentos manejados por el Área de Emisión.

- Asegurar que los proyectos internos e institucionales sean exitosos.

Supervisor de Proyectos de Emisión

- Alinear los proyectos del Área de Emisión con los Proyectos Estratégicos de la Compañía. - Optimizar los procesos internos, buscando la mejora continua en productividad, calidad y control de gestión.

- Garantizar la correcta emisión de pólizas, y mejorar la calidad de la Analista de Emisión emisión a través de capacitaciones continuas al personal. - Promover el cumplimiento de las políticas y procedimientos del Área de Emisión.

- Garantizar la correcta emisión de pólizas, y mejorar la calidad de la

Analista Junior de Emisión emisión a través de capacitaciones continuas al personal. - Promover el cumplimiento de las políticas y procedimientos del Área de Emisión.

- Emitir correctamente las pólizas asignadas por la Oficina Virtual de manera oportuna.

- Verificar que se tenga toda la información necesaria para realizar la Asistente de Emisión emisión de póliza. - Realizar las renovaciones y endosos que se soliciten validando que los datos sean consistentes.

Nota. Relación de funciones por cargo del proceso seleccionado. Elaboración propia. 


\section{(4)}

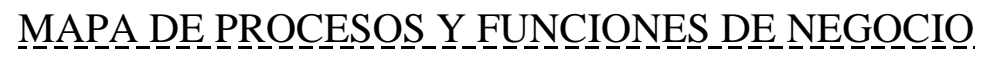

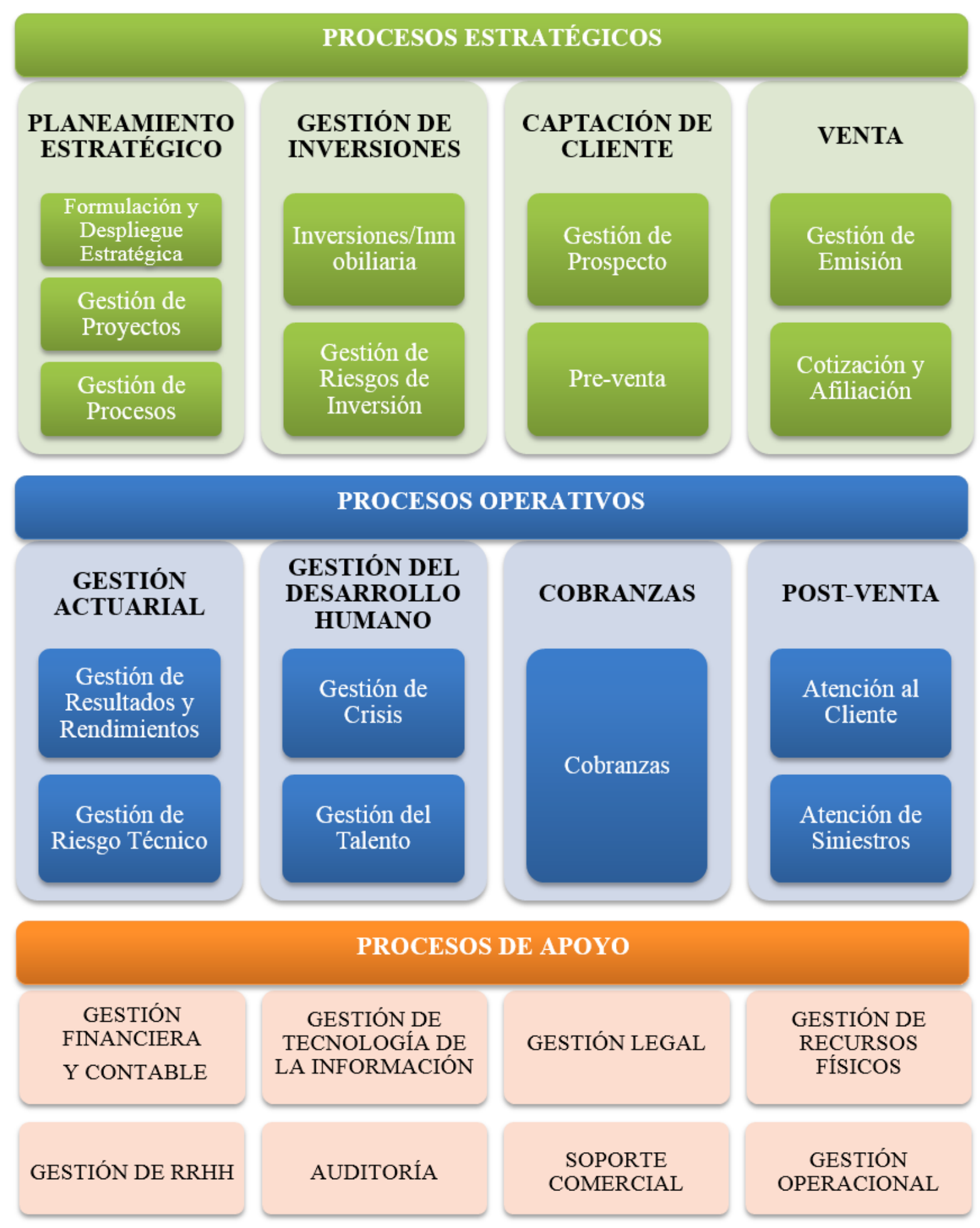

Figura $N^{\circ} 24$ Mapa de Procesos, Adaptado de "Mapa de Procesos y funciones de Negocio y descripción de una entidad aseguradora en Lima", Elaboración propia, 2018. 


\section{()}

Tabla $\mathrm{N}^{\circ} 22$

Descripción de Procesos

\begin{tabular}{|c|c|c|}
\hline Tipo & Procesos & Descripción \\
\hline \multirow{4}{*}{ Estratégico } & $\begin{array}{l}\text { Planeamiento } \\
\text { Estratégico }\end{array}$ & $\begin{array}{l}\text { Es el proceso que se encarga de definir la visión de la } \\
\text { empresa a mediano y largo plazo, así como también las } \\
\text { estrategias para alcanzarlas a través del análisis de las } \\
\text { fortalezas, debilidades, oportunidades y amenazas. Es el } \\
\text { proceso que da inicio al proceso de planificación de la } \\
\text { empresa. }\end{array}$ \\
\hline & $\begin{array}{l}\text { Gestión de } \\
\text { Inversiones }\end{array}$ & $\begin{array}{l}\text { Es la gestión que se encarga de ofrecer funciones para } \\
\text { ayudar en la planificación, la inversión y los procesos de } \\
\text { financiación. }\end{array}$ \\
\hline & Captación de Cliente & $\begin{array}{l}\text { Es el proceso que se encarga de la búsqueda de clientes } \\
\text { potenciales para convertirlos en clientes finales. }\end{array}$ \\
\hline & Venta & $\begin{array}{l}\text { Es el proceso que se encarga de las ventas de productos o } \\
\text { servicios, la cual constituye la base de las operaciones de la } \\
\text { empresa. }\end{array}$ \\
\hline \multirow{4}{*}{ Operativos } & Gestión Actuarial & $\begin{array}{l}\text { Es el proceso que se encarga de definir la gestión de } \\
\text { resultados, rendimiento y riesgos técnicos de la empresa. }\end{array}$ \\
\hline & $\begin{array}{l}\text { Gestión del } \\
\text { Desarrollo Humano }\end{array}$ & $\begin{array}{l}\text { Es el proceso que se encarga de la gestión de crisis y del } \\
\text { talento humano. }\end{array}$ \\
\hline & $\underline{\text { Cobranzas }}$ & $\begin{array}{l}\text { Se encarga del desarrollo de actividades y estrategias para } \\
\text { alcanzar el cobro de deudas. }\end{array}$ \\
\hline & Post-Venta & $\begin{array}{l}\text { Estable los canales de comunicación hacía el Cliente. Con } \\
\text { el fin de que el Cliente tenga manera para manifestar } \\
\text { reclamos, sugerencias, solicitar información o plantear } \\
\text { inquietudes sobre el producto y/o servicio de la } \\
\text { organización. }\end{array}$ \\
\hline \multirow[t]{2}{*}{ Ароуо } & $\begin{array}{l}\text { Gestión Financiera y } \\
\text { Contable }\end{array}$ & $\begin{array}{l}\text { Es el proceso que se encarga de la eficiencia administrativa } \\
\text { del capital de trabajo dentro de un criterio de riesgos y } \\
\text { rentabilidad; además, de orientar la estrategia financiera } \\
\text { para garantizar la disponibilidad de fuentes de financiación. } \\
\text { Asimismo se encarga de llevar un registro y control de las } \\
\text { operaciones financieras que se lleva a cabo en la } \\
\text { organización. }\end{array}$ \\
\hline & $\begin{array}{l}\text { Gestión de } \\
\text { Tecnología de la } \\
\text { Información }\end{array}$ & $\begin{array}{l}\text { Es el proceso que se encarga de planificar, diseñar, ejecutar } \\
\text { y monitorear la estrategia de las tecnologías de la } \\
\text { información. Además, de supervisar y evaluar el } \\
\text { alineamiento de los sistemas de información a los procesos } \\
\text { de la organización. }\end{array}$ \\
\hline
\end{tabular}




\section{(1)}

Gestión Legal

Es la que se encarga de controlar la legalidad de los actos

Gestión de Recursos
Físicos

administrativos y emisión de conceptos jurídicos relacionados con el objeto y función de la empresa.

Es el proceso que se encarga de la adquisición, manejo y administración de elementos, equipos e inmuebles y los procesos para su almacenamiento, custodia, inventario, distribución y mantenimiento, servicio generales, archivos y correspondencia.

Este proceso se encarga de gestionar y coordinar la

Gestión de RRHH aplicación de las normas y los procedimientos de los recursos humanos. Las cuales desarrollan y aplican en los sistemas de información en la gestión del talento humano.

Es el proceso que se encarga de regular la planificación,

Auditoría organización, realización y comunicación de las auditorías internas de la empresa.

Está integrado por el gerente comercial y da a conocer la definición de actividades relacionadas con el cliente, de tal

Soporte Comercial modo de asegurar la correcta determinación de los requisitos relacionados con el producto y/o servicio estableciendo disposiciones eficaces para la comunicación con los clientes.

Es el proceso que se encarga de la producción de bienes y Gestión Operacional servicios, basados en toma de decisiones sobre eficiencia y efectividad.

Nota. Descripción de los procesos del negocio. Elaboración propia. 


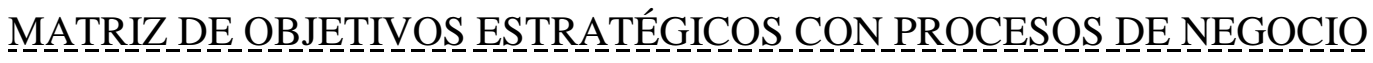

Tabla $\mathrm{N}^{\circ} 23$

Matriz de objetivos estratégicos versus procesos de negocio.

\begin{tabular}{|c|c|c|c|c|c|c|c|c|c|c|c|}
\hline \multirow{2}{*}{ MACRO PROCESO } & \multicolumn{11}{|c|}{ OBJETIVO ESTRATEGICOS } \\
\hline & OE1 & OE2 & OE3 & OE4 & OE5 & OE6 & OE7 & OE8 & OE9 & OE10 & OE11 \\
\hline PLANEAMIENTO ESTRATÉGICO & $\mathrm{X}$ & & & & & $\mathrm{X}$ & & $\mathrm{X}$ & & $\mathrm{X}$ & \\
\hline GESTIÓN DE INVERSIONES & & $\mathrm{X}$ & & & & $\mathrm{X}$ & & & & $\mathrm{X}$ & \\
\hline CAPTACIÓN DE CLIENTE & & & & $X$ & $\mathrm{X}$ & & & & & & \\
\hline VENTA & $X$ & & $X$ & $X$ & $\mathrm{X}$ & & & & & & \\
\hline GESTIÓN ACTUARIAL & $X$ & & & & & & & & & & \\
\hline OTROS & & & & & & & & & $\mathrm{X}$ & & $\mathrm{X}$ \\
\hline COBRANZAS & & & & & & & & & & & \\
\hline POST-VENTA & & & & $X$ & $\mathrm{X}$ & & & & & & \\
\hline GESTIÓN FINANCIERA Y CONTABLE & & $\mathrm{X}$ & & & & & & & & & \\
\hline GESTIÓN DE TECNOLOGÍA DE LA INFORMACIÓN & & & $X$ & & & $\mathrm{X}$ & $\mathrm{X}$ & & & & \\
\hline GESTIÓN LEGAL & & & & & & & & & & & \\
\hline GESTIÓN DE RECURSOS FÍSICOS & & & & & & & $\mathrm{X}$ & & & & \\
\hline GESTIÓN DE RRHH & & & & & & & & & $X$ & & $\mathrm{X}$ \\
\hline AUDITORÍA & & & & & & & & $X$ & & & \\
\hline SOPORTE COMERCIAL & & & & & & & & $X$ & & & \\
\hline GESTIÓN OPERACIONAL & & & $\mathrm{X}$ & & & & $\mathrm{X}$ & & & & \\
\hline
\end{tabular}

Nota. Matriz de objetivos estratégicos versus procesos de negocio. Elaboración propia. 
ARQUITECTURA DE DATOS

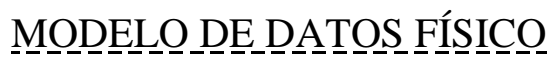




\section{$(1$}

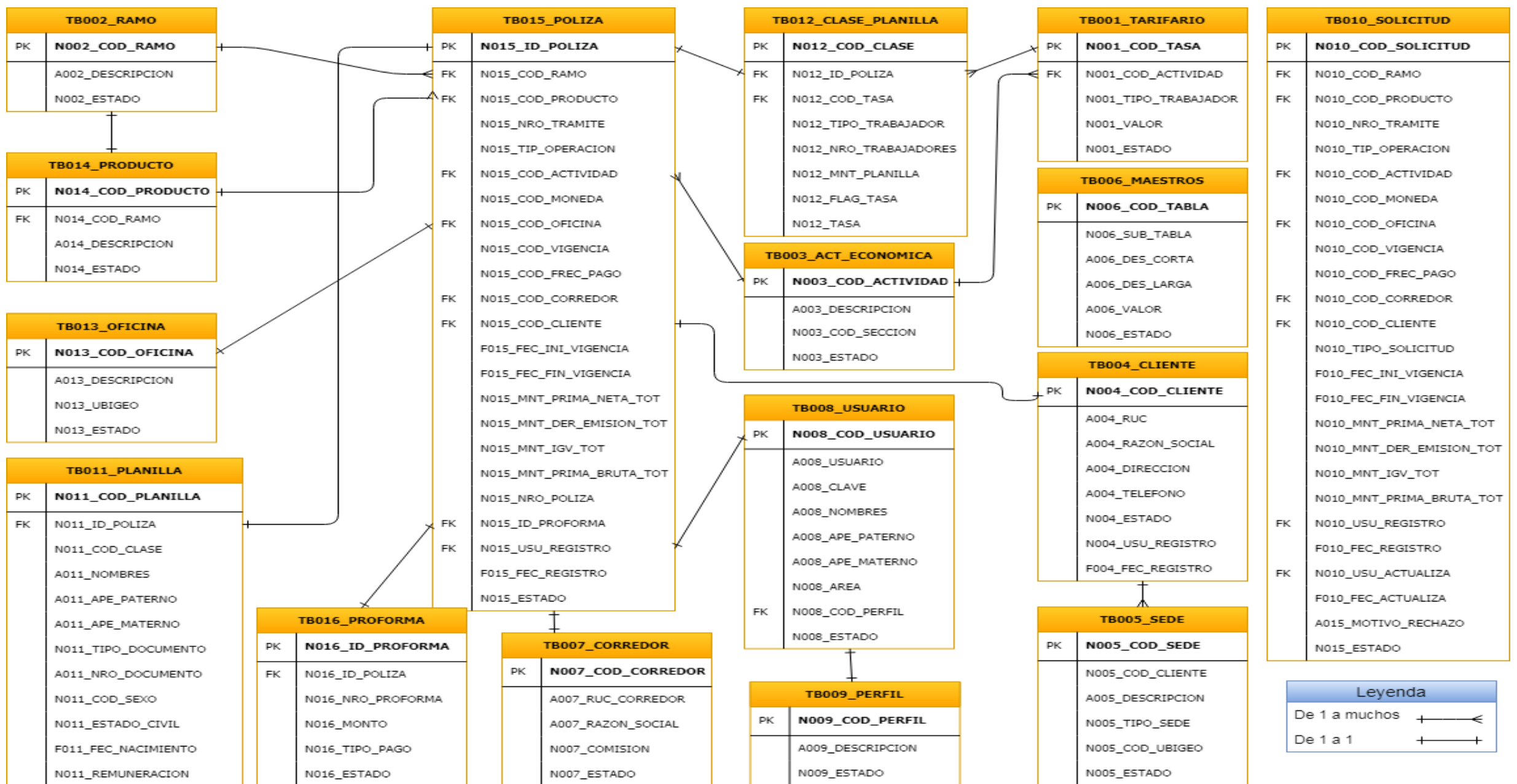




\begin{tabular}{|c|c|c|c|}
\hline \multicolumn{2}{|r|}{ TB017_OPERACION_SED } & \multicolumn{2}{|r|}{ TB018_OPERACION_MOV } \\
\hline \multirow[t]{16}{*}{ PK } & N017_ID_OPERACION & PK & N018_ID_HISTORIAL \\
\hline & N017_COD_RAMO & $\mathrm{FK}$ & N018_ID_OPERACION \\
\hline & N017_NRO_POLIZA & & N018_COD_RAMO \\
\hline & N017_COD_ESTADO & & N018_NRO_POLIZA \\
\hline & N017_FEC_ESTADO & & N018_COD_ESTADO \\
\hline & N017_COD_FUNCIONALIDAD & & N018_FEC_ESTADO \\
\hline & N017_COD_RESULTADO & & N018_COD_FUNCIONALIDAD \\
\hline & N017_DES_RESULTADO & & N018_COD_RESULTADO \\
\hline & N017_COD_CLIENTE & & N018_DES_RESULTADO \\
\hline & N017_COD_CORREDOR & & N018_COD_CLIENTE \\
\hline & A017_MSI_USUARIO & & N018_COD_CORREDOR \\
\hline & N017_TIPO_ANULACION & & A018_MSI_USUARIO \\
\hline & N017_USU_REGISTRA & & N018_TIPO_ANULACION \\
\hline & F017_FEC_REGISTRA & & N018_NRO_REINTENTO \\
\hline & N017_USU_ACTUALIZA & & N018_USU_REGISTRA \\
\hline & F017_FEC_ACTUALIZA & & F018_FEC_REGISTRA \\
\hline & & & N018_USU_ACTUALIZA \\
\hline & & & F018_FEC_ACTUALIZA \\
\hline
\end{tabular}

Figura N 25 Arquitectura de Datos. Adaptado de "Modelo de Datos del Proceso Seleccionado (TO BE)”, Elaboración propia, 2018. 


\section{(1)}

Tabla $\mathrm{N}^{\circ} 24$

Tabla de Descripción de Tablas del TOBE

\begin{tabular}{|c|c|}
\hline Nombre de Tabla & Descripción \\
\hline TB001_TARIFARIO & $\begin{array}{l}\text { Tabla que representa el tarifario asignado para las clases } \\
\text { trabajadoras. Ejemplo: Administrativo }=\text { Tasa } 0.95\end{array}$ \\
\hline TB002_RAMO & $\begin{array}{l}\text { Tabla que contiene información de los tipos de Ramos. } \\
\text { Ejemplo: SCTR Pensión y SCTR Salud. }\end{array}$ \\
\hline TB003_ACT_ECONOMICA & $\begin{array}{l}\text { Tabla que contiene la información de la actividad } \\
\text { económica a la que se dedica el cliente. Ejemplo: } \\
\text { Construcción. }\end{array}$ \\
\hline TB004_CLIENTE & Tabla que representa la información de Clientes. \\
\hline TB005_CLIENTE_SEDE & $\begin{array}{l}\text { Tabla que contiene la información de Sedes que pertenecen } \\
\text { a los clientes }\end{array}$ \\
\hline TB006_MAESTROS & $\begin{array}{l}\text { Tabla que representa la información de registros Maestros } \\
\text { de Información. Ejemplo: Estados de Póliza, Tipo de } \\
\text { Moneda, etc. }\end{array}$ \\
\hline TB007_CORREDOR & Tabla que representa la información de Corredores \\
\hline TB008_USUARIO & Tabla que tiene la información de Usuarios del Sistema. \\
\hline TB009_PERFIL & Tabla que contiene la información de Perfiles del Sistema. \\
\hline TB010_SOLICITUD & Tabla que contiene la información de Solicitudes de Póliza. \\
\hline TB011_PLANILLA & $\begin{array}{l}\text { Tabla que contiene la relación de asegurados relacionados a } \\
\text { una Póliza. }\end{array}$ \\
\hline TB012_CLASE_PLANILLA & $\begin{array}{l}\text { Tabla que comprende la información de los tipos de } \\
\text { asegurados con las que se generó una Póliza. Ejemplo: } \\
\text { Administrativo, Mediano Riesgo, Alto Riesgo. }\end{array}$ \\
\hline TB013_OFICINA & Tabla que representa las oficinas de la organización. \\
\hline TB014_PRODUCTO & Tabla que representa el producto perteneciente a un Ramo. \\
\hline TB015_POLIZA & Tabla que contiene la información de condiciones de Póliza. \\
\hline TB016_PROFORMA & $\begin{array}{l}\text { Tabla que contiene la información de Proforma de Pago de } \\
\text { una Póliza. }\end{array}$ \\
\hline TB017_OPERACION_SED & $\begin{array}{l}\text { Tabla que guarda los datos de las operaciones realizadas por } \\
\text { un usuario. }\end{array}$ \\
\hline TB018_OPERACION_MOV & $\begin{array}{l}\text { Tabla que guarda los datos de los movimientos de la tabla } \\
\text { TB017_OPERACION_SED }\end{array}$ \\
\hline
\end{tabular}

Nota. Descripción de tablas del TOBE. Elaboración propia. 


\section{(1)}

Tabla $\mathrm{N}^{\circ} 25$

Diccionario de datos de las tablas del TOBE

\begin{tabular}{|c|c|c|c|c|}
\hline \multirow{2}{*}{$\begin{array}{c}\text { Tabla } \\
\text { Columna }\end{array}$} & \multicolumn{4}{|c|}{ TB001_TARIFARIO } \\
\hline & $\begin{array}{c}\text { Tipo de } \\
\text { Dato }\end{array}$ & Descripción & PK & FK \\
\hline N001_COD_TASA & Number & Código de tasa & $\mathrm{Si}$ & \\
\hline N003_COD_ACTIVIDAD & Number & Código de actividad económica & & $\mathrm{Si}$ \\
\hline N001_TIPO_TRABAJADOR & Number & $\begin{array}{l}\text { Tipo de trabajador (Ejemplo: } \\
\text { Administrativo) }\end{array}$ & & \\
\hline N001_VALOR & Decimal & Valor de la tasa & & \\
\hline N001_ESTADO & Number & $\begin{array}{l}\text { Estado del registro (Ejemplo: } 1 \\
=\text { Activo) }\end{array}$ & & \\
\hline
\end{tabular}

\begin{tabular}{|c|c|c|c|c|}
\hline Tabla & \multicolumn{4}{|c|}{ TB002_RAMO } \\
\hline Columna & Tipo de Dato & Descripción & $\mathrm{PK}$ & FK \\
\hline N002_COD_RAMO & Number & Código de ramo & $\mathrm{Si}$ & \\
\hline A002_DESCRIPCION & Number & Descripción de ramo & & $\mathrm{Si}$ \\
\hline N002_ESTADO & Number & $\begin{array}{l}\text { Estado del registro (Ejemplo: } \\
1=\text { Activo) }\end{array}$ & & \\
\hline
\end{tabular}

Tabla

Columna

N003_COD_ACTIVIDAD

A003_DESCRIPCION

NO03_COD_SECCION
TB003_ACT_ECONOMICA

Tipo de Dato

Descripción

PK FK

Código de actividad económica

$\mathrm{Si}$

Descripción de la actividad
económica

Varchar

Código de la sección de la actividad económica 


\begin{tabular}{|c|c|c|c|c|}
\hline N003_ESTADO & Number & istro (Ejemplo: & & \\
\hline Tabla & \multicolumn{4}{|c|}{ TB004_CLIENTE } \\
\hline Columna & & Descripción & & FK \\
\hline N004_COD_CLIENTE & Number & Código de cliente & $\mathrm{Si}$ & \\
\hline A004_RUC & Varchar & Ruc de cliente & & \\
\hline A004_RAZON_SOCIAL & Varchar & $\begin{array}{l}\text { Razón social del } \\
\text { cliente }\end{array}$ & & \\
\hline A004_DIRECCION & Varchar & $\begin{array}{l}\text { Dirección del } \\
\text { cliente }\end{array}$ & & \\
\hline A004_TELEFONO & Varchar & $\begin{array}{l}\text { Teléfono del } \\
\text { cliente }\end{array}$ & & \\
\hline N004_ESTADO & Number & $\begin{array}{l}\text { Estado del cliente } \\
\text { (Ejemplo: } 1= \\
\text { Activo) }\end{array}$ & & \\
\hline N004_USU_REGISTRO & Number & $\begin{array}{l}\text { Usuario de } \\
\text { registro }\end{array}$ & & \\
\hline F004_FEC_REGISTRO & Date & Fecha de registro & & \\
\hline
\end{tabular}

\begin{tabular}{|c|c|c|c|c|}
\hline Tabla & \multicolumn{4}{|c|}{ TB005_SEDE } \\
\hline Columna & Tipo de Dato & Descripción & $\begin{array}{l}\mathrm{P} \\
\mathrm{K}\end{array}$ & FK \\
\hline N005_COD_SEDE & Number & Código de sede & $\mathrm{Si}$ & \\
\hline N005_COD_CLIENTE & Number & Código de cliente & & $\mathrm{Si}$ \\
\hline
\end{tabular}




\section{(1)}

\begin{tabular}{lll} 
A005_DESCRIPCION & Varchar & $\begin{array}{l}\text { Descripción de la } \\
\text { sede }\end{array}$ \\
N005_TIPO_SEDE & Number & $\begin{array}{l}\text { Tipo de sede } \\
\text { (Ejemplo: } \\
\text { Principal) }\end{array}$ \\
N005_COD_UBIGEO & Number & $\begin{array}{l}\text { Código de ubigeo } \\
\text { de la sede }\end{array}$ \\
& & $\begin{array}{l}\text { Estado del } \\
\text { registro (Ejemplo: } \\
1=\text { Activo) }\end{array}$ \\
\hline N005_ESTADO & Number &
\end{tabular}

Tabla

Columna

Tipo de Dato

TB006_MAESTROS

\begin{tabular}{|c|c|c|c|}
\hline Columna & Tipo de Dato & Descripción & $\begin{array}{ll}\mathrm{P} & \mathrm{FK} \\
\mathrm{K}\end{array}$ \\
\hline N006_COD_TABLA & Number & Código de Tabla & $\mathrm{Si}$ \\
\hline N006_SUB_TABLA & Varchar & $\begin{array}{l}\text { Código de Sub } \\
\text { Tabla }\end{array}$ & \\
\hline A006_DES_CORTA & Number & Descripción corta & \\
\hline A006_DES_LARGA & Number & Descripción larga & \\
\hline A006_VALOR & Number & Valor del registro & \\
\hline N006_ESTADO & Number & $\begin{array}{l}\text { Estado del } \\
\text { registro (Ejemplo: } \\
1=\text { Activo) }\end{array}$ & \\
\hline
\end{tabular}

Tabla

Columna

N007_COD_CORREDOR
TB007_CORREDOR

Tipo de Dato

Descripción

$\begin{array}{ll}\mathrm{P} & \mathrm{FK} \\ \mathrm{K} & \end{array}$

Código corredor 


\section{(1)}

\begin{tabular}{lll} 
A007_RUC_CORREDOR & Varchar & Ruc de corredor \\
A007_RAZON_SOCIAL & Varchar & $\begin{array}{l}\text { Razón social de } \\
\text { corredor }\end{array}$ \\
& & $\begin{array}{l}\text { Estado del } \\
\text { registro (Ejemplo: } \\
1=\text { Activo) }\end{array}$ \\
\hline N007_ESTADO & Number &
\end{tabular}

\begin{tabular}{|c|c|c|c|c|}
\hline Tabla & \multicolumn{4}{|c|}{ TB008_USUARIO } \\
\hline Columna & Tipo de Dato & Descripción & $\begin{array}{l}\mathrm{P} \\
\mathrm{K}\end{array}$ & FK \\
\hline N008_COD_USUARIO & Number & Código de usuario & $\mathrm{Si}$ & \\
\hline A008_USUARIO & Varchar & Usuario & & \\
\hline A008_CLAVE & Number & Clave & & \\
\hline A008_NOMBRES & Number & $\begin{array}{l}\text { Nombres de } \\
\text { usuario }\end{array}$ & & \\
\hline A008_APE_PATERNO & Number & Apellido paterno & & \\
\hline A008_APE_MATERNO & Number & Apellido materno & & \\
\hline N008_AREA & Number & $\begin{array}{l}\text { Área de } \\
\text { organización }\end{array}$ & & \\
\hline N008_COD_PERFIL & Number & Código de perfil & & \\
\hline N008_ESTADO & Number & $\begin{array}{l}\text { Estado del } \\
\text { registro (Ejemplo: } \\
1=\text { Activo) }\end{array}$ & & \\
\hline
\end{tabular}




\section{(1)}

\begin{tabular}{|c|c|c|c|}
\hline Columna & Tipo de Dato & Descripción & $\begin{array}{ll}\mathrm{P} & \mathrm{FK} \\
\mathrm{K} & \mathrm{n}\end{array}$ \\
\hline N009_COD_PERFIL & Number & Código de perfil & $\mathrm{Si}$ \\
\hline A009_DESCRIPCION & Varchar & $\begin{array}{l}\text { Descripción de } \\
\text { perfil }\end{array}$ & \\
\hline N009_ESTADO & Number & $\begin{array}{l}\text { Estado del } \\
\text { registro (Ejemplo: } \\
1=\text { Activo) }\end{array}$ & \\
\hline
\end{tabular}

\begin{tabular}{|c|c|c|c|c|}
\hline \multirow{2}{*}{$\begin{array}{c}\text { Tabla } \\
\text { Columna }\end{array}$} & \multicolumn{4}{|c|}{ TB010_SOLICITUD } \\
\hline & Tipo de Dato & Descripción & $\begin{array}{l}\mathrm{P} \\
\mathrm{K}\end{array}$ & FK \\
\hline N010_COD_SOLICITUD & Number & $\begin{array}{l}\text { Código } \\
\text { solicitud }\end{array}$ & $\mathrm{Si}$ & \\
\hline N010_COD_RAMO & Number & Código de ramo & & $\mathrm{Si}$ \\
\hline N010_COD_PRODUCTO & Number & $\begin{array}{l}\text { Código de } \\
\text { producto }\end{array}$ & & $\mathrm{Si}$ \\
\hline N010_NRO_TRAMITE & Number & $\begin{array}{l}\text { Número de } \\
\text { trámite }\end{array}$ & & \\
\hline N010_TIP_OPERACION & Number & Tipo de operación & & \\
\hline N010_COD_ACTIVIDAD & Number & $\begin{array}{l}\text { Código de } \\
\text { actividad }\end{array}$ & & $\mathrm{Si}$ \\
\hline N010_COD_MONEDA & Number & $\begin{array}{l}\text { Código de } \\
\text { moneda }\end{array}$ & & \\
\hline N010_COD_OFICINA & Number & Código de oficina & & $\mathrm{Si}$ \\
\hline N010_COD_VIGENCIA & Number & $\begin{array}{l}\text { Código de } \\
\text { vigencia ( } \\
\text { Ejemplo: Anual ) }\end{array}$ & & \\
\hline
\end{tabular}




\begin{tabular}{|c|c|c|}
\hline N010_COD_FREC_PAGO & Number & $\begin{array}{l}\text { Código de } \\
\text { frecuencia pago ( } \\
\text { Ejemplo: Mensual } \\
\text { ) }\end{array}$ \\
\hline N010_COD_CORREDOR & Number & $\begin{array}{l}\text { Código de } \\
\text { corredor }\end{array}$ \\
\hline N010_COD_CLIENTE & Number & Código de cliente \\
\hline N010_TIPO_SOLICITUD & Number & Tipo de solicitud \\
\hline F010_FEC_INI_VIGENCIA & Date & $\begin{array}{l}\text { Fecha inicio de } \\
\text { vigencia }\end{array}$ \\
\hline F010_FEC_FIN_VIGENCIA & Date & $\begin{array}{l}\text { Fecha fin de } \\
\text { vigencia }\end{array}$ \\
\hline $\begin{array}{l}\text { N010_MNT_PRIMA_NETA_T } \\
\text { OT }\end{array}$ & Decimal & $\begin{array}{l}\text { Monto prima neta } \\
\text { de póliza }\end{array}$ \\
\hline $\begin{array}{l}\text { N010_MNT_DER_EMISION_T } \\
\text { OT }\end{array}$ & Decimal & $\begin{array}{l}\text { Monto derecho de } \\
\text { emisión de póliza }\end{array}$ \\
\hline N010_MNT_IGV_TOT & Decimal & Monto IGV \\
\hline $\begin{array}{l}\text { N010_MNT_PRIMA_BRUTA_ } \\
\text { TOT }\end{array}$ & Decimal & $\begin{array}{l}\text { Monto prima } \\
\text { bruta total }\end{array}$ \\
\hline N010_USU_REGISTRO & Number & $\begin{array}{l}\text { Usuario de } \\
\text { registro }\end{array}$ \\
\hline F010_FEC_REGISTRO & Date & Fecha de registro \\
\hline
\end{tabular}




\begin{tabular}{|c|c|c|c|c|}
\hline N010_USU_ACTUALIZA & Number & $\begin{array}{l}\text { Usuario de } \\
\text { actualización }\end{array}$ & & $\mathrm{Si}$ \\
\hline F010_FEC_ACTUALIZA & Date & $\begin{array}{l}\text { Fecha de } \\
\text { actualización }\end{array}$ & & \\
\hline A010_MOTIVO_RECHAZO & Varchar & $\begin{array}{l}\text { Descripción de } \\
\text { motivo de rechazo } \\
\text { de solicitud }\end{array}$ & & \\
\hline N010_ESTADO & Number & $\begin{array}{l}\text { Estado de la } \\
\text { solicitud } \\
\text { (Ejemplo: } 1= \\
\text { Vigente) }\end{array}$ & & \\
\hline Tabla & \multicolumn{4}{|c|}{ TB011_PLANILLA } \\
\hline Columna & Tipo de Dato & Descripción & $\begin{array}{l}\mathrm{P} \\
\mathrm{K}\end{array}$ & FK \\
\hline N011_COD_PLANILLA & Number & Código de planilla & $\mathrm{Si}$ & \\
\hline N011_ID_POLIZA & Number & $\begin{array}{l}\text { Identificador de } \\
\text { póliza }\end{array}$ & & $\mathrm{Si}$ \\
\hline A011_NOMBRES & Varchar & $\begin{array}{l}\text { Nombres de } \\
\text { asegurado }\end{array}$ & & \\
\hline A011_APE_PATERNO & Varchar & $\begin{array}{l}\text { Apellido paterno } \\
\text { de asegurado }\end{array}$ & & \\
\hline A011_APE_MATERNO & Varchar & $\begin{array}{l}\text { Apellido materno } \\
\text { de asegurado }\end{array}$ & & \\
\hline N011_TIPO_DOCUMENTO & Number & $\begin{array}{l}\text { Tipo de } \\
\text { documento } \\
\text { (Ejemplo: } 1=\text { Dni } \\
\text { ) }\end{array}$ & & \\
\hline A011_NRO_DOCUMENTO & Varchar & $\begin{array}{l}\text { Número de } \\
\text { documento }\end{array}$ & & \\
\hline N011_COD_SEXO & Number & $\begin{array}{l}\text { Código de sexo } \\
\text { (Ejemplo: } 1= \\
\text { Femenino ) }\end{array}$ & & \\
\hline
\end{tabular}




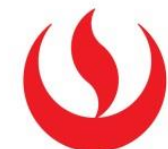

$\begin{array}{lll}\text { N011_ESTADO_CIVIL } & \text { Varchar } & \begin{array}{l}\text { Código de estado } \\ \text { civil (Ejemplo: } 1 \\ \text { S }\end{array} \\ \text { Soltero ) } & \begin{array}{l}\text { Fecha de } \\ \text { nacimiento de } \\ \text { asegurado }\end{array} \\ \text { F011_FEC_NACIMIENTO } & \text { Date } & \begin{array}{l}\text { Remuneración del } \\ \text { asegurado }\end{array} \\ \text { N011_REMUNERACION } & \text { Decimal } & \end{array}$

\begin{tabular}{|c|c|c|c|c|}
\hline Tabla & \multicolumn{4}{|c|}{ TB012_CLASE_PLANILLA } \\
\hline Columna & Tipo de Dato & Descripción & $\begin{array}{l}\mathrm{P} \\
\mathrm{K}\end{array}$ & FK \\
\hline N012_COD_CLASE & Number & $\begin{array}{l}\text { Código de clase } \\
\text { trabajadora }\end{array}$ & $\mathrm{Si}$ & \\
\hline N012_ID_POLIZA & Number & $\begin{array}{l}\text { Identificador de } \\
\text { póliza }\end{array}$ & & $\mathrm{Si}$ \\
\hline N012_COD_TASA & Varchar & Código de tasa & & $\mathrm{Si}$ \\
\hline N012_TIPO_TRABAJADOR & Number & $\begin{array}{l}\text { Código clase } \\
\text { trabajadora } \\
\text { (Ejemplo: } \\
\text { 1=Administrativo) }\end{array}$ & & \\
\hline N012_NRO_TRABAJADORES & Number & $\begin{array}{l}\text { Número de } \\
\text { trabajadores }\end{array}$ & & \\
\hline N012_MNT_PLANILLA & Decimal & $\begin{array}{l}\text { Monto de planilla } \\
\text { por clase } \\
\text { trabajadora }\end{array}$ & & \\
\hline N012_FLAG_TASA & Number & $\begin{array}{l}\text { Flag de cambio de } \\
\text { tasa (Ejemplo: } 1= \\
\text { Cambio de tasa) }\end{array}$ & & \\
\hline N012_TASA & Decimal & Valor de tasa & & \\
\hline
\end{tabular}

Tabla

Columna
TB013_OFICINA

Tipo de Dato
Descripción 


\section{(4)}

N013_COD_OFICINA

N013_DESCRIPCION

N013_UBIGEO

N013_ESTADO
Number

Varchar

Number

Number
Código de oficina $\mathrm{Si}$

Descripción de oficina

Código de ubigeo de oficina

Estado del

registro (Ejemplo:

$1=$ Activo)

\begin{tabular}{|c|c|c|c|c|}
\hline Tabla & \multicolumn{4}{|c|}{ TB014_PRODUCTO } \\
\hline Columna & Tipo de Dato & Descripción & $\begin{array}{l}\mathrm{P} \\
\mathrm{K}\end{array}$ & FK \\
\hline N014_COD_PRODUCTO & Number & $\begin{array}{ll}\text { Código } & \mathrm{de} \\
\text { producto } & \end{array}$ & $\mathrm{Si}$ & \\
\hline N014_COD_RAMO & Number & Código de ramo & & $\mathrm{Si}$ \\
\hline N014_DESCRIPCION & Number & $\begin{array}{l}\text { Descripción del } \\
\text { producto }\end{array}$ & & \\
\hline N014_ESTADO & Number & $\begin{array}{l}\text { Estado del } \\
\text { registro (Ejemplo: } \\
1=\text { Activo) }\end{array}$ & & \\
\hline
\end{tabular}

\begin{tabular}{|c|c|c|c|c|}
\hline Tabla & \multicolumn{4}{|c|}{ TB015_POLIZA } \\
\hline Columna & Tipo de Dato & Descripción & $\begin{array}{l}\mathrm{P} \\
\mathrm{K}\end{array}$ & FK \\
\hline N015_ID_POLIZA & Number & $\begin{array}{l}\text { Identificador de } \\
\text { póliza }\end{array}$ & $\mathrm{Si}$ & \\
\hline N015_COD_RAMO & Number & Código de ramo & & $\mathrm{Si}$ \\
\hline N015_COD_PRODUCTO & Number & $\begin{array}{l}\text { Código de } \\
\text { producto }\end{array}$ & & $\mathrm{Si}$ \\
\hline N015_NRO_TRAMITE & Number & $\begin{array}{l}\text { Número de } \\
\text { trámite }\end{array}$ & & \\
\hline
\end{tabular}




\section{(1)}

N015_TIP_OPERACION

Number

Tipo de operación

N015_COD_ACTIVIDAD Number

Código de

actividad

$\mathrm{Si}$

Código de

N015_COD_MONEDA Number

moneda

N015_COD_OFICINA

Number

Código de oficina

$\mathrm{Si}$

Código de

N015_COD_VIGENCIA Number

Vigencia (

Ejemplo: Anual )

Código de

N015_COD_FREC_PAGO Number

N015_COD_CORREDOR Number

Frecuencia pago (

Ejemplo: Mensual

)

Código de

corredor

N015_COD_CLIENTE Number

Código de cliente

$\mathrm{Si}$

F015_FEC_INI_VIGENCIA Date

Fecha inicio de vigencia

Fecha fin de

F015_FEC_FIN_VIGENCIA Date

vigencia

N015_MNT_PRIMA_NETA_T

OT

Decimal

Monto prima neta

de póliza

Monto derecho de emisión de póliza

OT

Decimal

N015_MNT_IGV_TOT

Decimal

Monto IGV 


\begin{tabular}{|c|c|c|c|c|}
\hline $\begin{array}{l}\text { N015_MNT_PRIMA_BRUTA_ } \\
\text { TOT }\end{array}$ & Decimal & $\begin{array}{l}\text { Monto prima } \\
\text { bruta total }\end{array}$ & & \\
\hline N015_NRO_POLIZA & Varchar & Número de póliza & & $\mathrm{Si}$ \\
\hline N015_ID_PROFORMA & Varchar & $\begin{array}{l}\text { Identificador de } \\
\text { proforma }\end{array}$ & & \\
\hline N015_USU_REGISTRO & Number & $\begin{array}{l}\text { Usuario de } \\
\text { registro }\end{array}$ & & $\mathrm{Si}$ \\
\hline F015_FEC_REGISTRO & Date & Fecha de registro & & \\
\hline N015_ESTADO & Number & $\begin{array}{l}\text { Estado de la } \\
\text { póliza (Ejemplo: } 1 \\
=\text { Vigente) }\end{array}$ & & \\
\hline Tabla & \multicolumn{4}{|c|}{ TB016_PROFORMA } \\
\hline Columna & Tipo de Dato & Descripción & $\begin{array}{l}\mathrm{P} \\
\mathrm{K}\end{array}$ & FK \\
\hline N016_ID_PROFORMA & Number & $\begin{array}{l}\text { Identificador de } \\
\text { proforma }\end{array}$ & $\mathrm{Si}$ & \\
\hline N016_ID_POLIZA & Number & $\begin{array}{l}\text { Identificador de } \\
\text { póliza }\end{array}$ & & $\mathrm{Si}$ \\
\hline N016_NRO_PROFORMA & Decimal & $\begin{array}{l}\text { Número } \quad \text { de } \\
\text { proforma }\end{array}$ & & \\
\hline N016_MONTO & Number & $\begin{array}{l}\text { Monto de la } \\
\text { proforma } \\
\text { generada }\end{array}$ & & \\
\hline N016_TIPO_PAGO & Number & $\begin{array}{l}\text { Tipo de pago } \\
\text { (Ejemplo: } 1= \\
\text { Contado) }\end{array}$ & & \\
\hline N016_ESTADO & Number & $\begin{array}{l}\text { Estado del } \\
\text { registro (Ejemplo: } \\
1=\text { Activo) }\end{array}$ & & \\
\hline
\end{tabular}




\begin{tabular}{|c|c|c|c|c|c|}
\hline Tabla & & TB017_OPERACION_SED & & & \\
\hline Columna & Tipo de Dato & Descripción & & PK & FK \\
\hline N017_ID_OPERACION & Number & Identificador de operación & & $\mathrm{Si}$ & \\
\hline N017_COD_RAMO & Number & Código de ramo & & & \\
\hline N017_NRO_POLIZA & Number & Número de póliza & & & \\
\hline N017_COD_ESTADO & Number & $\begin{array}{l}\text { Código de estado } \\
\text { operación: }\end{array}$ & & & \\
\hline & & $\begin{array}{l}\text { 1.PENDIENTE, } \\
\text { 2:EN PROCESO, } \\
\text { 3: PROCESADO, } \\
\text { 4: NO PROCESADO }\end{array}$ & & & \\
\hline N017_FEC_ESTADO & Date & Fecha de alta de operación & & & \\
\hline N017_COD_FUNCIONALIDAD & Number & Código de funcionalidad: & & & \\
\hline & & $\begin{array}{l}\text { 1: EMISIÓN, } \\
\text { DECLARACIÓN, } \\
\text { INCLUSIÓN, } \\
\text { EXCLUSIÓN, } \\
\text { RENOVACION, }\end{array}$ & $\begin{array}{l}2: \\
3: \\
4 . \\
6:\end{array}$ & & \\
\hline N017_COD_RESULTADO & Number & $\begin{array}{l}\text { Operación Correcta } 0 ; \mathrm{E} \\
\text { MQ -1; Error Agente -2; } \\
\text { DLL -3; Error Oracle -4; } \\
\text { Informix -5; }\end{array}$ & $\begin{array}{l}\text { rror } \\
\text { rror } \\
\text { rror }\end{array}$ & & \\
\hline N017_DES_RESULTADO & Varchar & Descripción del resultado & & & \\
\hline N017_COD_CLIENTE & Number & Código de cliente & & & \\
\hline
\end{tabular}




\section{(1)}

$\begin{array}{lll}\text { N017_COD_CORREDOR } & \text { Number } & \text { Código de corredor } \\ \text { A017_MSJ_USUARIO } & \text { Varchar } & \begin{array}{l}\text { Descripción del mensaje a } \\ \text { mostrar al usuario }\end{array} \\ \text { N017_TIPO_ANULACION } & \text { Number } & \begin{array}{l}\text { Tipo de anulación: 1 } \\ \text { Manual, por 2 = Agente }\end{array} \\ \text { N017_USU_REGISTRA } & \text { Number } & \text { Usuario de registro } \\ \text { F017_FEC_REGISTRA } & \text { Date } & \text { Fecha de registro } \\ \text { N017_USU_ACTUALIZA } & \text { Number } & \text { Usuario de actualización } \\ & & \\ \text { F017_FEC_ACTUALIZA } & \text { Date } & \text { Fecha de actualización }\end{array}$

\begin{tabular}{|c|c|c|c|c|}
\hline Tabla & \multicolumn{4}{|c|}{ TB018_OPERACION_MOV } \\
\hline Columna & Tipo de Dato & Descripción & $\begin{array}{l}\mathrm{P} \\
\mathrm{K}\end{array}$ & $\begin{array}{l}\mathrm{F} \\
\mathrm{K}\end{array}$ \\
\hline N018_ID_HISTORIAL & Number & $\begin{array}{l}\mathrm{de} \\
\mathrm{de}\end{array}$ & $\mathrm{Si}$ & \\
\hline N018_ID_OPERACION & Number & de & & $\mathrm{Si}$ \\
\hline N018_COD_RAMO & Number & de & & \\
\hline N018_NRO_POLIZA & Number & de & & \\
\hline N017_COD_ESTADO & Number & & & \\
\hline & & & & \\
\hline
\end{tabular}


2:EN PROCESO,

3:

PROCESADO,

4: $\quad$ NO

PROCESADO

N017_FEC_ESTADO Date

Fecha de alta de operación

N017_COD_FUNCIONALI Number
DAD

Código de

funcionalidad:

1: EMISIÓN, 2: DECLARACIÓN , 3: INCLUSIÓN, 4. EXCLUSIÓN, 6:

RENOVACION, Operación Correcta 0;Error

N017_COD_RESULTADO Number MQ -1; Error Agente -2; Error DLL -3; Error Oracle -4; Error Informix -5 ;

N017_DES_RESULTADO Varchar

Descripción del resultado

N017_COD_CLIENTE_Number

Código de cliente

N017_COD_CORREDOR Number

A017_MSJ_USUARIO Varchar

N017_TIPO_ANULACION Number

N017_USU_REGISTRA Number

Código de corredor

Descripción del mensaje a mostrar al usuario Tipo de anulación:

Manual o por Agente

Usuario de registro 


\section{1}

F017_FEC_REGISTRA Date Fecha de registro

N017_USU_ACTUALIZA Number

Usuario de

actualización

Fecha

de

F017_FEC_ACTUALIZA Date

actualización

Nota. Diccionario de datos de las tablas del TOBE. Elaboración propia. 


\section{$(1)$}

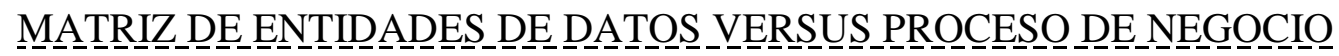

Tabla $N^{\circ} 26$

Matriz de Entidades de Datos versus Proceso de Negocio TOBE

$$
\text { MACRO PROCESOS }
$$

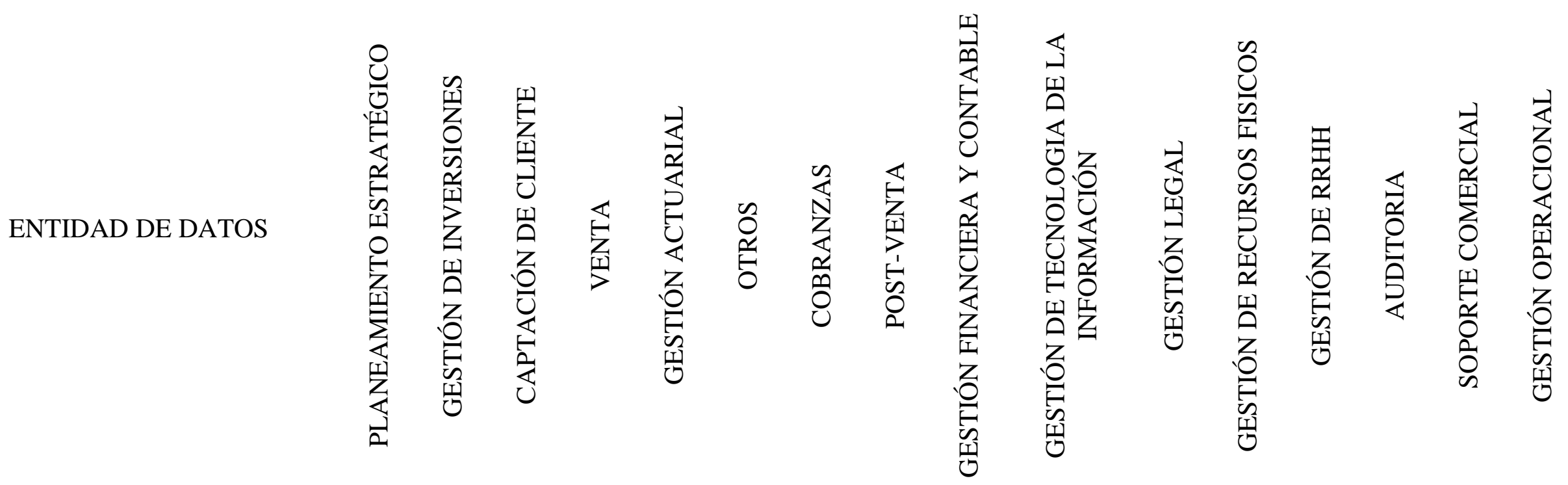

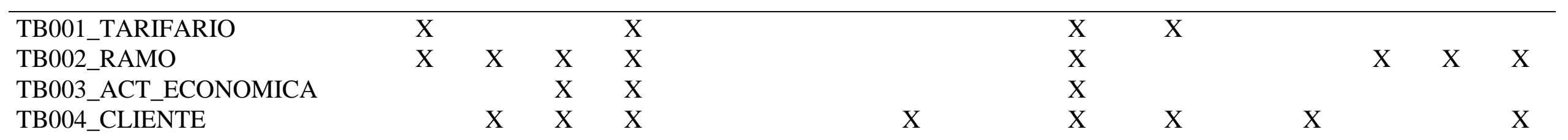


TB005_CLIENTE_SEDE

TB006_MAESTROS

TB007_CORREDOR

TB008_USUARIO

TB009_PERFIL

TB010 SOLICITUD

TB011_PLANILLA

TB012_CLASE_PLANILLA

TB013 OFICINA

TB014_PRODUCTO

TB015_POLIZA

TB016_PROFORMA

TB017_OPERACION_SED

TB018_OPERACION_MOV
X

$\begin{array}{ccc} & \mathrm{X} \\ & & \\ & & \\ & & \\ & & \\ & & \\ & \mathrm{X} & \\ & & \\ \mathrm{X} & \mathrm{X} & \mathrm{X} \\ & \mathrm{X} & \mathrm{X} \\ & \mathrm{X} & \\ & \mathrm{X} & \end{array}$

X

X

X

X

X

$\mathrm{X}$

$\mathrm{X}$
$\mathrm{X}$

$X$
$X$

Nota. Matriz de entidades de datos versus proceso de negocio del TOBE. Elaboración propia. 


\section{(1)}

\section{ARQUITECTURA DE APLICACIÓN}

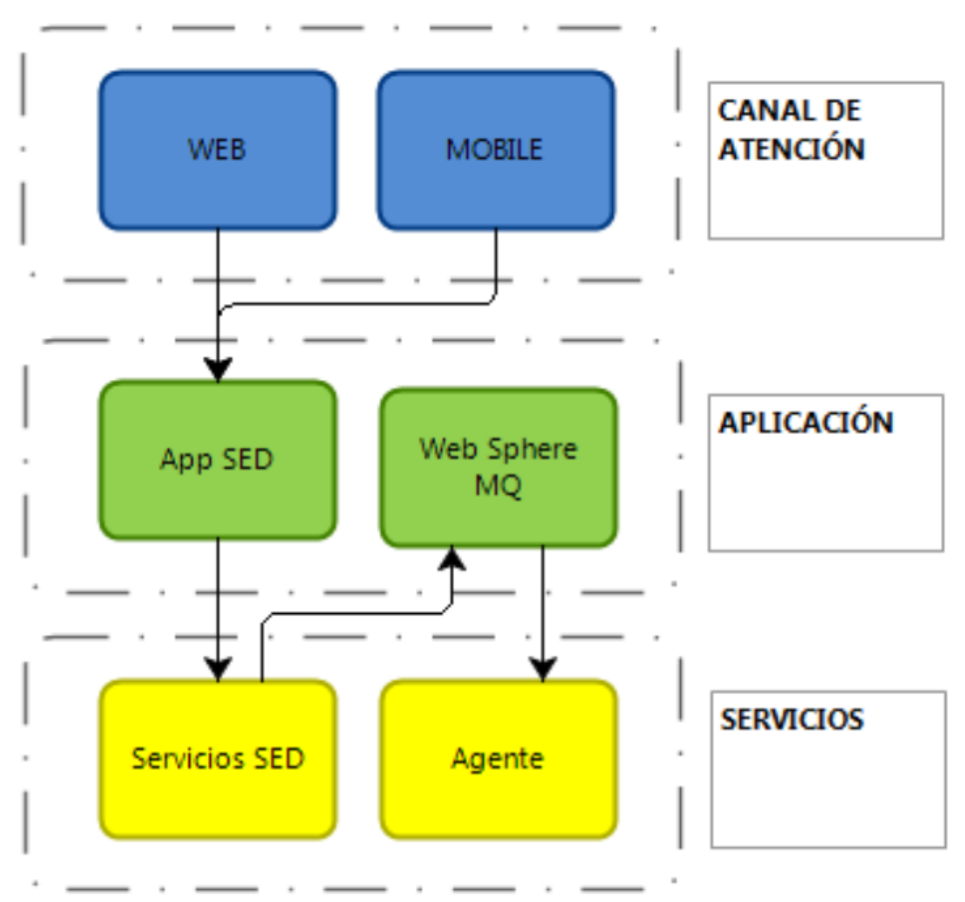

Figura $N^{\circ} 26$ Arquitectura de Aplicación. Adaptado de "Arquitectura de Aplicación SED (TO BE)”, Elaboración propia, 2018.

A continuación se pasa a detallar el grafico anterior:

Los usuarios de conectan mediante su PC, laptop o móvil al Sistema de Emisión a Distancia mediante el aplicativo AppSED, este a su vez invoca al servicio que ejecuta el software Web Sphere MQ que se encargará de la distribución de colas, el cual mediante el Agente generará la carga de hilos de procesos. 


\section{ARQUITECTURA TECNOLÓGICA}

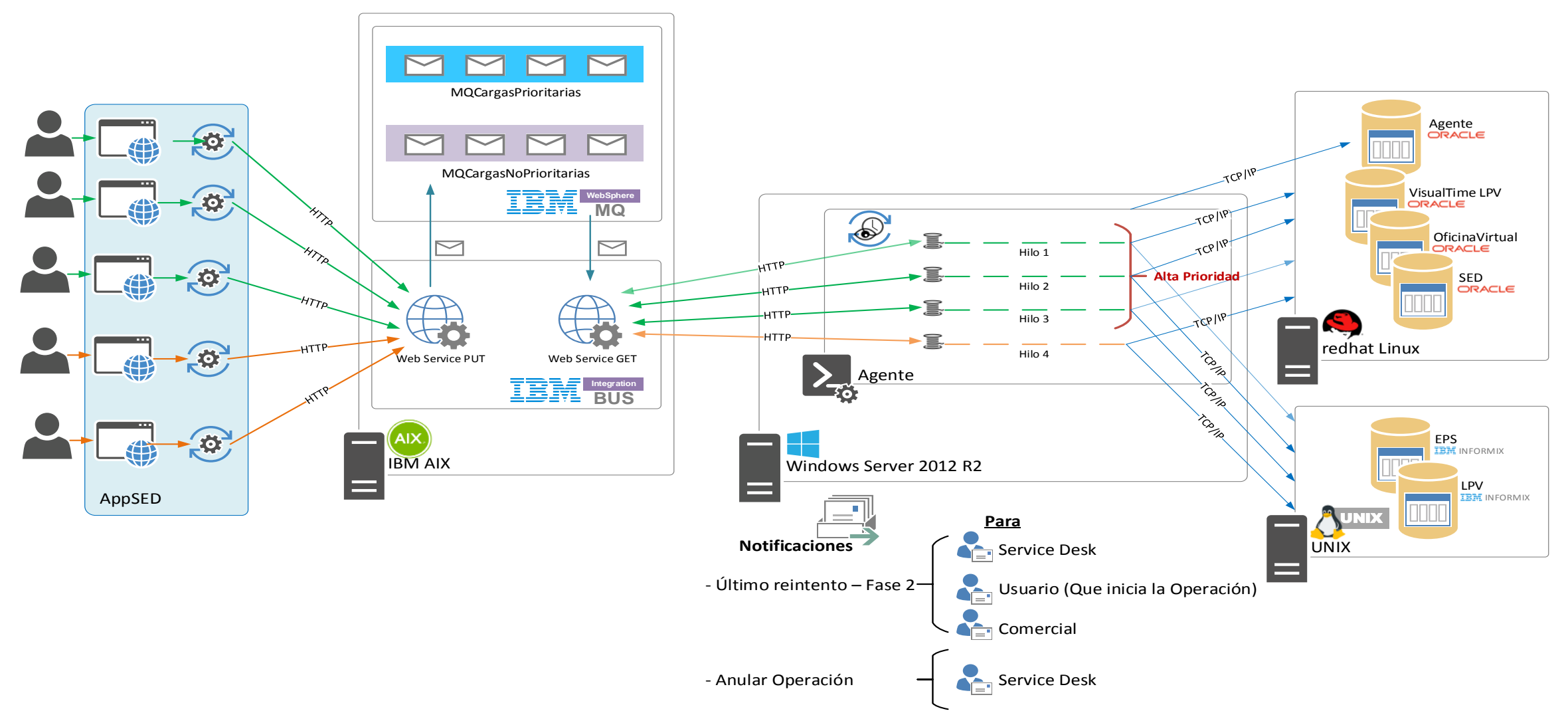

Figura $N^{\circ} 27$ Arquitectura Tecnológica, Adaptado de “Arquitectura Tecnológica SED (TO BE)", Elaboración propia, 2018. 


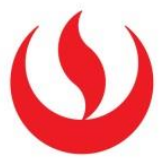

Dónde:

1. AppSed

- Representa la aplicación SED con usuarios concurrentes que generan a través de su interfaz operaciones de póliza las cuales los datos resultantes son serializados y enviados por medio de un servicio web SOAP expuesto en el bus de datos hacia el servidor de colas según su prioridad.

- Se considera mensajes de alta prioridad a los que contienen registros de datos mayor a 600 (este parámetro es configurable), caso contrario se considera de menor prioridad.

2. IBM Integración BUS

- Permite orquestar los servicios web expuestos que permitirá colocar y obtener el mensaje en la cola respectivo del servidor IBM MQ Websphere.

3. Agente

- Representa los servicios de aplicación Windows que gestionan un número de hilos determinado encargados de obtener los mensajes colocados en las colas según la prioridad a través de un servicio web SOAP expuesto, ejecutar el proceso de emisión y registrar los datos en sus respectivas base de datos.

- El número de hilos máximo considerado es de 10 hilos entre hilos de mensajes de colas de alta y baja prioridad.

- El número de conexiones en paralelo será igual al número de hilos en ejecución.

- Para el manejo de pool de conexiones se ha considera los siguientes parámetros iniciales:

- Connection LifeTime: 0

- Max Pool Size : 30

- Min Pool Size : 10

- Connection TimeOut : 360

Estos parámetros se pueden modificar de manera que se vaya calibrando la aplicación hasta que ejecute su proceso en el mejor performance.

- El agente enviará una serie de notificaciones de correo mediante SMTP, de acuerdo al último reintento de fase 2 y cuando los mensajes que hayan terminado sus fases de reintentos se encuentren desatendidos más de 15 días. Este dato es parametrizable. 


\section{4}

Tabla $\mathrm{N}^{\circ} 27$

Descripción de componentes de Arquitectura Tecnológica

Servidor Especificación Alto nivel

Web S.O.: IBM AIX, Procesador: 16 cores Power7, Memoria: 32 GB

Aplicación $\quad$ S.O.: Windows Server 2012 R2, Procesador: 8 cores 3Ghz, Memoria: 16 GB

Base de Datos S.O.: Redhat Linux, Procesador: 16 cores , Memoria: 32 GB

Base de Datos S.O.: UNIX, Procesador: 8 cores, Memoria: 16 GB

Nota. Descripción de componentes de arquitectura tecnológica del TOBE. Elaboración propia. 


\section{(}

\section{ANÁLISIS DE BRECHAS}

\section{$\underline{\text { ARQUITECTURA DE NEGOCIO }}$}

Tabla $\mathrm{N}^{\circ} 28$

Análisis de Brechas - Emisión de Póliza SCTR-Arquitectura de Negocio

\begin{tabular}{|c|c|c|c|c|c|c|c|c|}
\hline \multirow[b]{2}{*}{ Arquitectura Base } & \multicolumn{8}{|c|}{ Arquitectura Destino } \\
\hline & 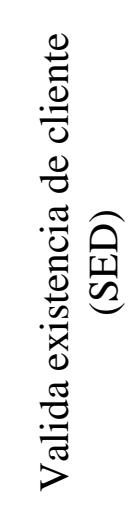 & 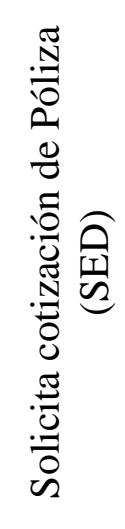 & 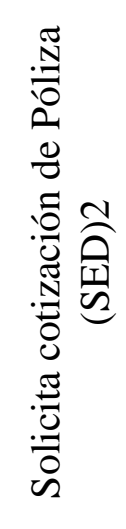 & 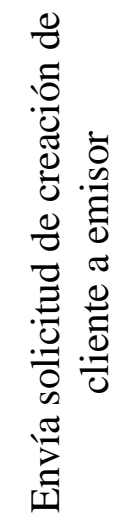 & 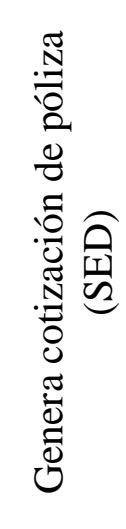 & 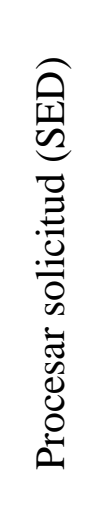 & 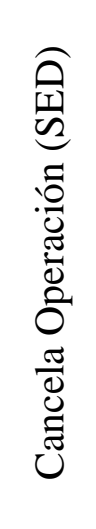 & 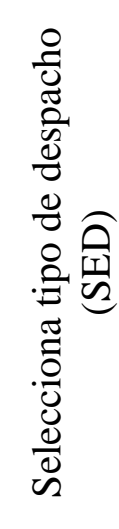 \\
\hline Valida existencia de cliente (SED) & M-1 & & & & & & & \\
\hline Solicita cotización de Póliza (SED) & & A-1 & & & & & yenda & \\
\hline $\begin{array}{l}\text { Solicita vía correo creación de } \\
\text { cliente a comercial }\end{array}$ & & & M-2 & & $\begin{array}{l}\mathrm{M}: \mathrm{Ma} \\
\mathrm{A}: \mathrm{Act}\end{array}$ & $\begin{array}{l}\text { ntener } \\
\text { ualizar }\end{array}$ & & \\
\hline $\begin{array}{l}\text { Envía solicitud de creación de } \\
\text { cliente a emisor }\end{array}$ & & & & M-3 & $\begin{array}{l}\text { E: Elin } \\
\mathrm{N}: \mathrm{Nu}\end{array}$ & $\begin{array}{l}\text { inar } \\
\text { vo } \\
\end{array}$ & & \\
\hline Genera cotización de póliza (SED) & & & & & M-4 & & & \\
\hline Procesar solicitud (SED) & & & & & & A-2 & & \\
\hline Cancela Operación (SED) & & & & & & & M-5 & \\
\hline Selecciona tipo de despacho (SED) & & & & & & & & M-6 \\
\hline
\end{tabular}

Nota. Análisis de brechas del sub proceso emisión de póliza SCTR. Elaboración propia.

Brecha A-1: Se actualizará el proceso de carga de planilla de la cotización, para que la planilla cargada se guarde en Base de Datos y no se quede en memoria.

Brecha A-2: Se actualizará el procesar solicitud para que esta se maneje de forma asíncrona. 


\section{(1)}

Tabla $\mathrm{N}^{\circ} 29$

Análisis de Brechas - Inclusión de Asegurados en Póliza SCTR-Arquitectura de Negocio

\begin{tabular}{|c|c|c|c|c|c|c|c|c|}
\hline \multirow[b]{2}{*}{ Arquitectura Base } & \multicolumn{8}{|c|}{ Arquitectura Destino } \\
\hline & 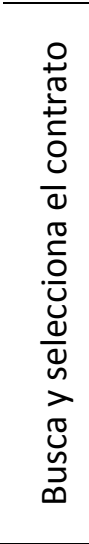 & 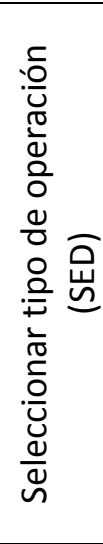 & 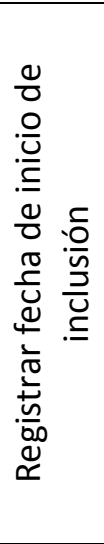 & 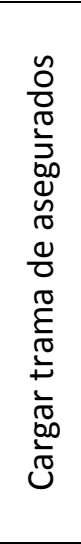 & 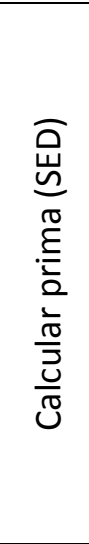 & 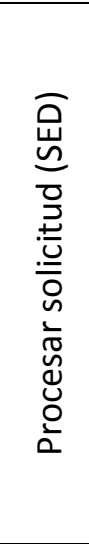 & 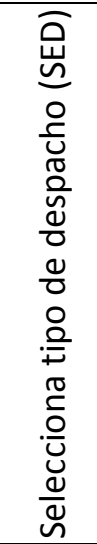 & 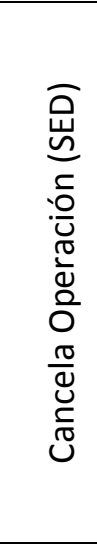 \\
\hline Busca y selecciona el contrato & $M-7$ & & & & & & & \\
\hline Seleccionar tipo de operación (SED) & & $A-3$ & & & & & & \\
\hline Registrar fecha de inicio de inclusión & & & $M-8$ & & & & & \\
\hline Cargar trama de asegurados & & & & $A-1$ & & & & \\
\hline Calcular prima (SED) & & & & & $M-9$ & & & \\
\hline Procesar solicitud (SED) & & & & & & $A-4$ & & \\
\hline Selecciona tipo de despacho (SED) & & & & & & & M-10 & \\
\hline Cancela Operación (SED) & & & & & & & & M-11 \\
\hline
\end{tabular}

Nota. Análisis de brechas del sub proceso inclusión de asegurados en póliza SCTR. Elaboración propia.

Brecha A-3: Se actualizará el proceso de carga de planilla de la cotización, para que la planilla cargada se guarde en Base de Datos y no se quede en memoria.

Brecha A-4: Se actualizará el procesar solicitud para que esta se maneje de forma asíncrona. 


\section{()}

Tabla $\mathrm{N}^{\circ} 30$

Análisis de Brechas - Exclusión de Asegurados en Póliza SCTR-Arquitectura de Negocio

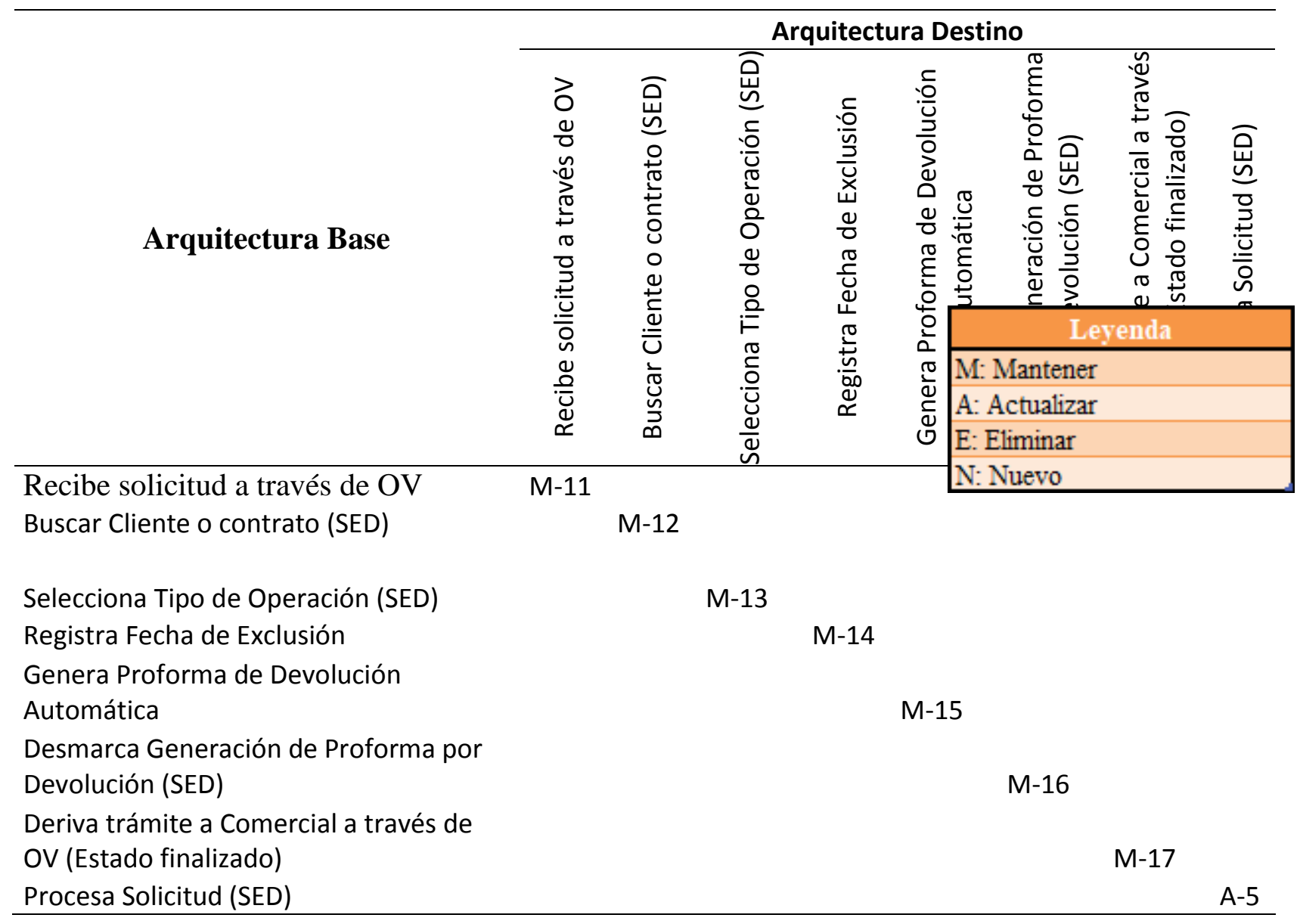

Nota. Análisis de brechas del sub proceso exclusión de asegurados en póliza SCTR. Elaboración propia.

Brecha A-5: Se actualizará el procesar solicitud para que esta se maneje de forma asíncrona 


\section{(1)}

Tabla $\mathrm{N}^{\circ} 31$

Análisis de Brechas - Renovación de Póliza SCTR-Arquitectura de Negocio

\begin{tabular}{|l|}
\hline \multicolumn{1}{|c|}{ Leyenda } \\
\hline M: Mantener \\
A: Actualizar \\
E: Eliminar \\
N: Nuevo \\
\hline
\end{tabular}

Arquitectura Base

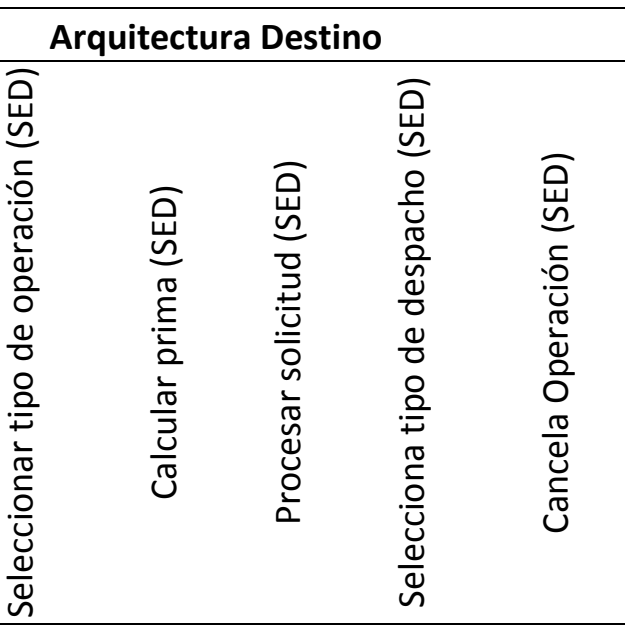

Busca y selecciona el contrato

$\mathrm{M}-17$

Seleccionar tipo de operación (SED)

$\mathrm{M}-18$

Calcular prima (SED)

M-19

Procesar solicitud (SED)

A-6

Selecciona tipo de despacho (SED)

M-20

Cancela Operación (SED)

$M-21$

Nota. Análisis de brechas del sub proceso renovación de póliza SCTR. Elaboración propia.

Brecha A-6: Se actualizará el procesar solicitud para que esta se maneje de forma asíncrona 


\section{$\underline{\text { ARQUITECTURA DE DATOS }}$}

Tabla $N^{\circ} 32$

Análisis de Brechas - Arquitectura de Datos

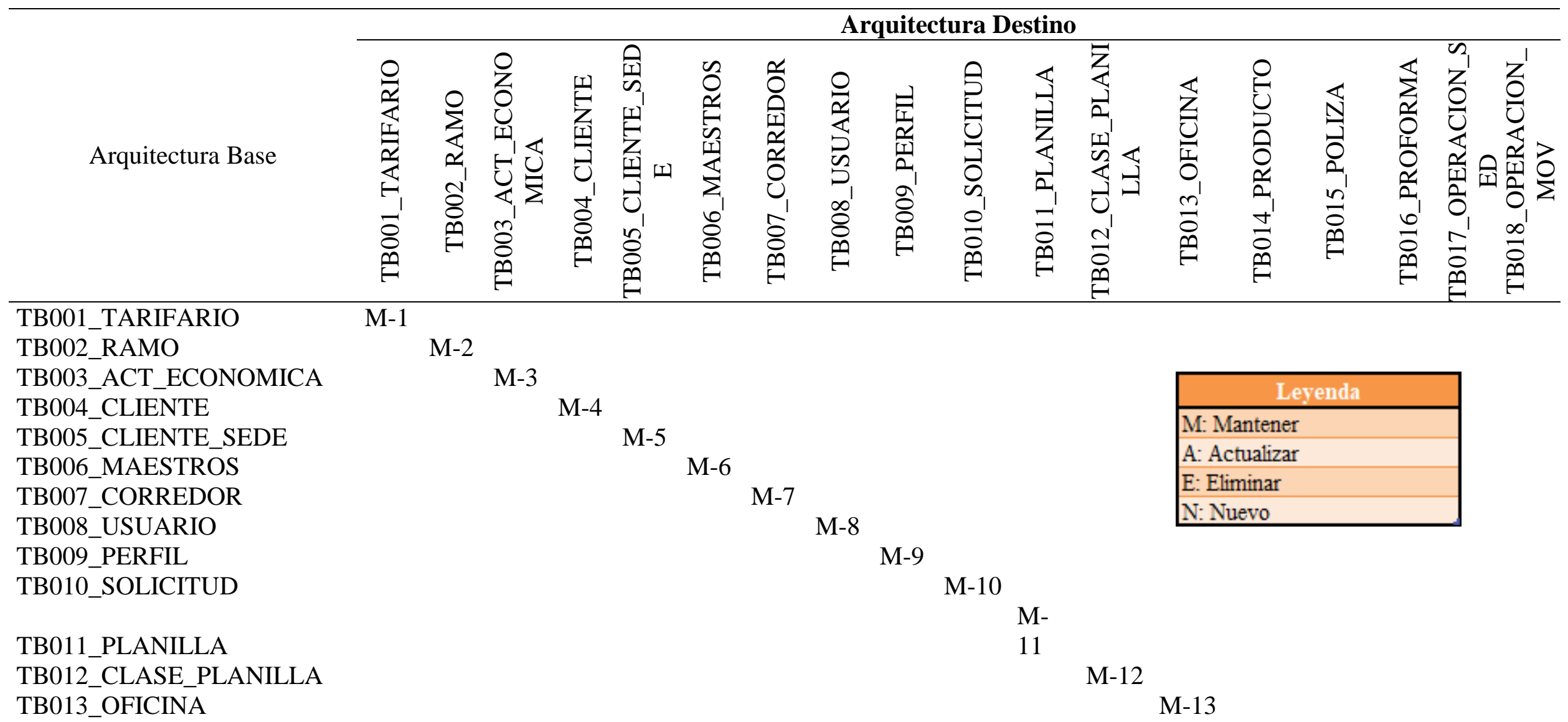


TB014_PRODUCTO

TB015_POLIZA

TB016_PROFORMA

NUEVO
M-14

M-15

M-16

$\mathrm{N}-$

$1 \quad \mathrm{~N}-2$

Nota. Análisis de brechas de la arquitectura de datos. Elaboración propia. 


\section{(1)}

Brecha N-1: Se añade la tabla “TB017_OPERACION_SED” que guarda las operaciones realizadas por un usuario. En esta tabla se registrará las operaciones que se envíen al Agente.

Brecha N-2: Se adiciona la tabla "TB018_OPERACION_MOV” en la cual se registrará el historial de movimientos realizados por cada operación de la tabla “TB017_OPERACION_SED”.

\section{ARQUITECTURA DE APLICACIÓN}

Tabla $\mathrm{N}^{\circ} 33$

Análisis de Brechas - Arquitectura de Aplicación

\begin{tabular}{|c|c|c|c|c|}
\hline \multirow[b]{2}{*}{ Arquitectura Base } & \multicolumn{3}{|c|}{ Arquitectura Destino } & \multirow[b]{2}{*}{ 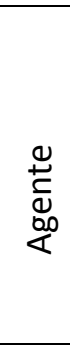 } \\
\hline & $\begin{array}{l}\text { 岃 } \\
\text { 呈 } \\
\frac{0}{<}\end{array}$ & 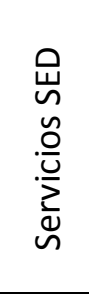 & $\begin{array}{l}0 \\
\sum \\
0 \\
\frac{0}{d} \\
\frac{1}{0} \\
\sim \\
0 \\
3 \\
3\end{array}$ & \\
\hline App SED & $M-1$ & & & \\
\hline Servicios SED & & $M-2$ & & \\
\hline NUEVO & & & $\mathrm{N}-1$ & $\mathrm{~N}-2$ \\
\hline
\end{tabular}

Nota. Análisis de brechas de la arquitectura de aplicación. Elaboración propia.

Brecha N-1: Se necesita adquirir el software de mensajería Web Sphere MQ

Brecha N-2: Se necesita implementar el software Agente para gestionar los "hilos " de procesos

\section{ARQUITECTURA DE TECNOLÓGICA}

Tabla $\mathrm{N}^{\circ} 34$

Análisis de Brechas - Arquitectura Tecnológica 


\begin{tabular}{|c|c|c|c|c|c|}
\hline Arquitectura Base & 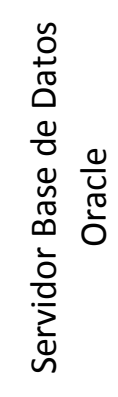 & 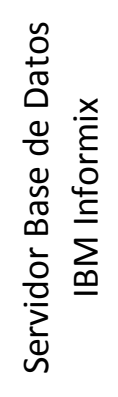 & $\begin{array}{l}\frac{0}{0} \\
3 \\
\frac{1}{0} \\
\frac{0}{2} \\
\stackrel{2}{\infty}\end{array}$ & 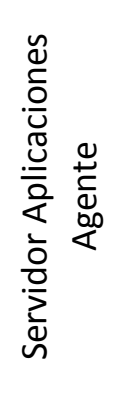 & \\
\hline
\end{tabular}

Servidor Base de Datos

Oracle

Servidor Base de Datos

IBM Informix

Servidor Web

Servidor Aplicaciones

NUEVO

M-1

$M-2$

M-3

Nota. Análisis de brechas de la arquitectura tecnológica. Elaboración propia.

Brecha A-1: Se necesita actualizar el servidor de aplicaciones con el software Agente para gestionar los "hilos" de procesos

Brecha N-1: Se necesita adquirir el servidor de colas IBM AIX
$\mathrm{N}-1$

(1) 


\section{(1)}

\section{PLAN DE IMPLEMENTACIÓN Y MIGRACIÓN}

Se tendrá que desarrollar el siguiente entregable: 


\section{CUADRO RESUMEN DEL PLAN DE MIGRACIÓN}

Tabla $N^{\circ} 35$

Cuadro resumen del Plan de Migración

\begin{tabular}{|c|c|c|c|c|c|c|}
\hline Arquitectura & Brecha & Proyecto & Problema & Costos & $\begin{array}{l}\text { Solución } \\
\text { Potencial }\end{array}$ & Riesgos \\
\hline Negocio & $\begin{array}{l}\text { A-1: Se actualizará el proceso } \\
\text { de carga de planilla de la } \\
\text { cotización, para que la planilla } \\
\text { cargada se guarde en Base de } \\
\text { Datos y no se quede en } \\
\text { memoria. } \\
\text { A-2: Se actualizará el procesar } \\
\text { solicitud para que esta se } \\
\text { maneje de forma asíncrona. } \\
\text { A-3: Se actualizará el proceso } \\
\text { de carga de planilla de la } \\
\text { cotización, para que la planilla } \\
\text { cargada se guarde en Base de } \\
\text { Datos y no se quede en } \\
\text { memoria. } \\
\text { A-4: Se actualizará el procesar } \\
\text { solicitud para que esta se } \\
\text { maneje de forma asíncrona. } \\
\text { A-5: Se actualizará el procesar } \\
\text { solicitud para que esta se } \\
\text { maneje de forma asíncrona }\end{array}$ & $\begin{array}{c}\text { Rediseño del } \\
\text { Sistema de } \\
\text { Emisión a } \\
\text { Distancia (SED) }\end{array}$ & $\begin{array}{l}\text { Cumplimiento } \\
\text { de la normativa } \\
\text { de emisión de } \\
\text { póliza de SCTR } \\
\text { dispuesto por la } \\
\text { SBS. }\end{array}$ & $\begin{array}{c}\mathrm{S} / 825,000 \text { a S/ } \\
1^{\prime} 485,000\end{array}$ & $\begin{array}{l}\text { Implementar un } \\
\text { sistema de } \\
\text { emisión de } \\
\text { pólizas de SCTR } \\
\text { que soporte } \\
\text { operaciones de } \\
\text { gran magnitud } \\
\text { en simultáneo }\end{array}$ & $\begin{array}{l}\text { R1: Cambio en } \\
\text { las normativas } \\
\text { especificadas } \\
\text { por la SBS } \\
\text { R2: No adquirir } \\
\text { la arquitectura } \\
\text { tecnológica en la } \\
\text { fecha } \\
\text { programada } \\
\text { R3: El personal } \\
\text { a cargo de la } \\
\text { implementación } \\
\text { no se encuentre } \\
\text { debidamente } \\
\text { capacitada } \\
\text { R4: No contar } \\
\text { con el debido } \\
\text { licenciamiento }\end{array}$ \\
\hline
\end{tabular}


A-6: Se actualizará el procesar

de software

solicitud para que esta se

maneje de forma asíncrona

$\mathrm{N}-1$ : Se añade la tabla

"TB018_OPERACION_SED"

que guarda las operaciones

realizadas por un usuario. En

esta tabla se registrará las

operaciones que se envíen al

Agente.

N-2: Se adiciona la tabla

"TB019_OPERACION_MOV"

Datos en la cual se registrará el

historial de movimientos

realizados por cada operación

de la tabla

"TB018_OPERACION_SED".

N-3: Se adiciona la tabla

"TB020_MENSAJE_SED", en

esta tabla se guardará los

mensajes resultantes de por

cada operación realizada, sea

exitosa o no.

$\mathrm{N}-2$ : Se necesita adquirir el

software Agente para gestionar

Aplicaciones los "hilos " de procesos

$\mathrm{N}-3$ : Se necesita adquirir el

software de mensajería Web

Sphere MQ. 
A-1: Se necesita actualizar el

servidor de aplicaciones con el

software Agente para gestionar

Tecnología

los "hilos" de procesos

$\mathrm{N}-1$ : Se necesita adquirir el

servidor de colas IBM AIX

Nota. Cuadro resumen del plan de migración. Elaboración propia. 


\section{(1)}

\section{ESTRATEGIA DE IMPLEMENTACIÓN Y MIGRACIÓN}

Tabla $\mathrm{N}^{\circ} 36$

Plan de Implementación y Migración

\begin{tabular}{|c|c|}
\hline Tarea & Consideración \\
\hline Plan de Comunicación & $\begin{array}{l}\text { Antes, durante y después del despliegue } \\
\text { Emisión de documentación técnica y funcional }\end{array}$ \\
\hline Plan de Capacitación & $\begin{array}{l}\text { Antes del despliegue, a todas las áreas involucradas } \\
\text { Asimismo transferencia de conocimientos técnicos al área } \\
\text { de mesa de ayuda }\end{array}$ \\
\hline $\begin{array}{l}\text { Plan de Implementación de } \\
\text { Servidores }\end{array}$ & $\begin{array}{llcccc}\text { Definir fecha de ejecución } & \text { (considerar la } & \text { no } \\
\text { disponibilidad) en coordinación } & \text { con el área } & \text { de } \\
\text { infraestructura } & & & & & \end{array}$ \\
\hline Plan de Instalación de programas & $\begin{array}{l}\text { Definir la herramienta y orden de instalación en } \\
\text { coordinación con el área de infraestructura }\end{array}$ \\
\hline Plan de Despliegue & $\begin{array}{l}\text { Definir si se realizará masivamente o en fases } \\
\text { Verificar la implementación de la infraestructura antes del } \\
\text { despliegue }\end{array}$ \\
\hline
\end{tabular}

Nota. Plan de implementación y migración. Elaboración propia. 
DESGLOSE DE LA IMPLEMENTACIÓN DE PROYECTOS Y CARTERAS

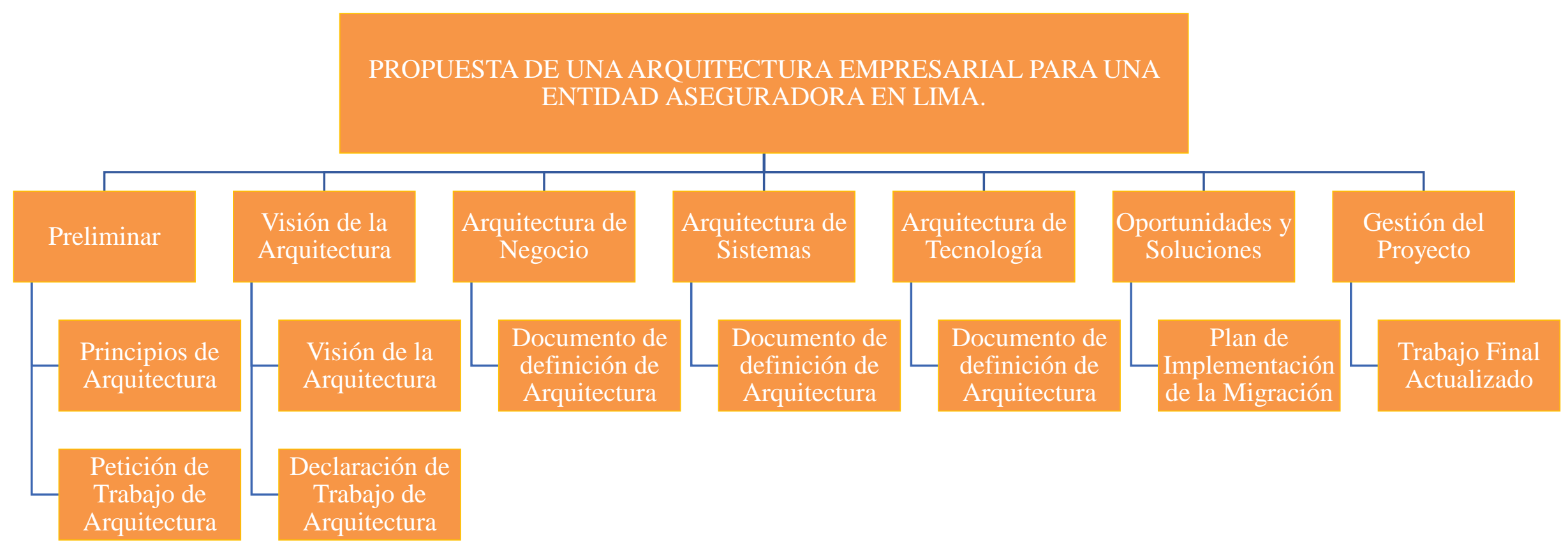

Figura $N^{\circ} 28 \mathrm{EDT}$

Fuente: Elaboración propia. 


\section{(1)}

\section{MÉTODOS ÁGILES PARA EL DESARROLLO DE SOFTWARE}

En base al plan de mitigación y la estrategia de implementación, en esta sección se especificará.

\section{IDENTIFICACIÓN DE FORTALEZAS Y DEBILIDADES}

Mediante el análisis FODA, se procederá a realizar un análisis interno el cual tendrá como objetivo identificar las fortalezas, oportunidades, debilidades y amenazas de la organización.

\section{Fortalezas}

- F001: Posicionamiento en el mercado por asistencia médica y automóviles.

- F002: Diversificación de productos.

- F003: Liderazgo en costos (SOAT)

- F004: Amplia cobertura, descentralización de oficinas, cuenta con 38 oficinas a nivel nacional en 20 regiones.

- F005: Amplia trayectoria en el mercado de asegurador ... (La Positiva, 2018)

- F006: Solidez financiera por alianzas a nivel internacional ... (Medina, 2018)

- F007: Reconocimiento por innovación. ("La Positiva Seguros obtiene premio de Innovate Perú del Ministerio de Producción”, 2018)

\section{Debilidades:}

- D001: Casos de insatisfacción por el servicio brindado de los proveedores (Talleres, clínicas, procuradores entre otros).

- D002: Algunos procesos de la organización no se encuentran debidamente documentados.

- D003: Poco uso de metodologías agiles para desarrollo de proyectos en la organización.

- D004: En los proyectos no toda la documentación es actualizada cuando se presentan cambios de alcance; debido a las fechas de entregas comprometidas. 


\section{(1)}

\section{Oportunidades:}

- O001: Baja penetración de seguros en segmentos de ingresos medios y bajos.

- O002: Bajo poder de negociación de los proveedores.

- O003: Amplio mercado para inversión.

- O004: La inseguridad y crisis del sector público, propician la conciencia de la adquisición de un seguro. (APESEG, 2018).

\section{Amenazas:}

- A001: Riesgos de la Naturaleza

- A002: Incertidumbre en la política del país.

- A003: Nuevas leyes y normas por parte de la SBS

- A004: Alianzas estratégicas entre entidades bancarias y aseguradoras del mismo grupo

\section{DIAGNÓSTICO DEL GRUPO}

En base al análisis FODA realizado en el punto anterior, se han identificado los riesgos y problemas potenciales para el proyecto PRY01. Luego del análisis realizado y tomando como referencia el marco de referencia CYNEFIN; con el fin de identificar las condiciones del hábitat del proceso de gestión de emisión de pólizas SCTR para abordar el proyecto en mención.

Con las debilidades y amenazas identificadas, se identificó tres riesgos potenciales:

- R001: Posible retraso y sobre costos en la adquisición de equipos por parte del área de infraestructura, debido a la inflexibilidad y procesos de burocracia propias del área.

- R002: Incumplimiento o entrega de producto no esperado por poca experiencia en proyectos agiles.

- R003: Documentación de procesos no actualizada debido al poco o nulo control sobre esto.

En base a los riesgos identificados, se determina que el equipo del proyecto se ubica en un escenario complicado conforme al marco de referencia CYNEFIN. Al verse reflejado la 


\section{(1)}

dependencia del conocimiento y experiencia de usuarios claves, frecuentemente la información compartida es incompleta y esta situación tiende a empeorar por documentación no actualizada. Por otro lado, por la alta demanda del proceso y la búsqueda de una pronta solución, se requiere expertos que den una solución eficiente para el proyecto. Finalmente, se debe reforzar el enfoque ágil y capacidad de auto-gestión con el fin de contribuir con el objetivo del proyecto.

\section{IDENTIFICACIÓN DE LAS DINÁMICAS PROPUESTAS}

A raíz del diagnóstico realizado, y conociendo las debilidades que están asociadas al proceso de gestión de emisión de pólizas SCTR y a los equipos de trabajo, se propone trabajar con el marco ágil Scrum para el desarrollo del proyecto propuesto; debido a que, la organización necesita obtener resultados en corto tiempo. Resultados o entregables que den valor al negocio.

El principal beneficio que se busca al proponer SCRUM, como marco de referencia para el desarrollo del software, es la entrega de funcionalidad y valor al negocio en menor tiempo que una metodología tradicional (Agile Alliance, 2001). A continuación se describen las dinámicas propias el marco SCRUM:

\section{SPRINT PLANNING}

Tal como se define en la Guía para el cuerpo de conocimiento de Scrum (SBOK, 2017). Esta reunión se lleva a cabo antes del Sprint, como parte de los procesos de comprometer Users Stories, identificar tareas, estimar tareas y crear el Sprint Backlog.

"El Sprint Planning se divide en dos partes. En la primera parte de la reunión se trata el ¿Qué? se va a hacer en el siguiente Sprint y en la segunda parte, se discute el ¿Cómo?. La primera parte está organizada y liderada por el Product Owner y la segunda parte por el Scrum Team. La única labor del Scrum Master es asegurarse de que la reunión existe como parte de Scrum”. Jeronimo Palacios (2018)

En esta dinámica participa el Product Owner, Scrum Master y el Scrum Team. Asimismo, en esta dinámica se define los ítems del Product Backlog a desarrollar en el Sprint a comenzar, estos son priorizados por el Product Owner. De ser necesario el Scrum Team puede plantear 


\section{(1)}

cambios en la prioridad, por complejidad o restricción técnica. La reunión debe durar máximo dos horas y el esfuerzo para desarrollar una User Story no debe durar más de dos semanas. Asimismo, el Scrum Team descompone las User Story en tareas y se auto asigna estas. Cabe indicar que para el control de avance se emplea el Scrum Taskboard, el cual se actualiza con el avance que realiza el Scrum Team.

\section{DAILY SCRUM}

Según la Guía para el cuerpo de conocimiento de SCRUM (SBOK, 2017). Es una breve reunión diaria con un tiempo de 15 minutos. La duración de la reunión es muy corta y se busca que todos los integrantes del Scrum Team estén presentes. Sin embargo, la reunión no se cancela o se retrasa si uno o más miembros no pueden asistir. El Daily Scrum es organizado por el Scrum Master, donde cada miembro del Scrum Team brinda información en forma de respuesta a tres preguntas específicas:

- ¿Qué he hecho desde la última reunión?

- ¿Qué tengo planeado hacer antes de la siguiente reunión?

- ¿Qué impedimentos u obstáculos (si los hubiera) estoy enfrentando en la actualidad?

Para el proyecto esta dinámica debe durar 15 minutos y los integrantes del Scrum Team deben responder las siguientes preguntas: ¿En qué trabajó ayer? ¿En qué trabajará hoy? y ¿Qué impedimentos tiene para realizar su trabajo?. Esto con el fin de obtener un reporte del progreso del Sprint.

\section{SPRINT REVIEW}

Tal como se define en la Guía para el cuerpo de conocimiento de SCRUM (SBOK, 2017). Los miembros del equipo de Scrum y los Stakeholders relevantes participan en las reuniones de revisión del Sprint para aceptar los entregables que cumplan con los criterios de aceptación de las User Stories y rechazar los entregables no aceptables. Tales reuniones se convocan al final de cada Sprint. El Scrum Team demuestra los logros del Sprint, incluyendo las nuevas funcionalidades o los productos elaborados. Esto brinda una oportunidad para que el Product Owner y el(los) Stakeholder(s) inspeccionen lo que se ha completado hasta el 


\section{(1)}

momento y determinen si deben realizarse cambios en el proyecto o en los procesos en Sprints posteriores.

En este proyecto le permite al Product Owner debe verificar que el entregable el sprint culminado cumpla con las expectativas planteadas. Para lo cual el Product Owner verifica que las User Stories desarrolladas y proporciona feedback al Scrum Team. Resaltar que esta reunión debe durar como máximo dos horas.

\section{SPRINT RETROSPECTIVE}

Como se menciona en la Guía para el cuerpo de conocimiento de SCRUM (SBOK, 2017), la retrospectiva del Sprint es un elemento importante del marco de trabajo de Scrum y es el último paso en un Sprint. Todos los miembros del Scrum Team asisten a la reunión, misma que organiza y modera el Scrum Master. Es esencial celebrar esta reunión es un entorno abierto y relajado a fin de fomentar la completa participación de todos los miembros del equipo. Las discusiones en la reunión de retrospectiva del Sprint abarcan tanto lo que salió mal como lo que salió bien.

Los propósitos de la Retrospectiva de Sprint (Schwaber \& Sutherland, 2017, 1) son:

- Inspeccionar el resultado del último Sprint en cuanto a personas, relaciones, procesos y herramientas.

- Identificar y ordenar los elementos que salieron bien y proponer mejoras; y,

- Crear un plan para implementar las mejoras a la vez que el Equipo Scrum desempeña su trabajo.

Esta dinámica se realiza después del Sprint Review. En esta se identifican las lecciones aprendidas; asimismo, se discute el feedback que proporciono el Product Owner en el Sprint Review. Esta dinámica tiene como fin mejorar el proceso de desarrollo mediante una lista de acciones aceptables. Asimismo, resaltar que debe durar como máximo una hora. 


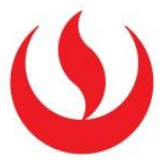

\section{COMPOSICIÓN DE LOS GRUPOS DE TRABAJO}

En esta sección, se define los roles del equipo de trabajo que se encargaran del desarrollo del proyecto PROY01. Estos roles están basados en el marco de trabajo de Scrum. Los roles principales son Scrum Master, Product Owner y miembros del Scrum Team. A continuación, se define el detalle de cada rol que tendrá los miembros del equipo:

\section{PRODUCT OWNER}

Según la guía para el cuerpo de conocimiento de SCRUM (SBOK, 2017), "el Product Owner representa los intereses de los Stakeholders para el Development Team. El Product Owner es responsable de asegurar una comunicación clara sobre el producto y los requisitos de funcionalidad del servicio, definir los Definition of Done y asegurar que se cumplan dichos criterios. En otras palabras, el Product Owner es responsable de asegurar que el Development Team entregue valor."

Para este proyecto, el rol corresponde al Product Owner, quien pertenecerá al área de emisión reportando al gerente de emisión. Se debe relacionar con el SCRUM Master y los miembros del SCRUM Team. Este rol es proveedor de la visión y los requisitos a los pares y especialistas con quienes interactúe con el objetivo de mejorar la productividad de los procesos de emisión y el bienestar de las personas que ejecuten tareas en ese mismo proceso. Este rol será cubierto por Apoderado Senior de Emisión.

Las principales responsabilidades del rol Product Owner son las siguientes:

- Ser el representante de los Stakeholders en la organización.

- Acopiar los requisitos para transmitirlos al Scrum Team.

- Crea las User Stories.

- Prioriza los elementos del Product Backlog.

- Define los Definition of Done.

- Elabora el cronograma de planificación del lanzamiento.

- Explica las User Stories al Scrum Team. 


\section{(1)}

- Acepta o rechaza los entregables.

- Proporciona la retroalimentación necesaria al Scrum Master y al Scrum Team.

- Ayuda a enviar los lanzamientos del producto y se coordina con los Stakeholders.

Las competencias requeridas el rol Product Owner son las siguientes:

- Educación y Certificaciones

- Inglés intermedio

- Educación superior concluida.

- Grado universitario o superior en Ingeniería de Industrial o Sistemas

- Dominio y buen manejo en procesos de emisión de pólizas.

- Estudios y/o certificación Product Owner

- Conocimiento en herramientas de gestión de proyectos (Jira y Trello)

- Experiencia

- Mínimo cinco años de experiencia en área de emisión de pólizas

- Experiencia como Product Owner

- Experiencia en el mercado de seguros.

- Habilidades Blandas

- Alta capacidad de negociación u persuasión.

- Alta capacidad de resolución de problemas y conflictos.

- Liderazgo y Compromiso

- Excelente nivel de comunicación.

- Proactivo.

- Ordenado, organizado y con capacidad de autogestión 


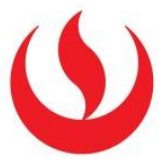

\section{SCRUM MASTER}

Según la guía para el cuerpo de conocimiento de SCRUM (SBOK, 2017), “el Scrum Master es el "líder servicial" del Development Team y es quien modera y facilita las interacciones del equipo como coach y motivador del mismo. Este rol es responsable de asegurarse que el Development Team tenga un ambiente de trabajo productivo protegiéndolo de influencias externas, eliminando todos los obstáculos y haciendo que se cumplan los principios, aspectos y procesos de Scrum."

Para este proyecto, el rol corresponde al SCRUM Master, quien pertenece al área de sistemas de información reportando al gerente de TI. Se relaciona con el Product Owner y los miembros del SCRUM Team. Este rol es el principal facilitador de las herramientas y el flujo continuo de trabajo del equipo para atender los requerimientos de desarrollo del software de acuerdo con los requerimientos del Product Owner en los proyectos de desarrollo que le sean asignados en la compañía. Este rol será cubierto por un jefe de proyecto de sistemas de información. Es el principal asesor del equipo para asegurar el cumplimiento de la filosofía ágil.

Las principales responsabilidades del rol SCRUM Master son las siguientes:

- Facilita la selección del Scrum Team.

- Garantizar que los recursos de respaldo estén disponibles para el funcionamiento del proyecto sin problemas.

- Coordina la creación del cronograma de planificación del lanzamiento.

- Organiza reuniones con el Scrum Team para estimar y comprometer User Stories.

- Ayuda al Scrum Team a crear la lista de tareas para el siguiente Sprint.

- Ayuda al Scrum Team a desarrollar el Sprint Backlog.

- Ayuda al Scrum Team a crear los entregables acordados para el Sprint.

- Organiza las reuniones de revisión del Backlog priorizado del producto.

- Garantiza que exista un ambiente ideal para el Scrum Team del proyecto en los sucesivos Sprints. 


\section{(1)}

Las competencias requeridas el rol SCRUM Master son las siguientes:

- Educación y Certificaciones

- Inglés intermedio

- Educación superior concluida.

- Grado universitario o superior en Ingeniería de sistemas, informática o industrial

- Dominio y buen manejo de Tecnología

- Certificación en SCRUM Master

- Conocimiento en el mercado de seguros.

- Conocimiento en herramientas de gestión de proyectos (Jira y Trello)

- Experiencia

- Mínimo cinco años de experiencia en proyectos de sistemas.

- Mínimo tres años de experiencia liderando equipos de trabajo.

- Experiencia mínima de dos años como SCRUM Master

- Experiencia en procesos logísticos

- Habilidades Blandas

- Alta capacidad de resolución de problemas y conflictos

- Interesado en investigación y nuevas tendencias tecnológicas

- Creatividad y pensamiento crítico

- Liderazgo y Compromiso

- Excelente nivel de comunicación

- Capacidad de trabajo en equipo

- Proactivo.

- Ordenado y organizado 


\section{(1)}

- Capacidad de autogestión

\section{SCRUM TEAM}

Según la guía para el cuerpo de conocimiento de SCRUM (SBOK, 2017), “al Scrum Team en ocasiones se le conoce como equipo de desarrollo, ya que este es responsable del desarrollo del producto, servicio o de cualquier otro resultado. Consiste en un grupo de personas que trabajan en las User Stories en el Sprint Backlog para crear los entregables del proyecto.”

Los perfiles requeridos para el desarrollo del proyecto y los que formaran parte del Scrum Team son:

\section{ARQUITECTO DE SOLUCIONES}

Este rol es responsable de asegurar el mínimo impacto de todo desarrollo sobre el funcionamiento de las demás aplicaciones de la compañía de acuerdo con los requisitos recibidos bajo metodologías ágiles con autonomía y de acuerdo con los estándares definidos en la organización. Este rol será cubierto por personal interno y será asignado a tiempo parcial en función a los requerimientos del proyecto.

Las principales funciones son las siguientes:

- Proporcionar lineamientos de arquitectura a quienes realizaran el desarrollo de los componentes de acuerdo con los requisitos proporcionados por el Producto Owner y las mejores prácticas que pueden ser aplicadas en la Organización Objetivo.

- Proponer alternativas de solución ante problemas técnicos complejos presentados por el equipo.

- Responder a situaciones complejas, inesperadas, o inestables con profesionalismo y bajo los estándares descritos en las normas de la organización objetivo. Usa reglas y herramientas analíticas estándares para detectar una causa raíz y dar una amplia gama de soluciones. 


\section{(1)}

- Trabajar con profesionales senior y no senior estableciendo objetivos y planes para el desarrollo de los proyectos asignados.

\section{ANALISTA TÉCNICO}

Este rol es responsable de coordinar las tareas relacionadas con cambios la arquitectura tecnológica con los requisitos recibidos, bajo metodologías ágiles con autonomía y de acuerdo con los estándares definidos en la organización. Este rol será cubierto por personal interno y será asignado a tiempo parcial en función a los requerimientos del proyecto.

Las principales funciones son las siguientes:

- Coordina las tareas de acuerdo con los requisitos proporcionados por el Producto Owner.

- Da soporte a los demás miembros del equipo en el dominio de la plataforma de desarrollo.

- Proporcionar estimaciones de esfuerzo y tiempo a sus supervisores sobre los trabajos realizados e informar oportunamente cualquier desviación sobre fecha y alcances previstos.

- Desarrollar labores de análisis de requerimiento y diseño de solución.

\section{ANALISTA PROGRAMADOR NET}

Este rol es responsable de desarrollar software bajo plataforma ASP.NET y de acuerdo con los requisitos recibidos, bajo metodologías ágiles con autonomía y de acuerdo con los estándares definidos en la organización. Este rol será cubierto por personal tercero

Las principales funciones son las siguientes:

- Apoyar la Elaboración de los artefactos de Análisis Funcional, Casos de Uso, Casos de Prueba, Análisis Técnico.

- Desarrollar las labores de construcción.

- Apoyar la creación de data de prueba. 


\section{(1)}

- Realizar la ejecución de pruebas y generación de evidencias.

\section{$\underline{\text { ANALISTA DE CALIDAD }}$}

Este rol es responsable de elaborar las tareas de pruebas sobre una aplicación. Donde debe definir las pruebas funcionales y no funcionales necesarias.

Las principales funciones son las siguientes:

- Conocimiento en métodos y técnicas de pruebas.

- Habilidades para diagnosticar y resolver problemas.

- Conocimiento del sistema o la aplicación que está siendo probada (Deseable).

- Conocimiento del trabajo en red y de la arquitectura del sistema.

\section{Product Owner}

+ Equipo de Desarrollo

+ Scrum Master
- Optimiza el valor del producto

- Gestiona el Product Backlog

- Crea incrementos terminados

- Se gestiona a si mismo

- Gestiona el proceso Scrum

- Elimina impedimentos

\section{= Equipo Scrum}

Figura $N^{\circ} 29$ Cuadro de Roles Scrum. Adaptado de "Roles Scrum”, por Jerónimo Palacios, 2018.

\section{DEFINICIÓN DE LAS HERRAMIENTAS A UTILIZAR}

En esta sección se define las herramientas o artefactos que se emplearan en el desarrollo del proyecto mediante el marco SCRUM. En este caso, artefacto se refiere a elementos físicos que se producen como resultado de la aplicación de SCRUM, los artefactos son los siguientes: Las User Stories, Product Backlog, Planning Poker, Sprint Backlog, Burndown Chart y Scrum Taskboard. 


\section{(1)}

\section{USER STORIES}

Según la guía para el cuerpo de conocimiento de SCRUM (SBOK, 2017). "Los User Stories se apegan a una estructura específica predefinida y son una forma simple de documentar los requerimientos y funcionalidades que desea el usuario final. Un User Story incluye tres elementos sobre el requerimiento: ¿Quién? ¿Qué? y ¿Por qué?; los requerimientos expresados en los User Stories son oraciones breves, sencillas y fáciles de entender.” Jerónimo Palacios (2018)

\section{USER STORIES DEL PROYECTO}

A continuación, se describen las User Stories identificados para el proyecto PRY01.

- HU1: Como usuario, quiero poder procesar una emisión de póliza de forma asíncrona para poder realizar más operaciones.

- HU2: Como usuario, quiero poder procesar una renovación de póliza de forma asíncrona para poder realizar más operaciones.

- HU3: Como usuario, quiero poder procesar una declaración de póliza de forma asíncrona para poder realizar más operaciones.

- HU4: Como usuario, quiero poder procesar una inclusión de asegurados en póliza existente de forma asíncrona para poder realizar más operaciones.

- HU5: Como usuario, quiero poder procesar una exclusión de asegurados de una póliza existente de forma asíncrona para poder realizar más operaciones.

- HU6: Como usuario, quiero poder procesar una solicitud de emisión de póliza de forma asíncrona para poder realizar más operaciones.

- HU7: Como usuario, quiero poder procesar una solicitud de renovación de póliza de forma asíncrona para poder realizar más operaciones.

- HU8: Como usuario, quiero poder procesar una solicitud de declaración de póliza de forma asíncrona para poder realizar más operaciones.

- HU9: Como usuario, quiero poder procesar una solicitud de inclusión de póliza de forma asíncrona para poder realizar más operaciones. 


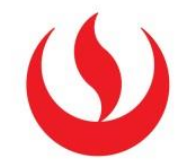

\section{PRODUCT BACKLOG}

Según la "Guía para el cuerpo de conocimiento de Scrum” (SBOK, 2017), "el Product Owner desarrolla Product Backlog que contiene una lista priorizada de los requerimientos del negocio y de los proyectos escritos en forma de épicas, que son User Stories de alto nivel. El Product Backlog se basa en tres factores principales: valor, riesgo o incertidumbre y dependencias. También incluye cambios aprobados que pueden ser priorizados adecuadamente.” Jerónimo Palacios (2018)

El Product Backlog contiene la lista de User Stories, la cual es priorizada por el Product Owner Para el presente proyecto se emplea un esquema basado en Paired Comparison, que consiste en comparar las historias de usuarios unas con otras y determinar cuál es más importante con respecto a otra (Satpathy, 2013). En una reunión que el Product Owner lleva a cabo con los interesados, debe acordar una comparación entre las historias de usuario y determinar la prioridad de cada historia.

\section{$\underline{\text { BACKLOG DEL PROYECTO }}$}

Tabla $\mathrm{N}^{\circ} 37$

Users Stories Del Proyecto PROYO1

\begin{tabular}{llc}
\hline Código Historia de usuario & Valor \\
\hline
\end{tabular}

HU1 Como usuario, quiero poder procesar una emisión de póliza de forma asíncrona para poder realizar más operaciones.

HU2 Como usuario, quiero poder procesar una renovación de póliza de forma asíncrona para poder realizar más operaciones.

HU3 Como usuario, quiero poder procesar una declaración de póliza de forma asíncrona para poder realizar más operaciones.

HU4 Como usuario, quiero poder procesar una inclusión de asegurados en póliza existente de forma asíncrona para poder realizar más operaciones.

Como usuario, quiero poder procesar una exclusión de asegurados de

HU5 una póliza existente de forma asíncrona para poder realizar más operaciones.

HU6 Como usuario, quiero poder procesar una solicitud de emisión de póliza de forma asíncrona para poder realizar más operaciones. 


\section{(1)}

HU7 Como usuario, quiero poder procesar una solicitud de renovación de póliza de forma asíncrona para poder realizar más operaciones.

HU8 Como usuario, quiero poder procesar una solicitud de declaración de póliza de forma asíncrona para poder realizar más operaciones.

HU9 Como usuario, quiero poder procesar una solicitud de inclusión de póliza de forma asíncrona para poder realizar más operaciones.

Nota. Relación de Users Stories del proyecto. Elaboración propia

Nota: Se ha asignado un valor que representa la importancia de cada User Story para el negocio. Se ha asignado 5 para las más importantes y uno para las menos importantes. Elaboración propia.

\section{PLANNING POKER}

Para Grenning (2002) es una técnica para calcular el tiempo de desarrollo de una funcionalidad en base a un consenso. El Product Owner lee la historia de usuario y los desarrolladores estimas el esfuerzo en base a cartas enumeradas que usualmente son 1, 3, 5, 8,10,13, 15 y 40 (por lo peculiar son en horas; sin embargo, podrían ser días). Antes de estimar el esfuerzo cada desarrollador deberá preguntar a detalle de la funcionalidad a desarrollar, una vez asimilado la historia de usuario cada desarrollador estima el esfuerzo con una carta el cual colocará sobre la mesa. Se eliminará las cartas con mayores y menores números; y se seleccionará los números más centrales. Romeu (2014). 


\section{(1)}
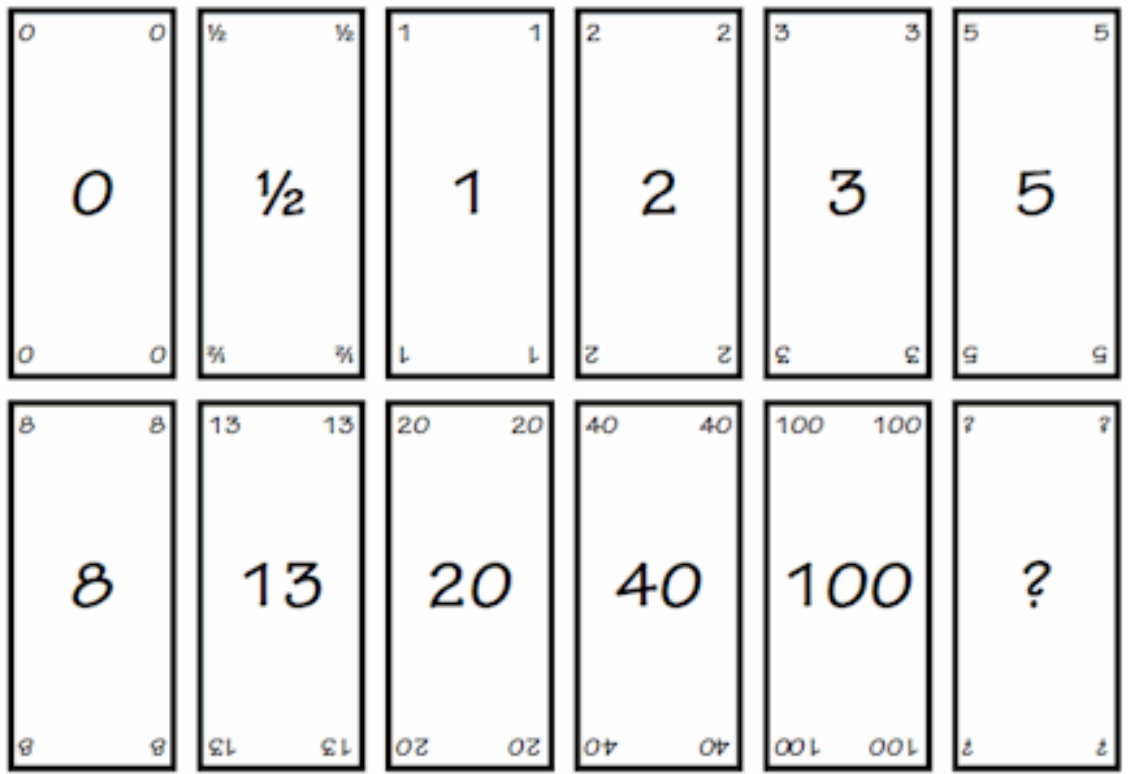

Figura $N^{\circ} 30$ Planing Poker. Adaptado de "Barajas Planning Poker", Elaboración propia, 2018.

Esta técnica será empleada para fines de estimación de esfuerzo. Por lo cual a cada miembro del Scrum Team se le entregará una baraja con los siguientes valores: 1, 2, 3, 5, 8, 13 y “?”. Los números representan los días de esfuerzo que puede tomar cada User Story. Por otro parte, para la carta “?” representa que no se puede estimar, por lo cual la User Story deberá refinarse o desglosarse. Además, se tendrá la carta con la descripción "Pausa" la cual puede ser usada para tomar un receso si es que no se llega a algún acuerdo especificó.

\section{ESTIMACIONES CON PLANNING POKER PARA EL PROYECTO}

Tabla $\mathrm{N}^{\circ} 38$

Estimación en días de las Users Stories del Proyecto PROYO1

\begin{tabular}{clc}
\hline Código & \multicolumn{1}{c}{ Historia de usuario } & $\begin{array}{c}\text { Esfuerzo } \\
\text { (Días) }\end{array}$ \\
\hline HU1 & $\begin{array}{l}\text { Como usuario, quiero poder procesar una emisión de póliza de } \\
\text { forma asíncrona para poder realizar más operaciones. }\end{array}$ & 10 \\
HU2 & $\begin{array}{l}\text { Como usuario, quiero poder procesar una renovación de póliza } \\
\text { de forma asíncrona para poder realizar más operaciones. }\end{array}$ & 6
\end{tabular}




\section{(1)}

HU3 Como usuario, quiero poder procesar una declaración de póliza

de forma asíncrona para poder realizar más operaciones.

Como usuario, quiero poder procesar una inclusión de

HU4 asegurados en póliza existente de forma asíncrona para poder realizar más operaciones.

Como usuario, quiero poder procesar una exclusión de

HU5 asegurados de una póliza existente de forma asíncrona para poder realizar más operaciones.

HU6 Como usuario, quiero poder procesar una solicitud de emisión de póliza de forma asíncrona para poder realizar más operaciones.

Como usuario, quiero poder procesar una solicitud de

HU7 renovación de póliza de forma asíncrona para poder realizar más operaciones.

Como usuario, quiero poder procesar una solicitud de

HU8 declaración de póliza de forma asíncrona para poder realizar más operaciones.

HU9 Como usuario, quiero poder procesar una solicitud de inclusión de póliza de forma asíncrona para poder realizar más operaciones.

Nota. Estimación en días de las Users Stories del proyecto. Elaboración propia

\section{SPRINT BACKLOG}

Según la "Guía para el cuerpo de conocimiento de Scrum" (SBOK, 2017). "La lista de tareas que llevará a cabo el Scrum Team en el siguiente Sprint se denomina Sprint Backlog. Es común que el Sprint Backlog esté representado en un Scrumboard o tablero de tareas, el cual proporciona una constante representación visual del estado de los Users Stories en el Backlog. En el Sprint Backlog también se incluye cualquier riesgo asociado a las tareas. Cualquier actividad de mitigación de riesgos para atender los riesgos identificados también se incluirían como tareas en el Sprint Backlog. Una vez que el Development Team finaliza y se compromete al Sprint Backlog, no se deben agregar nuevas User Stories; sin embargo, las tareas que pudieron haberse pasado por alto o ignoradas de las User Stories comprometidas pudieran ser agregadas.” Jerónimo Palacios (2018)

El Sprint Backlog proporciona una perspectiva del trabajo a realizar durante el Sprint en curso. Esta gestionado por el Scrum Team, el cual se encargad de mantenerlo actualizado, de 


\section{(1)}

esta manera se visualiza la evolución del trabajo durante el Sprint en curso; asimismo, se analizan los posibles riesgos.

Después del Sprint Planning, el Scrum Team obtiene una lista de tareas en los que van a trabajar durante un Sprint.

\section{$\underline{\text { SPRINT BACKLOG PARA SPRINT } 0}$}

Para el proyecto PROY01 se ha identificado un SPRINT 0, en el cual se agrupa las actividades pre operativas necesarias para el inicio del proyecto. Estas actividades están relacionadas con conceptualizaciones arquitectónicas iniciales, configuración del entorno de desarrollo. Adicionalmente, en este Sprint se realizará la implementación del Agente y Manejador de colas propias del proyecto. Estas soluciones son pre requisito para los posteriores Sprints.

Tabla $N^{\circ} 39$

Tareas del Sprint 0 del Proyecto PROYO1

\begin{tabular}{lcl}
\hline \multicolumn{1}{c}{ Tarea } & $\begin{array}{c}\text { Esfuerzo } \\
\text { (horas) }\end{array}$ & \multicolumn{1}{c}{ Responsable } \\
\hline Contratación de personal tercero & 6 Scrum Master \\
Reunión del Kick Off & 2 Product Owner \\
Configurar entorno de desarrollo & 8 Scrum Master y Scrum Team \\
Realizar capacitación sobre marco Scrum & 8 Scrum Master \\
& \multicolumn{2}{c}{ Arquitecto de Solución y Scrum } \\
Capacitación funcional y técnica de los sistemas & 4 Team \\
Elaboración de Arquitectura solución alto nivel & 16 Arquitecto de Solución \\
\hline Nota. Tareas del Sprint 0 del proyecto. Elaboracion propla
\end{tabular}

Nota. Tareas del Sprint 0 del proyecto. Elaboración propia

\section{$\underline{\text { SPRINT BACKLOG PARA SPRINT } 1}$}

En esta sección se han identificado los User Stories que se seleccionan para iniciar el primer Sprint de tres semanas de duración. Se han seleccionado los User Stories por valor y dependencia desde el punto de vista del negocio y en acuerdo al esfuerzo que el Scrum Team puede atender en el periodo de tres semanas. A continuación, se muestra el Sprint 1 como primera iteración para el Product Owner. 


\section{(}

Tabla $\mathrm{N}^{\circ} 40$

Sprint 1 del Proyecto PROYO1

\begin{tabular}{clc}
\hline Código & \multicolumn{1}{c}{ Historia de usuario } & $\begin{array}{c}\text { Esfuerzo } \\
\text { (Días) }\end{array}$ \\
\hline HU1 & $\begin{array}{l}\text { Como usuario, quiero poder procesar una emisión de póliza de forma } \\
\text { asíncrona para poder realizar más operaciones. }\end{array}$ & 10 \\
HU6 & $\begin{array}{l}\text { Como usuario, quiero poder procesar una solicitud de emisión de póliza de } \\
\text { forma asíncrona para poder realizar más operaciones. }\end{array}$ & 5 \\
\hline
\end{tabular}

Nota. Sprint 1 del proyecto. Elaboración propia

De la misma forma, el Scrum Team ha definido el desglose de tareas y esfuerzo. Asimismo, cada integrante se ha auto-asignado las tareas correspondientes de acuerdo a sus capacidades.

Tabla $\mathrm{N}^{\circ} 41$

Tareas del Sprint 1 del Proyecto PROYO1

\begin{tabular}{|c|c|c|c|}
\hline $\begin{array}{l}\text { User } \\
\text { Story }\end{array}$ & Tarea & $\begin{array}{c}\text { Esfuerzo } \\
\text { (horas) }\end{array}$ & Responsable \\
\hline \multirow{8}{*}{ HU1 } & Bajar carga de planilla de asegurados a BD & 12 & $\begin{array}{l}\text { Arquitecto de } \\
\text { soluciones }\end{array}$ \\
\hline & Reformular Proceso de Emisión & 16 & $\begin{array}{l}\text { Arquitecto de } \\
\text { soluciones }\end{array}$ \\
\hline & $\begin{array}{l}\text { Emisión de pólizas con Concurrencia ( } 10 \text { archivos } \\
\text { Excel de } 600 \text { registros cada uno) }\end{array}$ & 6 & Analista técnico \\
\hline & $\begin{array}{l}\text { Emisión /Disponibilidad de la información } \\
\text { Refrescamiento. } \\
\text { Ocultar operaciones No procesadas luego de } 15 \text { días }\end{array}$ & 6 & $\begin{array}{l}\text { Analista técnico / } \\
\text { Analista } \\
\text { programador } 1\end{array}$ \\
\hline & Emisión / Consulta de Estados de Operaciones. & 8 & $\begin{array}{c}\text { Analista } \\
\text { programador } 1\end{array}$ \\
\hline & Emisión / Panel de Operaciones & 8 & $\begin{array}{c}\text { Analista } \\
\text { programador } 1\end{array}$ \\
\hline & Elaboración de casos de pruebas & 10 & $\begin{array}{l}\text { Analista de } \\
\text { calidad }\end{array}$ \\
\hline & Elaboración de Plan de pruebas & 6 & $\begin{array}{c}\text { Analista de } \\
\text { calidad }\end{array}$ \\
\hline
\end{tabular}




\section{(1)}

Reformular proceso de Solicitud de Aprobación

12

Arquitecto de soluciones

Aprobar Solicitud (Emisión) / Concurrencia (10

Archivos Excel de 600 registros cada uno).

$4 \quad$ Analista técnico

Aprobar Solicitud (Emisión) / Disponibilidad de la Información.

Refrescamiento.

8

Analista técnico /

Ocultar operaciones No Procesadas luego de 15 días.

Analista

programador 2

HU7

Aprobar Solicitud (Emisión) / Consulta de Estados de
Operaciones.

Aprobar Solicitud (Emisión) / Panel de Operaciones

Elaboración de casos de pruebas

\begin{tabular}{|c|c|c|c|}
\hline \multirow{8}{*}{$\begin{array}{c}\text { HU1 / } \\
\text { HU7 }\end{array}$} & Proceso de reintento Automático & 8 & $\begin{array}{c}\text { Analista } \\
\text { programador } 2\end{array}$ \\
\hline & Proceso de reintento Temporizado & 8 & $\begin{array}{c}\text { Analista técnico / } \\
\text { Analista } \\
\text { programador } 1\end{array}$ \\
\hline & Proceso de reintento Manual & 8 & $\begin{array}{c}\text { Analista técnico / } \\
\text { Analista } \\
\text { programador } 2\end{array}$ \\
\hline & Envió de notificaciones vía correo electrónico & 4 & $\begin{array}{c}\text { Analista } \\
\text { programador } 1\end{array}$ \\
\hline & Flujo de validación Agente caído. & 6 & $\begin{array}{c}\text { Analista } \\
\text { programador } 2 \\
\end{array}$ \\
\hline & Errores técnicos. & 6 & $\begin{array}{c}\text { Analista } \\
\text { programador } 2\end{array}$ \\
\hline & Elaboración de casos de pruebas & 10 & $\begin{array}{l}\text { Analista de } \\
\text { calidad }\end{array}$ \\
\hline & Elaboración de Plan de pruebas & 6 & $\begin{array}{l}\text { Analista de } \\
\text { calidad }\end{array}$ \\
\hline
\end{tabular}

Nota. Relación de tareas del Sprint 1. Elaboración propia 


\section{(}

\section{BURNDOWN CHART}

Es un diagrama para saber cuánto tiempo falta para completar el trabajo. En la práctica es un diagrama de dos ejes, en el eje $\mathrm{X}$ va el tiempo (puede ser en días) y en el eje $\mathrm{Y}$ la cantidad de trabajo comprometida con el cliente, todo esto es respecto al sprint (Romeu, 2013).

Romeu (2013) indica 3 motivos por la cual contar con un Burndown chart es útil.

- Ayuda a poder responder la pregunta: ¿cuánto falta para terminar?

- Son visuales y fáciles de entender.

- No cuestan nada de mantener: Actualizar el diagrama es tan sencillo como sumar el número de días ideales que quedan tras el día anterior y trazar una línea.

En Scrum el Burndown Chart es una importante herramienta gráfica, pues permite transparencia sobre la situación del trabajo realizado sobre el Sprint. Asimismo, permite determinar el esfuerzo pendiente para dar por terminado el Sprint y si es necesario realizar adaptaciones para cumplir con el objetivo del Sprint. A continuación se muestra un ejemplo:

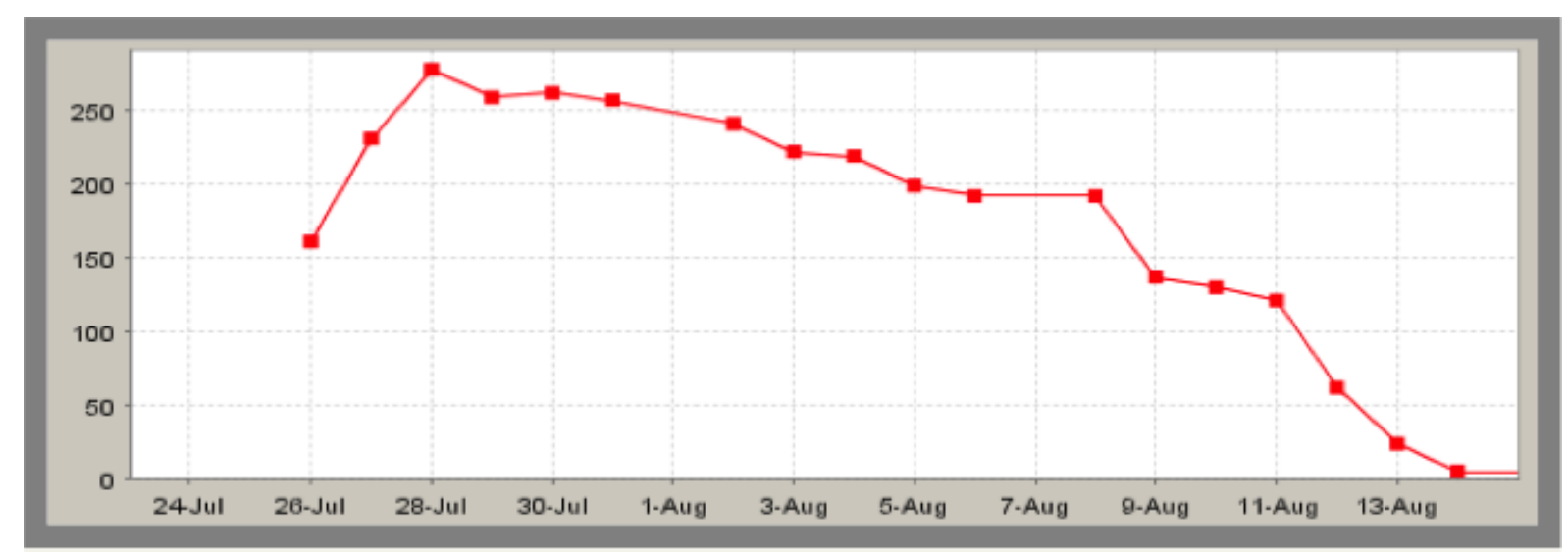

Figura $N^{\circ} 31$ Diagrama Burndown. Adaptado de “Guía Fundamental de Scrum”, Elaboración propia.

\section{SCRUM TASKBOARD}

Para Albaladejo (2010) el tablero Scrum es: "La lista de objetivos a completar en la iteración (Product Backlog Items) se puede gestionar mediante un tablero o pizarra de tareas (Scrum Taskboard) que actúa como radiador de información" (párr. 1.). 


\section{(1)}

Para Albaladejo (2010) el tablero debe ser visible para todos. Cuenta con 3 columnas: pendiente, en curso y hecho. Estos determinan el estado del User Story.

El Scrum Taskboard permite una visibilidad de las tareas del Sprint que se está llevando a cabo. Cada tarea es ubicada en una columna inicial la cual se denomina "Pendiente", la cual actualiza su estado en el momento que el miembro del Scrum Team que se comprometió a hacerla inicie su atención, por lo cual pasa a la columna "En proceso". Cuando la tarea es finalizada pasa a la columna "Terminado"

\section{$\underline{\text { SCRUM TASKBOARD DEL SPRINT } 1}$}

Para el proyecto PROY01, se emplea el TRELLO como herramienta para formular el Scrum Taskboard. En medida que las tareas sean atendidas y terminada, se actualizarán sus estados.

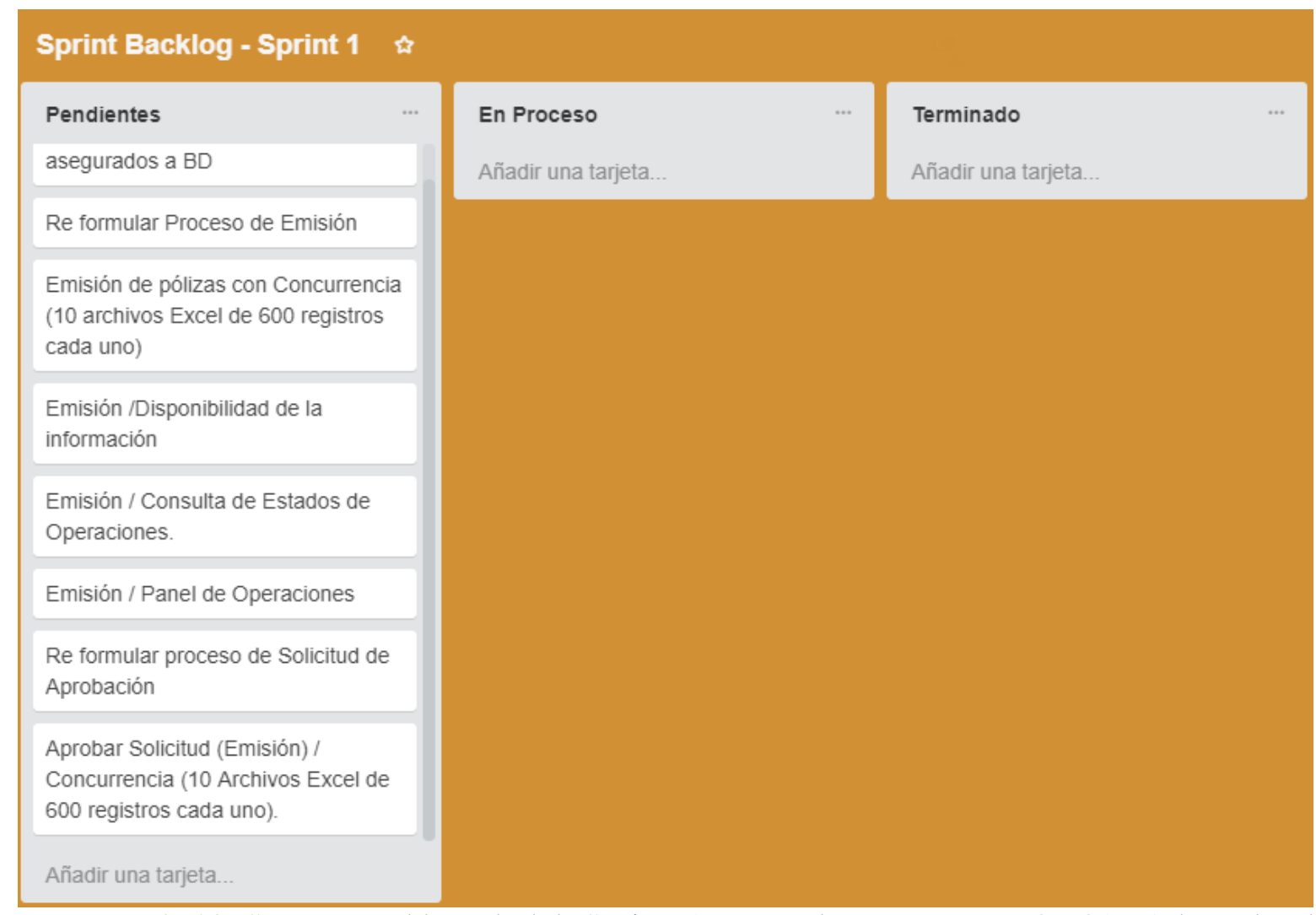

Figura $N^{\circ} 32$ Scrum Taskboard del Sprint 1 para el proyecto PROY01, Adaptado del https://trello.com 


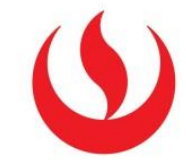

\section{DEFINITION OF DONE}

Los DoD para el Sprint 1 se definen a continuación:

- Garantizar que se realice la revisión de pares del desarrollo.

- Garantizar que el visto bueno por arquitecto de soluciones sobre la arquitectura propuesta

- No evidenciar bloqueos de base de datos por el procesamiento en simultáneo de 10 archivos Excel con 600 registros de manera concurrente.

- No evidenciar caídas de la aplicación en la validación en simultáneo de 10 archivos Excel con 600 registros de manera concurrente.

- Permitir consultar el estado de las operaciones desde que son iniciados hasta su culminación.

- Obtener la aprobación del Product Owner.

\section{COSTOS DEL PROYECTO}

Para el primer Sprint, se consideran las horas de las tareas auto asignadas por cada miembro del equipo. Para el caso específico de los Desarrolladores, y el Scrum Master, se considera su participación a tiempo completo. En el caso del Product Owner, se considera un 50\% de asignación al proyecto. 


\section{COSTOS DEL SPRINT 0}

Tabla $\mathrm{N}^{\circ} 42$

Costos del Sprint 0

Asignación en horas

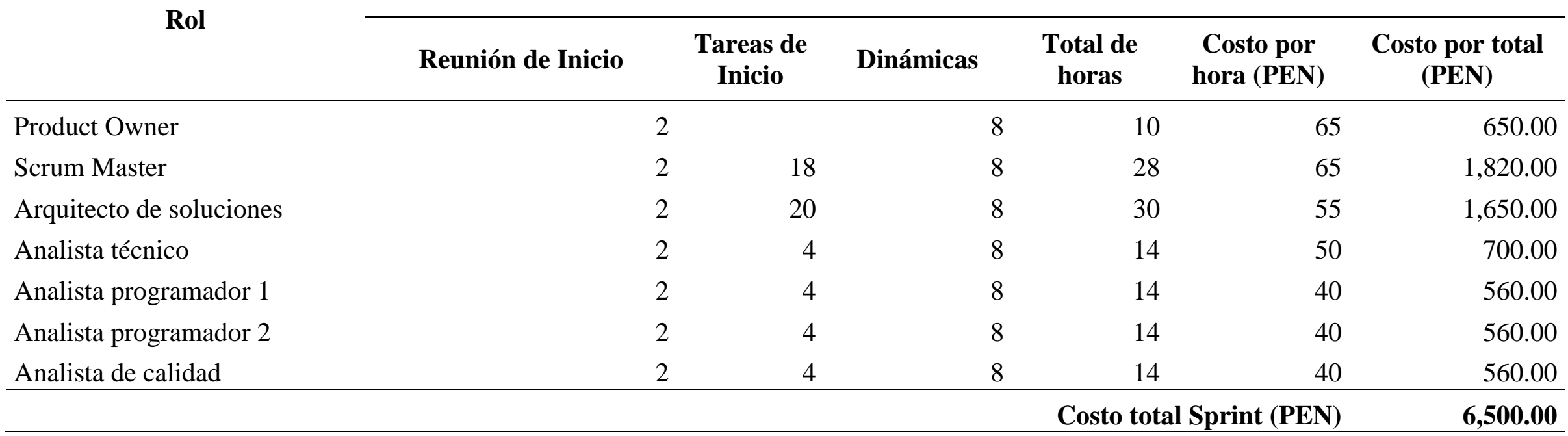

Nota. Costos del sprint 0. Elaboración propia 


\section{COSTOS DEL SPRINT 1}

Tabla $\mathrm{N}^{\circ} 43$

Costos del Sprint 1

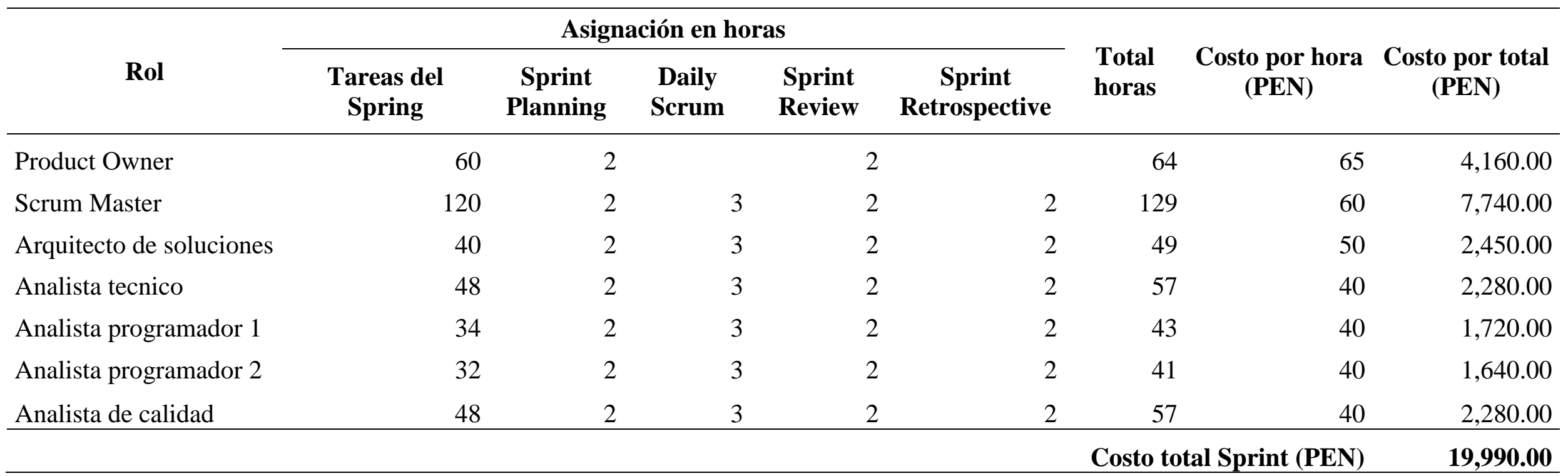

Nota. Costos del sprint 1. Elaboración propia 


\section{(1)}

\section{COSTOS TOTAL DEL PROYECTO}

Por otro lado, para el costo total del proyecto, se considera por la estimación de esfuerzo realizarlo en tres Sprints.

Tabla $\mathrm{N}^{\circ} 44$

Relación de atención de Users Stories por Sprint

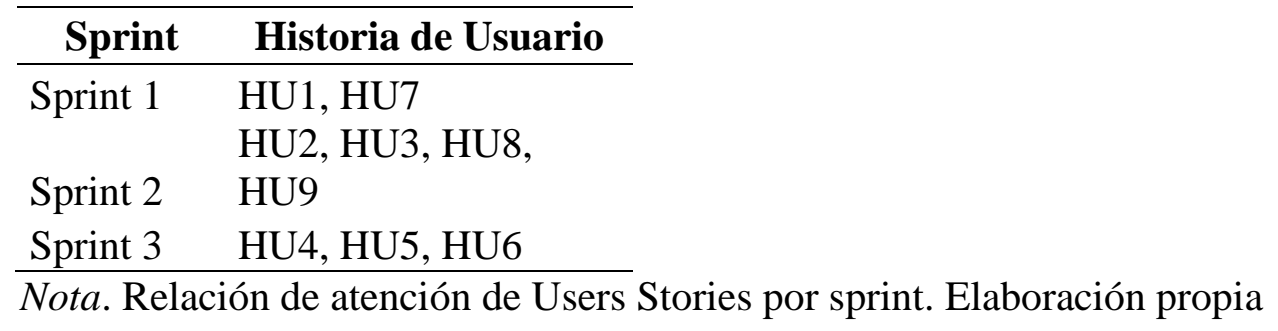

Por lo consiguiente, el costo total del proyecto, en orden de atención, en donde, se incluye el Sprint 0 , se muestra a continuación:

Tabla $\mathrm{N}^{\circ} 45$

Resumen general de los costos del proyecto

\begin{tabular}{lr}
\hline \multicolumn{1}{c}{ Sprint } & \multicolumn{1}{c}{ Costo (PEN) } \\
\hline Sprint 0 & $6,500.00$ \\
Sprint 1 & $19,990.00$ \\
Sprint 2 & $19,990.00$ \\
Sprint 3 & $19,990.00$ \\
\hline Total & $\mathbf{6 6 , 4 7 0 . 0 0}$ \\
\hline
\end{tabular}

Nota. Resumen general de los costos del proyecto. Elaboración propia 


\section{(}

\section{CONCLUSIONES}

En el presente capitulo se ha desarrollado una propuesta de arquitectura empresarial, mediante la aplicación del marco TOGAF. Para ello se realizó un análisis de la línea base de la organización (AS-IS), para luego realizar el contraste con el análisis de línea destino (TOBE) con el fin de identificar las brechas correspondientes.

En el análisis correspondiente se identificó brechas en la arquitectura de datos, arquitectura de negocio y arquitectura de tecnología. A raíz de este análisis se identificó la necesidad de la implementación de un proyecto de mejora para el proceso de negocio de Gestión de Emisión. El proyecto seleccionado es "Rediseño del Sistema de Emisión a Distancia (SED)". Asimismo, se describió el impacto de los riesgos que conllevaría la implementación de la propuesta.

Por otro lado, se realizó el análisis de FODA para identificar las fortalezas, debilidades, oportunidades y amenazas de la organización y su relación con el presente proyecto. Adicionalmente, se empleó del marco de trabajo CYNEFIN, el cual sirvió para identificar el grado de complejidad del entorno que se va a enfrentar el equipo de trabajo del proyecto propuesto.

Finalmente, para el desarrollo del proyecto propuesto se escogió el marco SCRUM; debido a que, por necesidad del negocio y apoyo en los objetivos estratégicos de la organización se requiere funcionalidades que den valor a la organización en corto plazo. 


\section{(1)}

\section{CAPÍTULO 4: PROPUESTA DEL PROYECTO}

\section{RESUMEN EJECUTIVO}

Actualmente el sistema SED está presentando problemas en la emisión de pólizas SCTR, debido a la formación de colas de servicio causado a la emisión masiva de las pólizas.

Se propondrá presentar un proyecto de arquitectura empresarial para la entidad aseguradora, la cual tendrá como resultado una mejora en la arquitectura de sistemas basada en la creación de un servicio de colas asíncrono que garantice una atención eficiente en la emisión masiva de pólizas de SCTR.

La atención asíncrona de las solicitudes masivas de emisión de pólizas SCTR permitirá un mayor número de creación de pólizas diarias, lo cual significa un mayor incremento de las ventas.

El proyecto costará aproximadamente $S / 819,897.78$ y se calcula que en 24 meses se llegará al punto de equilibrio.

El proyecto hará eficiente el proceso masivo de emisión de pólizas de SCTR, aminorando los tiempos de atención y permitiendo una mayor atención de los mismos.

\section{MARCO TEÓRICO}

\section{ARQUITECTURA EMPRESARIAL}

Según Adriana Molano (Molano 2015) "Una de las disciplinas de la informática que mayor peso ha cobrado en los últimos años es la Arquitectura Empresarial (AE, en inglés 'Enterprise Architecture'), que puede explicarse en función de las metas de una organización y en cómo 


\section{(1)}

desde los sistemas se pueden proponer formas de organizar sus procesos para optimizar los recursos y lograr así los objetivos propuestos."

Las empresas que desarrollen su Arquitectura Empresarial tienen las herramientas necesarias para la toma de decisiones debido a la gran cantidad de información disponible. Esto es posible gracias a que mediante la Arquitectura Empresarial ayuda a definir los lineamientos informáticos que prevean las actuales y futuras necesidades.

\section{TOGAF}

"TOGAF es un marco de arquitectura empresarial que ayuda a definir los objetivos comerciales y alinearse con los objetivos comerciales en torno al desarrollo de software empresarial. El Open Group Architecture Framework (TOGAF) es una arquitectura empresarial que ofrece un marco de alto nivel para el desarrollo de software empresarial. Ayuda a organizar el proceso de desarrollo a través de un enfoque sistemático para reducir los errores, mantener los plazos, mantenerse dentro del presupuesto y alinear la TI con las unidades de negocios para producir resultados de calidad.” CIO España. (2018)

\section{SCRUM}

"Scrum es un proceso en el que se aplican de manera regular un conjunto de buenas prácticas para trabajar colaborativamente, en equipo, y obtener el mejor resultado posible de un proyecto. Estas prácticas se apoyan unas a otras y su selección tiene origen en un estudio de la manera de trabajar de equipos altamente productivos.” Proyectos Ágiles org (2018).

\section{GESTIÓN DE LOS RIESGOS DEL PROYECTO}

Basándonos en la guía de proyectos PMBOK, la gestión de los riesgos del Proyecto se desarrolla enmarcado en los procesos que llevan a cabo la planificación de la gestión, la identificación, el análisis, la respuesta a los riesgos y el monitoreo y control en un determinado proyecto. 


\section{(1)}

Cada proceso interactúa entre sí con los demás procesos e incluyen el esfuerzo de una o más personas, dependiendo de la magnitud del proyecto. La frecuencia de cada proceso es de por lo menos una vez en cada proyecto y/o fases.

Cada riesgo es un evento o condición incierta, ubicado siempre en un futuro; tiene un impacto en por lo menos un objetivo del proyecto y estos pueden incluir el alcance, el cronograma, el costo y la calidad.

La organización debe comprometerse de manera proactiva con la gestión de riesgos a lo largo del proyecto. Se debe tener en cuenta que los riesgos existen desde la concepción del proyecto, por tanto, no gestionar el riesgo significaría aumentar el impacto que pueda darse con la materialización de un riesgo y que podría conducir el proyecto al fracaso.

Los riesgos se gestionarán en las siguientes etapas:

- Planificar la gestión de Riesgos

- Identificar los Riesgos

- Realizar el análisis cualitativo de los riesgos

- Realizar el análisis cuantitativo de los riesgos

- Planificar la respuesta a los Riesgos

- Monitorear y controlar los Riesgos

\section{HERRAMIENTAS PARA EL ANÁLISIS FINANCIERO}

\section{VAN}

El valor actual neto, es una herramienta financiera que indica la diferencia entre el dinero que ingresa a la empresa y la cantidad que se invierte en un proyecto para poder evaluar si producirá beneficios a la empresa.

El VAN tiene una tasa de interés conocido como tasa de corte y es usada constantemente. Esta tasa de corte es asignada por la persona que evalúa el proyecto, y puede ser el interés a largo plazo existente en el mercado actual o la tasa en la rentabilidad de una empresa. 


\section{(1)}

Mediante el VAN se puede conocer si un proyecto es viable o no antes de iniciarse, y al mismo tiempo saber que tan rentable es y la opción que más nos conviene.

Su principal ventaja es poder homogenizar los flujos de caja netos en el momento actual, asimismo es capaz de reducir a una sola unidad las cantidades de dinero generados o que se van aportando. El VAN también es una de las mejores opciones para homogenizar la tasa de interés con una alta fiabilidad.

\section{TIR}

Es la tasa interna de retorno o tasa de descuento obtenida en el proyecto, la cual nos permite que el VAN sea como mínimo igual a la inversión.

El TIR es un indicador muy fiable en lo concerniente a rentabilidad de un proyecto específico.

Tanto el VAN y el TIR son herramientas financieras complementarias y nos ayudan a obtener valiosa información de las empresas o proyectos en la que deseamos invertir, siempre y cuando se disponga del $100 \%$ de las ganancias en los proyectos que ejecutaremos.

\section{POSICIONAMIENTO}

\section{PLANTEAMIENTO DEL PROBLEMA}

El proyecto tuvo como finalidad de que tanto como el Cliente o Corredor, cuenten con la opción de poder realizar las operaciones que tienen que ver con el tratamiento de pólizas SCTR mediante el sistema SED. Sin embargo, el sistema no fue expuesto a un control de calidad adecuado, debido a esto se presentaron problemas de rendimiento, a continuación, se describe los principales problemas:

- Problemas de procesamiento; debido a que la arquitectura implementada en la aplicación no permite el procesamiento en paralelo de emisión y gestión de las pólizas.

- Problemas con el manejo de concurrencia con lo cual los usuarios finales experimentan bloqueo en la aplicación, indisponibilidad del sistema y pérdida de transacciones con lo 


\section{(1)}

cual el procesamiento no se llega a completar, ocasionando retraso en sus procesos y atención a sus usuarios finales, así como inconsistencia de información.

Debido a los problemas antes mencionados genera pérdida de venta de pólizas o renovaciones de las mismas, lo cual impacta de forma directa a los objetivos de la organización.

Tabla $\mathrm{N}^{\circ} 46$

Cuadro de Problemas y Causas

\begin{tabular}{|c|c|c|}
\hline Nro & Problema & Causas \\
\hline 1 & $\begin{array}{l}\text { Retraso en emisión de pólizas de } \\
\text { SCTR }\end{array}$ & $\begin{array}{l}\text { - Debido al proceso síncrono en la emisión } \\
\text { masiva de póliza de SCTR }\end{array}$ \\
\hline 2 & $\begin{array}{l}\text { Pérdida de carteras de clientes por } \\
\text { falta de disponibilidad }\end{array}$ & $\begin{array}{l}\text { - Atención tardía en toma de solicitudes de } \\
\text { póliza de SCTR }\end{array}$ \\
\hline 3 & $\begin{array}{l}\text { Bloqueo de la base de datos del core } \\
\text { business }\end{array}$ & $\begin{array}{l}\text { - Debido a la carga de planillas con más de } \\
600 \text { registros }\end{array}$ \\
\hline 4 & $\begin{array}{l}\text { Impacto negativo en la productividad } \\
\text { en áreas operativas y estratégicas de la } \\
\text { organización }\end{array}$ & $\begin{array}{l}\text { - Disminución de solicitudes de emisión de } \\
\text { pólizas de SCTR }\end{array}$ \\
\hline
\end{tabular}

Nota: Problemas detectadas en los procesos de gestión comercial y gestión de emisión. Elaboración propia.

\section{OBJETIVOS}

\section{OBJETIVO GENERAL}

Elaborar una propuesta de arquitectura empresarial para la organización, la cual permita alinear los proyectos de TI a las estrategias del negocio; incorporando marco de trabajo ágil para el desarrollo de proyectos en el proceso de gestión de emisión.

\section{OBJETIVOS ESPECÍFICOS}


- Reconocer los objetivos estratégicos y procesos de negocio de la organización objetivo.

- Elegir un proceso clave o estratégico, e identificar la relación con los objetivos estratégicos de la organización.

- Determinar los beneficios tangibles e intangibles del proyecto.

- Desarrollar los cuatro dominios de arquitectura base y destino enfocados en el proceso seleccionado.

- Reconocer las brechas entre la arquitectura base y destino desarrollados.

- Definir un plan de migración para alcanzar la arquitectura destino y proponer una solución tecnológica que permita reducir las brechas encontradas.

- Identificar las fortalezas y debilidades del equipo para afrontar un proyecto del plan de migración.

- Realizar un diagnóstico del grupo de trabajo que va a ejecutar el proyecto tecnológico.

- Identificar las dinámicas que deben implementarse para ejecutar el proyecto.

- Formar un equipo de trabajo con los conocimientos necesarios para la implementación de la solución tecnológica.

- Identificar las herramientas que se deben utilizar en el proyecto tecnológico seleccionado. 


\section{(1)}

\section{INDICADORES DE ÉXITO}

Teniendo en cuenta los objetivos estratégicos de la empresa, se proponen los siguientes indicadores que medirán el éxito del proyecto.

Tabla $\mathrm{N}^{\circ} 47$

Tabla de Indicadores de Éxito del proyecto

\begin{tabular}{|c|c|c|c|c|}
\hline $\begin{array}{l}\text { Obj. } \\
\text { Est. }\end{array}$ & Indic & Descripción & Actual & Meta al 2019 \\
\hline OE2 & IN1 & $\begin{array}{l}\text { Disminución en gastos por } \\
\text { sobretiempos en asistentes de } \\
\text { emisión y soporte de mesa de } \\
\text { ayuda (helpdesk) }\end{array}$ & $\begin{array}{c}\text { - Asist. Emis. S/25 } \\
\text { x hora / } 2 \text { a } 3 \text { horas } \\
\text { x día } \\
\text { - Help Desk S/30 x } \\
\text { hora / } 1 \text { hora x día }\end{array}$ & $\begin{array}{c}\text { - Asist. Emis. S/25 } \\
\text { x hora / } 0 \text { horas x } \\
\text { día } \\
\text { - Help Desk S/30 x } \\
\text { hora / } 0 \text { hora x día }\end{array}$ \\
\hline OE3 & IN2 & $\begin{array}{l}\text { Cantidad de horas no } \\
\text { disponibles al mes }\end{array}$ & 1 hora $\mathrm{x}$ mes & 0.05 horas por mes \\
\hline OE5 & IN3 & $\begin{array}{l}\% \text { de aumento de cartera de } \\
\text { clientes al mes }\end{array}$ & $5 \%$ al mes & $18 \%$ al mes \\
\hline OE7 & IN4 & $\begin{array}{l}\text { Cantidad de sesiones iniciadas } \\
\text { cada día en el sistema SED a } \\
\text { nivel nacional }\end{array}$ & 60 sesiones & 350 sesiones \\
\hline
\end{tabular}

Según el indicador IN1, "Disminución en gastos por sobretiempos en asistentes de emisión y soporte de mesa de ayuda (help desk)" alineado a un objetivo estratégico, el cual garantice la eficiencia en los gastos y costos donde se estima obtener una reducción en los gastos por horas de sobretiempo de los asistentes de emisión y las horas en soporte externo.

Según el indicador IN2, "Cantidad de horas no disponibles al mes" basado en la atención del objetivo estratégico OE3 donde se busca conseguir total disponibilidad de los recursos tecnológicos hacía nuestros clientes y colaboradores.

Para el indicador IN3, “\% de aumento de cartera de clientes al mes" se busca atender al objetivo estratégico OE5 logrando incrementar la cartera de clientes de manera progresiva e incremental en forma mensual, debido a una pronta y oportuna atención en la emisión de pólizas. 


\section{(1)}

Finalmente, para el indicador IN4 "Cantidad de sesiones iniciadas cada día en el sistema SED a nivel nacional" se busca conseguir el objetivo estratégico OE7, el cual garantiza la cobertura nacional alcanzando el máximo de sesiones conectadas por oficinas y agencias en cada una de las sedes descentralizadas a nivel nacional.

\section{ALCANCE DEL PROYECTO}

El presente proyecto propone elaborar una arquitectura empresarial para una entidad aseguradora. Para ello, se tomará un proceso de negocio dentro de todos los conformados dentro de las líneas de servicios de la organización; en este caso, se tomará el proceso de Gestión de Emisión el cual pertenece al macro proceso de venta el cual es de suma importancia para la organización. Por lo tanto, se debe plantear lineamientos necesarios para mejorar los procesos y dar soporte a los objetivos estratégicos relacionados de la organización.

En lo que corresponde a la arquitectura empresarial se realizará un análisis de la situación actual de la arquitectura empresarial de la organización mediante el AS-IS, revisando sus tres componentes como son: arquitectura de negocio, arquitectura de sistemas de información y arquitectura tecnológica. Para luego, realizar una nueva propuesta de la arquitectura empresarial mediante el TO-BE, en el cual, se evidenciará el detalle de sus tres componentes definidos anteriormente en el marco de referencia, que estará basado en TOGAF. Para lo cual se desarrollarán los artefactos petición de trabajo de arquitectura, documento de definición de arquitectura y plan de la implementación de la migración respectivamente.

Por parte del alcance del enfoque de desarrollo de software ágil. Previamente, se hará la identificación de fortalezas y debilidades del equipo de trabajo, con el fin de realizar un diagnóstico para identificar sus habilidades blandas y duras. Posteriormente, se harán dinámicas para fortalecer las habilidades del equipo y convertir en oportunidades las debilidades identificadas. Para luego, conformar el equipo y trabajar el proyecto que de valor al negocio de forma productiva. 


\section{()}

\section{RESTRICCIONES}

Las restricciones del proyecto son las siguientes:

Tabla $N^{\circ} 48$

Tabla de Restricciones

\begin{tabular}{cc}
\hline Restricciones & Descripción \\
\hline
\end{tabular}

Tiempo de ejecución

Consideración de normas ISO

Financieros

Normas y leyes
Deberá realizarse en un plazo de 4 meses

El proyecto basa sus servicios en estándares internacionales para lo cual cuenta con las certificaciones de calidad y seguridad ISO 9001:2008.

El presupuesto destinado para hacer el presente estudio de arquitectura deberá ser de S/ 825,000 a S/ 1'485,000. Cualquier ampliación presupuestal deberá ser presentada y sustentada ante la Gerencia General.

- Normas y Leyes de la Superintendencia de Banca y Seguros $\mathrm{y}$ AFP - Ley 29946: Ley del Contrato de Seguro - Ley $\mathrm{N}^{\circ}$ 29733: Ley de protección de datos personales PCM - Ley N ${ }^{\circ}$ 29571: Código de Protección y Defensa del Consumidor

Nota: Listado de restricciones a considerar delimitados por la empresa. Elaboración propia.

\section{IMPACTO EN LA ORGANIZACIÓN}

El proyecto realiza una propuesta en los dominios de la Arquitectura Empresarial de la empresa, mediante un enfoque metodológico que expone la forma de cómo se desarrollará el proyecto de desarrollo de software, el cual resolverá los problemas en el proceso de emisión de pólizas SCTR. 


\section{(1)}

Luego de análisis de la problemática existente y el desarrollo de la arquitectura de la línea base, se han obtenido las brechas en los dominios de Arquitectura de Sistemas y Tecnología. Por tanto, se ha determinado que el impacto de la propuesta se enfoca en el proceso de emisión de pólizas SCTR, los datos, las aplicaciones y en la infraestructura tecnológica gestionada por el área de Tecnologías de la Información.

\section{ORGANIZACIÓN DEL PROYECTO}

\section{EQUIPO DEL PROYECTO}

El equipo del proyecto estará conformado por: 


\section{()}

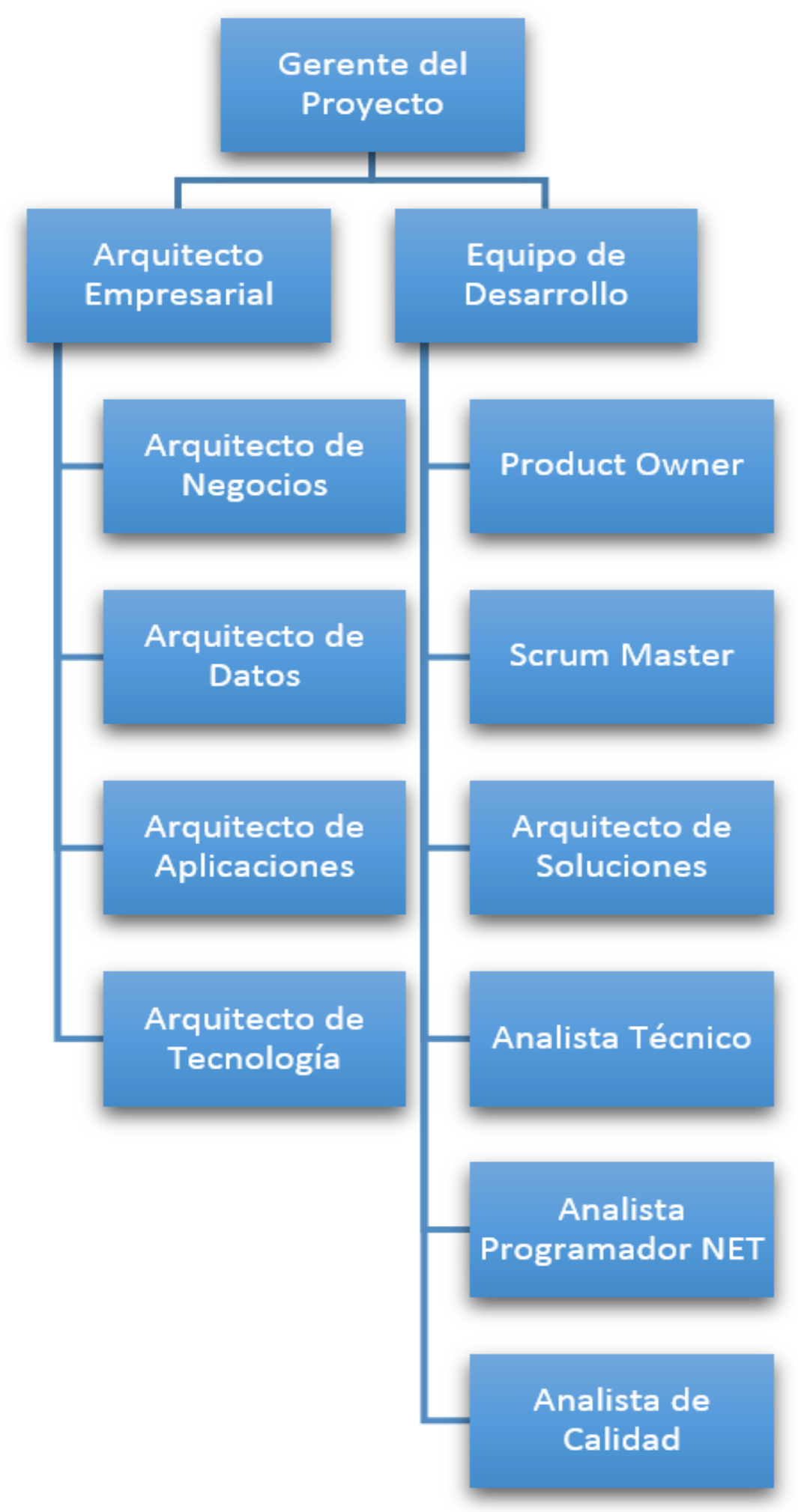

Figura $N^{\circ} 33$ Organigrama del Proyecto. Elaborado por empresa objetivo. 


\section{()}

Tabla $\mathrm{N}^{\circ} 49$

Tabla de Roles y Responsabilidades

\begin{tabular}{ccccc}
\hline Rol & Miembro & \multicolumn{4}{c}{ Responsabilidades } \\
\hline & $\begin{array}{l}\text { Organiza la tecnología para cumplir con los } \\
\text { objetivos del negocio. }\end{array}$
\end{tabular}

Arquitecto de Negocios

Apoderado

Senior

Emisión

Empresarial

Arquitecto

Soluciones

de

Se encarga del modelado de los procesos del de negocio y del análisis de requerimientos.

Configura estrategias empresariales de alto nivel basado en la tecnología.

Optimiza la gestión de la información a través del entendimiento de las necesidades del negocio y las capacidades tecnológicas.

Se encarga de la estrategia de los sistemas de TI de la empresa.

Elaborar los entregables de la Arquitectura de de Datos.

Arquitecto de

Datos

Arquitecto

Soluciones

Define el diseño de la base de datos.

Elaborar los entregables de la Arquitectura de Aplicaciones.

Arquitecto de Arquitecto de

Aplicaciones

Soluciones

Define la arquitectura de la solución, frameworks e integración de tecnologías.

Elaborar los entregables de la Arquitectura de Tecnológica.

Arquitecto de

Arquitecto

Soluciones

Diseñar y distribuir la infraestructura tecnológica. 
Gerente de

Consultoría

(Product Owner)
Apoderado

Senior

Emisión

Ayuda a desarrollar un plan de colaboración.

Representa a todos los interesados en el producto final.

Responsable del Product Backlog.

de Responsable de obtener el resultado de mayor valor posible para los usuarios o clientes.

Define los criterios de aceptación para cada User Story.

Acepta/rechaza los entregables.

Facilitador; el responsable de ayudar al equipo a entender los objetivos y contribuye a crear los planes para alcanzarlos, utilizando herramientas que permitan alcanzar un consenso en los desacuerdos.

Encargado de gestionar Scrum en el equipo; ayudar al equipo a llevar con éxito el marco ágil Scrum (dinámicas, herramientas, etc.)

Facilita la selección del Development Team.

Gerente de Proyecto (Scrum Master)
Gerente

Emisión
Ayuda al Product Owner en la creación del Backlog de Priorizado del Producto y en la definición de los criterios de terminado.

Organiza las reuniones del Development Team para estimar User Stories.

Organiza reuniones del Development Team para comprometer User Stories.

Ayuda al Development Team a crear la lista de tareas para el siguiente Sprint.

Garantiza que exista un ambiente ideal para el Development Team del proyecto en los sucesivos 


\section{(1)}

Sprints.

Representa al equipo principal de Scrum para proporcionar lecciones del proyecto actual en caso de ser necesario.

Proporcionar lineamientos de arquitectura a quienes realizarán el desarrollo de los componentes, de acuerdo con los requisitos proporcionados por el Product Owner y las mejores prácticas que pueden ser aplicadas en la organización objetivo.

Proponer alternativas de solución ante problemas técnicos complejos presentados por el equipo.

Arquitecto de Soluciones

Analista Técnico
Arquitecto de Soluciones
Analista

Técnico
Responder a situaciones complejas, inesperadas o inestables, con profesionalismo y bajo los estándares descritos en las normas de la organización objetivo. Usa reglas y herramientas analíticas estándares para detectar una causa raíz y dar una amplia gama de soluciones.

Trabajar con profesionales Senior y no Senior, estableciendo objetivos y planes para el desarrollo de los proyectos asignados.

Coordina las tareas de acuerdo con los requisitos proporcionados por el Product Owner.

Da soporte a los demás miembros del equipo en el dominio de la plataforma de desarrollo.

Proporcionar estimaciones de esfuerzo y tiempo a sus supervisores sobre los trabajos realizados e informar oportunamente cualquier desviación sobre fecha $\mathrm{y}$ alcances previstos.

Desarrollar labores de análisis de requerimiento y diseño de solución. 


\section{(1)}

Apoyar la Elaboración de los artefactos de Análisis Funcional, Casos de Uso, Casos de Prueba, Análisis Técnico.

$\begin{array}{ll}\text { Analista } & \text { Analista } \\ \text { Programador NET } & \text { Programador } \\ & \text { NET }\end{array}$

Analista de Analista Calidad
Desarrollar las labores de construcción. Apoyar la creación de data de prueba.

Realizar la ejecución de pruebas y generación de evidencias.

Conocimiento en métodos y técnicas de prueba.

Habilidades para diagnosticar y resolver problemas. de

Calidad Conocimiento del sistema o la aplicación que está siendo probada (deseable).

Conocimiento del trabajo en red y de la arquitectura del sistema.

Nota: Listado de responsabilidades según los roles. Elaboración propia. 


\section{(}

\section{STAKEHOLDERS}

Tabla $\mathrm{N}^{\circ} 50$

Tabla de Stakeholders

\begin{tabular}{|c|c|}
\hline Stakeholders & Necesidades \\
\hline Gerente General & $\begin{array}{l}\text { Se encarga de garantizar la viabilidad del negocio, asegurar la } \\
\text { supervivencia, buscar crecimiento, fija el marco estratégico y asegurar } \\
\text { su compresión en toda la organización. }\end{array}$ \\
\hline Gerente de TI & $\begin{array}{l}\text { Se encarga de planificar, diseñar, ejecutar y monitorear la estrategia de } \\
\text { las tecnologías de la información. Además, de supervisar y evaluar el } \\
\text { alineamiento de los sistemas de información a los procesos de la } \\
\text { organización. }\end{array}$ \\
\hline Gerente Comercial & $\begin{array}{l}\text { Gestiona las actividades relacionadas con el cliente, de tal modo de } \\
\text { asegurar la correcta determinación de los requisitos relacionados con el } \\
\text { producto y/o servicio estableciendo disposiciones eficaces para la } \\
\text { comunicación con los clientes. }\end{array}$ \\
\hline $\begin{array}{l}\text { Gerente de } \\
\text { Marketing }\end{array}$ & $\begin{array}{l}\text { Se encarga de gestionar el desarrollo de estrategias de marketing a corto } \\
\text { y largo plazo de la organización. Estas estrategias pueden ser: } \\
\text { desarrollo de la marca, inteligencia competitiva y relaciones públicas. }\end{array}$ \\
\hline Gerente de Emisión & $\begin{array}{l}\text { Se encarga de gestionar la emisión de pólizas según los lineamientos } \\
\text { enviados por suscripción. Asimismo, del control y seguimiento de las } \\
\text { pólizas generadas. Además, de las post operaciones a la emisión de una } \\
\text { póliza. }\end{array}$ \\
\hline
\end{tabular}

Nota: Listado de Stakeholders o interesados. Elaboración propia.

\section{RECURSOS REQUERIDOS}

Tabla $N^{\circ} 51$

Tabla de recursos según el tipo 


\section{(1)}

$\begin{array}{ll} & \text { - Arquitecto de Negocios } \\ & \text { - Arquitecto Empresarial } \\ & \text { - Arquitecto de TI } \\ \text { Equipo del proyecto } & \text { - Gerente de Consultoría } \\ & \text { - Gerente de Proyecto } \\ & \text { - Analista Técnico } \\ & \text { - Analista Programador (2) } \\ & \text { - Gerente General } \\ & \text { - Gerente de TI } \\ & \text { - Gerente Comercial } \\ & \text { - Gerente de Marketing } \\ \text { Stakeholders } & \text { - Gerente de Emisión } \\ & \text { - Servidor para el Agente (1) } \\ & \text { - Servidor de base de datos (2) } \\ \text { Equipamiento Hardware } & \text { - Servidor de Aplicaciones Web (1) } \\ & \text { - Licencia Oracle 11g Enterprise } \\ & \text { - Licencia Informix 10 } \\ & \text { - Licencia Red Hat Linux } \\ & \text { - Licencia Web Sphere MQ } \\ & \text { - Visual Studio 2017 Enterprise } \\ & \text { - Windows Server 2012 R2 } \\ \text { Equipamiento Software } & \end{array}$

Nota: Listado de recursos de personal, software e infraestructura tecnológica. Elaboración propia.

\section{FASES E HITOS DEL PROYECTO}

Tabla $\mathrm{N}^{\circ} 52$

Fases e hitos del proyecto

Fase del proyecto Hito del Proyecto Fecha estimada Entregables incluídos

Propuesta de

Arquitectura

Preliminar

$05 / 04 / 2018$

Petición del Trabajo de

Empresarial

Arquitectura

Propuesta de Arquitectura de

Arquitectura Negocios, Sistemas y

Tecnología

$30 / 04 / 2018$

Documento de

definición de

Arquitectura de

Negocios 
Propuesta de Arquitectura Empresarial

Iniciación

Planificación

Ejecución

Seguimiento y Control

Spring Review

Hitos de Springs 1, 2 y 3

Oportunidades y

Soluciones

$01 / 05 / 2018$

Implementación del

Agente y Manejador de Colas

04/07/2018

Kick Off del Proyecto

16/07/2018

Product Backlog

Sprint Backlog

Análisis Funcional y

Técnico

Casos de Prueba

$21 / 09 / 2018$

3

$25 / 09 / 2018$

Software producido

(Fuentes)

Evidencias de Prueba

Pase a QA/Prod.

Acta de Comité de

Seguimiento

Solicitud de Control de

Cambios

Cierre Cierre del proyecto
$27 / 09 / 2018$
Acta de Cierre

Nota: Listado de fases e hitos del proyecto. Elaboración propia.

\section{ENFOQUES DEL TRABAJO}

En la propuesta presentada se ha utilizado el marco de referencia TOGAF, el cual permite analizar la situación actual mediante la arquitectura de línea base y proponer una arquitectura destino y definir una cartera de proyectos como resultado del análisis de brechas. También se ha utilizado el marco de referencia Scrum, el cual nos propone un desarrollo ágil para proyectos de desarrollo de software. Por último, para el seguimiento en gestión de proyectos se usó como referencia la guía del PMI.

Para el uso de TOGAF se utilizaron los documentos o entregables: Petición de trabajo de Arquitectura, Documentos de definición de Arquitectura (Negocio, Sistemas y Tecnología) y 


\section{(1)}

el Plan de implementación y migración. La cartera de proyectos resultante logra el alineamiento de los procesos a los objetivos estratégicos de la empresa, cubriendo las brechas obtenidas en el estudio de la arquitectura de línea destino.

Se hicieron usos de las dinámicas y herramientas de Scrum, logrando una metodología ágil para los proyectos de desarrollo de software.

\section{RIESGOS Y MITIGACIÓN}

En esta sección se ven los siguientes riesgos identificados. El método se basa en la evaluación de la probabilidad e impacto en los riesgos identificados para obtener un resultado de acuerdo a su complejidad e incertidumbre. Para luego, controlar en mayor medida (mediante la Respuesta al Riesgo) aquellos riesgos que puedan causar mayor problema y que puedan afectar significativamente el proyecto.

\begin{tabular}{|l|l|l|l|l|l|}
\hline \multirow{2}{*}{ Probabilidad } & \multicolumn{3}{c|}{ Impacto } & \multicolumn{1}{c|}{ Alto } \\
\cline { 2 - 6 } & Muy Bajo (0.10) & $\begin{array}{l}\text { Bajo } \\
(0.25)\end{array}$ & Medio (0.50) & (0.75) & Muy Alto (1.00) \\
\hline Muy Probable (0.90) & & & & & \\
\hline Probable (0.70) & & & & & \\
\hline Moderado (0.50) & & & & & \\
\hline Bajo (0.30) & & & & & \\
\hline Muy Bajo (0.10) & & & & \\
\hline
\end{tabular}

\begin{tabular}{|l|l}
\hline Leyenda & \multicolumn{1}{|l}{} \\
\hline Muy Alto & \\
\hline Alto \\
\hline Medio & \\
\hline Bajo & \\
\hline Muy Bajo & \\
\hline
\end{tabular}

Figura $N^{\circ} 33$ Clasificación de los riegos, Elaboración propia, 2018. 
Tabla N ${ }^{\circ} 55$

Matriz de Riesgo

\begin{tabular}{|c|c|c|c|c|c|c|c|}
\hline $\mathrm{N}^{\mathrm{o}}$ & Riesgo & Probabilidad & Impacto & Resultado & Estrategia & Responsable & Respuesta al Riesgo \\
\hline 1 & $\begin{array}{l}\text { Cambio en las } \\
\text { normativas } \\
\text { especificadas por la } \\
\text { SBS }\end{array}$ & 0.10 & 1.00 & 0.10 & $\begin{array}{l}\text { Afiliación a } \\
\text { boletines diarios } \\
\text { de SBS }\end{array}$ & Área Legal & $\begin{array}{l}\text { El área legal dispondrá de toda la información } \\
\text { relevante de normativas ante una } \\
\text { actualización de las mismas. }\end{array}$ \\
\hline 2 & $\begin{array}{l}\text { No adquirir la } \\
\text { arquitectura } \\
\text { tecnológica en la } \\
\text { fecha programada }\end{array}$ & 0.10 & 1.00 & 0.10 & $\begin{array}{l}\text { Contrato con } \\
\text { proveedor }\end{array}$ & $\begin{array}{l}\text { Gerente de } \\
\text { Proyecto }\end{array}$ & $\begin{array}{l}\text { El Gerente de Proyecto tendrá un respaldo } \\
\text { mediante el proveedor asignado a la entidad } \\
\text { para responder ante cualquier necesidad en } \\
\text { infraestructura tecnológica. }\end{array}$ \\
\hline 3 & $\begin{array}{l}\text { El personal a cargo de } \\
\text { la implementación no } \\
\text { se encuentre } \\
\text { debidamente } \\
\text { capacitada }\end{array}$ & 0.25 & 1.00 & 0.25 & $\begin{array}{l}\text { Taller de } \\
\text { capacitación }\end{array}$ & $\begin{array}{l}\text { Gerente de } \\
\text { Proyecto }\end{array}$ & $\begin{array}{l}\text { El Gerente de Proyecto asignará talleres de } \\
\text { capacitación al personal que no tenga el } \\
\text { conocimiento previo al proyecto. }\end{array}$ \\
\hline 4 & $\begin{array}{l}\text { No contar con el } \\
\text { debido licenciamiento } \\
\text { de software }\end{array}$ & 0.10 & 1.00 & 0.10 & $\begin{array}{l}\text { Contrato con } \\
\text { proveedores }\end{array}$ & $\begin{array}{l}\text { Gerente de } \\
\text { Proyecto }\end{array}$ & $\begin{array}{l}\text { El Gerente de Proyecto tendrá un respaldo } \\
\text { mediante el proveedor asignado a la entidad } \\
\text { para responder ante cualquier necesidad en } \\
\text { adquisición de licencias de software. }\end{array}$ \\
\hline
\end{tabular}




\begin{tabular}{|c|c|c|c|c|c|c|c|}
\hline 5 & $\begin{array}{l}\text { Cambiar el alcance } \\
\text { y/o requerimientos } \\
\text { una vez iniciado el } \\
\text { proyecto }\end{array}$ & 0.25 & 1.00 & 0.25 & $\begin{array}{l}\text { Tener un } \\
\text { repositorio } \\
\text { (Product } \\
\text { Backlog) donde } \\
\text { el Gerente de } \\
\text { Consultoría } \\
\text { registre y } \\
\text { cambie su } \\
\text { alcance o } \\
\text { requerimiento en } \\
\text { todo momento }\end{array}$ & $\begin{array}{l}\text { Gerente de } \\
\text { consultoría }\end{array}$ & $\begin{array}{l}\text { El Gerente de consultoría (Product Owner) da } \\
\text { la aceptación formal sobre el alcance y los } \\
\text { requerimientos funcionales (User Stories o } \\
\text { historias de usuario) que serán registrados en } \\
\text { el Product Backlog. Luego, en los eventos de } \\
\text { Sprint Planning, se realiza un refinamiento de } \\
\text { los nuevos requerimientos existentes o } \\
\text { creados por el Gerente de Consultoría, para } \\
\text { luego priorizar el Product Backlog y crear } \\
\text { el(los) siguiente(s) Sprint(s) por el equipo de } \\
\text { desarrollo. De esta manera, se controla que a } \\
\text { pesar que haya cambios en el ciclo de vida del } \\
\text { proyecto, se puede ir controlando los cambios } \\
\text { dados en todo momento. }\end{array}$ \\
\hline 6 & $\begin{array}{l}\text { Rotación de personal } \\
\text { calificado }\end{array}$ & 0.20 & 1.00 & 0.20 & $\begin{array}{l}\text { Plan de } \\
\text { bonificaciones }\end{array}$ & $\begin{array}{l}\text { Gerente de } \\
\text { RRHH }\end{array}$ & $\begin{array}{l}\text { Brindar incentivos para los miembros clave, } \\
\text { para que el éxito del proyecto no se vea } \\
\text { afectado. }\end{array}$ \\
\hline 7 & $\begin{array}{l}\text { Fallo de conexión de } \\
\text { acceso al servicio a } \\
\text { internet }\end{array}$ & 0.05 & 1.00 & 0.05 & $\begin{array}{l}\text { Tener contratos } \\
\text { con distintos } \\
\text { proveedores de } \\
\text { servicio }\end{array}$ & $\begin{array}{l}\text { Gerente de } \\
\text { Proyecto }\end{array}$ & $\begin{array}{l}\text { Contar con distintos proveedores para tener } \\
\text { alta disponibilidad de acceso al internet }\end{array}$ \\
\hline
\end{tabular}




\begin{tabular}{|c|c|c|c|c|c|c|c|}
\hline 8 & $\begin{array}{l}\text { Tareas no } \\
\text { Programadas }\end{array}$ & 0.10 & 0.50 & 0.05 & $\begin{array}{l}\text { Tener un } \\
\text { repositorio } \\
\text { (Product } \\
\text { Backlog) donde } \\
\text { se puede realizar } \\
\text { el seguimiento y } \\
\text { control de todas } \\
\text { las tareas }\end{array}$ & $\begin{array}{l}\text { Gerente de } \\
\text { consultoría }\end{array}$ & $\begin{array}{l}\text { El Gerente de Consultoría (Product Owner) } \\
\text { tiene el registro de todas las tareas o } \\
\text { requerimientos (User Stories o historias de } \\
\text { usuario) en un repositorio llamado Product } \\
\text { Backlog. Para luego con el equipo de } \\
\text { desarrollo, hacer seguimiento y control de } \\
\text { todas las tareas según la priorización } \\
\text { asignada. Por último, en base a la priorización } \\
\text { se crean los Sprints que se van a ejecutar de } \\
\text { acuerdo a iteraciones durante el ciclo de vida } \\
\text { del desarrollo del proyecto, de este modo se } \\
\text { controla que todas las tareas se realicen. }\end{array}$ \\
\hline
\end{tabular}

Nota: Listado de riesgos encontrados en el proyecto. Elaborado por empresa objetivo. 


\section{(4)}

\section{ESTUDIO DE FACTIBILIDAD}

\section{COSTOS DEL PROYECTO}

A continuación los costos que se incluyen para el desarrollo del proyecto:

Tabla $\mathrm{N}^{\circ} 56$

Resumen de costos del Proyecto

\begin{tabular}{lr}
\hline \multicolumn{1}{c}{ Concepto } & \multicolumn{1}{c}{ Montos } \\
\hline Servidor del Agente & $\mathrm{S} / 37,654.78$ \\
Alquiler de Suite MQ & $\mathrm{S} / 506,000.00$ \\
Implementación del componente Agente y el manejador de colas & $\mathrm{S} / 276,243.00$ \\
Licencia Microsoft Windows server 2016 & $\mathrm{S} / 20,126.85$ \\
Licencia Oracle Database Enterprise & $\mathrm{S} / 155,325.12$ \\
Red Hat Enterprise Linux Server & $\mathrm{S} / 1,141.23$ \\
Recursos varios & $\mathrm{S} / 66,470.00$ \\
\hline Total & $\mathrm{S} / 1,062,960.98$ \\
\hline
\end{tabular}

Nota: Costos detallado por licencias de software, equipos y servicios. Elaborado por empresa objetivo.

Se muestra a continuación el estudio de factibilidad considerando los costos de infraestructura, y de implementación de software.

Los costos de infraestructura consideran los de licenciamiento en sistema operativo, bases de datos, software, servidor y los de su mantenimiento respectivo, hardware y software.

\section{ANALISIS DE VIABILIDAD Y RENTABILIDAD}

Tabla $\mathrm{N}^{\circ} 57$

Tabla de Factibilidad (Flujo de caja neto y egresos)

\begin{tabular}{lllll}
\hline & Año & 0 & 1 & 2 \\
\hline INGRESOS & & &
\end{tabular}

Flujo caja neto (Venta de Pólizas SCTR)

TOTAL INGRESOS

EGRESOS

$\begin{array}{lll}\mathrm{S} / 0.00 & \mathrm{~S} / 1,856,433.77 & \mathrm{~S} / 2,156,879.56 \\ \mathrm{~S} / 0.00 & \mathrm{~S} / 1,856,433.77 & \mathrm{~S} / 2,156,879.56\end{array}$


Servidor del Agente

Alquiler de Suite MQ

Implementación del componente

Agente y el manejador de colas

Licencia Microsoft Windows server

2016

Licencia Oracle Database Enterprise

Red Hat Enterprise Linux Server

Recursos

TOTAL EGRESOS

FLUJO EFECTIVO

FLUJO ACUMULADO
$\mathrm{S} / 37,654.78$

$\mathrm{S} / 506,000.00$

$\mathrm{S} / 2,500.00$

$\mathrm{S} / 2,500.00$

$\mathrm{S} / 506,000.00$

$\mathrm{S} / 506,000.00$

S/276,243.00

S/20,126.85

$\mathrm{S} / 155,325.12$

$\mathrm{S} / 1,141.23$

$\mathrm{S} / 66,470.00$

$\mathrm{S} / 1,062,960.98$

$\mathrm{S} / 1,062,960.98$

$\mathrm{S} / 341,717.50$

$\mathrm{S} / 350.00$

$\mathrm{S} / 34,171.50$

$\mathrm{S} / 350.00$

$\mathrm{S} / 850,567.50$

$\mathrm{S} / 543,021.50$

$\mathrm{S} / 1,005,866.27 \quad \mathrm{~S} / 1,613,858.06$

$\mathrm{S} / 1,062,960.98$
$-\mathrm{S} / 57,094.71 \quad \mathrm{~S} / 1,556,763.35$

Nota: Detalle de los conceptos de ingreso y egresos para la ejecución del proyecto.

Elaborado por empresa objetivo.

Tabla $\mathrm{N}^{\circ} 58$

Indicadores financieros del análisis de rentabilidad del proyecto

\begin{tabular}{lr}
\hline \multicolumn{1}{c}{ Indicadores Financieros } & \multicolumn{1}{c}{ Valor } \\
\hline$\%$ Tasa de Interés & $10 \%$ \\
VAN (Valor Actual Neto) & $\mathrm{S} / 1,185,229.89$ \\
TIR (Tasa Interna de Retorno) & $79 \%$ \\
\hline
\end{tabular}

Nota: Valores obtenidos de acuerdo con el análisis del proyecto. Elaborado por empresa objetivo.

Según el resultado de la evaluación financiera, se ha obtenido un VAN de S/1'185,229.89 con una tasa de interés del $10 \%$ (impuesta por la empresa objetivo) la cual sustenta la viabilidad del proyecto y se obtiene además una tasa interna de retorno (TIR), según la proyección de sólo 2 años, la cual será de $79 \%$ el cual demuestra que el proyecto de inversión es rentable. Esta proyección representa una gran oportunidad de inversión en un proyecto que puede brindarle la posibilidad de incrementar las ventas (de gastar S/1'062,960.98 a ganar S/1'556,763.35 en sólo 2 años) y mejorar el desempeño del trabajo tanto para la organización como para el cliente, el cual se sentirá más identificado con la marca. 


\section{BIBLIOGRAFÍA}

Economía Finanzas (2018). VAN y TIR. Recuperado de

https://www.economiafinanzas.com/que-son-van-tir/ [Consulta: 7 de junio de 2018]

Project Management Institute PMI (2018). Guide and Standards. Recuperado de https://www.pmi.org/pmbok-guide-standards [Consulta: 7 de junio de 2018]

\section{APROBACIÓN}




\section{(1)}

\section{CONCLUSIONES}

- Se ha logrado entender la problemática del negocio, el cual ha llevado a alinear los procesos del mismo hacía los objetivos estratégicos de la organización, asimismo identificar las áreas que requieren una mayor atención y mejora.

- Se ha logrado evidenciar que los aplicativos existentes al inicio del proyecto, produjeron a largo plazo la problemática en los procesos de Gestión comercial y Gestión de Emisión al evolucionar de manera aislada del sistema web organizacional.

- Se ha logrado proponer una solución alineada a los objetivos estratégicos de la empresa, que asegura la mejora continua de los procesos debido a una arquitectura sólida y escalable.

- Se ha evidenciado el uso de mejores prácticas y estándares de codificación en el desarrollo del agente que será invocado por el sistema SED. 


\section{(1)}

\section{RECOMENDACIONES}

- Se recomienda que los interesados clave dentro del proyecto cuenten con capacitaciones en la gestión de proyectos, debido a que, al no contar con la experiencia de trabajar en estos tipos de proyectos se puede presentar dificultades en el desarrollo de la propuesta de la arquitectura empresarial con el área de TI.

- Se recomienda que en el caso el equipo de proyecto no cuente con el conocimiento adecuado, utilice un marco de trabajo ágil con SCRUM. Estos deben ser capacitados en talleres prácticos donde pueden desarrollar sus habilidades como un equipo cohesivo y auto disciplinado.

- Se recomienda que en cada Retrospectiva luego del Sprint Review se cree un documento de lecciones aprendidas como apoyo de dudas o consultas para futuros proyectos de desarrollo o en sí para el próximo Sprint. 


\section{(1)}

\section{GLOSARIO DE TÉRMINOS}

1. Agente: (Informática) Es una parte del software que actúa para un usuario u otro programa. El agente tiene la autoridad de decidir cuándo una acción es apropiada, no son estrictamente invocados para una tarea, sino que se activan ellos mismos.

2. AS-IS: (Tal como es) Es la descripción de la realidad actual de la empresa.

3. Core Business: En el campo del management empresarial es frecuente que aparezca el concepto de 'Core business' que podemos traducir por "actividad principal" o mejor "negocio principal" de una empresa.

4. DevOps: Es una asociación entre el desarrollo de software y las operaciones de TI que pone de relieve la comunicación, la colaboración y la integración.

5. Framework: (Marco de trabajo) Es una estructura real o conceptual destinada a servir de soporte o guía para la construcción de algo que expande la estructura en algo útil.

6. Hardware: es la parte física de un ordenador o sistema informático, está formado por los componentes eléctricos, electrónicos, electromecánicos y mecánicos.

7. Help desk: Mesa de ayuda que proporciona soporte ante una necesidad y/o problema tecnológico para poder lograr su solución.

8. Línea base: Es la situación actual en la que se encuentra el proceso

9. Línea de destino: Es la situación a la que se espera llegar con la implementación de un proyecto de arquitectura empresarial.

10. Matriz RACI: Matriz que describe la relación entre las actividades de un proyecto y las responsabilidades asociadas a ellas.

11. Open Source: Es una expresión de la lengua inglesa que pertenece al ámbito de la informática. Aunque puede traducirse como "fuente abierta", suele emplearse en nuestro idioma directamente en su versión original, sin su traducción correspondiente.

12. Póliza: Se entiende por póliza, el presente contrato de seguro constituido por la Solicitud de Seguro, las Condiciones Generales, las Condiciones Particulares, las 


\section{(1)}

Condiciones Especiales y Endosos así como los demás documentos que, por acuerdo expreso de las partes, formen parte integrante del mismo.

13. Scrum: Marco de referencia basada en una filosofía de desarrollo ágil creada por Hirotaka Takeuchi e Ikujiro Nonaka en el año 1986.

14. Software: Es un programa o conjunto de programas de cómputo que incluye datos, procedimientos y pautas que permiten realizar distintas tareas en un sistema informático.

15. Stakeholders: Es una palabra del inglés que, en el ámbito empresarial, significa "interesado" o "parte interesada", y que se refiere a todas aquellas personas u organizaciones afectadas por las actividades y las decisiones de una empresa.

16. Testing: Es la aplicación de técnicas a un producto bajo prueba con el fin de brindar información relativa a la calidad del software, a los diferentes actores involucrados en un proyecto.

17. TO-BE: (Como será) Es la descripción de la situación en la que deseamos que se encuentre la empresa.

18. Workspace: Espacio digital de trabajo donde se desarrolla un proyecto. 


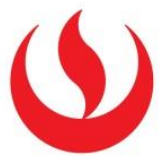

\section{SIGLARIO}

1. ADM: Método de desarrollo de arquitectura (del inglés Architecture Development Method)

2. EDT: Estructura de desglose de trabajo

3. FODA: Fortalezas, Oportunidades, Debilidades, Amenazas

4. IaaS: La infraestructura como servicio (IaaS) es una infraestructura informática inmediata que se aprovisiona y administra a través de Internet.

5. PaaS: Plataforma como servicio (PaSS) es un entorno de desarrollo e implementación completo en la nube, con recursos que permiten entregar todo, desde aplicaciones sencillas basadas en la nube hasta aplicaciones empresariales sofisticadas habilitadas para la nube.

6. PMBOK: Guía de los Fundamentos para la Dirección de Proyectos

7. PMI: El Project Management Institute (PMI) es una organización sin fines de lucro que avanza la profesión de la dirección de proyectos a través de estándares y certificaciones reconocidas mundialmente, a través de comunidades de colaboración, de un extenso programa de investigación y de oportunidades de desarrollo profesional.

8. SED: Sistema de Emisión a Distancia

9. SCTR: Seguro Complementario de Trabajo de Riesgo

10. TIR: Tasa interna de Retorno

11. TOGAF: (Open Group Architecture Framework) Es una arquitectura empresarial que ofrece un marco de alto nivel para el desarrollo de software empresarial.

12. VAN: Valor actual neto 


\section{(}

\section{BIBLIOGRAFÍA}

Universidad Santiago de Cali. (2013) Estudio de las prácticas de Arquitectura Empresarial en las grandes empresas del valle del Cauca. Recuperado de http://revistas.usc.edu.co/index.php/Ingenium/article/view/87\#.WsEmlS_SG9Z [Consulta: 13 de Abril de 2018].

CIO España. (2018) ¿Qué es TOGAF? Una metodología de arquitectura empresarial para negocios. Recuperado de http://www.ciospain.es/finanzas/que-es-togaf-una-metodologia-dearquitectura-empresarial-para-negocios [Consulta: 20 de Abril de 2018].

Corporación Colombia Digital. (2018) ¿Qué es TOGAF?. Recuperado de https://colombiadigital.net/actualidad/articulos-informativos/item/8163-que-es-togaf.html [Consulta: 20 de Abril de 2018].

J. A. Zachman. (1987) 1987 IBM System Journal: un marco para la arquitectura de sistemas de información. Recuperado de https://www.zachman.com/resources/ea-articlesreference/49-1987-ibm-systems-journal-a-framework-for-information-systems-architecture [Consulta: 2 de Junio de 2018].

Corporación Colombia Digital. (2018) ¿Qué es Arquitectura Empresarial?. Recuperado de https://colombiadigital.net/actualidad/articulos-informativos/item/8123-que-es-arquitecturaempresarial.html [Consulta: 23 de Abril de 2018].

WordPress (10 de julio de 2014). FASES DE DESARROLLO DE TOGAF [Arquitectura Empresarial]. Recuperado de https://chae201411700810326.wordpress.com/2014/07/10/fases-de-desarrollo-de-togaf/ [Consulta: 20 de abril de 2018] 


\section{(1)}

Avante (27 de enero de 2016). Comparativa metodologías ágiles vs tradicionales. Recuperado de: http://www.avante.es/comparativa-metodologias-agiles-vs-tradicionales/ [Consulta: 20 de Abril de 2018].

Proyectos Ágiles ORG (Sin fecha). Qué es Scrum. Recuperado de https://proyectosagiles.org/que-es-scrum/ [Consulta: 13 de Abril de 2018].

La Positiva Vida (2018). Conócenos. Recuperado de https://www.lapositiva.com.pe/wps/portal/corporativo/home/nosotros\#conocenos/ [Consulta: 23 de mayo del 2018].

La Positiva Vida (2018). Acceso externo del Sistema SED para Cliente. Recuperado de https://www.lapositiva.com.pe/wps/webcorporativa/principal/seguros/clientes/1112/c-1112 [Consulta: 23 de mayo del 2018].

La Positiva Vida (2018). Acceso externo del Sistema SED para Corredores. Recuperado de https://www.lapositiva.com.pe/wps/webcorporativa/principal/seguros/corredores/1111/c$\underline{1111}$ [Consulta: 23 de mayo del 2018].

La Positiva Vida (2018). Acceso externo del Sistema SED. Recuperado de http://sed.lapositivavida.com.pe/URPI/LPV.Web.ApSED/LoginSed.aspx [Consulta: 23 de mayo del 2018].

Diario Correo (05 de marzo de 2018). Compañía portuguesa acuerda compra del 51\% de La Positiva Seguros. Recuperado de https://diariocorreo.pe/economia/compania-portuguesaacuerda-compra-del-51-de-la-positiva-seguros-806434/ [Consulta: 23 de mayo del 2018].

América Sistemas (16 de mayo de 2018). La Positiva Seguros obtiene premio de Innovate Perú del Ministerio de Producción. Recuperado de http://www.americasistemas.com.pe/lapositiva-seguros-recibe-reconocimiento-del-gobierno/ [Consulta: 23 de mayo del 2018]. 
APESEG (2018). Informe trimestral del sistema asegurador - Primer trimestre 2018. Recuperado de https://www.apeseg.org.pe/wpcontent/uploads/2018/05/Resultados Sistema Asegurador 1T18.pdf [Consulta: 23 de mayo del 2018].

OBS Business School (Sin fecha). Las 5 etapas en los "Sprints" de un desarrollo Scrum. Recuperado de: https://www.obs-edu.com/es/blog-investigacion/project-management/las-5etapas-en-los-sprints-de-un-desarrollo-scrum [Consulta: 20 de Abril de 2018].

Everis Cloud (2018). Caso de Éxito: Aseguradora internacional. Recuperado de https://everis.cloud/caso-de-exito-aseguradora-internacional/ [Consulta: 13 de abril de 2018]

Everis Cloud (2018). Caso de Éxito: Aseguradora internacional. Recuperado de https://everis.cloud/caso-de-exito-santillana-negocios-digitales/ [Consulta: 13 de abril de 2018]

The open group. (2018). TOGAF® VERSIÓN 9.1. Recuperado de https://publications.opengroup.org/g116 [Consulta: 15 de Abril de 2018]

UNIVERSIDAD PERUANA DE CIENCIAS APLICADAS 2016 Reglamento de Grados y Títulos. Lima.

Análisis FODA (2018). FODA: Matriz o Análisis FODA - Una herramienta esencial para el estudio de la empresa. Recuperado de http://www.analisisfoda.com [Consulta: 20 de mayo del 2018]

Espinoza, P. (2007). Análisis y Evaluación de la Percepción del FODA en Instituciones Educativas. (Tesis de Maestría, Tecnológico de Monterrey, Escuela de grados en educación. Querétaro: México). Recuperado de 
https://repositorio.itesm.mx/bitstream/handle/11285/568693/DocsTec_6455.pdf?sequence=1 \&isAllowed $=\mathrm{y}$ [consulta: 05 de junio del 2018]. 


\section{(1)}

\section{ANEXOS 1 - CARTA FIRMADA}

\section{APROBACIÓN DE TEMA DE TESIS}

Yo. Lerewzo Jumior Benitas Cisneros

Codigo de alkmno vo011 45142

Ya. Jonathan Camba Faggiani

Código de alumno U20iO13872

De fa carrera de Ingenieria de Sistemas EPE, autor(a)es) de la Tesis titulada

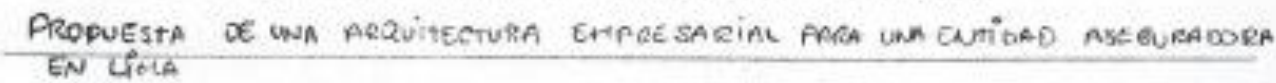
DECLARO QUE

El tema de tesis es autentico, siendo resultado de un trabsjo personal que no se ha coplado. y quve menciona de forma clara y exacta su arigen o autor, tanto en el cuerpo del fex10, fustracoones, cuabros, tabias u ofros que tengan derechos de autor.

La Empresa Ln Pesitiva séfuros tiene conocimiento de la información uțzada en la elaboración del documento y autoriza que conclundo el documento tesis, este quede publicado en ia web de ia universidac, en la modalidad:

I I pubblica, io cual significa que cualquier persona natural o juridica puede acceder al contenido

[ $X$ ] privada, to cual significa que durante los tres primseros anos, toda persons natural o juridica interesada en acceder al conlenibo, debera contar con autorzación de la empresa. Pasados los tres âríos el contenido de la tesis pasa a modo público.

En este sentido, soy (somos) consciente(s) de que el hecho de no respetar los derechos de autor. ylo no tenet el consentimiento de la empresa objeto de estudio, son objeto de sanciones universitarias y/o tegates.

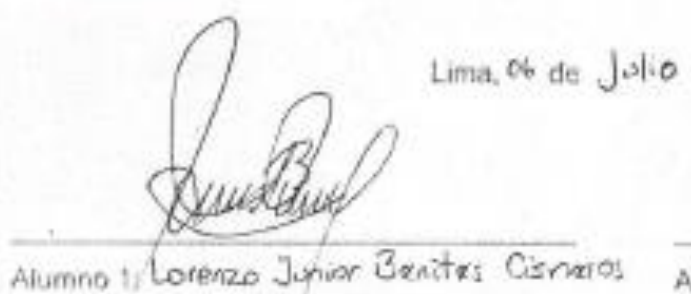

Codino de alumne. U201135142

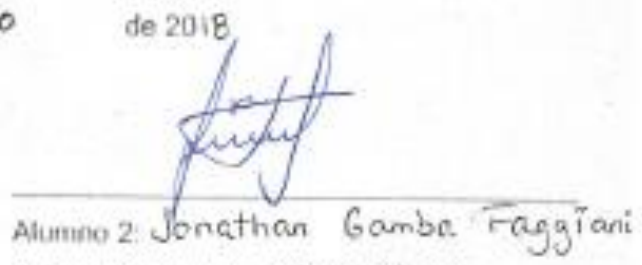

Codigo de alumno, U201013872

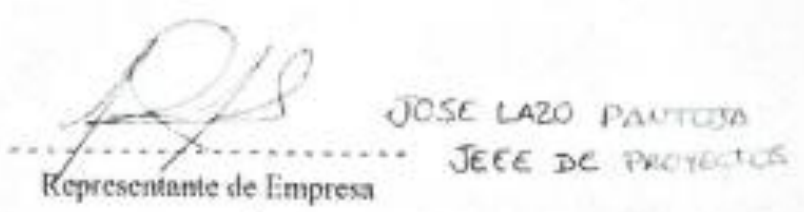

